\title{
Can a Diabetes Self-management Program Improve Diabetes Distress? Analysis from a Randomized Clinical Trial
}

\author{
Md Raihan K. Khan
}

West Virginia University, rkk0006@mix.wvu.edu

Follow this and additional works at: https://researchrepository.wvu.edu/etd

Part of the Cardiovascular Diseases Commons, Community Health and Preventive Medicine Commons, Endocrine System Diseases Commons, Epidemiology Commons, and the Nutritional Epidemiology Commons

\section{Recommended Citation}

Khan, Md Raihan K., "Can a Diabetes Self-management Program Improve Diabetes Distress? Analysis from a Randomized Clinical Trial" (2021). Graduate Theses, Dissertations, and Problem Reports. 8296. https://researchrepository.wvu.edu/etd/8296

This Dissertation is protected by copyright and/or related rights. It has been brought to you by the The Research Repository @ WVU with permission from the rights-holder(s). You are free to use this Dissertation in any way that is permitted by the copyright and related rights legislation that applies to your use. For other uses you must obtain permission from the rights-holder(s) directly, unless additional rights are indicated by a Creative Commons license in the record and/ or on the work itself. This Dissertation has been accepted for inclusion in WVU Graduate Theses, Dissertations, and Problem Reports collection by an authorized administrator of The Research Repository @ WVU. For more information, please contact researchrepository@mail.wvu.edu. 
Can a Diabetes Self-management Program Improve Diabetes Distress?

Analysis from a Randomized Clinical Trial

Md Raihan Kabir Khan

Dissertation submitted to the School of Public Health at West Virginia University in partial fulfillment of the requirements for the degree of

Doctor of Philosophy in Public Health

Ranjita Misra, Ph.D., CHES, FASHA, FESG, Chair

Ruchi Bhandari, Ph.D.

Danielle Davidov, Ph.D.

Sijin Wen, Ph.D.

Department of Social and Behavioral Sciences

Morgantown, West Virginia

2021

Keywords: Diabetes, Diabetes Distress, Hypertension, Diabetes Self-Management Copyright 2021 Md Raihan K Khan 


\section{Abstract \\ Can a Diabetes Self-management Program Improve Diabetes Distress?}

\section{Analysis from a Randomized Clinical Trial}

\section{Md Raihan Kabir Khan}

Background: Type 2 diabetes mellitus (T2DM) is a highly prevalent chronic disease and one of the leading causes of morbidity and mortality in the United States (US) and in West Virginia (WV), a mostly rural Appalachian state. West Virginia has the highest prevalence of diabetes $(16.0 \%)$ in the nation. Furthermore, the prevalence of two common comorbidities of T2DM, i.e., obesity (38.1\%) and hypertension (43.5\%), is the highest and second highest in WV. Chronic diseases are frequently associated with psychological stress. Diabetes distress is psychological stress prevalent in T2DM individuals, which encompasses emotional stress and worries related to diabetes self-care regimen and complications on a day-to-day basis. T2DM individuals who experience diabetes distress have poor glycemic status due to nonadherence to diet, physical activity, medication regimen. Diabetes self-management education (DSME) programs are proven to help T2DM individuals improve diabetes outcomes. However, very few studies have assessed the impact of DSME programs on reducing diabetes distress. The Diabetes and Hypertension Self-Management Program (DHSMP), which combined three evidence-based, widely accepted, and scientifically acclaimed disease management programs was one of the first evidence-based 12 weeks randomized controlled trials (RCT) on diabetes self-management in WV. The DHSMP was a 12-week randomized control trial (RCT) non-pharmacological lifestyle intervention delivered by trained health coaches and experts. Eighty nine adults with comorbid T2DM and hypertension were randomized into the intervention $(n=44)$ and 6-month, wait-listed control group $(\mathrm{n}=45)$. Eighty five and 81 participants completed the 12- and 24-week assessments with a completion rate of $91 \%$. The program was implemented in two churches in Morgantown and Charleston, WV, in 2018-2019.

Specific Aims: This doctoral research utilized data from the DHSMP to determine the effectiveness of DHSMP to reduce diabetes distress in T2DM individuals. Three aims were explored for this dissertation research. Aim 1 evaluated the impact of DHSMP on changes in diabetes distress among the participants at post-intervention ( 24 weeks) from the baseline; Aim 2 evaluated the predictors (demographic, clinical, and behavioral factors) and changes in diabetes distress at 12- and 24 weeks. Aim 3 had two sub-aims. Aim 3a explored DHSMP participants' everyday lived experiences and challenges to managing diabetes and its related distress \& Aim $3 \mathrm{~b}$ explored the efficacy of DHSMP participation on the participants' perceptions of program components that were deemed helpful for adherence to diabetes self-management behaviors and reducing diabetes-related distress.

Methods: All participants completed baseline, 12- and 24-week assessments, which included anthropometrics, behavioral and clinical factors for the larger study. The participants completed three self-reported surveys that were used for this study: the Diabetes Distress Scale (DDS), and Morisky Medication Adherence Survey (MMAS), and Lifestyle Profile II Survey. Demographic information included age, gender, body mass index, race, level of education, number of household members, duration of diabetes and hypertension, family history, and access to health insurance. Clinical data included serum cortisol, serum cholesterol, glycosylated hemoglobin or 
HbA1c. The dependent variables included diabetes distress (total diabetes distress, and 4 domains) and serum cortisol. Bivariate relationships were analyzed between the dependent variables and demographic, behavioral, and clinical variables. A linear mixed model with main effects assessed the effect of program attendance on diabetes distress (Aim 1), and behavioral and clinical predictors of diabetes distress and changes after the DHSMP intervention (Aim 2). For Aim 3, qualitative data were collected using semi-structured phone interviews (33 participants) and 4 focus groups (23 participants). Quantitative data entry and analysis were conducted using Research Electronic Data Capture (REDCap) and IBM Statistical Package for Social Sciences (SPSS) for Windows (version 27), respectively. Qualitative data entry and coding were completed by two coders, and thematic analysis was conducted using NVivo.

Results: The mean age was $60.82 \pm 12.16$ years of age. The majority (64\%) were females and Non-Hispanic Whites (90.2\%). Overall, the study participants had mild total diabetes distress, emotional distress, physician-related distress, and interpersonal distress. However, participants had moderate regimen-related distress. Participation in DHSMP reduced diabetes distress by 0.16 point between baseline and 24 weeks. Greater adherence to medication regimen, dietary guidelines, glycemic and lipid control among program participants reduced diabetes distress, and its domains. A dose-response relationship was noted with greater attendance for the 12-week DHSMP sessions resulted in significant reduction in diabetes distress and regimen-related distress for participants. The participant narratives (qualitative analysis) revealed an understanding of the interconnectedness of the four domains of the diabetes distress experienced by participants, as well as improvement in their coping strategies with knowledge/skills from participation in the program. Participants described physical and emotional challenges in the day-to-day management of their disease and maintaining relationships and communication with family, friends, and health care providers regarding their distress.

Conclusion: Findings demonstrated that diabetes distress was prevalent in rural adults with T2DM, and participation in DSME or evidence-based self-management programs such as the DHSMP reduce diabetes distress. Results have several implications for DSME programs, health care providers in rural Appalachia, and public health research. Findings from this dissertation research indicate that DSME programs such as DHSMP can help T2DM individuals self-manage their diabetes distress which they experience in their everyday life. Health care providers, especially in rural Appalachia, should inform their T2DM patients on diabetes distress and educate them on managing it using diabetes self-management strategies. 


\section{Acknowledgment}

I write my sincere gratitude to my dissertation committee members for the continuous support and mentoring I have received from them. Dr. Ranjita Misra, I cannot thank you enough for the mentoring, guidance, encouragement you gave me throughout this process. I could not have come to this point without your unconditional support. Dr. Sijin Wen, you have dedicated countless hours at your office to help me learn complex statistical topics that I never learned from any other sources. I appreciate your dedication to mentoring doctoral students. Dr. Ruchi Bhandari, you have been supporting me since the first day I started working with you. I appreciate the numerous hours you have spent teaching me epidemiology, advising on research and career related topics. Dr. Danielle Davidov, thank you for guiding me to learn and conduct qualitative studies. I learned the basics of the qualitative study from you, and your expert support was essential to complete my dissertation. For the qualitative study (Aim 3), I also would like to thank Brenna Kirk, who worked as the second coder and was a great help in completing the qualitative analysis. I also thank Sara Nayeem, and Hannah Abraham, who volunteered as notetakers with me during the focus groups. Sarah Opatz conducted the semi-structured phone interviews for the qualitative study, and I am grateful to her. DHSMP health coaches were an integral part of the study; a special thanks to them. I thank all the DHSMP participants as well. I also thank Dr. Stephen Davis for agreeing to join my doctoral defense on very short notice. Dr. Samantha Shawley-Brzoska also deserves special thanks who helped me learn Redcap and supported me with advice from time to time.

The leadership of the Department of Social and Behavioral Sciences (SBHS), and the School of Public Health (SPH), West Virginia University (WVU) were highly supportive of me. I thank Dr. Keith Zullig, Chair of SBHS, for his guidance and ensuring financial support throughout my doctoral program. I also thank Dr. Alfgeir Kristjansson, SPH Program Director, Dr. Linda Alexander, Senior Associate Dean for Academic, Student and Faculty Affairs for SPH, and Dr. Jeffrey Coben, Associate Vice President for Health Affairs \& Dean of SPH for their support and encouragement.

I also want to acknowledge the support of my family members. My parents' love and support were always an encouragement for me. My sister, aunts, uncles, and in-laws never lost their faith in me. Especial thanks to some uncles and aunts: Dr. Shobnom Ferdous, Zinat Ferdous, Shahnaz Sharmin, Gulshan Ara, ASM Ahsan, Dr. Ruhul Quddus, Ruhul Bari, Mustafa Anwar, Mujibur Rahman, Md Moniruzzaman. Also, my best friend Dr. Sojib Zaman was always there to support me. Lastly, my wife, Nancy Khan, deserves a big thanks for everything she has done to support me during this journey. Your support and encouragement were necessary to complete this dissertation. Thank you again keeping patience all these years while living with a stressed doctoral student.

This research is dedicated to all the people living with diabetes and comorbidities. 


\section{TABLE OF CONTENTS}

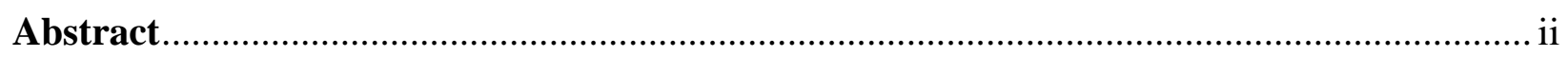

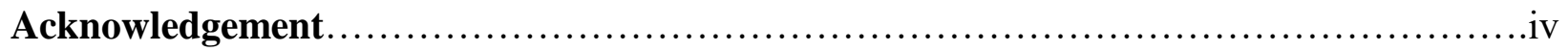

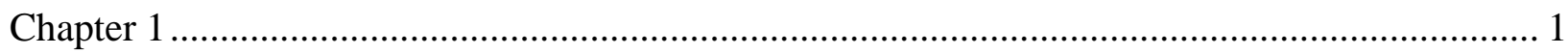

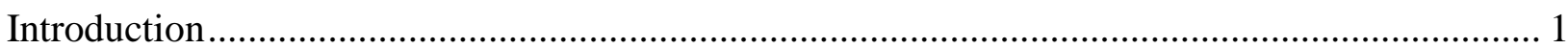

1.1 Prevalence of Diabetes and Hypertension................................................................. 1

1.1.1 Poor Health Status and High Prevalence of Chronic Diseases in the Appalachian Region 2

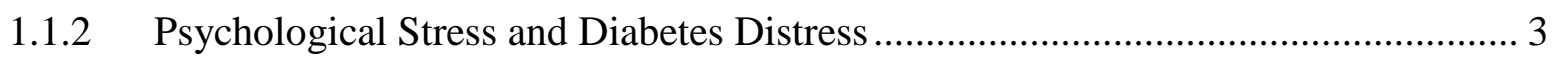

1.2 Diabetes Distress and Self-management Behaviors ..................................................... 5

1.2.1 Lifestyle Modifications Have Improved Diabetes Self-management........................ 7

1.2.2 Lifestyle Programs at Faith-based Settings........................................................... 8

1.2.3 Community-based Participatory Research (CBPR) Improves the Success of

Community Programs …………………………..................................................... 9

1.4 Qualitative Research ....................................................................................... 11

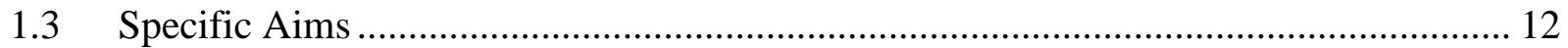

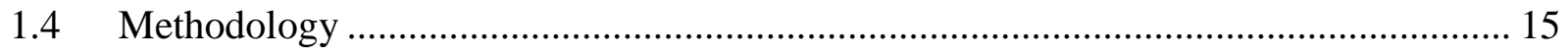

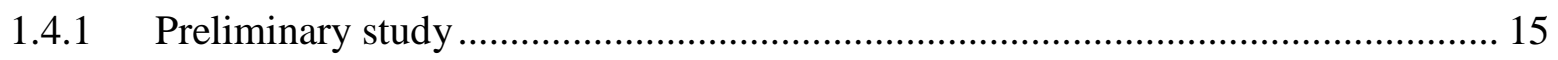

1.5 Diabetes and Hypertension Self-Management Program …………………………........ 16

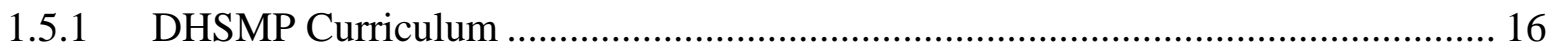

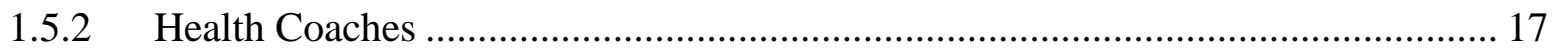

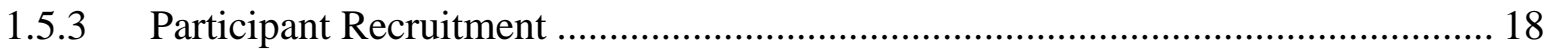

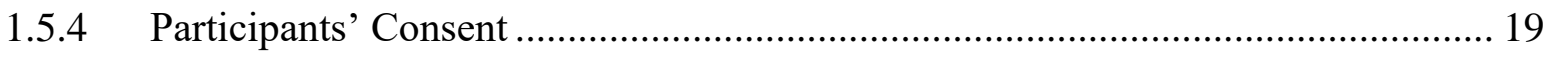

1.5.5 Program Sessions and Study Procedure ........................................................... 20

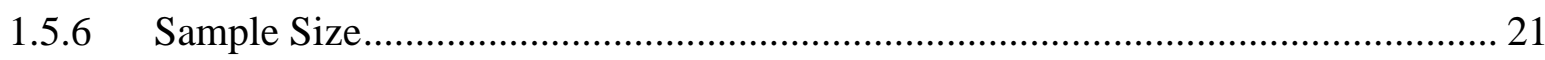

1.5.7 Quantitative Data Collection.............................................................................. 21

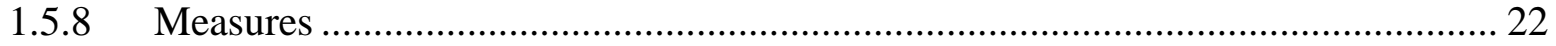

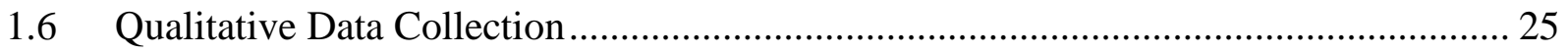

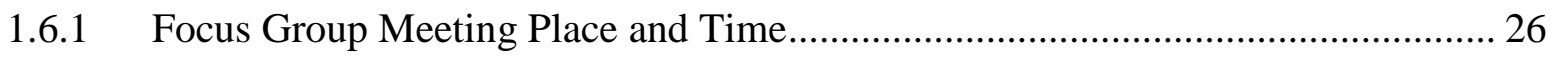

1.6.2 Logistics for the Focus Group Meetings.............................................................. 26

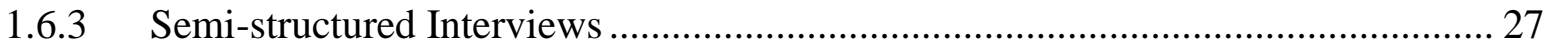

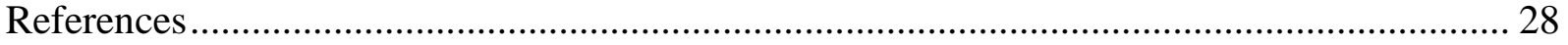




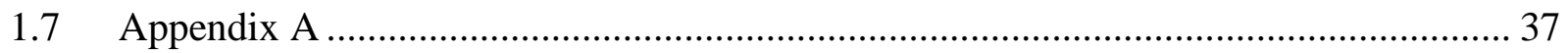

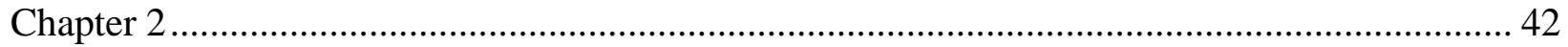

Aim 1: To evaluate the impact of DHSMP on changes in diabetes distress at 24 weeks from the

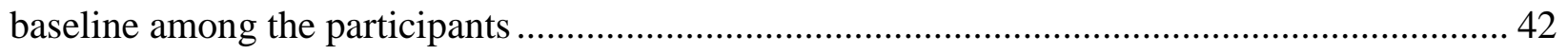

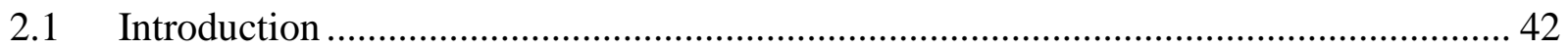

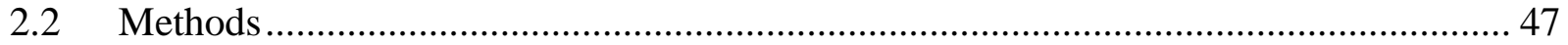

2.2.1 Study Design and Sample Selection .................................................................... 47

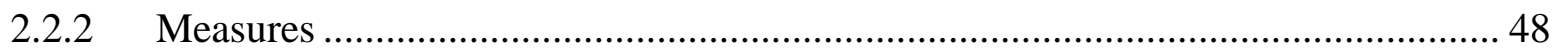

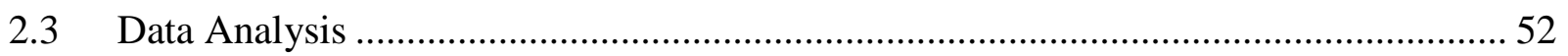

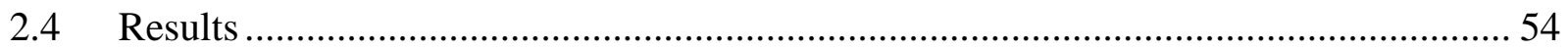

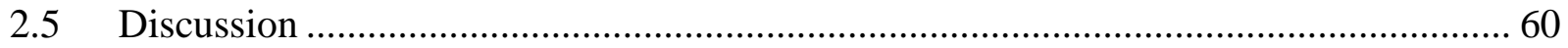

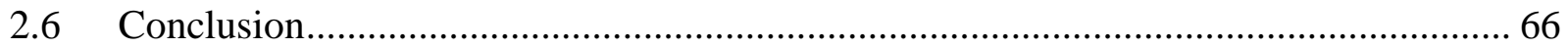

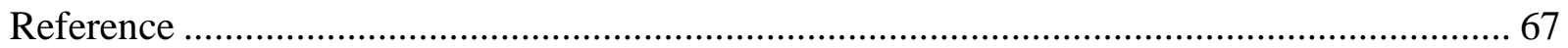

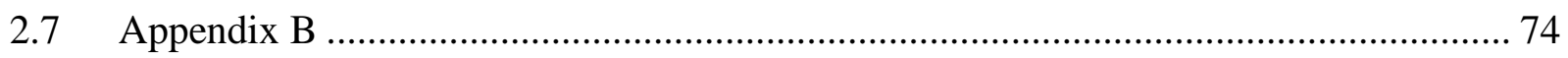

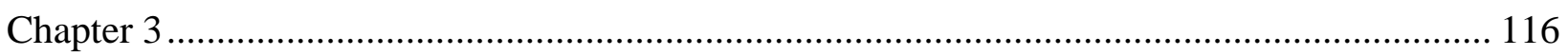

Aim 2: To evaluate the impact of clinical variables (HbA1c, blood pressure, serum cholesterol) and behavioral variables (diet, physical activity, and medication adherence) on change in diabetes distress among participants of the DHSMP at 12 weeks and 24 weeks ....................... 116

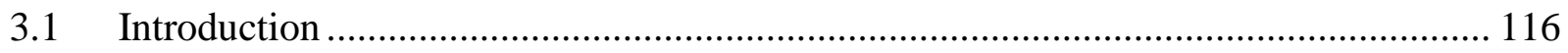

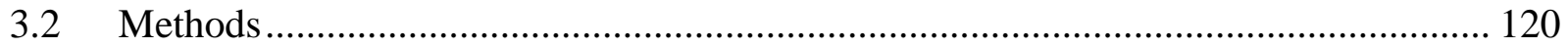

3.2.1 Study Design and Sample Selection ……………………………...................... 121

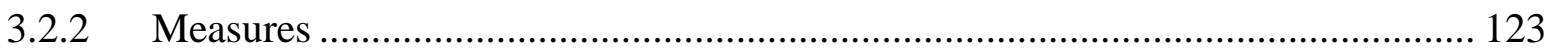

3.2.3 Dependent and Predictor Variables ..................................................................... 124

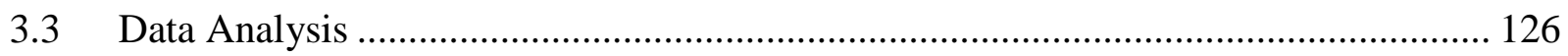

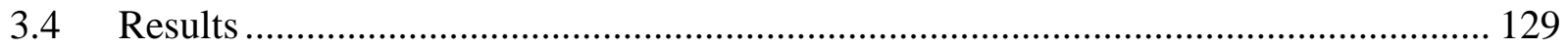

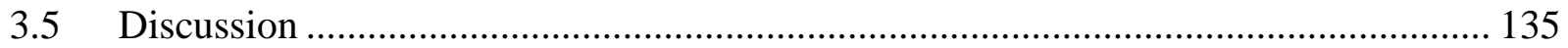

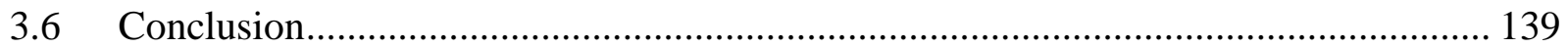

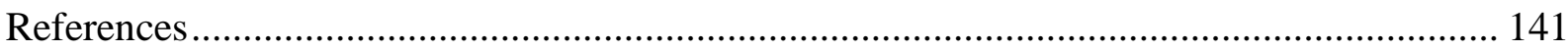

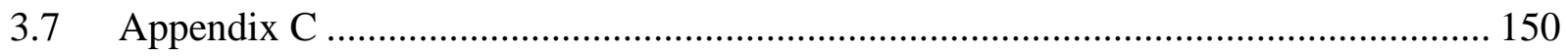

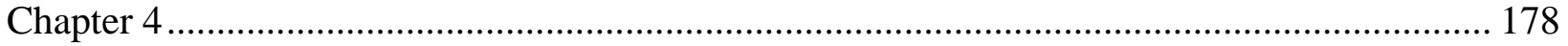

Aim 3a: To understanding everyday lived experiences and challenges to managing diabetes and its related distress among participants in a self-management program .................................... 178

Aim 3b: To explore the efficacy of DHSMP participation on the participants' reported improvement in diabetes self-management behaviors and reducing diabetes-related distress ... 178 


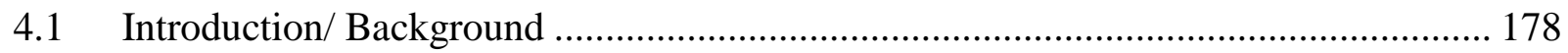

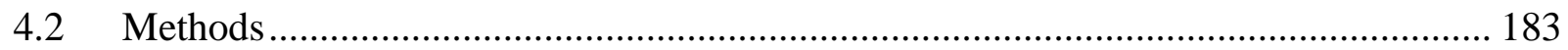

4.2.1 4.2.1 Diabetes and Hypertension Self-Management Program (DHSMP) ............ 184

4.2.2 Data collection procedures............................................................................. 184

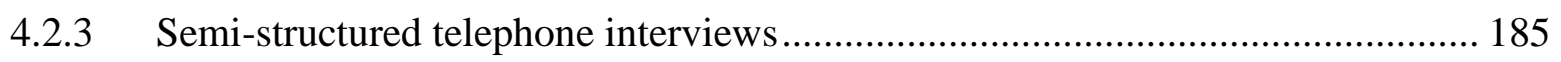

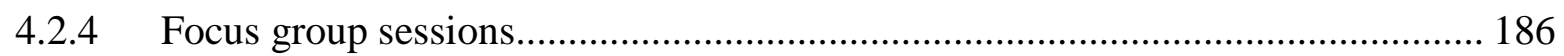

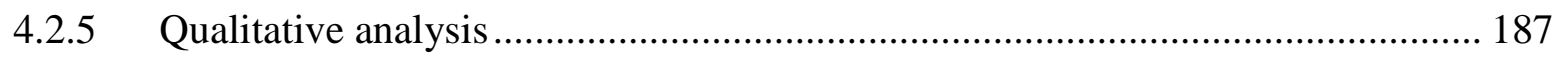

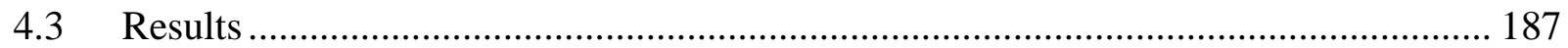

4.3.1 Diabetes Distress Domains ........................................................................ 188

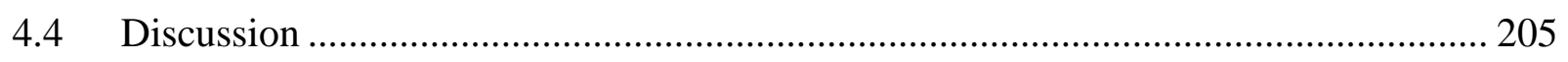

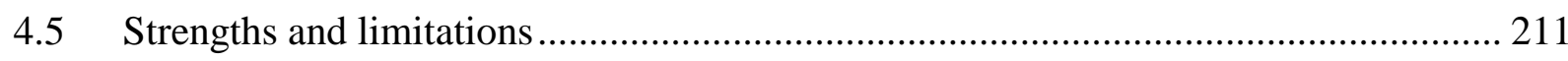

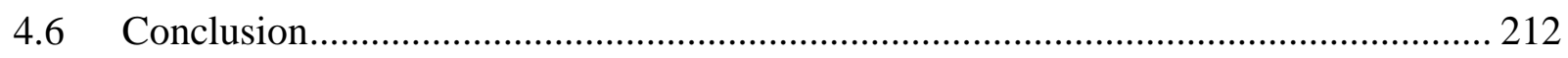

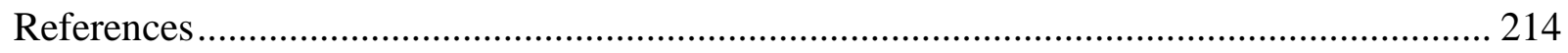

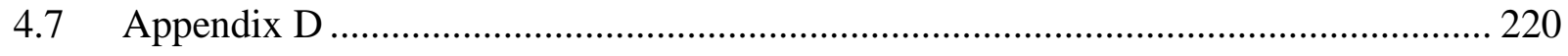

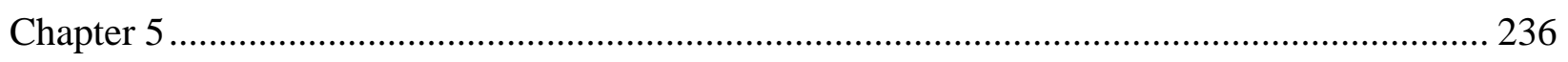

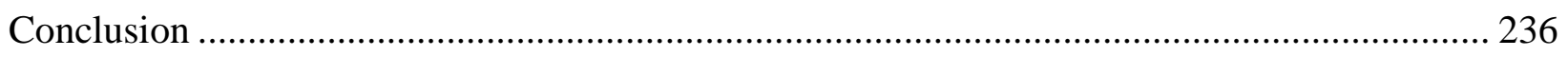

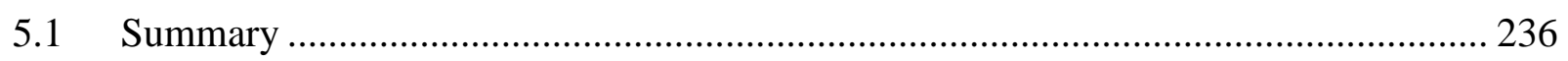

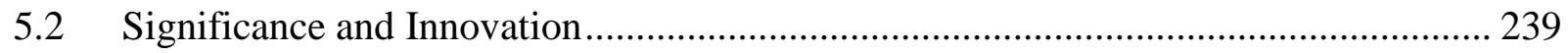

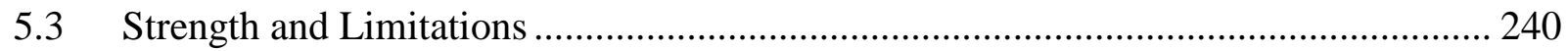

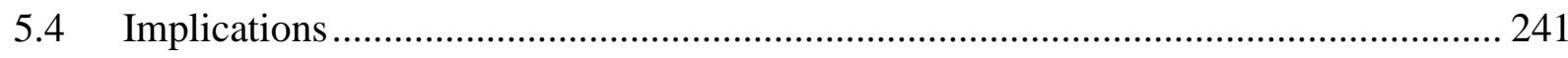

5.5 Recommendations for Future Research ………….............................................. 242

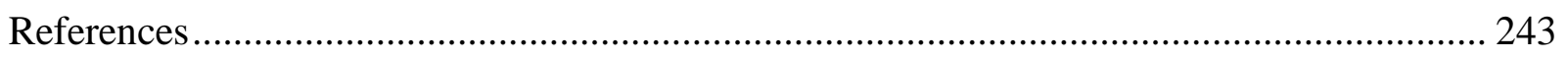




\section{Chapter 1}

\section{Introduction}

\subsection{Prevalence of Diabetes and Hypertension}

Type 2 diabetes mellitus (T2DM) is a chronic disease caused by an acquired and/or inherited deficiency of insulin by the pancreas or ineffective insulin production. ${ }^{1}$ The body is unable to respond properly to the action of insulin it has already produced. A T2DM diagnosis is based on several tests : (a) using fasting or random plasma glucose, (b) oral glucose tolerance test, or (c) glycosylated hemoglobin (HbAlc). ${ }^{1}$ Glycosylated hemoglobin or HbAlc measures the percentage of blood sugar attached to hemoglobin, the oxygen-carrying protein in red blood cells. It depends on the concentration of glucose in the blood and the duration of exposure and reflects the average plasma glucose over the previous 8-12 weeks. Thus, both the World Health Organization (WHO) and the American Diabetes Association (ADA) recommend measuring HbA1c as a confirmatory test for T2DM. ${ }^{2,3}$ T2DM is more common than type 1 diabetes mellitus and accounts for approximately $90 \%$ to $95 \%$ of all diabetes cases. ${ }^{4}$

Hypertension or high blood pressure is the condition in which the pressure of the blood flow through the artery wall is higher than normal. ${ }^{6}$ Studies have shown that diabetes and hypertension coexist in approximately $68.4 \%$ of diagnosed individuals. ${ }^{7,8}$ Moreover, cardiovascular disease (CVD) is four times higher in people who have both diabetes and hypertension than in those who have either hypertension or diabetes. ${ }^{9}$ The association between diabetes and hypertension can be explained by the role of the adrenergic system in both conditions. ${ }^{10}$ These mechanisms include incretin-mediated control of the renin-angiotensinaldosterone system and the calcium-calmodulin pathway. Incretin hormone regulation is associated with obesity and T2DM. ${ }^{11,12}$ Moreover, individuals who have uncontrolled 
hypertension and do not take antihypertensive medicines are at higher risk of developing T2DM. ${ }^{10}$

\subsubsection{Poor Health Status and High Prevalence of Chronic Diseases in the Appalachian Region}

West Virginia (WV) is the only state that is entirely within Appalachia. ${ }^{13}$ WV's unique geographic, demographic, and health characteristics may contribute to the higher prevalence of chronic diseases and poor health outcomes in the state. For example, WV is the third most rural state, with only 77 people per square mile. ${ }^{14}$ Rural residents have worse health and more injuries and death than urban areas. Further, rural residents differ in their health beliefs and attitudes from their urban counterparts in WV. They are more likely to be obese and hypertensive ${ }^{15,16}$, and receive fewer wellness checkups as compared to urban dwellers. ${ }^{17}$ Studies have shown that WV has more older residents (the second oldest), low educational levels, and low socioeconomic status, ${ }^{18}$ all of which are risk factors for chronic diseases such as T2DM and hypertension. In addition, it has the highest rates of diabetes (16.2\%), heart attacks (7.5\%), and heart disease $(7.4 \%) .{ }^{19-21}$ Hence, it is not surprising that the combined direct and indirect cost of health care due to diabetes is approximately $\$ 2.5$ billion in $\mathrm{WV}^{20,22}$

Chronic diseases account for $69.8 \%$ of all deaths in WV. ${ }^{23}$ The obesity rates in 2014 and 2016 were $35.7 \%$, and $37.7 \%$, respectively. In fact, a $2 \%$ increase in obesity rate within two years resulted in WV being ranked as the fattest state in the US. ${ }^{19,24}$ Obesity is frequently associated with chronic diseases such as diabetes, hypertension, and other CVDs. ${ }^{24}$ Also, the high obesity level has resulted in $\$ 1.4$ to $\$ 1.8$ billion in preventable direct medical costs for the state. ${ }^{24}$ Ageadjusted mortality rates (per 100,000) of obesity, T2DM, and hypertension in WV are 4.4, 45.3, and 15.1, respectively, whereas, for the US, these rates are $1.9,21.2$, and 8.5 , respectively. ${ }^{24}$ Hence, all three causes of mortality are significantly higher in WV than nationally. ${ }^{24}$ Finally, 
WV adults have the worst health life expectancy and second-worst well-being in the US. ${ }^{25}$ With a majority (91\%) of WV counties considered as medically underserved areas, access to preventative care and self-management education is a major concern. ${ }^{26-30}$ Thus, challenges to diabetes education and recommended preventive care/disease self-management are amplified, particularly in rural, medically underserved, and impoverished regions because of limitations in local infrastructure and health care resources.

Lastly, approximately $10.5 \%$ of the total US population has diabetes, whereas, in WV, the prevalence is approximately $16 \% .^{20,31}$ Diabetes is frequently associated with mental health issues such as depression, and thus the incidence of depression in WV $(23.8 \%)$ is also higher than the

general US population (17.4\%). ${ }^{31} \mathrm{~A}$ similar higher prevalence is also noted for hypertension, i.e., $42.7 \%$ as compared to $30.9 \%$ nationally. ${ }^{31}$ These statistics show the need for diabetes selfmanagement education programs that improve disease self-care in WV adults with diabetes and other comorbid chronic conditions.

\subsubsection{Psychological Stress and Diabetes Distress}

The term diabetes distress was first proposed in the peer-reviewed literature in 1995 by a group of psychologists and psychiatrists from the Joslin Diabetes Centre. ${ }^{32}$ Research has focused on understanding the emotional distress a T2DM individual may feel and the factors contributing to or perpetuating diabetes distress. Psychological stress, defined as an uncomfortable emotional experience accompanied by predictable biochemical, physiological, and behavioral changes in the person, ${ }^{33}$ complicates the effective management of T2DM. ${ }^{34}$ Although most people experience stress in their lifetimes, excessive stress can have adverse effects on the cardiovascular, neuroendocrine, and central nervous systems and the immune response. ${ }^{35}$ Adaptation and adjustments to the stress occur; however, chronic stress that persists in a person's 
life can cause serious psychological conditions such as anxiety, depression, and insomnia. ${ }^{34,33}$ This is because of the "wear and tear" of stress on the body that shifts homeostasis and is known as allostatic load. ${ }^{36}$ The altered equilibrium of the human body or homeostasis for chronically stressed individuals can influence increased heart rate and blood pressure and a higher level of metabolic hormones such as cortisol and insulin. ${ }^{36}$

T2DM individuals often experience frustration because of complex disease management, adherence to a strict diet and medication regimen for self-care, overwhelming relationships with health care providers, and social events with friends and families. ${ }^{37}$ This emotional stress, because of the continuous worries, concerns, and the burden of managing diabetes, is identified as diabetes distress. ${ }^{38,39}$ Hence, diabetes distress is defined as the emotional response of an individual with diabetes because of unpleasant stressors originating from diabetic complications and lifestyle changes. ${ }^{38}$ Research shows that T2DM individuals tend to be distressed about their diabetes management, which is different from those who are clinically depressed. ${ }^{40}$

Individuals with diabetes have higher rates of depression than those without the disease. ${ }^{41}$ Depression is a mood disorder that is diagnosed by detecting associated symptoms of emotion, cognition, and behavior. ${ }^{38}$ Depression and distress are positively associated. ${ }^{41-43}$ Furthermore, severe or exacerbated diabetes distress could lead to depression in the diabetic person. ${ }^{44}$ Hence, with the high prevalence of both diabetes and depression in WV, we can expect a high prevalence of diabetes distress in T2DM individuals.

Diabetes distress has been assessed by multiple scales and measurement methods in the last several decades. ${ }^{38}$ The Questionnaire on Stress in Patients with Diabetes-Revised (QSD-R) and Problem Areas in Diabetes scale (PAID) were developed to measure the emotional response of the diabetic person to the disease. ${ }^{32,45}$ However, these scales were criticized for their general 
assessment, not being extensive, and not exploring different aspects of diabetes management. ${ }^{37,40}$ Therefore, Polonsky and colleagues developed the Diabetes Distress Scale (DDS) ${ }^{37,40}$ This scale has 17 questions that are divided into 4 domains: emotional burden, physician-related burden, regimen-related burden, and interpersonal distress. ${ }^{40}$

Besides survey measures to assess diabetes distress, studies have also used clinical markers such as serum cortisol to assess the individual's distress. Cortisol is a major glucocorticoid hormone secreted by the adrenal cortex during psychological and physical stress. ${ }^{46-48}$ The physiologic reaction to distress occurs in the hypothalamic-pituitary-adrenal axis (HPA) pathway that is activated during acute and chronic stress. The activated hypothalamus signals the anterior pituitary gland to secrete the adrenocorticotrophic hormone (ACTH), which eventually promotes the secretion of mineralocorticoids, e.g., aldosterone and glucocorticoids such as cortisol, in the bloodstream. ${ }^{47,49} \mathrm{~T} 2 \mathrm{DM}$ individuals often have elevated cortisol levels. ${ }^{49-51}$ It is assumed that T2DM individuals undergo chronic psychological stress that activates the HPA pathway to elevate serum cortisol levels. ${ }^{52}$ This chronic elevation changes the regular homeostasis of the body toward altered homeostasis or allostatic load. ${ }^{47}$ Chronic psychosocial stress can lead to hypertension and poor glycemic control in T2DM individuals..$^{39,53,54-56}$

\subsection{Diabetes Distress and Self-management Behaviors}

Research has consistently shown that diabetes distress is associated with lower levels of selfcare. $^{53,57-61}$ Diabetes self-management comprises of adherence to a healthy diet, physical activity, and medication regimen. Medication adherence or compliance is defined as "the extent to which an individual acts in accordance with the prescribed interval and dose of a dosing regimen." ${ }^{\prime 62}$ If a person follows the health care provider's recommendations about the medications' timing, dosage, and frequency, that person is compliant or adherent to the 
prescription. T2DM individuals' quality of life is related to their medication adherence. ${ }^{63} \mathrm{~T} 2 \mathrm{DM}$ individuals need to perform daily diabetes self-management activities, including taking medications as prescribed by their physician. Lower medication adherence results in a lower quality of life. ${ }^{64}$ Multiple studies have shown a relationship between diabetes distress and medication adherence. For example, Kumar noted that individuals with low physician-related distress, low interpersonal distress, and low regimen-related distress had significantly higher medication adherence. ${ }^{65}$ Individuals who had a higher level of medication adherence had lower diabetes distress. ${ }^{63}$ In another study of Asian adults with T2DM, participants with low diabetes distress had approximately three times higher likelihood of having high medication adherence as compared to those who had high diabetes distress. ${ }^{66}$

Physical activity is another important element in the self-management of T2DM. Evidence shows that physical activity alone can be as effective as a combination of diet and physical activity to lower the progression from prediabetes to T2DM. ${ }^{67,68}$ The American Diabetic Association recommends at least 150 minutes per week of physical activity for people who are either pre-diabetic or have T2DM. ${ }^{69} \mathrm{~T} 2 \mathrm{DM}$ individuals can reduce their risk for obesity, hypertension, hyperlipidemia, and cardiovascular complications by performing recommended physical activity ${ }^{70}$ Research also shows that physical activity and activity can effectively prevent and reduce psychological stress and anxiety. ${ }^{71,72}$ Meta-analysis and systemic reviews show that physical activity can help reduce clinical depression. ${ }^{73,74}$ Roshanaei-Moghaddam has shown that depression can be a risk factor for decreased physical activity. ${ }^{75} \mathrm{~T} 2 \mathrm{DM}$ individuals who participate in more physical activity show improved mood compared to those who lead a sedentary life. ${ }^{76}$ Although the relationship between depression and diabetes distress was noted earlier, ${ }^{44}$ limited research has been conducted on assessing the relationship between diabetes 
distress and physical activity. A general assumption can be postulated that diabetes distress and physical activity can have an inverse relationship.

Another important lifestyle factor related to diabetes self-management is diet. A healthy diet is important for T2DM individuals. A healthy diet improves the glycemic status (lower glycosylated hemoglobin) of T2DM individuals. ${ }^{77-80}$ In addition, having a healthy diet helps reducing obesity, and hypertension which are frequent comorbidities found in T2DM individuals. ${ }^{81,82}$ Research also shows that diet is associated with diabetes distress. ${ }^{34,11}$ Fisher and team reported that a healthier diet can help reduce diabetes distress. ${ }^{34,11}$

\subsubsection{Lifestyle Modifications Have Improved Diabetes Self-management}

In a traditional medical system, T2DM individuals are treated by health care professionals in clinical settings and receive medicine and health care advice. However, in recent decades, diabetes self-management education (DSME) has become an essential part of a holistic diabetes

care model. ${ }^{83}$ Vermunt et al. reported that a 2.5-year randomized controlled lifestyle intervention program significantly reduced diabetes risk factors. ${ }^{84} \mathrm{~A}$ meta-analysis has reported that obese T2DM individuals can benefit from intervention programs that help them manage their weight. ${ }^{85}$ Research has shown that along with pharmacological therapy, diabetes self-management programs aimed at managing diet and weight could effectively reduce the diabetic burden of the participants. ${ }^{86}$ The landmark UK Prospective Diabetes Study (UKPDS) proved that management of glycemic status was associated with significant improvement in reducing both micro- and macrovascular damage in T2DM individuals. ${ }^{87,88}$ Another influential study, the "Look AHEAD" trial, reported that intensive lifestyle intervention programs could improve the glycemic status, lipid profile, blood pressure, and overall quality of life among individuals with T2DM. ${ }^{89}$ Research has shown that diabetes self-management programs help participants improve their 
glycemic status. ${ }^{90}$ However, no study has explored the impact of lifestyle programs on reductions in diabetes distress in rural areas, as is proposed for this study.

\subsubsection{Lifestyle Programs at Faith-based Settings}

Public health intervention programs have utilized faith-based settings for many years. ${ }^{91}$ Faithbased locations provide an easily accessible and socially acceptable setting for community-based intervention programs. Furthermore, faith-based settings help build trust among the participants about the program. ${ }^{92}$ Numerous studies have shown faith-based lifestyle intervention programs, especially diabetes management programs, were effective in improving participants' health awareness and overall health status. ${ }^{91,93-103}$ For example, a 12-week, single-blinded, clusterrandomized community trial with two intervention arms conducted among African-Americans in a faith-based setting (churches) in Augusta, GA, helped reduce participants' weight and fasting plasma glucose levels. ${ }^{99}$ The educational sessions were done at churches. ${ }^{99}$ Another physical activity program in Pennsylvania included members of local churches randomly assigned to an intervention or a wait-listed control group. Results showed that the participants' physical activity improved. ${ }^{97}$ A feasibility trial among South Asians in the United Kingdom to reduce the risk of T2DM in faith-based settings has reported the study was socially acceptable to the community members. ${ }^{100}$ In addition, a feasibility study among African-Americans in North Carolina implemented a 12-week church-based physical activity intervention program in which the participants took part in 60-minute interactive sessions and high-energy dance aerobics at the local church. ${ }^{104}$ Results were similar to prior feasibility studies in a church setting, and the program participants' had successful weight loss and maintenance. ${ }^{104}$ Historically, faith-based organizations, such as churches, have been important places to provide care and service for the 
community members. Such a setting works as an acceptable common meeting place for the community and provides a strong infrastructure to deliver the intervention. ${ }^{92}$

\subsubsection{Community-based Participatory Research (CBPR) Improves the Success of Community Programs}

In recent decades, community-based participatory research (CBPR) has become a popular research strategy among public health researchers. ${ }^{105}$ CBPR is an approach to conducting research in which the researcher and community work together to develop and implement acceptable and culturally competent intervention methods. ${ }^{105,106}$ Active participation of community members in developing the intervention strategy is one of the major components of the CBPR study. ${ }^{107}$ Many public health researchers are now working on intervention programs to reduce the burden of complications of diabetes, including diabetes self-management programs. ${ }^{108}$ Involving community members in creating a culturally, linguistically, and health literacyappropriate lifestyle self-management program is an example of the CBPR approach. Intervention programs utilizing the CBRP approach for diabetes self-management have shown effectiveness and feasibility to implement in many target communities. ${ }^{109-114}$ Balagopal et al. conducted a 6-month CBPR-based diabetes prevention and management intervention in India, delivered by community health workers. Results showed that participants' knowledge of diabetes and comorbidities improved by approximately $50 \%$ after participating in the intervention, and the intervention successfully reduced participants' fasting blood glucose level and systolic and diastolic blood pressure. ${ }^{109}$ A CBPR-based approach to implementing a 12-week diabetes prevention education program in rural African communities helped its participants improve their knowledge of diabetes and healthy eating and increase their physical activities. ${ }^{110}$ A culturally appropriate diabetes self-management intervention delivered by community health workers was completed among American Samoa in 2012. ${ }^{112}$ At the end of the study, 28\% of the participants 
reduced their risk from a "diabetic high-risk" to a low-risk group. ${ }^{112}$ A qualitative study among the Mexican American population provided valuable information for family support to manage T2DM. ${ }^{113}$ Another qualitative study among American Indians in Montana offered participants' perspectives on barriers and facilitators of a healthy diet and physical activity in their communities. ${ }^{115}$ Participants shared valuable insights into encouraging the American Indian population to eat healthily and perform more physical activity. ${ }^{115}$ Such information sharing and the CBPR approach can be a valuable strategy in developing a culturally appropriate intervention in Appalachian communities.

\subsection{Models to Predict Behavior Change}

Changing health behavior is often a challenging task that requires an understanding of the underlying influencing factors related to the behavior. In that regard, health behavior theories help researchers and practitioners understand the underlying influencers and plan and implement behavioral interventions. ${ }^{116,117}$ Among several important health behavior theories, SelfDetermination Theory (SDT) is a meta-theory on human motivation that defines intrinsic and extrinsic sources of motivation and describes the roles of both intrinsic and extrinsic motivation on human behavior and social development. ${ }^{118}$ According to the SDT, a person's behavior is motivated by intrinsic and extrinsic motivating factors, and together, these two sets of factors influence the person to achieve the three basic human needs: autonomy, competence, and relatedness. According to Ryan and Deci, a person has a natural drive that inspires him/her to behave in certain ways. This internal drive is called intrinsic motivation. ${ }^{118}$ Extrinsic motivation comes from external sources and yields external rewards. ${ }^{118}$ Autonomy, defined as the person's feeling that he/she is the master of his/her own destiny and has at least some control over life and $^{118}$ competence, indicates the person's desire to master the tasks that are important to 
him/her. ${ }^{118}$ The third human need, relatedness, reflects the person's desire to develop close and affectionate relationships with others and to feel understood and cared for by others. ${ }^{118,119}$ Satisfaction and achievement of the three human needs, i.e., autonomy, competence, and relatedness, influence the initiation and maintenance of human behaviors. ${ }^{119}$ Prior meta-analysis has shown that utilization of SDT in health intervention programs yielded positive health outcomes. ${ }^{119}$ Research also indicates that adopting SDT in diabetes intervention programs can improve participants' medication adherence and quality of life. ${ }^{120}$

\subsection{Qualitative Research}

Qualitative method explores the understanding of participants' behavior "how and why people respond to disease management practices". In addition, such methods also provide comprehensive answers to questions on T2DM individuals' experiences and diabetes distress as meaning-making agents in everyday lives, have the flexible nature of exploration that is advantageous to the researchers, and can provide an in-depth understanding within their natural setting. ${ }^{121}$ Since there is a paucity of research on diabetes distress in rural Appalachian communities, use of qualitative approaches can unveil valuable information on participants' lived experiences. In addition, qualitative research can help create new research questions that can later be explored epidemiologically. ${ }^{122,123}$

There is a gap in the literature on T2DM individuals' perceptions about the benefits of selfmanagement programs to help them cope with their diabetes distress. Hence, qualitative research can be an excellent approach to assessing the DHSMP participants' views and perspectives on their diabetes distress and understanding of the impact of DHSMP program participation on diabetes distress. 
Qualitative description (QD), often cited as the first preference for qualitative researchers in the discipline of public health, is an appropriate approach for answering these research questions. ${ }^{124}$ QD allows researchers to examine an issue through the lens of the participants by exploring how they describe their own experiences related to the issue in question. Instead of applying any philosophical idea or building any specific theory from the qualitative exploration, the researchers learn more about the overall situation by exploring participants' surface-level descriptions of the issue. ${ }^{124}$

\subsection{Specific Aims}

The objective of this doctoral research was to determine whether the Diabetes and Hypertension Self-Management Program (DHSMP) can reduce the burden of distress in the participants. The central hypothesis was that educating individuals to improve their self-management of diabetes and other comorbid conditions would help them cope with diabetes distress and improve disease outcomes. The rationale for this study was that effective disease self-management through lifestyle modifications could reduce diabetes distress in T2DM individuals. If the DHSMP is found to reduce diabetes distress, the findings will have the potential to improve individuals' self-care and overall health status and delivery of lifestyle programs to address disease distress and coping.

As part of a larger study, this research utilized data from the DHSMP, a 12-week randomized control trial (RCT) lifestyle intervention for adults with T2DM and high blood pressure in West Virginia (2018-2019). Trained health coaches delivered the program sessions (75 minutes every week for 12 consecutive weeks) in two churches in Morgantown and Charleston, WV. Ninetyone participants were randomized into the intervention and wait-listed control group. Participants except two dropouts completed a baseline, 12- and 24-week assessments, which included 
anthropometrics, behavioral and clinical factors for the larger study. Since the wait-listed control group completed 24-week assessment prior to their program participation, baseline and 24-week assessments were used for associations and linear mixed models in this research. Diabetes distress was assessed using survey measures specific to diabetes distress and serum cortisol. Control variables included HbA1c, lipid profile as well as demographic variables.

Only limited research explores the effectiveness of lifestyle programs in addressing diseaserelated distress in T2DM individuals. While many diabetes self-management programs have been shown to improve fasting blood glucose (FBS) and HbA1c levels among the participants, ${ }^{125}$ no research has explored whether these programs can reduce overall diabetes distress in T2DM adults. Studies have measured diabetes distress with self-reported surveys or serum cortisol levels, but both measures will be used for this study.

\section{Aim 1: To evaluate the impact of DHSMP on changes in diabetes distress at 24 weeks from the baseline among the participants.}

Hypothesis 1a. Participants randomized to receive the 12-week DHSMP will have a significantly greater reduction in their total diabetes distress at 6 months, measured by the validated 17-item diabetes distress scale (DDS), as compared to the control group

Hypothesis $1 b$. Participants randomized to receive the 12-week DHSMP will have a significantly greater reduction in their emotional distress at 6 months, measured by the validated 17-item diabetes distress scale (DDS), as compared to the control group.

Hypothesis 1c. Participants randomized to receive the 12-week DHSMP will have a significantly greater reduction in their physician-related distress, measured by the validated 17item diabetes distress scale (DDS), as compared to the control group. 
Hypothesis 1 . Participants randomized to receive the 12-week DHSMP will have a significantly greater reduction in their regimen-related distress, measured by the validated 17item diabetes distress scale (DDS), as compared to the control group.

Hypothesis 1e. Participants randomized to receive the 12-week DHSMP will have a significantly greater reduction in their interpersonal distress, measured by the validated 17 -item diabetes distress scale (DDS), as compared to the control group.

Hypothesis 1f. Participants randomized to receive the 12-week DHSMP will have a significantly greater reduction in their serum cortisol level at 6 months as compared to the control group.

\section{Aim 2: To evaluate the impact of clinical variables (HbA1c, blood pressure, serum cholesterol) and behavioral variables (diet, physical activity, and medication adherence) on change in diabetes distress among participants of the DHSMP at 12 weeks and 24 weeks.}

Hypothesis 2.a: Glycosylated hemoglobin will have a positive association with diabetes distress [measured by the validated 17-item diabetes distress scale (DDS)] and serum cortisol at 12 weeks and 24 weeks.

Hypothesis 2.b: Blood pressure will have a positive association with diabetes distress [measured by the validated 17-item diabetes distress scale (DDS)] and serum cortisol at 12 weeks and 24 weeks.

Hypothesis 2.c: Serum cholesterol will have a positive association with diabetes distress [measured by the validated 17-item diabetes distress scale (DDS)] and serum cortisol at 12 weeks and 24 weeks. 
Hypothesis 2.d: Diet will have a negative association with diabetes distress [measured by the validated 17-item diabetes distress scale (DDS)] and serum cortisol at 12 weeks and 24 weeks.

Hypothesis 2.e: Physical activity will have a negative association with diabetes distress [measured by the validated 17-item diabetes distress scale (DDS)] and serum cortisol at 12 weeks and 24 weeks.

Hypothesis 2.f: Medication adherence will have a negative association with diabetes distress [measured by the validated 17-item diabetes distress scale (DDS)] and serum cortisol at 12 weeks and 24 weeks.

Aim 3a: To understand DHSMP participants' everyday lived experiences and challenges to managing diabetes and its related distress.

Aim 3b: To explore the efficacy of DHSMP participation on the participants' reported improvement in diabetes self-management behaviors and reducing diabetes-related distress.

\subsection{Methodology}

\subsubsection{Preliminary study}

I worked with my mentor, Dr. Ranjita Misra, on her pilot RCT to implement the DHSMP program in the spring of 2017 (HOPE grant funded by WVCTSI). The study examined the feasibility and efficacy of a 12-week DHSMP on improving self-management behavior and health outcomes. The program was implemented at the United Methodist Church in Morgantown, WV. Twenty adults with comorbid T2DM and HTN were recruited and randomized to the intervention and a 3-month wait-listed control group and completed 
assessments at baseline, 12 and 24 weeks. Diabetes distress was measured by the Diabetes Distress Scale (DDS); higher scores indicated higher disease-related distress. Changes in diabetes distress in the participants after the 12 -week intervention showed that $70 \%$ of the participants indicated a reduction in their distress. In general, diabetes distress declined in participants with $\mathrm{HbA1c} \leq 8 \%(\mathrm{r}=0.28, \mathrm{p}=0.4)$ and systolic/diastolic blood pressure $\leq 140 / 80 \mathrm{~mm}$ $\mathrm{Hg}(\mathrm{r}=0.045, \mathrm{P}=0.18)$.

\subsection{Diabetes and Hypertension Self-Management Program}

As indicated earlier, the DHSMP is a lifestyle education program in which T2DM individuals receive information, skills, and support to improve their self-management behaviors for improved health outcomes and to reduce comorbidities such as obesity and hypertension.

\section{Study Sites}

The DHSMP was implemented in two study sites: Morgantown and Charleston, the two largest cities in WV. The study site in Morgantown was the Woodland United Methodist Church, and the site in Charleston was the Village Chapel Church. Adults with comorbid T2DM and hypertension were recruited from the greater Morgantown and Charleston areas. The intervention was built on prior collaboration. Both churches provided a central location for the program sessions and data collection, adequate space and facilities to support the program, including large halls to conduct the program sessions and blood screenings, and free parking for the participants and the research team.

\subsubsection{DHSMP Curriculum}

The DHSMP curriculum was based on three evidence-based, widely accepted, and scientifically acclaimed disease self-management programs. DHSMP used the Centers for Disease Control and Prevention (CDC)'s National Diabetes Prevention Program (DPP) curriculum that incorporates 
lifestyle modification education and skills to prevent or delay T2DM. ${ }^{126}$ The second curriculum was from the Association of Diabetes Care \& Education Specialists' (previously known as the American Association of Diabetes Educators) ADCES7 self-care behaviors that provides 7 key behavioral areas (healthy coping, healthy eating, being active, monitoring blood sugar levels, taking medication, problem solving and reducing risks) for modifications and diabetes selfmanagement for better health outcomes. ${ }^{127}$ The ADCES7 was developed by diabetes care and education specialists to provide a framework for assessment, intervention, and evaluation of diabetes management programs. ${ }^{127}$ Lastly, the DHSMP team incorporated the Eighth Joint National Committee (JNC8) guideline developed by the American Family Physicians (AFP) to help with the self-management of hypertension. The AFP recommends this evidence-based guideline for adults suffering from hypertension. ${ }^{128}$ For example, the Dietary Approaches to Stop Hypertension or $\mathrm{DASH}^{82}$ eating plan that has shown to lower high blood pressure and improve cholesterol levels were incorporated into the healthy eating session. Hence, the DHSMP incorporated guidelines to ensure that the participants received current, evidence-based lifestyle education to manage both comorbid conditions of diabetes and hypertension.

\subsubsection{Health Coaches}

Use of lifestyle health coaching in the prevention and management of chronic disease is a popular and evidence-based public health strategy. Multiple studies have shown that health coaches can help people manage their chronic diseases and adhere to medicine and lifestyle modifications. ${ }^{129-131}$ The DHSMP used health coaches as trainers for program sessions and oneon-one coaching sessions with participants to answer questions and provide motivation and support for lifestyle modifications. The health coaches were graduate and undergraduate students of West Virginia University (WVU). The Health Coaches (HCs) were recruited through a 
competitive process and provided 15 hours of training by a multidisciplinary team of public health researchers and health care providers to familiarize them with the DHSMP curriculum, lifestyle modifications, study protocol, assessments, and standardization of data collection and educational sessions. During the training, the health coaches learned about chronic diseases such as diabetes and its comorbidities such as disease epidemiology, risk factors, prevention, and management strategies. Mock practice simulated the 12-week educational modules and feedback was provided. This allowed HCs to improve and ensure the quality of the program delivery, cultural tailoring and literacy appropriateness of the HCs and study personnel. The health coaches were also assigned 7-8 participants for weekly (regular) communications for follow-up after each session to answer questions, encourage lifestyle modifications and problem-solve as needed. Weekly HC communication used participant's preferred communication method selected by the participants, i.e., phone calls, text messaging, or email.

\subsubsection{Participant Recruitment}

Participants at both locations (Morgantown and Charleston, WV) were recruited using recruitment flyers, social media advertisements (Facebook), and presentations at diabetes support group meetings and churches. Recruitment flyers were distributed in local groceries, markets, and public places. Interested adults ( $\geq 21$ years old) with comorbid T2DM and hypertension completed the initial screening (done at churches or public places for easy access) for eligibility. The eligibility criteria included English-speaking adults who were $\geq 21$ years of age, had cooccurring diagnosis of T2DM and hypertension, willingness to be randomized and complete intervention and assessments. Women who were pregnant or breastfeeding, inability to perform the study assessments, and conditions that contraindicated DASH diet or limited physical activity excluded participants from the program. Eligible participants were invited to attend the baseline 
assessment and were randomized to the intervention and wait-listed control group by the study biostatistician Dr. Sijin Wen.

\subsubsection{Participants' Consent}

Potential participants provided consent to be part of the study prior to screening for eligibility. They were given information and informed of the objective of the DHSMP by the PI and/or program coordinator. All the eligible participants were given a paper copy of the consent form and reviewed it before signing it. Further, participants were asked to receive a medical clearance from their health care providers (if they had one) to participate in the study. All program sessions were video recorded, and participants who missed the session were provided the option to view it in a closed YouTube ${ }^{132}$ DHSMP account. Hence, a media release form was requested at the first program session so the program sessions could be video recorded and uploaded for viewing.

At the end of the DHSMP (for both intervention and wait-listed control group), qualitative assessments (focus groups and semi-structured phone interviews) were conducted to assess the participants' views on the benefits and barriers of lifestyle modifications and their satisfaction with the DHSMP. The questions and probes also included participants' perspectives of diabetes distress and how DHSMP helped manage their distress. For the qualitative assessments, interested DHSMP participants from the active intervention and wait-listed control group were recruited to participate in a 90-minute focus group at the intervention sites as well as phone interviews that lasted approximately 30-45 minutes. Focus group participants were provided with a cover letter with details of confidentiality and informed that they could leave the discussion at any time without penalty or consequence. They re-consented to participate in the focus group discussion. 


\subsubsection{Program Sessions and Study Procedure}

The 12-week DHSMP program included an educational session (75 minutes) per week, for 12 consecutive weeks. Completion of food log and activity log was encouraged, and food and activity logs were provided at every session. Participants were provided with pedometer to track their steps and Calorie King book ${ }^{133}$ to complete the logs every day of the week. For completing the food logs, participants had to list their daily food intake and provide details of the food items and quantities they consumed during each meal or snacks. Inclusion of beverages and water intake were required. Participants were educated on how to calculate macro nutrients (fat, protein, carbohydrates) and total calories per meal and for each day to complete the food logs. In the physical activity log, they recorded their daily steps using the pedometer. Participants were also encouraged to arrive 30 minutes before the program started so the program staff could measure their weight at each session. At the end of each session, participants were encouraged to develop a specific behavior-changing goal for the next week and 10 minutes were allowed for question and answers regarding materials covered during the session. During each program session, the health coaches delivered that week's educational materials, and discussed problemsolving regarding the previous week's materials. Additionally, during some sessions health coaches also demonstrated physical activity and practiced those with the participants. Healthy meals and cooking demonstrations were also provided to the participants during the nutrition sessions. In addition, potluck and model meals for festive events (Thanksgiving, Easter, etc.) were also provided. Participants received printed copies of each week's educational materials. As noted, the sessions were video-recorded and uploaded in a closed YouTube channel available to only the DHSMP participants. 


\subsubsection{Sample Size}

The total number of participants who were eligible and participated in the DHSMP intervention (active and wait-listed control groups) was 89 . Of the 89 participants who completed, A total of 42 participants agreed to participate in the qualitative assessments (semi-structured phone interviews $=33$ and 4 focus group sessions $(\mathrm{N}=23)$. Fourteen participants overlapped in their participation for both assessments. The 4 focus groups represented participants of intervention and control groups in both sites: Charleston, WV = 5 participants; Morgantown, WV intervention group $=6$ participants, and 2 focus groups for the wait-listed control group that consisted of 6 participants each. Appendix A Figure 1 provides a schematic representation of the sample size for the qualitative assessments.

\subsubsection{Quantitative Data Collection}

The current study was based on the study design employed by the parent RCT with a repeated measure study design (0, 3, 6 month assessments). The participants were randomized into an active DHSMP intervention group and a 6-month (24 weeks) wait-listed control group. The necessary pretest/baseline data were collected at the beginning of the program for both groups. For the intervention group, the baseline, 12-week, and 24-week data were collected on March 24 and $25^{\text {th }}$, June 16 and $17^{\text {th }}$, and September 15 and 16th, 2018, respectively. For the wait-listed control group, baseline and second baseline data were collected on March 24 and September 15, 2018, respectively. The second baseline overlapped the 24-week assessment for the intervention group and hence provided the data for comparison of DHSMP effectiveness between the two groups. The 12-week, and 24-week assessments of the wait-listed control group (i.e., the 36week and 48-week data for the program) were collected on December 1, 2018, and March 02, 2019. Each assessment included behavioral, clinical, and anthropometric data collection (see Appendix A Figure 2, study design schema). For each assessment, the participants' fasting serum 
samples were analyzed for glycosylated hemoglobin (HbA1c), serum lipids (total cholesterol, low-density lipoproteins or LDL, high-density lipoproteins or HDL, and triglycerides), and fasting serum cortisol level. Trained phlebotomists collected blood specimens, and laboratory testing was conducted by the Medical Laboratory facility associated with WVU Medicine Hospital in Morgantown. In both study locations, the blood samples were centrifuged and transported to the laboratory in Morgantown for standardization of blood tests. The participants completed three self-reported surveys that were used for this study: the Diabetes Distress Scale (DDS), Morisky Medication Adherence Survey (MMAS), and Lifestyle Profile II Survey.

\subsubsection{Measures}

\subsubsection{Demographics}

Demographic variables included age, gender, body mass index (BMI), race, level of education, number of household members, diabetes duration, hypertension duration, family history of diabetes, family history of hypertension, and access to health insurance. Age was calculated using the participant's date of birth. BMI was calculated using participants' height and weight. The education level was a categorical variable with multiple categories (less than or equal to high school, some college, associate's degree, college graduate, and master's professional and post-graduate degree). Responses to the education level were recategorized into less than or equal to high school, some college education or associate degree, and college graduate, postgraduate or professional degree. Race was a categorical variable, and responses included African American, American Indian or Alaskan Native, White, and other (including Hispanic or Latino and two or more races). Responses to the race variable were recategorized into non-White and White because there were very few non-White participants in the program, reflective of the $92 \%$ non-Hispanic Whites in WV. ${ }^{134}$ The participants' areas of residence, i.e., rural or urban area, were calculated using their self-reported zip codes and an online tool maintained by the Federal 
Office of Rural Health Policy (FORHP). ${ }^{135}$ FORHP uses the eligibility criteria for rural or urban areas that has been set up by three government agencies: the U.S. Census Bureau, the Office of Management and Budget (OMB), and the Economic Research Service, U.S. Department of Agriculture (USDA-ERS) ${ }^{136}$ FORHP defines rural areas outside an urbanized area (UA) or urban cluster (UC). A UA consists of an urban nucleus of 50,000 or more population, and a UC consists of the nucleus of UA and a total land area of less than 2 square miles with a population density of 1,000 per square mile. ${ }^{136}$ The number of household members was a continuous variable self-reported by the participants. Access to health insurance was a categorical variable that had 8 response options (uninsured, dual eligible, Medicaid, Medicare, Medicare plus supplemental, Medicare only, third party, and unknown) and was recoded into two options (yes, no). Diabetes duration and hypertension duration were two continuous variables self-reported by the participants. Family history of diabetes and hypertension were self-reported chronic conditions among family members: siblings (brother, sister), parents (father, mother), and other family members (grandparents, uncles, aunts). The response options were summed and recategorized into yes/no for family history.

\subsubsection{Dependent Variable}

Diabetes Distress: The validated Diabetes Distress Scale (DDS) was used for measuring participant's diabetes distress. The DDS is a 17-item Likert scale that measures the total diabetes distress as well as distress resulting from 4 domains: emotional distress, physician-related distress, regimen-related distress, and interpersonal distress. The response options for the questions ranged from 1 (not a problem) to 6 (a very serious problem). Responses were summed to create the total diabetes distress score and domain scores. A score of $\geq 3$ indicated the respondent had high levels of diabetes distress, while a score between 2.0 to 2.9 indicated moderate distress..$^{37,137}$ 
$\underline{\text { Serum cortisol: }}$ To measure serum cortisol level, participants' blood samples were collected by trained phlebotomists during each assessment, and the laboratory testing was conducted by the Medical Laboratory facility associated with WVU Medicine Hospital in Morgantown. Serum cortisol level is reported as $\mathrm{mcg} / \mathrm{dL}$.

\subsubsection{Predictor Variable}

Medication Adherence: The Morisky Medication Adherence Scale (MMAS) was used for measuring medication adherence in the participants. ${ }^{40,138,139}$ The MMAS is a valid and reliable self-reported measure for assessing medication adherence for individuals with T2DM and other

chronic conditions, first introduced in 1986. ${ }^{40,138,139}$ It had 8 questions with a range of 0-8, with scores of 8 reflecting high adherence, 7-6 reflecting medium adherence, and $<6$ reflecting low adherence. ${ }^{139,140}$

Lifestyle factors (Physical Activity and Diet): The Lifestyle Profile II Scale ${ }^{141}$ was used to measure the diet and physical activity of the participants. The scale had 52 items and 6 domains, of which 8 items were regarding diet and 9 were about physical activity. Participants reported their level of agreement to the diet and physical activity statement in four point response options: (1) never, (2) sometimes, (3) often, and (4) routinely. The questions were summed for a total range of 8-32 for diet, and 9-36 for physical activity scores. The summed numbers were divided by 8 (diet), and 9 (physical activity) to calculate the mean diet and physical activity score (range $1-4) .{ }^{142}$

Hba1c and Serum Cholesterol: These variables were measured using the participants' blood samples that were analyzed by the medical laboratory affiliated with West Virginia University (WVU) Medicine. HbA1c was measured in percentage, and serum cholesterol levels were measured in $\mathrm{mg} / \mathrm{dL}$. 
Attendance: Program attendance was measured by calculating the attendance score to determine a dose-response relationship between program attendance and diabetes distress. Total attendance score was calculated from attending the 12 weekly DHSMP educational sessions. Participants for the active intervention group were assigned a score of " 1 " for each session attended and " 0 " for missing the session. Hence, the attendance score ranged from 1-12 depending on the number of sessions attended during the 12 weeks of the DHSMP intervention. Participants in the wait-listed control group were assigned 0 for their attendance score.

All data were double-entered by two trained staff and electronically stored using Research Electronic Data Capture (REDCAP) ${ }^{143}$ managed by WV CTSI. After the initial data entry, the data management team reviewed the data for missingness and errors and corrected as necessary.

\subsection{Qualitative Data Collection}

For Specific Aim 3, focus group and semi-structured interviews were utilized to explore the participants' experiences and challenges in managing their diabetes-related distress and the impact of participating in the program on their self-management and associated diabetes distress. At the end of DHSMP, focus groups were conducted for quality improvement and program evaluation purposes. Two senior researchers (DD and RM) prepared questions and probes related to the program evaluation and quality assessment. Aim 3 specific questions were incorporated into the existing focus groups questions. Tanenbaum et al.'s qualitative study on diabetes distress was used as a reference to tailor questions for the current study. ${ }^{144}$ I (RK) worked with DD and RM to prepare the questions and probes related to diabetes distress. Focus groups were facilitated by DD, who is a quality study specialist, and the DHSMP program coordinator was trained to complete semi-structured telephone interviews with interested DHSMP participants. Audio recordings of the focus group sessions and phone interviews were transcribed verbatim 
via a professional transcription service $(\mathrm{Rev})^{145}$, and strategies for data coding and organization were identified prior to the analysis. Two coders (RK, and BK) independently cleaned, read, and open coded each transcript. ${ }^{146}$ NVIVO 12.0 software was used to facilitate data management and analysis ${ }^{147}$ for themes and subthemes to understand the factors related to the participants' diabetes distress, what challenges they faced in managing their diabetes distress, and how they resolved those challenges. The data were transcribed and analyzed for themes and subthemes to understand the factors related to the participants' diabetes distress, what challenges they faced in managing their diabetes distress, and how they resolved those challenges. Focus group questions and semi-structured questions and probes are included in the appendix section.

\subsubsection{Focus Group Meeting Place and Time}

Focus group sessions took place in the two churches where the DHSMP weekly sessions were conducted. Interested participants were notified of the date/time at least two weeks before the focus group session. Focus group meetings were approximately 90 minutes in duration.

\subsubsection{Logistics for the Focus Group Meetings}

DD facilitated the focus group sessions. Two other students and I assisted DD by taking notes during the focus groups, managing the recording devices, and keeping time, so the sessions did not run over time. The group discussions were audio-recorded in two recording devices for qualitative analysis of the focus groups. Before initiating the focus group session, participants were given a cover letter describing the study and their rights as participants and were debriefed on the audio recording procedures. After that, they were asked to provide verbal informed consent to participate in the focus group and permission to record the conversations. Focus groups questions and probes are included in the appendix section. 


\subsubsection{Semi-structured Interviews}

Semi-structured interviews were conducted by the DHSMP program coordinator, who asked the participants questions on how the DHSMP helped them reduce their diabetes distress (see Appendix). These interviews were conducted over the telephone and were recorded with an audio recorder. The phone interviews were scheduled based on participants' time preferences and lasted approximately between 30-45 minutes. Details of their confidentiality and verbal consent were obtained prior to the start of the interviews. Furthermore, participants were informed that they had thy option to not respond to any question they felt uncomfortable with or stop the interview at any time without penalty or consequence. Interviews were completed in a closed office space to ensure the confidentiality of participants' responses. 


\section{References}

1. DeFronzo RA, Ferrannini E, Zimmet P, Alberti G. International Textbook of Diabetes Mellitus. John Wiley \& Sons, Incorporated; 2015.

2. American Diabetes Association. Glycemic Targets: Standards of Medical Care in Diabetes-2018. 2018.

3. World Health Organization. Glycated haemoglobin (HbA1c) for the diagnosis of diabetes. Text. 2011 2011;doi:https://www.ncbi.nlm.nih.gov/books/NBK304271/

4. World Health Organization. Diabetes mellitus. World Health Organization,. Updated 2010-11-22 19:43:33. http://www.who.int/mediacentre/factsheets/fs138/en/

5. High Blood Pressure Facts (2018).

6. National Heart Lung and Blood Institute. High Blood Pressure. National Heart, Lung and Blood Institute. 2018. https://www.ncbi.nlm.nih.gov/pubmed/

7. Center for Disease Control and Prevention. Prevent Complications. Center for Disease Control and Prevention,. Updated 2018-05-10. 2018.

https://www.cdc.gov/diabetes/managing/problems.html

8. Center for Disease Control and Prevention. National Diabetes Statistics Report, 2020. 2020. https://www.cdc.gov/diabetes/pdfs/data/statistics/national-diabetes-statistics-report.pdf

9. Lastra G, Syed S, Kurukulasuriya LR, Manrique C, Sowers JR. Type 2 diabetes mellitus and hypertension: An update. Endocrinol Metab Clin North Am. Mar 2014;43(1):103-22.

doi:10.1016/j.ecl.2013.09.005

10. Cryer MJ, Horani T, DiPette DJ. Diabetes and Hypertension: A Comparative Review of Current Guidelines. The Journal of Clinical Hypertension. 2016/02/01 2015;18(2):95-100. doi:10.1111/jch.12638

11. Nauck MA, Meier JJ. Incretin hormones: Their role in health and disease. Diabetes, obesity \& metabolism. Feb 2018;20 Suppl 1:5-21. doi:10.1111/dom.13129

12. University of Washington. Incretins. https://courses.washington.edu/conj/bess/incretins/incretins.html

13. Appalachian Regional Commission. The Appalachian Region. 2018. https://www.arc.gov/appalachian_region/mapofappalachia.asp

14. US Census Bureau. 2010 Census: Population Density Data (Text Version). 2018. 201805-04T11:28:10.459-04:00. https://www.census.gov/data/tables/2010/dec/density-data-text.html 15. Zizzi S, Goodrich D, Wu Y, et al. Correlates of physical activity in a community sample of older adults in Appalachia. Journal of aging and physical activity. Oct 2006;14(4):423-38.

16. Parks SE, Housemann RA, Brownson RC. Differential correlates of physical activity in urban and rural adults of various socioeconomic backgrounds in the United States. Journal of epidemiology and community health. Jan 2003;57(1):29-35.

17. Newsome MA, Hazelett T, Sawhney M. Differences in Health-related Behaviors and Attitudes between Urban, Rural, and Isolated Households in Western West Virginia. The West Virginia medical journal. Jul-Aug 2015;111(4):30-7.

18. WV Department of Health and Human Resources. WV Health Status Atlas. http://www.wvdhhr.org/bph/oehp/atlas/default.htm\#WVUS

19. WV Department of Health and Human Resources. West Virginia Behavioral Risk Factor Surveillance System Report. 2016.

20. American Diabetes Association. The Burden of Diabetes in West Virginia. American

Diabetes Association. 2020. https://www.diabetes.org/resources/statistics/statistics-by-state 
21. WV Department of Health and Human Resources. West Virginia Behavioral Risk Factor Surveillance System Report. 2018. http://www.wvdhhr.org/bph/hsc/pubs/brfss/2018/BRFSS2018.pdf

22. Big Picture WV Diabetes Infographic

23. West Virginia Bureau for Public Health. West Virginia Vital Statistics. 2010. http://www.wvdhhr.org/bph/hsc/pubs/vital/2010/2010Vital.pdf

24. West Virginia Division of Health and Human Resources. Addressing obesity and related chronic diseases. 2018. https://dhhr.wv.gov/hpcd/FocusAreas/Pages/Combating-Obesity-inWest-Virginia.aspx

25. Jia H, Zack MM, Thompson WW. State Quality-Adjusted Life Expectancy for U.S. adults from 1993 to 2008. Quality of life research : an international journal of quality of life aspects of treatment, care and rehabilitation. Aug 2011;20(6):853-63. doi:10.1007/s11136-0109826-y

26. Jackson BM, Gutierrez ML, Relyea GE, et al. Unmet Primary Care Needs in Diabetic Patients with Multimorbidity in a Medically Underserved Area. Health services research and managerial epidemiology. 05/11/2017 2017;4doi:10.1177/2333392817702760

27. Boren SA. A review of health literacy and diabetes: opportunities for technology. Journal of diabetes science and technology. 2009 Jan 2009;3(1)doi:10.1177/193229680900300124

28. Chew L, Griffin J, Partin M, et al. Validation of screening questions for limited health literacy in a large VA outpatient population. Journal of general internal medicine. 2008 May 2008;23(5)doi:10.1007/s11606-008-0520-5

29. Cavanaugh K. Health literacy in diabetes care: explanation, evidence and equipment. Diabetes management (London, England). 2011 Mar 2011;1(2)doi:10.2217/dmt.11.5

30. Health Resources \& Services Administration. Medically Underserved Areas/Populations (MUA/P) Dashboard Health Resources \& Services Administration. 2020.

https://data.hrsa.gov/topics/health-workforce/shortage-areas

31. Center for Disease Control and Prevention. BRFSS Prevalence \& Trends Data. Accessed 2020/12/15. https://www.cdc.gov/brfss/brfssprevalence/

32. Polonsky WH, Anderson BJ, Lohrer PA, et al. Assessment of diabetes-related distress. Diabetes Care. Jun 1995;18(6):754-60.

33. Baum A. Stress, intrusive imagery, and chronic distress. Health psychology : official journal of the Division of Health Psychology, American Psychological Association. 1990;9(6):653-75.

34. American Psychological Association. Understanding chronic stress. http://www.apa.org/helpcenter/understanding-chronic-stress.aspx

35. Anderson NB. Levels of analysis in health science. A framework for integrating sociobehavioral and biomedical research. Annals of the New York Academy of Sciences. May 1 1998;840:563-76.

36. McEwen BS. Protection and damage from acute and chronic stress: allostasis and allostatic overload and relevance to the pathophysiology of psychiatric disorders. Annals of the New York Academy of Sciences. Dec 2004;1032:1-7. doi:10.1196/annals.1314.001

37. Polonsky WH, Fisher L, Earles J, et al. Assessing Psychosocial Distress in Diabetes. 2005-03-01 2005;doi:10.2337/diacare.28.3.626

38. Snoek FJ, Bremmer MA, Hermanns N. Constructs of depression and distress in diabetes: time for an appraisal. The lancet Diabetes \& endocrinology. Jun 2015;3(6):450-460.

doi:10.1016/s2213-8587(15)00135-7 
39. Hilliard ME, Yi-Frazier JP, Hessler D, Butler AM, Anderson BJ, Jaser S. Stress and A1c Among People with Diabetes Across the Lifespan. Curr Diab Rep. Aug 2016;16(8):67. doi:10.1007/s11892-016-0761-3

40. Fisher L, Glasgow RE, Mullan JT, Skaff MM, Polonsky WH. Development of a brief diabetes distress screening instrument. Ann Fam Med. May-Jun 2008;6(3):246-52. doi:10.1370/afm.842

41. Carper MM, Traeger L, Gonzalez JS, Wexler DJ, Psaros C, Safren SA. The differential associations of depression and diabetes distress with quality of life domains in type 2 diabetes. Journal of Behavioral Medicine. 2014/06/01 2014;37(3):501-510. doi:10.1007/s10865-0139505-x

42. Cassidy D, Karuthan C. Depression, distress and self-efficacy: The impact on diabetes self-care practices. PLoS One. 2017;12(3). doi:10.1371/journal.pone.0175096

43. Baradaran HR, Mirghorbani S-M, Javanbakht A, Yadollahi Z, Khamseh ME. Diabetes Distress and its Association with Depression in Patients with Type 2 Diabetes in Iran. Text. 2013 May 2013;

44. Gonzalez JS, Delahanty LM, Safren SA, Meigs JB, Grant RW. Differentiating symptoms of depression from diabetes-specific distress: relationships with self-care in type 2 diabetes. Diabetologia. 2008/10/01 2008;51(10):1822-1825. doi:10.1007/s00125-008-1113-X

45. Herschbach P, Duran G, Waadt S, Zettler A, Amm C, Marten-Mittag B. Psychometric properties of the Questionnaire on Stress in Patients with Diabetes--Revised (QSD-R). Health psychology : official journal of the Division of Health Psychology, American Psychological Association. Mar 1997;16(2):171-4.

46. Hannibal KE, Bishop MD. Chronic Stress, Cortisol Dysfunction, and Pain: A Psychoneuroendocrine Rationale for Stress Management in Pain Rehabilitation. Phys Ther. 2014;94(12):1816-25. doi:10.2522/ptj.20130597

47. Lee DY, Kim E, Choi MH. Technical and clinical aspects of cortisol as a biochemical marker of chronic stress. BMB Rep. 2015;48(4):209-16. doi:10.5483/BMBRep.2015.48.4.275 48. Dugué B, Leppänen EA, Teppo FA-M, Fyhrquist F, Gräsbeck R. Effects of psychological stress on plasma interleukins-1 beta and 6, C-reactive protein, tumour necrosis factor alpha, antidiuretic hormone and serum Cortisol. research-article.

http://dxdoiorg/101080/00365519309092553. 28 Aug 2009 2009;doi:11168348

49. Joseph JJ, Wang X, Spanakis E, et al. Diurnal salivary cortisol, glycemia and insulin resistance: The multi-ethnic study of atherosclerosis. Psychoneuroendocrinology. Dec 2015;62:327-35. doi:10.1016/j.psyneuen.2015.08.021

50. Bellastella G, Maiorino MI, De Bellis A, et al. Serum but not salivary cortisol levels are influenced by daily glycemic oscillations in type 2 diabetes. Endocrine. Jul 2016;53(1):220-6. doi:10.1007/s12020-015-0777-5

51. Duong M, Cohen JI, Convit A. High cortisol levels are associated with low quality food choice in type 2 diabetes. Endocrine. Feb 2012;41(1):76-81. doi:10.1007/s12020-011-9527-5

52. Chiodini I, Adda G, Scillitani A, et al. Cortisol secretion in patients with type 2 diabetes: relationship with chronic complications. Diabetes Care. Jan 2007;30(1):83-8. doi:10.2337/dc061267

53. Fisher L, Mullan JT, Arean P, Glasgow RE, Hessler D, Masharani U. Diabetes Distress but Not Clinical Depression or Depressive Symptoms Is Associated With Glycemic Control in Both Cross-Sectional and Longitudinal Analyses. 2010-01-01 2010;doi:10.2337/dc09-1238 
54. Matthews KA, Katholi CR, McCreath H, et al. Blood Pressure Reactivity to Psychological Stress Predicts Hypertension in the CARDIA Study. 2004-07-06 2004;doi:10.1161/01.CIR.0000133415.37578.E4

55. Gasperin D, Netuveli G, Dias-da-Costa JS, Pattussi MP. Effect of psychological stress on blood pressure increase: a meta-analysis of cohort studies. Cadernos de saude publica. 2018;25:715-726. doi:10.1590/S0102-311X2009000400002

56. Spruill TM. Chronic Psychosocial Stress and Hypertension. Curr Hypertens Rep. Feb 2010;12(1):10-6. doi:10.1007/s11906-009-0084-8

57. Hackett RA, Steptoe A. Type 2 diabetes mellitus and psychological stress - a modifiable risk factor. Nature reviews Endocrinology. Sep 2017;13(9):547-560. doi:10.1038/nrendo.2017.64

58. Zagarins SE, Allen NA, Garb JL, Welch G. Improvement in glycemic control following a diabetes education intervention is associated with change in diabetes distress but not change in depressive symptoms. OriginalPaper. Journal of Behavioral Medicine. 2011-06-21

2011;35(3):299-304. doi:doi:10.1007/s10865-011-9359-z

59. Aikens JE. Prospective Associations Between Emotional Distress and Poor Outcomes in Type 2 Diabetes. 2012-12-01 2012;doi:10.2337/dc12-0181

60. Tsujii S, Hayashino Y, Ishii H. Diabetes distress, but not depressive symptoms, is associated with glycaemic control among Japanese patients with type 2 diabetes: Diabetes Distress and Care Registry at Tenri (DDCRT 1). Diabetic medicine : a journal of the British Diabetic Association. 2012 Nov 2012;29(11)doi:10.1111/j.1464-5491.2012.03647.x

61. Chew BH, Vos R, Mohd-Sidik S, Rutten GE. Diabetes-Related Distress, Depression and Distress-Depression among Adults with Type 2 Diabetes Mellitus in Malaysia. PLoS One. 2016;11(3):e0152095. doi:10.1371/journal.pone.0152095

62. Cramer JA, Roy A, Burrell A, et al. Medication compliance and persistence: terminology and definitions. Value in health. 2008;11(1):44-47.

63. Jannoo Z, Wah YB, Lazim AM, Hassali MA. Examining diabetes distress, medication adherence, diabetes self-care activities, diabetes-specific quality of life and health-related quality of life among type 2 diabetes mellitus patients. J Clin Transl Endocrinol. 2017;9:48-54. doi:10.1016/j.jcte.2017.07.003

64. Khayyat SM, Mohamed MMA, Khayyat SMS, et al. Association between medication adherence and quality of life of patients with diabetes and hypertension attending primary care clinics: a cross-sectional survey. Quality of Life Research. 2019-04-01 2019;28(4):1053-1061. doi:10.1007/s11136-018-2060-8

65. Kumar N, Unnikrishnan B, Thapar R, et al. Distress and Its Effect on Adherence to Antidiabetic Medications Among Type 2 Diabetes Patients in Coastal South India. J Nat Sci Biol Med. 2017;8(2):216-20. doi:10.4103/0976-9668.210008

66. Chew B-C, Mohd-Sidik S, Sharif-Ghazali S. Negative effects of diabetes-related distress on health-related quality of life: an evaluation among the adult patients with type 2 diabetes mellitus in three primaryhealthcare clinics in Malaysia. Health and Quality of Life Outcomes. 2016;13(187)

67. Tuomilehto J, Lindstrom J, Eriksson JG, et al. Prevention of type 2 diabetes mellitus by changes in lifestyle among subjects with impaired glucose tolerance. $N$ Engl J Med. May 3 2001;344(18):1343-50. doi:10.1056/nejm200105033441801 
68. Knowler WC, Barrett-Connor E, Fowler SE, et al. Reduction in the incidence of type 2 diabetes with lifestyle intervention or metformin. N Engl J Med. Feb 7 2002;346(6):393-403. doi:10.1056/NEJMoa012512

69. Sigal RJ, Kenny GP, Wasserman DH, Castaneda-Sceppa C, White RD. Physical Activity/Exercise and Type 2 Diabetes. 10.2337/dc06-9910. Diabetes Care. 2006;29(6):1433. 70. Zinman B, Ruderman N, Campaigne BN, Devlin JT SS, American Diabetes Association. Physical Activity/Exercise and Diabetes Mellitus. 10.2337/diacare.26.2007.S73. Diabetes Care. 2003;26(suppl 1):s73.

71. Strohle A. Physical activity, exercise, depression and anxiety disorders. Journal of neural transmission (Vienna, Austria : 1996). Jun 2009;116(6):777-84. doi:10.1007/s00702-008-0092-x 72. Fox KR. The influence of physical activity on mental well-being. Public health nutrition. 1999;2(3a):411-418. doi:10.1017/S1368980099000567

73. Josefsson T, Lindwall M, Archer T. Physical exercise intervention in depressive disorders: Meta-analysis and systematic review. Scandinavian Journal of Medicine \& Science in Sports. 2014/04/01 2013;24(2):259-272. doi:10.1111/sms.12050

74. Mammen G, Faulkner G. Physical Activity and the Prevention of Depression: A Systematic Review of Prospective Studies. American journal of preventive medicine. 2013/11/01/ 2013;45(5):649-657. doi:https://doi.org/10.1016/j.amepre.2013.08.001

75. Roshanaei-Moghaddam B, Katon WJ, Russo J. The longitudinal effects of depression on physical activity. General Hospital Psychiatry. 2009/07/01/ 2009;31(4):306-315. doi:https://doi.org/10.1016/j.genhosppsych.2009.04.002

76. Lysy Z, Da Costa D, Dasgupta K. The association of physical activity and depression in Type 2 diabetes. Diabetic Medicine. 2008/10/01 2008;25(10):1133-1141. doi:10.1111/j.14645491.2008.02545.x

77. Coppell KJ, Kataoka M, Williams SM, Chisholm AW, Vorgers SM, Mann JI. Nutritional intervention in patients with type 2 diabetes who are hyperglycaemic despite optimised drug treatment--Lifestyle Over and Above Drugs in Diabetes (LOADD) study: randomised controlled trial. BMJ. 2010-07-20 2010;341(jul20 2):c3337-c3337. doi:10.1136/bmj.c3337

78. Song S, Lee J. Dietary Patterns Related to Triglyceride and High-Density Lipoprotein Cholesterol and the Incidence of Type 2 Diabetes in Korean Men and Women. Nutrients. 201812-20 2018;11(1):8. doi:10.3390/nu11010008

79. Brandão-Lima P, Carvalho G, Santos R, et al. Intakes of Zinc, Potassium, Calcium, and Magnesium of Individuals with Type 2 Diabetes Mellitus and the Relationship with Glycemic Control. Nutrients. 2018-12-08 2018;10(12):1948. doi:10.3390/nu10121948

80. Ojo O. Dietary Intake and Type 2 Diabetes. Nutrients. 2019-09-11 2019;11(9):2177. doi:10.3390/nu11092177

81. Paskett ED, Baltic RD, Young GS, et al. A Group Randomized Trial to Reduce Obesity among Appalachian Church Members: The Walk by Faith Study. Cancer Epidemiology Biomarkers \& Prevention. 2018-11-01 2018;27(11):1289-1297. doi:10.1158/1055-9965.epi-171085

82. National Heart Lung and Blood Institute. DASH Eating Plan. National Heart, Lung, and Blood Institute. 2021. https://www.ncbi.nlm.nih.gov/pubmed/

83. Xiaoqin He JLBW, Qiuming Yao, Ling Li, Ronghua Song, Xiaohong Shi, Jin-an Zhang. Diabetes self-management education reduces risk of all-cause mortality in type 2 diabetes patients: a systematic review and meta-analysis | SpringerLink. 2018;doi:10.1007/s12020-016$1168-2$ 
84. Vermunt PW, Milder IE, Wielaard F, et al. A lifestyle intervention to reduce Type 2 diabetes risk in Dutch primary care: 2.5 -year results of a randomized controlled trial. Diabet Med. Aug 2012;29(8):e223-31. doi:10.1111/j.1464-5491.2012.03648.x

85. Anderson JW, Kendall CW, Jenkins DJ. Importance of weight management in type 2 diabetes: review with meta-analysis of clinical studies. Journal of the American College of Nutrition. Oct 2003;22(5):331-9.

86. Stevens JW, Khunti K, Harvey R, et al. Preventing the progression to Type 2 diabetes mellitus in adults at high risk: A systematic review and network meta-analysis of lifestyle, pharmacological and surgical interventions. Diabetes Research and Clinical Practice. 2015/03/01/ 2015;107(3):320-331. doi:https://doi.org/10.1016/j.diabres.2015.01.027

87. Kela R, Davies MJ. Implications of UKPDS evidence. Practice Nursing. 2010;21(3):140142.

88. King P, Peacock I, Donnelly R. The UK Prospective Diabetes Study (UKPDS): clinical and therapeutic implications for type 2 diabetes. Br J Clin Pharmacol. Nov 1999;48(5):643-8. doi:10.1046/j.1365-2125.1999.00092.x

89. Pi-Sunyer X. The Look AHEAD Trial: A Review and Discussion Of Its Outcomes. Curr Nutr Rep. Dec 2014;3(4):387-91. doi:10.1007/s13668-014-0099-X

90. Lepard MG, Joseph AL, Agne AA, Cherrington AL. Diabetes Self-Management Interventions for Adults with Type 2 Diabetes Living in Rural Areas: A Systematic Literature Review. Curr Diab Rep. Jun 2015;15(6):608. doi:10.1007/s11892-015-0608-3

91. Levin J. Partnerships between the faith-based and medical sectors: Implications for preventive medicine and public health. Prev Med Rep. 2016;4:344-50.

doi:10.1016/j.pmedr.2016.07.009

92. National Center for Cultural Competence, Georgetown University Child Development Center, Georgetown University Medical Center. Partnerships between Health Care and FaithBased Organizations. 2001. https://nccc.georgetown.edu/documents/faith.pdf

93. Rhodes EC, Chandrasekar EK, Patel SA, et al. Cost-Effectiveness of a Faith-Based Lifestyle Intervention for Diabetes Prevention among African Americans: A Within-Trial Analysis. Diabetes Research and Clinical Practice. 2018/09/28/ 2018;doi:https://doi.org/10.1016/j.diabres.2018.09.016

94. Johnston JA, Konda K, Ablah E. Building Capacity Among Laity: A Faith-Based Health Ministry Initiative. Journal of Religion and Health. 2018/08/01 2018;57(4):1276-1284. doi:10.1007/s10943-017-0445-6

95. Kitzman H, Dodgen L, Mamun A, et al. Community-based participatory research to design a faith-enhanced diabetes prevention program: The Better Me Within randomized trial. Contemporary clinical trials. Nov 2017;62:77-90. doi:10.1016/j.cct.2017.08.003

96. Hou S-I, Cao X. A Systematic Review of Promising Strategies of Faith-Based Cancer Education and Lifestyle Interventions Among Racial/Ethnic Minority Groups. Journal of Cancer Education. 2017/09/13 2017;doi:10.1007/s13187-017-1277-5

97. Webb BL, Bopp MJ. Results of Walking in Faith: A Faith-Based Physical Activity Program for Clergy. Journal of Religion and Health. 2017/04/01 2017;56(2):561-574. doi:10.1007/s10943-016-0255-2

98. McElfish PA, Rowland B, Long CR, et al. Diabetes and Hypertension in Marshallese Adults: Results from Faith-Based Health Screenings. Journal of racial and ethnic health disparities. Nov 11 2016;doi:10.1007/s40615-016-0308-y 
99. Sattin RW, Williams LB, Dias J, et al. Community Trial of a Faith-Based Lifestyle Intervention to Prevent Diabetes Among African-Americans. Journal of community health. Feb 2016;41(1):87-96. doi:10.1007/s10900-015-0071-8

100. Willis A, Roshan M, Patel N, et al. A community faith centre based screening and educational intervention to reduce the risk of type 2 diabetes: A feasibility study. Diabetes Research and Clinical Practice. 2016/10/01/ 2016;120:73-80. doi:https://doi.org/10.1016/j.diabres.2016.07.025

101. Faith MS, Horn LV, Appel LJ, et al. Evaluating Parents and Adult Caregivers as "Agents of Change" for Treating Obese Children: Evidence for Parent Behavior Change Strategies and Research Gaps. 2012-03-06 2012;doi:10.1161/CIR.0b013e31824607ee 102. Gaillard T. Faith-Based Adult Learning Initiatives for Diabetes Education in the African American Community. Article. Adult Learning. Winter/Spring2007 2007;18(1/2):6-8. 103. Missouri Department of Health and Senior Services. Faith-based settings. 2018. https://health.mo.gov/data/InterventionMICA/HeartDiseaseandStroke/faithbased.html 104. Thompson WM, Berry D, Hu J. A Church-Based Intervention to Change Attitudes about Physical Activity among Black Adolescent Girls: A Feasibility Study. Public Health Nursing. 2013/05/01 2012;30(3):221-230. doi:10.1111/phn.12009

105. Horowitz CR, Goldfinger JZ, Muller SE, et al. A model for using community-based participatory research to address the diabetes epidemic in East Harlem. The Mount Sinai journal of medicine, New York. Jan-Feb 2008;75(1):13-21. doi:10.1002/msj.20017

106. Horn K, McCracken L, Dino G, Brayboy M. Applying community-based participatory research principles to the development of a smoking-cessation program for American Indian teens: "telling our story". Health education \& behavior : the official publication of the Society for Public Health Education. Feb 2008;35(1):44-69. doi:10.1177/1090198105285372

107. Harris J, Graue M, Dunning T, et al. Involving people with diabetes and the wider community in diabetes research: a realist review protocol. Systematic reviews. Nov 04 2015;4:146. doi:10.1186/s13643-015-0127-y

108. Lorig K, Ritter PL, Turner RM, English K, Laurent DD, Greenberg J. Benefits of Diabetes Self-Management for Health Plan Members: A 6-Month Translation Study. Journal of medical Internet research. Jun 24 2016;18(6):e164. doi:10.2196/jmir.5568

109. Balagopal P, Kamalamma N, Patel TG, Misra R. A community-based participatory diabetes prevention and management intervention in rural India using community health workers. The Diabetes educator. Nov-Dec 2012;38(6):822-34. doi:10.1177/0145721712459890 110. Cene CW, Haymore LB, Ellis D, et al. Implementation of the power to prevent diabetes prevention educational curriculum into rural African American communities: a feasibility study. The Diabetes educator. Nov-Dec 2013;39(6):776-85. doi:10.1177/0145721713507114

111. Chambers RA, Rosenstock S, Neault N, et al. A Home-Visiting Diabetes Prevention and Management Program for American Indian Youth: The Together on Diabetes Trial. The Diabetes educator. Dec 2015;41(6):729-47. doi:10.1177/0145721715608953

112. DePue JD, Rosen RK, Seiden A, et al. Implementation of a culturally tailored diabetes intervention with community health workers in American Samoa. The Diabetes educator. NovDec 2013;39(6):761-71. doi:10.1177/0145721713504630

113. McEwen MM, Murdaugh C. Partnering With Families to Refine and Expand a Diabetes Intervention for Mexican Americans. The Diabetes educator. Jul 2014;40(4):488-495. doi: $10.1177 / 0145721714528996$ 
114. Teufel-Shone NI, Gamber M, Watahomigie H, Siyuja TJ, Jr., Crozier L, Irwin SL. Using a participatory research approach in a school-based physical activity intervention to prevent diabetes in the Hualapai Indian community, Arizona, 2002-2006. Prev Chronic Dis. Sep 25 2014;11:E166. doi:10.5888/pcd11.130397

115. Brown BD, Harris KJ, Harris JL, Parker M, Ricci C, Noonan C. Translating the diabetes prevention program for Northern Plains Indian youth through community-based participatory research methods. The Diabetes educator. Nov-Dec 2010;36(6):924-35. doi:10.1177/0145721710382582

116. Rural Health Information Hub. Health Promotion and Disease Prevention Theories and Models. Rural Health Information Hub. 2021. https://www.ruralhealthinfo.org/toolkits/healthpromotion/2/theories-and-models

117. Crosby RA, Salazar LF, DiClemente RJ. How theory informs health promotions and public health practice. Health behavior theory for public health: Principles, foundations, and application. 2013:22-44.

118. Ryan RM, Deci EL. Self-Determination Theory. Center for Self-Determination Theory. https://selfdeterminationtheory.org/the-theory/

119. Ng J, Ntoumanis N, Thøgersen-Ntoumani C, et al. Self-Determination Theory Applied to Health Contexts: A Meta-Analysis. Perspectives on psychological science : a journal of the Association for Psychological Science. 2012 Jul 2012;7(4)doi:10.1177/1745691612447309 120. Williams GC, Patrick H, Niemiec CP, et al. Reducing the health risks of diabetes: how self-determination theory may help improve medication adherence and quality of life. The Diabetes educator. May-Jun 2009;35(3):484-492. doi:10.1177/0145721709333856

121. Nursing Co. What Is Qualitative Research? University of Utah. https://nursing.utah.edu/research/qualitative-research/what-is-qualitative-research.php 122. Magilvy JK, Thomas E. A first qualitative project: qualitative descriptive design for novice researchers. Journal for specialists in pediatric nursing : JSPN. Oct 2009;14(4):298-300. doi:10.1111/j.1744-6155.2009.00212.x

123. Carter SM, Centre for Values E, the Law in Medicine UoS, et al. Doing good qualitative research in public health: not as easy as it looks. New South Wales Public Health Bulletin. 2018;20(8):105-111. doi:10.1071/nb09018

124. Creswell JW, poth C, N. Qualitative Inquiry and Research Design (International Student Edition): Choosing Among Five Approaches. 4th ed. SAGE Publications, Inc; 2017.

125. MoraPablo, BuskirkAnn, LydenMaureen, G. P, BorsaLena, PetersenBettina. Use of a Novel, Remotely Connected Diabetes Management System Is Associated with Increased Treatment Satisfaction, Reduced Diabetes Distress, and Improved Glycemic Control in Individuals with Insulin-Treated Diabetes: First Results from the Personal Diabetes Management Study. research-article. https://homeliebertpubcom/dia. 2017-12-01

2017;doi:10.1089/dia.2017.0206

126. Center for Disease Control and Prevention. What Is the National DPP? 2018-0116T04:06:36Z 2018;

127. Tomky D, Tomky D, Cypress M, et al. AADE Position Statement. The Diabetes educator. 2008/05/01 2008;34(3):445-449. doi:10.1177/0145721708316625

128. James PA, University of Iowa IC, Oparil S, et al. 2014 Evidence-Based Guideline for the Management of High Blood Pressure in Adults: Report From the Panel Members Appointed to the Eighth Joint National Committee (JNC 8). JAMA. 2018;311(5):507-520.

doi:10.1001/jama.2013.284427 
129. Bennett HD, Coleman EA, Parry C, Bodenheimer T, Chen EH. Health coaching for patients with chronic illness. Family practice management. 2010;17(5):24.

130. Thom DH, Willard-Grace R, Hessler D, et al. The impact of health coaching on medication adherence in patients with poorly controlled diabetes, hypertension, and/or hyperlipidemia: a randomized controlled trial. Journal of the American Board of Family Medicine : JABFM. Jan-Feb 2015;28(1):38-45. doi:10.3122/jabfm.2015.01.140123

131. Thom DH, Ghorob A, Hessler D, De Vore D, Chen E, Bodenheimer TA. Impact of Peer Health Coaching on Glycemic Control in Low-Income Patients With Diabetes: A Randomized Controlled Trial. The Annals of Family Medicine. March 1, 2013 2013;11(2):137-144. doi:10.1370/afm.1443

132. Google LLC. Youtube. Google LLC. 2021.

133. Borushek A. The CalorieKing calorie, fat \& carbohydrate counter. 2018.

134. United States Census Bureau. QuickFacts: West Virginia. United States Census Bureau. 2020. https://www.census.gov/quickfacts/WV

135. Rural Health Information Hub. Am I Rural? Rural Health Information Hub. 2020. https://www.ruralhealthinfo.org/am-i-rural

136. Rural Health Information Hub. What is Rural? Rural Health Information Hub. 2021. https://www.ruralhealthinfo.org/topics/what-is-rural

137. Behavioral Diabetes Institure. Diabetes Distress Scale (DDS). Behavioral Diabetes Institure,. 2020. https://behavioraldiabetes.org/scales-and-measures/\#1448434304099-9078f27c$\underline{4106}$

138. Fisher L, Hessler DM, Polonsky WH, Mullan J. When is diabetes distress clinically meaningful?: establishing cut points for the Diabetes Distress Scale. Diabetes Care. Feb 2012;35(2):259-64. doi:10.2337/dc11-1572

139. Morisky DE, Green LW, Levine DM. Concurrent and predictive validity of a selfreported measure of medication adherence. Medical care. 1986:67-74.

140. Morisky DE, Ang A, Krousel-Wood M, Ward HJ. Predictive Validity of a Medication Adherence Measure in an Outpatient Setting. The Journal of Clinical Hypertension.

2008;10(5):348-354. doi:https://doi.org/10.1111/j.1751-7176.2008.07572.x

141. Walker SN, Sechrist KR, Pender NJ. The Health-Promoting Lifestyle Profile:

Development and Psychometric Characteristics. Nursing Research. 1987;36(2):76-81.

142. Asuzu CC, Walker RJ, Williams JS, Egede LE. Pathways for the relationship between diabetes distress, depression, fatalism and glycemic control in adults with type 2 diabetes. January 2017 2017;31(1):169-174. doi:10.1016/j.jdiacomp.2016.09.013

143. Vanderbilt University. About REDCap. https://projectredcap.org/about/

144. Tanenbaum ML, Kane NS, Kenowitz J, Gonzalez JS. Diabetes distress from the patient's perspective: Qualitative themes and treatment regimen differences among adults with type 2 diabetes. August 2016 2016;30(6):1060-1068. doi:10.1016/j.jdiacomp.2016.04.023

145. Rev. Rev.com; 2018. https://www.rev.com/

146. Khandkar SH. Open coding. University of Calgary. 2009;23:2009.

147. NVIVO. QSR International; 2020. https://www.qsrinternational.com/nvivo-qualitativedata-analysis-software

148. Mommersteeg PM, Herr R, Zijlstra WP, Schneider S, Pouwer F. Higher levels of psychological distress are associated with a higher risk of incident diabetes during 18 year follow-up: results from the British household panel survey. journal article. BMC Public Health. December 23 2012;12(1):1109. doi:10.1186/1471-2458-12-1109 


\subsection{Appendix A}

\section{Focus Group Questions}

We recently became interested in the concept of diabetes distress. Diabetes distress is defined as the emotional response of an individual with diabetes to stressors that originate from diabetes related complications, daily hassles and management of the disease. ${ }^{148}$ Diabetes distress includes, emotional distress (your own emotion related to diabetes and management of this issue including anger, anxiety etc), regimen related distress (regimen is the prescribed course of your medical treatment, any set of rules about medications, diet and physical activity that you should follow) physician related distress (support from health care provider on diabetes related care and concerns and interpersonal distress (lack of support, or no support at all or too critical support from family and friends).

1. We would like to hear from you about any diabetes-related distress you may have (currently or in the past), specific to the four areas I described earlier due to your disease (emotional distress, regimen related distress, physician related distress, and interpersonal distress).

2. Also, we would like to hear from you about any impact (positive and negative) that this program has had on your diabetes-related distress.

3. Would you be able to share any of your thoughts or ideas on how we can improve this program to help you better cope with managing diabetes distress? 


\section{Semi-structured interview questions and probes}

1. Please tell me what has been hard for you about having diabetes? What have you struggled with?

a. Probe:

i. Medical/Self-management (e.g. Glucose self-monitoring, taking medications, insulin)

ii. Emotional/personal.

iii. Social (family, fear of poor outcomes based on experiences of other people with diabetes).

iv. Talking to your doctor or health care provider about diabetes care.

2. Many people with diabetes find that their emotions affect their diabetes. Do you think your diabetes and emotions are related? How?

a. Probe:

i. Please think about your positive emotions

ii. What about negative emotions?

iii. Do you think emotions can affect diabetes and self-management?

1. If yes, how?

iv. Do you think diabetes affects your mood?

1. If yes, how?

v. What do you think about the emotional aspects of diabetes? From friends, family, health care providers?

3. Many people with chronic disease e.g. diabetes use lifestyle and educational programs to deal with the disease self-management. How do you feel the diabetes and hypertension selfmanagement program helped you to address the following diabetes related distress?

a. Emotional/personal issues 
b. Did the program give you information on how to talk to your doctor or health care provider about diabetes care?

i. If yes, how?

c. Do you think the program helped you to make changes in diet, physical activity, medication adherence, and stress?

i. If yes, how?

d. How do you think these changes helped you?

e. Do you think this program helped you to deal with emotional aspects of diabetes? If yes, who did you receive support from?
a. Health coaches?
b. Dr. Misra or other program staffs?
c. Family and friends?
d. Doctor or health care providers?

4. What did you struggle the most in making changes during the program?

a. Probe:

i. Think about your diet, food $\log$ ?

ii. Your physical activities, step counts?

iii. Monitoring your blood sugar and blood pressure?

iv. Taking medications and insulin?

v. Weight? 


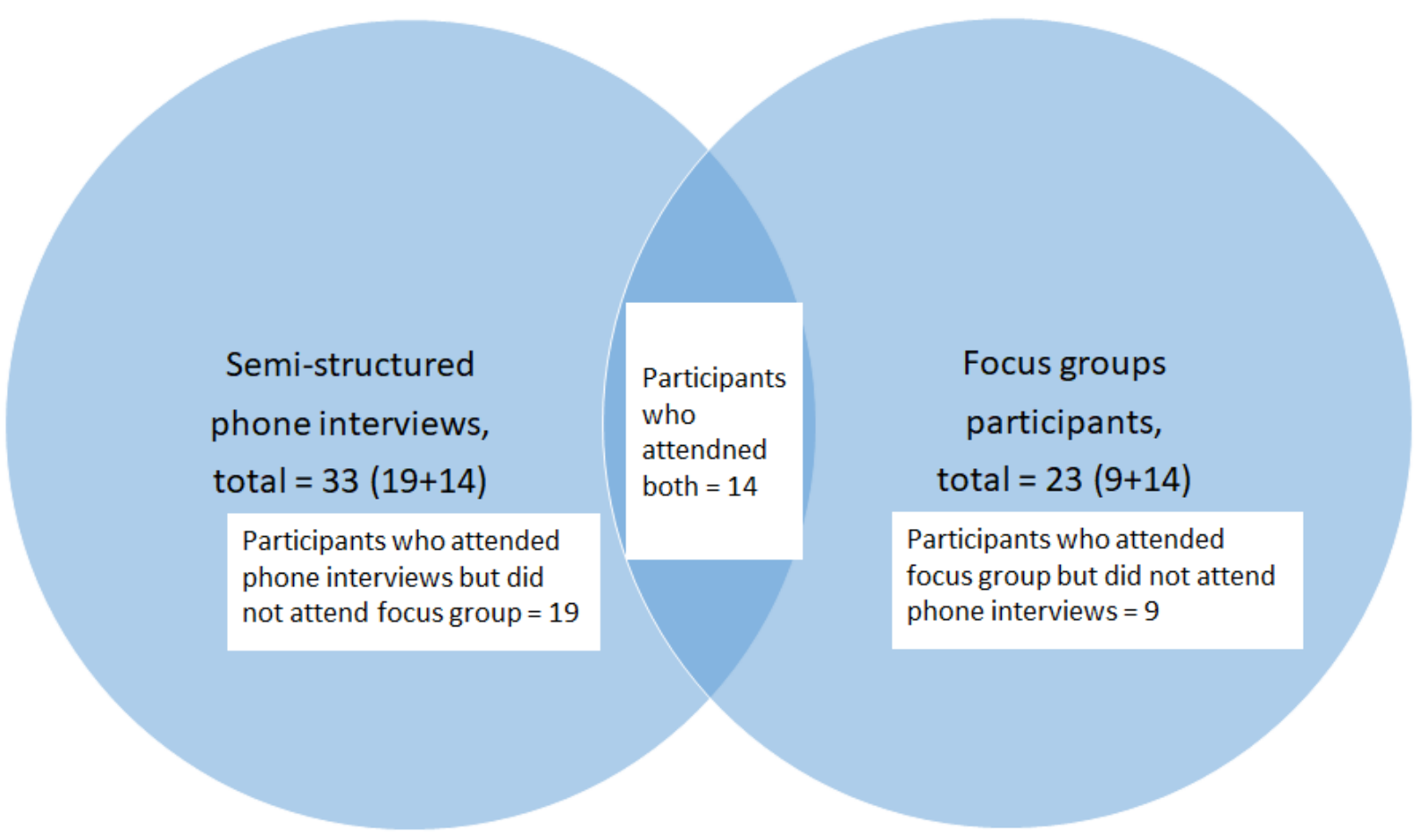

Figure 1. Sample size for qualitative focus group and semi-structured interviews 


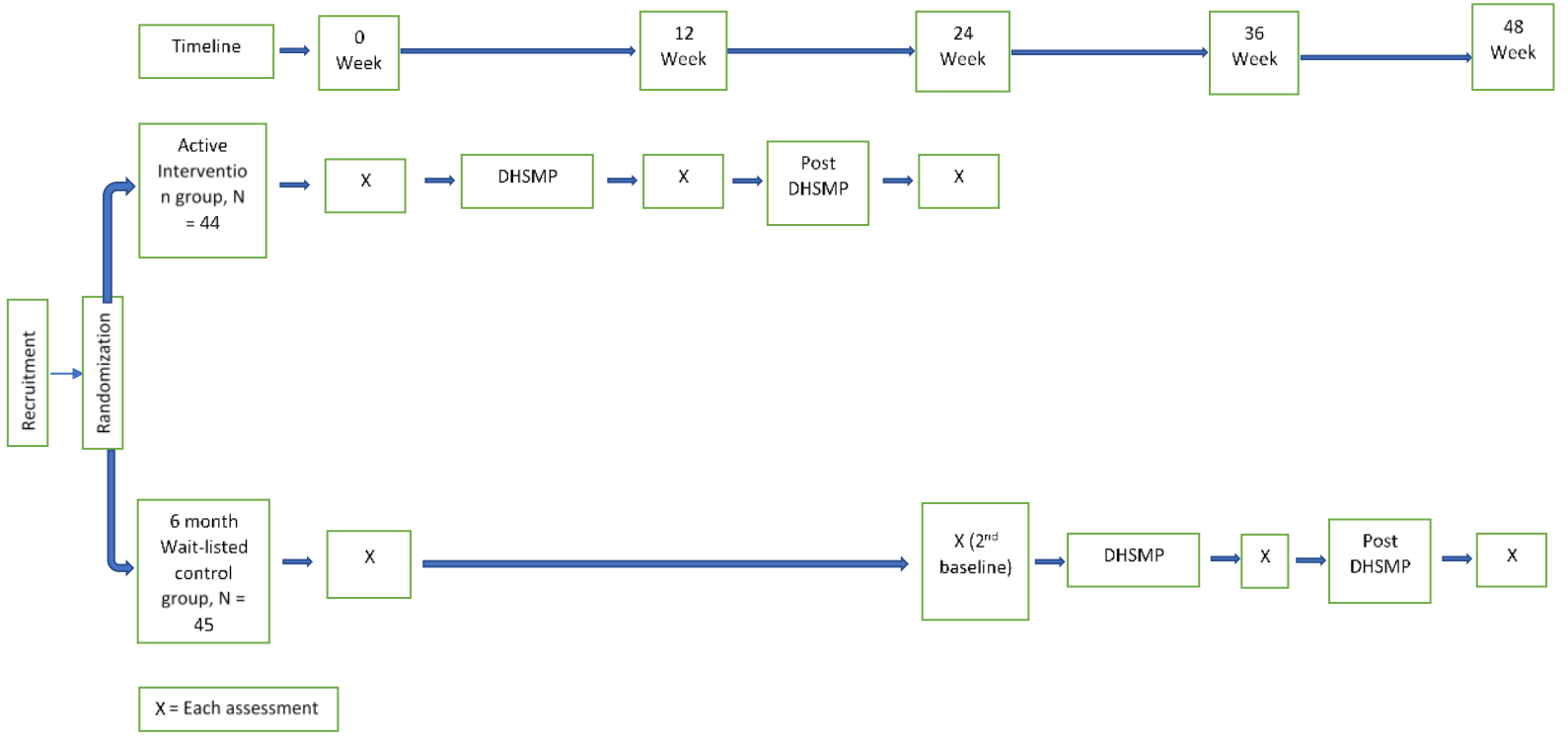

Figure 2. Study design schema. 


\section{Chapter 2}

\section{Aim 1: To evaluate the impact of DHSMP on changes in diabetes distress at 24 weeks from the baseline among the participants}

\subsection{Introduction}

Type 2 diabetes (T2DM), the most prevalent type of the disease, is a lifelong chronic condition. Between 1980 and 2014, the global prevalence of T2DM increased from $4.7 \%$ to $8.5 \% .{ }^{1,2}$ In the United States, 34.1 million individuals or $9.4 \%$ of the population are living with $\mathrm{T} 2 \mathrm{DM} ;{ }^{3}$ it is the $7^{\text {th }}$ leading cause of death in the US and globally. ${ }^{1,4}$ T2DM occurs when the body cannot produce adequate insulin or fails to utilize the available insulin produced by the pancreas. ${ }^{5}$ T2DM is a chronic metabolic disease that leads to significant complications if it is not controlled and managed properly. ${ }^{6}$ Long-term microvascular and macrovascular complications of T2DM include retinopathy, renal failure, foot ulceration, myocardial ischemia and infarction, and cerebral stroke. ${ }^{7}$ Myocardial ischemia, myocardial infarction, and cerebral stroke are among the leading global causes of death that are closely linked to this metabolic disease. ${ }^{1}$ The longer a person has T2DM, the higher is the person's risk of dying from ischemic heart disease and cerebral stroke. ${ }^{8}$ The economic cost of T2DM is also very high. The American Diabetes Association reported that in the US, the economic cost of T2DM was approximately $\$ 327$ billion in 2017 , of which $\$ 237$ billion was expended for direct treatment cost and $\$ 90$ billion for the loss of the patients' productivity over time. ${ }^{4}$

Stress is implicated both in the onset of diabetes and in influencing glycemic control. ${ }^{9}$ The complexities of the relationship between stress and diabetes are well known but less researched. Chronic stress that persists for years can alter the body's metabolic equilibrium (homeostatic). In turn, this situation can eventually have a negative impact on the endocrine system of the body. ${ }^{10}$ 
As a result, the levels of metabolic hormones such as insulin and cortisol increase. ${ }^{11}$ Studies have shown that psychological stress can alter the hypothalamic-pituitary-adrenal axis (HPA pathway), which influences the increased secretion of hormones such as cortisol from the anterior pituitary gland. ${ }^{10,12}$ The level of cortisol in serum increases due to both acute and chronic psychological stress. ${ }^{13,14}$ In individuals under chronic stress, the serum cortisol level remains at a higher level due to a damaged feedback mechanism caused by the chronic stress situation. ${ }^{10}$ Prior studies have shown that individuals with T2DM often have an elevated level of serum cortisol. ${ }^{12,15,16}$ Psychological stress is also frequently observed in individuals with $\mathrm{T} 2 \mathrm{DM}^{11}$ due to the emotional experience resulting from the biochemical, physiological, and behavioral changes in their life. ${ }^{17}$

Diabetes distress is psychological stress prevalent in individuals with T2DM. ${ }^{18-20}$ Because of the complexity of diabetes, individuals with T2DM are required to maintain specific selfmanagement activities that include healthy eating, regular physical activity, taking medications, and follow-up with healthcare providers. ${ }^{21}$ These self-management behaviors are often cumbersome. Therefore, individuals experience emotional stress and worries related to diabetes self-management and complications on a day-to-day basis. ${ }^{21-23}$ The entire spectrum of stress that comes from living with the disease can be categorized as emotional distress, interpersonal distress, physician-related distress, and regimen-related distress. ${ }^{23,24}$ Diabetes distress encompasses a broader and elaborate range of diabetes-related experiences that deals with the worries and concerns related to diabetes. ${ }^{24}$ It reflects a T2DM person's psychological traits with $70 \%$ of individuals with a high level of diabetes distress not clinically diagnosed with depression. ${ }^{25}$ However, diabetes distress is distinctly different from clinical depression. ${ }^{24,26}$ Clinical depression is characterized by the presence of at least five of nine diverse and well- 
defined symptoms (depressed mood, diminished interest, loss of appetite, loss of sleep, psychomotor changes, fatigue, guilt or worthlessness, impaired thinking, suicidality) that last a minimum of two weeks. ${ }^{24}$ Etiology behind these symptoms is unspecified, and the pathology or underlying stressors are unknown. ${ }^{24}$ Therefore, depression fails to consider the specific challenges faced due to diabetes.

Diabetes distress is commonly identified among T2DM individuals. ${ }^{11}$ A multinational study ${ }^{27}$ of approximately 9,000 individuals with diabetes across 17 countries revealed $44.6 \%$ of respondents had diabetes distress. ${ }^{27}$ Diabetes distress, including emotional distress, is associated with poor glycosylated hemoglobin (HbA1c), both in cross-sectional and longitudinal analyses in T2DM individuals. ${ }^{25,26,28-30}$ One study found a $10 \%$ reduction in diabetes distress reduced HbA1c by $0.25 \%$ among individuals with T2DM. ${ }^{28}$

Medication adherence, an important part of diabetes self-management, ${ }^{31}$ is also shown to lower diabetes distress in T2DM individuals ${ }^{32,33}$ However, higher diabetes distress is associated with a lower medication adherence ${ }^{34,35}$ and higher medication adherence was found to improve quality of life among T2DM individuals. ${ }^{36}$ Additional elements of diabetes self-management activity that impact diabetes distress are physical activity and diet. A combination of a healthy diet and adequate physical activity effectively improves glycemic status and lipid profile and reduces associated complications of T2DM. ${ }^{37-40}$ Studies also indicate that adequate physical activity and a healthy diet can help improve psychological stress among T2DM individuals. ${ }^{41-45}$

Diabetes self-management programs are shown to be effective in the control of individuals' glycemic status. ${ }^{46-48}$ Systematic reviews of randomized controlled trials on diabetes selfmanagement programs have noted that regardless of settings and other characteristic differences, diabetes self-management education (DSME) programs were successful in helping individuals 
with T2DM control their glycemic status and other lifestyle factors. ${ }^{47}$ Amageyi and colleagues showed that DSME programs successfully improved individuals' glycemic status, diabetes knowledge, and self-care behaviors and reduced emotional stress. ${ }^{48}$ In another systematic review, diabetes self-management programs resulted in improved clinical, psychological, and behavioral outcomes. ${ }^{46}$

West Virginia (WV), the only state situated entirely in the Appalachian region, has the highest prevalence of diabetes in the nation. ${ }^{49}$ Currently, $16.2 \%$ of the total adult population of WV has T2DM. ${ }^{50}$ The incidence rate of diagnosed diabetes is estimated at $14,000(0.96 \%$ of the adult population) new cases in WV. ${ }^{50}$ According to the 2017 WV Behavioral Risk Factor Surveillance System (BRFSS), the prevalence of obesity and hypertension in WV is also high, with $38.1 \%$ and $43.5 \%$, respectively. ${ }^{51} \mathrm{WV}$ ranks the highest and second highest in hypertension and obesity prevalence in the nation, respectively. ${ }^{51-53}$

More than half of WV (51\%) is officially designated a medically underserved area (MUA). ${ }^{54}$ Individuals living in MUAs tend to have low health literacy, which leads to poor management of chronic diseases such as diabetes and increase hospitalization rates ${ }^{55-58}$ Research shows that individuals with diabetes who live in MUAs receive inadequate primary care service and require enhanced access to diabetes health education to achieve diabetes self-management goals, psychological health care, and improved doctor-patient relationships. ${ }^{55}$ They also need support to improve their health literacy. ${ }^{55}$ Yet, limited studies in the Appalachian region or WV have focused on diabetes self-management education and its impact on reducing or managing diabetes distress. In fact, the current study may be the first to assess diabetes distress among T2DM individuals in WV. The aim of this study was to explore the efficacy of a community-based selfmanagement program to reduce diabetes distress, especially in rural individuals. More 
specifically, it evaluated the impact of participating in the Diabetes and Hypertension SelfManagement Program (DHSMP) on changes in diabetes distress (24 weeks vs. baseline) among the intervention group participants compared to the control group participants. The hypotheses related to the aims were as follows.

Hypothesis 1a. Participants randomized to receive the 12-week DHSMP will have a significantly greater reduction in their total diabetes distress at 6 months, measured by the validated 17-item diabetes distress scale (DDS), as compared to the control group. ${ }^{59}$

Hypothesis 1b. Participants randomized to receive the 12-week DHSMP will have a significantly greater reduction in their emotional distress at 6 months, measured by the validated 17-item diabetes distress scale (DDS), as compared to the control group. ${ }^{59}$

Hypothesis 1c. Participants randomized to receive the 12-week DHSMP will have a significantly greater reduction in their physician-related distress, measured by the validated 17item diabetes distress scale (DDS), as compared to the control group. ${ }^{59}$

Hypothesis 1d. Participants randomized to receive the 12-week DHSMP will have a significantly greater reduction in their regimen-related distress, measured by the validated 17item diabetes distress scale (DDS), as compared to the control group. ${ }^{59}$

Hypothesis 1e. Participants randomized to receive the 12-week DHSMP will have a significantly greater reduction in their interpersonal distress, measured by the validated 17 -item diabetes distress scale (DDS), as compared to the control group. ${ }^{59}$

Hypothesis 1f. Participants randomized to receive the 12-week DHSMP will have a significantly greater reduction in their serum cortisol level at 6 months as compared to the control group. 


\subsection{Methods}

I used data collected from the Diabetes and Hypertension Self-Management Program (DHSMP) to assess the impact of the program and program participation (attendance) on the participant's diabetes distress. The study was approved by the West Virginia University (WVU) Institutional Review Board (IRB).

\subsubsection{Study Design and Sample Selection}

\subsubsection{Diabetes and Hypertension Self-Management Program}

The DHSMP is one of the first randomized control trials (RCT) on diabetes self-management in WV. Participants included adults (21 years or older) with comorbid T2DM and hypertension. Pregnant or breastfeeding mothers, individuals with normal BMI, and those with restrictions for physical activity were excluded. The DHSMP program was implemented in two sites, Morgantown and Charleston, in WV during 2018-2019. Participants were randomly assigned to the intervention and wait-listed control group. Both the intervention and wait-listed control group participants attended educational sessions once a week for 12 consecutive weeks. Wait-listed control group participants waited six months ( 24 weeks) to attend the education sessions. The curriculum was adapted by combining curricula from two evidence-based diabetes selfmanagement programs: the Centers for Disease Control and Prevention (CDC)'s National Diabetes Prevention Program (DPP) and the Association of Diabetes Care \& Education Specialists' (previously known as the American Association of Diabetes Educators) ADCES7 self-care behaviors. ${ }^{60,61}$ The curriculum also included the Eighth Joint National Committee (JNC8) guideline developed by the American Family Physicians (AFP) for management of hypertension. ${ }^{62}$ Trained health coaches and experts led the educational sessions on diabetes selfmanagement. Health coaches were undergraduate and graduate students at WVU who received two days of training by the experts to familiarize themselves with the DHSMP curriculum and 
educational session materials. The study design schema (Appendix B Figure 1) is included in the appendix section.

\subsubsection{Data Collection}

A total of 89 individuals participated in the DHSMP program. The subjects included both intervention ( $\mathrm{N}=44)$ and wait-listed control group participants $(\mathrm{N}=45)$. Quantitative data were collected from the intervention participants at three time points: baseline, 12 weeks, and 24 weeks. For the wait-listed control group, there was one additional data collection time point: baseline 1, baseline 2 (24 weeks), 36 weeks, and 48 weeks. For clinical assessment, participants' fasting serum samples were collected at each assessment. They also completed anthropometrics and surveys during each assessment for this research: DDS, Morisky Medication Adherence Scale (MMAS) survey, and Lifestyle Profile II survey. In addition, demographics data were also collected at baseline.

\subsubsection{Measures}

\subsubsection{Demographic variables}

Demographic variables included age, gender, Body Mass Index (BMI), race, education level, number of household members, diabetes duration, hypertension duration, family history of diabetes, family history of hypertension, and access to health insurance. Age was calculated from the participant's date of birth. BMI was calculated using height and weight, measured by trained project personnel. The education level was a categorical variable, with multiple categories (less than or equal to high school, some college, associate degree, college graduate, and graduate degree). Responses to education levels were recategorized into three categories: less than or equal to high school, some college education or associate degree, and college graduate, postgraduate or professional degree. Race was a categorical variable (African American, American 
Indian or Alaskan Native, White, and others -include Hispanic or Latino and two or more races). Responses to the race variable were recategorized into non-White and White because there were very few non-White participants in the program and also because non-Hispanic Whites are the largest population group $(92 \%)$ in $\mathrm{WV} .{ }^{63}$

The participant's area of residence, i.e., rural or urban area, was calculated using the participant's self-reported zip code and an online tool maintained by the Federal Office of Rural Health Policy (FORHP).${ }^{64}$ To designate a rural or urban location, FORHP considers the eligibility criteria set up by three government agencies: U.S. Census Bureau, Office of Management and Budget (OMB), and Economic Research Service, and U.S. Department of Agriculture (USDA-ERS). ${ }^{65}$ For example, rural areas are outside an urbanized area (UA) or urban cluster (UC). A UA consists of an urban nucleus of 50,000 or more population, and a UC consists of the nucleus of UA and a total land area of less than two square miles with a population density of 1,000 per square mile. ${ }^{65}$

Number of household members was a continuous variable self-reported by the participants. Access to health insurance, originally a categorical variable with eight response options (uninsured, dual eligible, Medicaid, Medicare, Medicare plus supplemental, Medicare only, third party, unknown), was recoded into yes/no options (Table 1). Family history of diabetes and hypertension included these chronic conditions among family members: siblings (brother, sister), parents (father, mother), and other family members (grandparents, uncles, aunts). The response options were recategorized into family history (yes, no). Diabetes and hypertension duration were two continuous variables self-reported by the participants.

\subsubsection{Dependent and Predictor Variables}

\section{Dependent Variables}


Diabetes distress was measured using the DDS, ${ }^{59}$ a 17 -item Likert scale that is widely used to calculate a total diabetes distress score and four domains of distress: emotional distress, physician-related distress, regimen-related distress, and interpersonal distress. There were six response options for each of the 17 questions ranging from $1=$ not a problem to $6=$ a very serious problem. Responses were summed to calculate the total score and the four sub-scores (range 0-6). A score of $\geq 3$ indicates high distress, and a score between 2.0 to 2.9 indicates moderate distress. ${ }^{59}$ DDS measured total diabetes distress scores, and all four domains of distress (emotional distress, physician-related distress, regimen-related distress, and interpersonal distress) have been reported, proving the high internal consistency and validity in previous studies. ${ }^{66}$ According to Polonsky, internal consistency (Cronbach's alpha) of the scale was $0.93 .{ }^{67}$ Validity coefficients (Pearson correlation coefficient) of DDS were significantly associated with the Center for Epidemiological Studies Depression (CESD) scale $(r=0.55)$, disease management such as meal planning $(\mathrm{r}=0.30)$, exercise $(\mathrm{r}=0.13)$, and metabolic variables such as total cholesterol $(\mathrm{r}=0.20) .{ }^{66}$ In the current study, Cronbach's alpha of total diabetes distress, emotional distress, physician-related distress, regimen-related distress, and interpersonal distress was 0.96 , $0.94,0.93,0.94$, and 0.93 , respectively. Serum cortisol was measured by the clinical laboratory affiliated with West Virginia University (WVU) Medicine. The unit of measurement for serum cortisol was mcg/dL.

\section{Predictor Variables}

Clinical variables: HbA1c, and serum cholesterol (which includes HDL or high-density lipoprotein, LDL or low-density lipoprotein, and VLDL or very low-density lipoprotein) were measured by the clinical laboratory affiliated with West Virginia University (WVU) Medicine. 
Medication adherence: Self-reported medication adherence was measured using the Morisky Medication Adherence Scale (MMAS). The scale provides information on behaviors related to medication use that may be unintentional (e.g., forgetfulness) or intentional (e.g., not taking medications because of side effects). Prior research has shown good psychometric properties of the scale and used widely in studies with a reliability or Cronbach's alpha of $0.83 .{ }^{68-70}$ MMAS is an 8-item, structured, self-report measure of medication-taking behavior (range 0-8). Response choices are "yes" or "no" for items 1 through 7. Participant's responses were rated as 1 and 0 for each "no" and "yes" response, respectively, except for item 5, which was reverse coded. The response option for item 8 is a five-point Likert response scale. Responses for item 8 were "never", "once in a while", "sometimes", "usually", and "all the time", and these responses were scored $1,0.75,0.50,0.25$, and $0 .^{70}$ Total scores on the MMAS- 8 range from 0 to 8 , with scores of 8 reflecting high adherence, $7-6$ reflecting medium adherence, and $<6$ reflecting low adherence. Permission to use the scale was granted by Donald Morisky, the copyright holder of the instrument. ${ }^{71}$ In the current study, Cronbach's alpha for the medication adherence scale was 0.70 .

Lifestyle factors: The diet and physical activity subscales of the Health-Promoting Lifestyle Profile II (HPLPII) scale were utilized to measure the diet and physical activity of the participants. HPLPII scale is widely used by researchers to investigate health promoting lifestyle factors and the effects of health interventions to improve lifestyle. ${ }^{72,73}$ HPLPII scale has good overall reliability (Cronbach's alpha $=0.92) .{ }^{74}$ More specifically, reported Cronbach's alpha of the physical activity and diet subscales were 0.81 , and 0.76 , respectively. ${ }^{74}$ Physical activity, and diet were assessed by 8, and 9 questions, respectively. Each question had four Likert-type scale options $($ never $=1$, sometimes $=2$, often $=3$, and routinely $=4$ ). For diet, responses of item 3 (eat 6-11 servings of bread, cereal, rice, and pasta each day) were reverse coded. The questions 
assessed the frequency of participation in healthy dietary habits and physical activity. The total physician activity score and diet score were calculated by summing the 8 questions (range 8-32), and 9 questions (range 9-36), respectively, and dividing the sum by the total number of question to get the mean score; higher scores indicated a healthy dietary habit and an active lifestyle. ${ }^{74}$ In the current study, Cronbach's alpha for the physical activity and diet scale were 0.89 and 0.76 , respectively.

Program attendance: Program attendance was measured by calculating the attendance to the DHSMP educational sessions. Each session attendance was rated as "1" and absence as '0" and summed for the total attendance score (range 0-12). Program attendance allowed the determination of the dose-response relationship between program attendance and diabetes distress. Participants in the 12-week DHSMP intervention group had scores between 0-12; participants in the wait-listed control group were assigned attendance score of "0" for the active intervention time period.

\subsection{Data Analysis}

Data were double entered by two trained staff, reviewed for discrepancies, and corrected in the Research Electronic Data Capture (REDCap) hosted at West Virginia Clinical \& Translational Science. ${ }^{75,76}$ Microsoft Excel $^{77}$ was utilized to clean the data. Simple descriptive analysis was conducted for demographic variables. Mean and standard deviations (SD) were calculated for continuous parametric variables, and Median and Interquartile Range (IQR) were calculated for nonparametric continuous variables. Mean, and SD were reported as mean $\pm \mathrm{SD}$, and median and IQR were reported as median (IQR). Percentages were calculated for the categorical variables. Assumptions of normality and homogeneity of variance were checked using histogram, and Levene's test, respectively (Supplementary Table 1). 
Bivariate relationships were analyzed between the dependent variables (total diabetes distress, emotional distress, physician-related distress, regimen-related distress, and serum cortisol) and the independent variables. Independent variables included demographics (age, gender, education level, rural/urban residence, race, health insurance, diabetes and hypertension duration, family history of diabetes and hypertension, number of household members), lifestyle factors (physical activity, diet, medication adherence), glycosylated hemoglobin, serum cholesterol, systolic blood pressure, and program attendance). For parametric dependent variables, Pearson's correlation, and one-way ANOVA were utilized, and for nonparametric dependent variables, Spearman's correlation, Mann-Whitney U test, and Kruskal-Wallis test were used. Only variables with significant bivariate correlations with dependent variables were considered for multivariate analysis. Correlation matrices with significant relationships are shown in the appendix B (Figure 3a to Figure $3 h)$.

Multivariate models were used to assess the association between the dependent and predictor variables. In addition, a consideration of a minimum of 10 samples for each predictor variable in mixed-model analysis limited the number of predicted variable to ${ }^{78,79}$ Relevant predictor variables for mixed model analysis included diabetes duration, number of household members, education, serum cholesterol (LDL for physician-related distress) (VLDL for serum cortisol), glycosylated hemoglobin (for regimen-related distress), medication adherence, physical activity, diet, and program attendance.

To handle the repeated measurements over time from the same participants, a linear mixed model with main effect was conducted to assess the effect of program attendance (attendance score) on each of the six dependent variables: total diabetes distress and four domains (emotional distress, physician-related distress, regimen-related distress, and interpersonal distress) and 
serum cortisol. Because data from participants were collected for various time points $(0,3$, and 6 months), a repeated measure analysis was considered to be appropriate as it allowed to examine baseline and post-program changes in diabetes distress; participants were treated as a random effect in the model while time was treated as a repeated measure.

A linear mixed model is designed to handle missing data and will give unbiased estimates of effects provided that the probability of missing data depends only on the covariates in the model or data are "missing at random", which researchers often regard as a reasonable practice. ${ }^{80}$ The linear mixed model includes fixed-effects of independent variables and time, with participant effects treated as random to account for the dependence among repeated observations on the same participants. ${ }^{81}$ The significance level was set to $\mathrm{p}<0.05$. Data analysis was conducted using IBM SPSS Statistics for Windows, Version 27.0. ${ }^{82}$

\subsection{Results}

Descriptive statistics of the demographic variables (Appendix B Table 1) indicate the mean age of the participants was 60.82 [mean \pm SD $60.82 \pm 12.16$ ] years. The percentage of overweight and obese participants was $13.8 \%$ and $81.6 \%$, respectively. On average, the participants' median (IQR) diabetes and hypertension duration were 10.63 years (13.93) and 14.83 (22.28) years, respectively. Approximately two-thirds of the participants (64.04\%) were females, and $86.52 \%$ reported having a family history of both chronic conditions (i.e., diabetes and hypertension). The majority were Non-Hispanic Whites (90.2\%), which is representative of the WV NHW population. Considering that the two study locations were the two largest cities in WV, it is not surprising that approximately two-thirds of the participants were urban dwellers. The majority or $69.66 \%$ reported they lived in an urbanized area or urban cluster of the state. Participants had access to healthcare, with $92.13 \%$ who reported having private or government health insurance 
coverage. Approximately half (49.4\%) of the total participants had a bachelor, graduate or professional degree. The mean number of educational sessions the intervention group participants attended was 6.82 [mean \pm SD $6.82 \pm 4.15]$ (range 1-12).

Appendix B Table 2 shows the descriptive statistics of diabetes distress and its domains, serum cortisol, clinical variables (glycosylated hemoglobin, serum cholesterol, systolic blood pressure, diastolic blood pressure), and behavioral factors (medication adherence, physical activity, and diet) at baseline. No significant difference was noted between the two groups at baseline for all the study variables: dependent, clinical, and behavioral factors ( $p>0.10)$. The baseline median (IQR) diabetes distress (total score) of the intervention vs. wait-listed control group participants was 1.79 (1.19) and 1.74 (0.96), respectively, indicating mild diabetes distress (total). In general, participants reported moderate regimen-related distress [mean \pm SD $2.61 \pm 1.27$ ], and mild emotional distress [median (IQR) 1.60 (1.40)], physician-related distress [median (IQR) 1.00 (0.50)], and interpersonal distress [median (IQR) 1.33 (1.25)] at baseline. The mean physical activity and diet score was 2.06 [mean \pm SD $2.06 \pm 0.09$ ], and 2.85 [mean \pm SD $2.06 \pm 0.07$ ], respectively. This indicates the majority of participants reported being physically active "sometimes" and followed a healthy diet "often" in a general week (range 1=never; 4=always). Thus, a higher score indicated a healthy dietary habit and an active lifestyle. ${ }^{74}$ Appendix B Table 3 shows the correlations among the dependent variables (total diabetes distress, emotional distress, physician-related distress, regimen-related distress, and serum cortisol) and continuous predictor variables (age, diabetes duration, number of household members, medication adherence, physical activity, diet, glycosylated hemoglobin, and serum cholesterol levels). To describe the strength of the correlation coefficient, Dancey and Reidy's categorization of strengths was used (i.e., -0.100 to -0.399 and 0.100 to 0.399 as weak, -0.400 to 
-0.699 and 0.400 to 0.699 as moderate, -0.700 to -0.999 and 0.700 to 0.999 as strong).$^{83,84}$ To interpret the strength of the relationships between the dependent and independent variables, scatter plots were included in the supplementary data analysis section (Appendix B Figure 2)(only significant relationships were included). A weak correlation coefficient indicates a large variation in the spread of values of the dependent variables from the fitted line in the scatterplot, and a moderate correlation coefficient indicates a reasonable spread of dependent variable values from the fitted line in the scatterplot. Physical activity had a significant negative (weak) correlation with total diabetes distress $(\rho=-0.232, p=0.05)$, and regimen-related distress $(r=-$ $0.311, \mathrm{p}<0.01)$. A negative association indicated that participants who were physically active had lower total diabetes and regimen-related distress as compared to those who reported a sedentary lifestyle. Medication adherence was negatively correlated with total diabetes distress $(\rho=-0.337, p<0.01)$ (weak correlation), emotional distress $(\rho=-0.315, p<0.01)$ (weak correlation), and regimen-related distress $(\mathrm{r}=-0.448, \mathrm{p}<0.01)$ (moderate correlation). This showed that participants who reported to be adherent to their medication regimens were more likely to have lower total diabetes distress, emotional distress, and regimen-related distress than those who had moderate or low medication adherence. The number of household members had a negative (weak) correlation with serum cortisol $(r=-0.275, p=0.02)$, indicating that individuals who lived with household members had lower serum cortisol levels as compared to those who lived alone. A significant but weak positive correlation between glycosylated hemoglobin and regimen-related distress $(\mathrm{r}=0.367, \mathrm{p}=0.01)$ was also identified. To put it another way, participants who had poorer glycemic control (or higher glycosylated hemoglobin levels) were more likely to have higher regimen-related distress. In reviewing the lipid levels, higher levels of cholesterol, especially the two types of bad lipoprotein profiles or LDL $(\rho=0.236, p=0.04)$ was 
related to participant's physician-related distress, and participant's VLDL levels $(r=0.251, p=$ 0.04) were also linked to higher level of stress i.e., serum cortisol.

Appendix B Table 4 shows the bivariate relationship between the dependent variables (total diabetes distress, emotional distress, physician-related distress, regimen-related distress, and serum cortisol), and the categorical predictor variables (gender, education level, rural/urban residence, race, health insurance, diabetes and hypertension duration, family history of diabetes and hypertension). A Kruskal-Wallis $\mathrm{H}$ test showed that there was a statistically significant difference in total diabetes distress $(H=7.754, \mathrm{p}=0.02)$ by participant's educational levels (high school, some college/associate degree, college graduate or professional degree). The mean rank diabetes distress score was 39.43 for high school educated, 27.74 for some college education or associate degree, and 43.68 for participants with college or professional degree. This indicates that individuals with the lowest and highest educational level had higher diabetes distress than those with an associate degree or some college education; the highest level of diabetes distress was reported among educated participants. Similar pattern was observed for interpersonal distress $(H=7.13, \mathrm{p}=0.02)$ and participants' educational level. The lowest levels of interpersonal distress were reported among individuals with some college or having an associate degree (mean rank $=28.65$ ) as compared to those who had a college or professional degree $($ mean rank $=43.34)$ and high school degree (mean rank $=38.86)$. Significant differences in the regimen-related distress was also noted by educational levels $(F=3.18, \mathrm{p}=0.01)$. Regimenrelated distress was highest among educated individuals, i.e., those with a college or professional degree $(2.93 \pm 1.30)$ as compared to the other two groups. Participants with a high school degree also had high regimen-related distress $(2.82 \pm 1.35)$, but the lowest score $(2.08 \pm 1.30)$ was reported among those with some college or an associate degree. No other demographic variable 
(gender, race. rural or urban residence, health insurance, family history of diabetes) had any significant bivariate relationship with the dependent variables, except for family history of hypertension $(\mathrm{F}=3.91, \mathrm{p}=0.05)$. Participants who reported a family history of hypertension had significantly lower serum cortisol levels $(12.87 \pm 3.92)$ than those without a family history of hypertension $(15.46 \pm 5.03)$. Physician-related distress approached significance among the five categories of annual salary $(\mathrm{H}=8.36, \mathrm{p}=0.08)$, as did the mean rank of interpersonal distress among Non-Hispanic Whites and minorities $(\mathrm{H}=219.50, \mathrm{p}=0.098)$. Non-Hispanic White participants had higher interpersonal distress (mean rank $=39.07$ ) than the non-White participants (mean rank $=27.45)$. Physician-related distress was highest among participants whose annual income was between $\$ 75,000$ to 100,000 (mean rank $=45.88$ ), followed by participants with lowest income $(<\$ 25,000$; mean rank $=42.50), \$ 25,000$ to 50,000 (mean rank $=$ 37.84 ), and $\$ 50,000$ to $\$ 75,000$ (mean rank $=28.91$ ). Participants with an annual income of $\geq$ $\$ 100,000$ had the lowest physician-related distress (mean rank $=26.00)$.

Appendix B Table 5 shows linear mixed-effect model results to determine the effect of program attendance on diabetes distress (dose-response relationship). The table shows that program attendance was a significant predictor of total diabetes distress and regimen-related distress for participants $(\mathrm{p}<0.05)$. Program attendance, medication adherence, and dietary habits were significant determinants of total diabetes distress in the multivariable model. The coefficients, SE and $\mathrm{p}$-values were program attendance (coefficient $=-0.024, \mathrm{SE}=0.012, \mathrm{p}=0.05$ ), medication adherence $($ coefficient $=-0.109, \mathrm{SE}=0.046, \mathrm{p}=0.02)$, and diet $($ coefficient $=-0.353, \mathrm{SE}=$ $0.157, \mathrm{p}=0.03)$, respectively. In other words, participants who attended a higher number of educational sessions were more likely to have lower total diabetes distress; on average, for one point increase in educational session attendance (range 1-12), participants' total diabetes distress 
declined by 0.02 . Greater adherence to medication regimen by participants was associated with lower total diabetes distress. This implied that, for one point increase in medication adherence score (range 0-8), participants' total diabetes distress declined by 0.11 . Similarly, for a unit increase in healthy dietary habits (range 1-4), participants' total diabetes distress declined by 0.35. Higher diet scores or healthy dietary habits of participants were more likely to be associated with lower total diabetes distress. Medication adherence $($ coefficient $=-0.152, \mathrm{SE}=$ $0.063, \mathrm{p}=0.02)$ had a significant main effect on emotional distress in the model. Specifically, participants who adhered to their routine medication regimen were more likely to report a lower emotional distress. A one point increase in medication adherence score (range 0-8) reduced the participant's emotional distress by 0.15 . However, program attendance did not have any significant relationship with emotional distress.

Participants' lipid profile (LDL level) was associated with their physician-related distress. LDL level (coefficient $=0.005, \mathrm{SE}=0.002, \mathrm{p}=0.02)$ had a significant main effect. This implied that the rate of change in physician-related distress is 0.005 per unit increase in participants' LDL levels. Participants with higher lipids or LDL levels were more likely to have higher physicianrelated distress than those with lower LDL levels. Similar to emotional distress, program attendance did not have any significant relationship with physician-related distress.

Program attendance (coefficient $=-0.043, \mathrm{SE}=0.017, \mathrm{p}=0.01)$, medication adherence (coefficient $=-0.129, \mathrm{SE}=0.063, \mathrm{p}=0.04)$, diet (coefficient $=-0.430, \mathrm{SE}=0.217, \mathrm{p}=0.05)$, and glycosylated hemoglobin (coefficient $=0.224, \mathrm{SE}=0.070, \mathrm{p}<0.01)$ had a significant main effect on regimen-related distress. On average, for every increase in attendance for the DHSMP group educational sessions (range 1-12), participants' regimen-related distress declined by 0.04 . Similarly, a unit increase in participants medication adherence score (0-8) reduced regimen- 
related distress by 0.13 . Healthy dietary habits and each unit score increase (range 1-9) was also associated with a decline in participant's regimen-related distress by 0.43 . Also, for unit decrease in glycosylated hemoglobin levels reduced participants' regimen-related distress by 0.22 . In other words, participants who attended more educational sessions, adhered to their medication regimen, followed the dietary guidelines and had glycemic control were more likely have lower regimen-related distress.

The number of household members (coefficient $=-0.741, \mathrm{SE}=0.360, \mathrm{p}=0.04$ ), and VLDL (coefficient $=0.058, \mathrm{SE}=0.027, \mathrm{p}=0.03$ ) had a significant main effect on serum cortisol. Individuals who lived with household members had lower serum cortisol levels as compared to those who lived alone, with an increase in each additional member associated with a lower serum cortisol level by 0.74 . Individuals who lived with household members had lower serum cortisol levels than those who lived alone. On average, for one point decrease in VLDL levels, participants' serum cortisol level declined by $0.06 \mathrm{nmol} / \mathrm{L}$. Results also showed that higher VLDL levels were associated with higher serum cortisol levels indicating a poor lipid profile is associated with higher stress response among participants. Attending the DHSMP educational sessions did not have a significant impact on serum cortisol level in the model.

\subsection{Discussion}

There have been limited studies to date on the use of community-based programs to show associations between program attendance and diabetes distress in Appalachian adults. The current study revealed that participation in diabetes self-management programs, such as DHSMP, was associated with lower diabetes distress. The negative association observed in this study between program attendance and total diabetes distress and regimen-related distress suggests that community-based programs may offer an effective method for helping people 
reduce diabetes-related distress and acquiring better self-management skills to address their regimen-related distress to improve outcomes. Hence, the results add to the literature on the benefits of community-based diabetes programs for people with diabetes and comorbid conditions such as hypertension.

Multiple studies have shown similar results in six-month DSME programs. ${ }^{28,85-87}$ Zagarins and colleagues reported that program participants reduced their diabetes distress and $\mathrm{HbA} 1 \mathrm{c}$ after attending a six-month DSME program. ${ }^{28}$ Similarly, a significant reduction in diabetes distress was noted by Dubois et al. among participants of a 6-month diabetes self-management program. ${ }^{86}$ Further, a meta-analysis showed a significant reduction of diabetes distress over time among the participants ${ }^{85}$; however, various domains of diabetes distress were not included in the meta-analysis. In a community health-worker (CHW)-led diabetes self-management program, attendance helped the participants reduce their diabetes distress. ${ }^{87}$ However, program impact on reducing diabetes distress in newly diagnosed T2DM individuals was not shown to be significant, as reported by Davies et al. ${ }^{88}$

The mean diabetes duration of the current study participants, $12.85 \pm 10.24$ years, was indicative of the long duration of the disease. Hence, for Appalachian adults, individuals with long-standing T2DM may benefit more from DSME programs to reduce diabetes-related distress; future research must examine the impact on newly diagnosed adults in West Virginia as diabetes distress may be tempered by a honeymoon phase and lack of complications and distress even without adequate diabetes self-care among these individuals.

In this study, participants who experienced diabetes distress tended to have poor adherence to their medication regimen. Adherence to medication regimen for adults affected by diabetes $(\sim 30$ million) and comorbid hypertension ( 70 million) in the United States is suboptimal. ${ }^{3,53,89}$ Both 
chronic conditions increase the risk for cardiovascular disease, the leading cause of death in West Virginia and United States. ${ }^{7,90}$ Hence, adherence to appropriate medical therapy as well as daily medication regimen for both chronic conditions can result in blood sugar and blood pressure control, reducing disease-related stress in individuals. Prior research has reported that individuals with higher levels of medication adherence have lower levels of diabetes distress. ${ }^{36}$ Conversely, another study noted that T2DM individuals with higher diabetes distress had significantly lower medication adherence. ${ }^{91}$ Yet in another study by Chew and colleagues, T2DM adults who were adherent to their medication regimens had three times lower diabetes distress than those who did not. ${ }^{22}$ Hence, DHSMP educational sessions provided content (e.g., understand, side effects, consequences of non-adherence, etc.) to improve medication-related patient education. They were also provided with guidelines and strategies to improve adherence to their mediation that may have resulted in a reduction in their diabetes-related distress.

Diabetes distress is influenced by a number of lifestyle factors, some of which are modifiable. In this study, we identified healthy dietary changes as a predictor of reducing diabetes distress. Diabetes is often associated with serious complications, such as heart disease, kidney failure, and stroke in West Virginia adults. ${ }^{92}$ Lack of nutrition knowledge has been reported to be a barrier to self-care in Appalachian adults. ${ }^{93}$ Hence, learning how to eat healthy can play a major role in lowering distress, especially in areas where people do not have access to low-cost fresh produce and other healthful whole foods, free nutrition, and diabetes education programs. The low socioeconomic status of the current study participants and the rural classification of the state makes access even more complex. Hence, the DHSMP educational sessions provided nutrition knowledge and skills regarding diabetes-related dietary modifications. In addition, health coaching, program handouts, cooking demonstrations, and encouragement for easy-to-make 
changes were provided to improve adherence to a healthier diet. In a longitudinal study, Fisher et al. reported that a poor diet was associated with developing diabetes distress over time. ${ }^{94}$ The authors noted that the odds of having higher diabetes distress increased among individuals with T2DM who had poor control of their dietary behavior $(\mathrm{OR}=0.82, \mathrm{CI}=0.65-0.99) .{ }^{94}$ This corroborates with our findings as well as results from a pragmatic trial that examined the effectiveness of an intervention to reduce diabetes distress and improve self-management among non-clinically depressed adults with T2DM. ${ }^{95}$ Results showed a reduction in diabetes distress was accompanied by improvements in healthy eating, physical activity, and medication adherence but not changes in HbA1c. ${ }^{95}$

Diabetes distress was significantly correlated with poor glycemic status and concurs with prior research. ${ }^{96}$ Because diabetes distress is associated with poor disease management, it is not surprising to find that approximately $2 / 3^{\text {rd }}$ of rural adult participants in this study had moderate to high diabetes distress with the most distress related to their regimen-related daily self-care activities. Although the mean baseline HbA1c was comparatively low (7.3), participation in the DHSMP intervention demonstrated improvement in glycemic status. Improved knowledge of diabetes, self-management, and coping with stressors may have not only helped improve the glycemic status but also enhanced the individuals' motivation and problem-solving skills leading to a reduction in diabetes distress. ${ }^{25}$ Prior studies have shown a positive association between glycosylated hemoglobin and diabetes distress. ${ }^{25,29,97}$ Studies also show that interventions that include psychological components targeting diabetes distress improve the glycemic status and reduced diabetes distress. ${ }^{98,99}$

A somewhat surprising finding is that individuals with higher lipid levels (serum LDL and VLDL) had higher diabetes distress and serum cortisol levels. Since abnormalities in lipids 
increase the risk for heart disease, self-management education programs such as the DHSMP delivered by nonprofessional staff such as health coaches are effective in significant improvements in lifestyle changes (dietary habits, and physical activity). To reduce LDL and VLDL (or bad cholesterol), a strong emphasis should be placed on not only lifestyle changes but also reduced intake of saturated/trans fat and dietary cholesterol as well as intake of fibrous vegetables. Such knowledge was covered in the dietary sessions to empower and engage participants to reduce cholesterol and related distress. Furthermore, stress reduction techniques (e.g., breathing techniques) as well as health coach support, and one-on-one weekly discussions may be efficacious. Elevated LDL and VLDL levels are commonly found in individuals with diabetic dyslipidemia, leading to cardiovascular complications. ${ }^{100,}{ }^{101}$ Cholesterol management is highly recommended for individuals with T2DM to reduce cardiovascular complications. ${ }^{102}$ Cholesterol is the precursor to cortisol and other steroid hormones. ${ }^{103-105}$ Prior studies have suggested that elevated cholesterol levels can also elevate serum cortisol levels, especially in T2DM individuals. ${ }^{103,106}$ Cortisol is often elevated among T2DM individuals ${ }^{12,15,16}$, and considered a major chronic psychological stress marker. ${ }^{10,107,108}$ Although DHSMP did not include diabetes distress, domain-specific, stress reduction techniques, the general strategies for stress reduction mentioned above seemed to assist T2DM individuals in coping with their distress and associated cortisol levels. Future intervention programs should include diabetes distress-specific stress reduction strategies for further evaluation.

Another interesting observation was that participant's education levels did not have any impact on diabetes distress as noted in prior research. In this study, $50 \%$ of participants with a high school degree reported moderate to high diabetes distress, and $54.5 \%$ of educated participants reported moderate to high diabetes distress. Further studies are required to explain this positive 
association between educational level and diabetes distress. However, a large population-based study in Sweden also found individuals with high education had more psychological distress than those with low and medium education after adjustment for confounders. ${ }^{109}$ It is possible that educated participants' had improved knowledge and understanding of not following related selfcare regimen may lead to higher distress. No association was found between physical activity and diabetes distress. Individuals with long-standing diabetes often have physical limitations and disabilities that can prevent them from achieving the recommendations for physical activity. ${ }^{110}$ Sedentary behavior is generally high in this rural state, and West Virginia has the highest rates of adult obesity in the country. ${ }^{51}$ Mental and psychological issues such as depression, anxiety, and coping with stress also frequently noted among adults with T2DM contribute to lower physical activity. ${ }^{111}$ In addition, the small sample size and social desirability bias ${ }^{112}$ should also be considered since some participants might overreport their physical activities to have a more favorable image of themselves.

The results of this study should be interpreted with the following limitations in mind. This was a cross-sectional study with self-reported measures, including diabetes duration and family history of diabetes, that may have recall bias. In addition, these self-reported surveys may also have social desirability bias. Although the study utilized validated surveys (DDS, MMAS, and HPLPII), participants could have misunderstood or misinterpreted some of the questions. Furthermore, there were some missing responses, and participant dropouts reduced the power of the statistical analysis. Although there was a significant gender difference between the intervention and wait-listed control group at baseline, the independent effect of gender on the dependent variables was not assessed. Since DHSMP participants were randomized, the gender difference was by chance. Furthermore, due to the smaller sample size, the number of variables 
in the multivariate models was limited. The majority of the participants were Non-Hispanic Whites and were town dwellers or lived in the suburbs since the program sites were located in the two largest cities (Charleston and Morgantown) of WV. In addition, approximately twothirds of the program's participants had either an associate degree or higher. Thus, the current study's results may not represent the vast MUAs of the state and cannot be generalized to the WV population.

\subsection{Conclusion}

The current study showed DHSMP program attendance was an independent predictor of lower diabetes distress and some of its domains. Behavioral factors such as medication adherence and dietary habits were significant determinants of diabetes distress. Results also showed improvement in self-care behaviors, glycemic status, and cholesterol level reduce diabetes distress. Given the impact of high diabetes distress on self-care and clinical factors, the findings suggest the usefulness of regularly appraising both life and diabetes-related stressors in the rural Appalachian population. Providers, especially primary healthcare providers in rural settings, can encourage individuals with T2DM to participate in DSME programs to improve their selfmanagement and to cope with diabetes-related distress. Future research should explore the prevention and management of diabetes distress as well as stress reduction techniques in DSME programs to improve health outcomes. 
Reference

1. World Health Organization. The top 10 causes of death. 2020.

https://www.who.int/news-room/fact-sheets/detail/the-top-10-causes-of-death

2. World Health Organization. Diabetes Facts Sheet. https://www.who.int/news-room/factsheets/detail/diabetes

3. Center for Disease Control and Prevention. National Diabetes Statistics Report, 2020. 2020. https://www.cdc.gov/diabetes/pdfs/data/statistics/national-diabetes-statistics-report.pdf

4. American Diabetes Association. Economic Costs of Diabetes in the U.S. in 2017. Diabetes Care. 2018;41(5):917. doi:10.2337/dci18-0007

5. American Diabetes Association. Diagnosis and Classification of Diabetes Mellitus. Diabetes Care. 2009-01-01 2009;32(Supplement_1):S62-S67. doi:10.2337/dc09-s062

6. Centers for Disease Control and Prevention. Complications Due to Diabetes. http://www.cdc.gov/diabetes/living/problems.html

7. Ralston S, Penman ID, Strachan MWJ, Hobson RP, Britton R, Davidson SS. Davidson's principles and practice of medicine. 23rd edition. ed. Elsevier; 2018.

8. National Institute of Diabetes and Digestive and Kidney Disease. Diabetes, Heart Disease, and Stroke. https://www.ncbi.nlm.nih.gov/pubmed/

9. Lloyd C, Smith J, Weinger K. Stress and Diabetes: A Review of the Links. Diabetes Spectrum. 2005-04-01 2005;18(2):121-127. doi:10.2337/diaspect.18.2.121

10. Lee DY, Kim E, Choi MH. Technical and clinical aspects of cortisol as a biochemical marker of chronic stress. BMB Rep. 2015;48(4):209-16. doi:10.5483/BMBRep.2015.48.4.275

11. Hackett RA, Steptoe A. Type 2 diabetes mellitus and psychological stress - a modifiable risk factor. Nature reviews Endocrinology. Sep 2017;13(9):547-560.

doi:10.1038/nrendo.2017.64

12. Joseph JJ, Wang X, Spanakis E, et al. Diurnal salivary cortisol, glycemia and insulin resistance: The multi-ethnic study of atherosclerosis. Psychoneuroendocrinology. Dec 2015;62:327-35. doi:10.1016/j.psyneuen.2015.08.021

13. Burke HM, Davis MC, Otte C, Mohr DC. Depression and cortisol responses to psychological stress: a meta-analysis. Psychoneuroendocrinology. Oct 2005;30(9):846-56. doi:10.1016/j.psyneuen.2005.02.010

14. Schedlowski M, Wiechert D, Wagner T, Tewes U. Acute psychological stress increases plasma levels of cortisol, prolactin and TSH. Life sciences. 1992 1992;50(17)doi:10.1016/00243205(92)90319-k

15. Bellastella G, Maiorino MI, De Bellis A, et al. Serum but not salivary cortisol levels are influenced by daily glycemic oscillations in type 2 diabetes. Endocrine. Jul 2016;53(1):220-6. doi:10.1007/s12020-015-0777-5

16. Duong M, Cohen JI, Convit A. High cortisol levels are associated with low quality food choice in type 2 diabetes. Endocrine. Feb 2012;41(1):76-81. doi:10.1007/s12020-011-9527-5

17. Baum A. Stress, intrusive imagery, and chronic distress. Health psychology : official journal of the Division of Health Psychology, American Psychological Association. 1990;9(6):653-75.

18. Peyrot M, Rubin RR, Lauritzen T, Snoek FJ, Matthews DR, Skovlund SE. Psychosocial problems and barriers to improved diabetes management: results of the Cross-National Diabetes Attitudes, Wishes and Needs (DAWN) Study. Diabetic Medicine. 2005-10-01

2005;22(10):1379-1385. doi:10.1111/j.1464-5491.2005.01644.x 
19. Nicolucci A, Kovacs Burns K, Holt RIG, et al. Diabetes Attitudes, Wishes and Needs second study (DAWN2 ${ }^{\mathrm{TM}}$ ): Cross-national benchmarking of diabetes-related psychosocial outcomes for people with diabetes. Diabetic Medicine. 2013-07-01 2013;30(7):767-777. doi:10.1111/dme.12245

20. Perrin NE, Davies MJ, Robertson N, Snoek FJ, Khunti K. The prevalence of diabetesspecific emotional distress in people with Type 2 diabetes: a systematic review and metaanalysis. Diabet Med. 2017;34:1508- 1520. doi:10.1111/dme.13448

21. Fisher L. Expert Interview, Diabetes Distress: A real and normal part of diabetes. In: Snouffer E, editor. Diabetes Voice: International Diabetes Federation; 2016. p. 29-34.

22. Chew B-H, Vos RC, Pouwer F, Rutten GEHM. The associations between diabetes distress and self-efficacy, medication adherence, self-care activities and disease control depend on the way diabetes distress is measured: Comparing the DDS-17, DDS-2 and the PAID-5. Diabetes Research and Clinical Practice. 2018/08/01/ 2018;142:74-84. doi:https://doi.org/10.1016/j.diabres.2018.05.021

23. Beverly L, Hughes A, Nelson L, Loyola M, Vela A. What is Diabetes Distress? Society of Behavioral Medicine. 2021. https://www.sbm.org/healthy-living/what-is-diabetes-distress

24. Fisher L, Gonzalez JS, Polonsky WH. The confusing tale of depression and distress in patients with diabetes: a call for greater clarity and precision. Diabet Med. Jul 2014;31(7):76472. doi:10.1111/dme.12428

25. Fisher L, Mullan JT, Arean P, Glasgow RE, Hessler D, Masharani U. Diabetes Distress but Not Clinical Depression or Depressive Symptoms Is Associated With Glycemic Control in Both Cross-Sectional and Longitudinal Analyses. 2010-01-01 2010;doi:10.2337/dc09-1238 26. Chew BH, Vos R, Mohd-Sidik S, Rutten GE. Diabetes-Related Distress, Depression and Distress-Depression among Adults with Type 2 Diabetes Mellitus in Malaysia. PLoS One. 2016;11(3):e0152095. doi:10.1371/journal.pone.0152095

27. Nicolucci A, Kovacs Burns K, Holt RIG, et al. Diabetes Attitudes, Wishes and Needs second study (DAWN2 ${ }^{\mathrm{TM}}$ ): cross-national benchmarking of diabetes-related psychosocial outcomes for people with diabetes. Diabetic medicine : a journal of the British Diabetic Association. 2013 Jul 2013;30(7)doi:10.1111/dme.12245

28. Zagarins SE, Allen NA, Garb JL, Welch G. Improvement in glycemic control following a diabetes education intervention is associated with change in diabetes distress but not change in depressive symptoms. OriginalPaper. Journal of Behavioral Medicine. 2011-06-21 2011;35(3):299-304. doi:doi:10.1007/s10865-011-9359-z

29. Aikens JE. Prospective Associations Between Emotional Distress and Poor Outcomes in Type 2 Diabetes. 2012-12-01 2012;doi:10.2337/dc12-0181

30. Tsujii S, Hayashino Y, Ishii H. Diabetes distress, but not depressive symptoms, is associated with glycaemic control among Japanese patients with type 2 diabetes: Diabetes Distress and Care Registry at Tenri (DDCRT 1). Diabetic medicine : a journal of the British Diabetic Association. 2012 Nov 2012;29(11)doi:10.1111/j.1464-5491.2012.03647.x

31. Schechter CB, Walker EA. Improving Adherence to Diabetes Self-Management Recommendations. Diabetes Spectrum. 2002-07-01 2002;15(3):170-175.

doi:10.2337/diaspect.15.3.170

32. Kumar N, Unnikrishnan B, Thapar R, et al. Distress and Its Effect on Adherence to Antidiabetic Medications Among Type 2 Diabetes Patients in Coastal South India. J Nat Sci Biol Med. 2017;8(2):216-20. doi:10.4103/0976-9668.210008 
33. Chew B-C, Mohd-Sidik S, Sharif-Ghazali S. Negative effects of diabetes-related distress on health-related quality of life: an evaluation among the adult patients with type 2 diabetes mellitus in three primaryhealthcare clinics in Malaysia. Health and Quality of Life Outcomes. 2016;13(187)

34. Zhang Z, Premikha M, Luo M, Venkataraman K. Diabetes distress and peripheral neuropathy are associated with medication non-adherence in individuals with type 2 diabetes in primary care. Acta diabetologica. 11/19/2020 2020;doi:10.1007/s00592-020-01609-2

35. Kretchy I, Koduah A, Ohene-Agyei T, Boima V, Appiah B. The Association between Diabetes-Related Distress and Medication Adherence in Adult Patients with Type 2 Diabetes Mellitus: A Cross-Sectional Study. Journal of diabetes research. 03/01/2020 2020;2020doi:10.1155/2020/4760624

36. Jannoo Z, Wah YB, Lazim AM, Hassali MA. Examining diabetes distress, medication adherence, diabetes self-care activities, diabetes-specific quality of life and health-related quality of life among type 2 diabetes mellitus patients. J Clin Transl Endocrinol. 2017;9:48-54. doi:10.1016/j.jcte.2017.07.003

37. Tuomilehto J, Lindstrom J, Eriksson JG, et al. Prevention of type 2 diabetes mellitus by changes in lifestyle among subjects with impaired glucose tolerance. $N$ Engl J Med. May 3 2001;344(18):1343-50. doi:10.1056/nejm200105033441801

38. Knowler WC, Barrett-Connor E, Fowler SE, et al. Reduction in the incidence of type 2 diabetes with lifestyle intervention or metformin. N Engl J Med. Feb 7 2002;346(6):393-403. doi:10.1056/NEJMoa012512

39. Zinman B, Ruderman N, Campaigne BN, Devlin JT SS, American Diabetes Association. Physical Activity/Exercise and Diabetes Mellitus. 10.2337/diacare.26.2007.S73. Diabetes Care. 2003;26(suppl 1):s73.

40. Lindström J, Louheranta A, Mannelin M, et al. The Finnish Diabetes Prevention Study (DPS). Diabetes Care. 2003;26(12):3230. doi:10.2337/diacare.26.12.3230

41. Strohle A. Physical activity, exercise, depression and anxiety disorders. Journal of neural transmission (Vienna, Austria : 1996). Jun 2009;116(6):777-84. doi:10.1007/s00702-008-0092-x 42. Fox KR. The influence of physical activity on mental well-being. Public health nutrition. 1999;2(3a):411-418. doi:10.1017/S1368980099000567

43. Josefsson T, Lindwall M, Archer T. Physical exercise intervention in depressive disorders: Meta-analysis and systematic review. Scandinavian Journal of Medicine \& Science in Sports. 2014/04/01 2013;24(2):259-272. doi:10.1111/sms.12050

44. Mammen G, Faulkner G. Physical Activity and the Prevention of Depression: A Systematic Review of Prospective Studies. American journal of preventive medicine. 2013/11/01/ 2013;45(5):649-657. doi:https://doi.org/10.1016/j.amepre.2013.08.001

45. Wardian J, Sun F. Factors Associated With Diabetes-Related Distress: Implications for Diabetes Self-Management. research-article. http://dxdoiorg/101080/009813892014884038. 9 Apr 2014 2014;doi:10.1080/00981389.2014.884038

46. Werfalli M, Raubenheimer PJ, Engel M, et al. The effectiveness of peer and community health worker-led self-management support programs for improving diabetes health-related outcomes in adults in low- and-middle-income countries: a systematic review. OriginalPaper. Systematic reviews. 2020-06-06 2020;9(1):1-19. doi:doi:10.1186/s13643-020-01377-8

47. Norris SL, Engelgau MM, Narayan KMV. Effectiveness of Self-Management Training in Type 2 Diabetes. 2001-03-01 2001;doi:10.2337/diacare.24.3.561 
48. Amagyei A, Meal A, Shaw I, Adams GG. Effectiveness of Community Health Workerled Diabetes Self-Management Education on Type 2 diabetes patients: A Systematic Review and Meta-Analysis. International Journal of Diabetes. 2020;1(2)

49. Appalachian Regional Commission. About the Appalachian Region. Appalachian Regional Commission. 2020. https://www.arc.gov/about-the-appalachian-region/

50. American Diabetes Association. The Burden of Diabetes in West Virginia. American

Diabetes Association. 2020. https://www.diabetes.org/resources/statistics/statistics-by-state

51. WV Department of Health and Human Resources. West Virginia Behavioral Risk Factor Surveillance System Report. 2018.

http://www.wvdhhr.org/bph/hsc/pubs/brfss/2018/BRFSS2018.pdf

52. Robert Wood Johnson Foundation. Adult Obesity Rates. Robert Wood Johnson

Foundation. 2021. https://stateofchildhoodobesity.org/adult-obesity/

53. Center for Disease Control and Prevention. BRFSS Prevalence \& Trends Data. Accessed 2020/12/15. https://www.cdc.gov/brfss/brfssprevalence/

54. Health Resources \& Services Administration. Medically Underserved Areas/Populations (MUA/P) Dashboard Health Resources \& Services Administration. 2020.

https://data.hrsa.gov/topics/health-workforce/shortage-areas

55. Jackson BM, Gutierrez ML, Relyea GE, et al. Unmet Primary Care Needs in Diabetic Patients with Multimorbidity in a Medically Underserved Area. Health services research and managerial epidemiology. 05/11/2017 2017;4doi:10.1177/2333392817702760

56. Boren SA. A review of health literacy and diabetes: opportunities for technology. Journal of diabetes science and technology. 2009 Jan 2009;3(1)doi:10.1177/193229680900300124

57. Chew L, Griffin J, Partin M, et al. Validation of screening questions for limited health literacy in a large VA outpatient population. Journal of general internal medicine. 2008 May 2008;23(5)doi:10.1007/s11606-008-0520-5

58. Cavanaugh K. Health literacy in diabetes care: explanation, evidence and equipment. Diabetes management (London, England). 2011 Mar 2011;1(2)doi:10.2217/dmt.11.5

59. Behavioral Diabetes Institure. Diabetes Distress Scale (DDS). Behavioral Diabetes Institure,. 2020. https://behavioraldiabetes.org/scales-and-measures/\#1448434304099-9078f27c4106

60. Center for Disease Control and Prevention. What Is the National DPP? 2018-0116T04:06:36Z 2018;

61. Tomky D, Tomky D, Cypress M, et al. AADE Position Statement. The Diabetes educator. 2008/05/01 2008;34(3):445-449. doi:10.1177/0145721708316625

62. James PA, University of Iowa IC, Oparil S, et al. 2014 Evidence-Based Guideline for the Management of High Blood Pressure in Adults: Report From the Panel Members Appointed to the Eighth Joint National Committee (JNC 8). JAMA. 2018;311(5):507-520.

doi:10.1001/jama.2013.284427

63. United States Census Bureau. QuickFacts: West Virginia. United States Census Bureau. 2020. https://www.census.gov/quickfacts/WV

64. Rural Health Information Hub. Am I Rural? Rural Health Information Hub. 2020.

https://www.ruralhealthinfo.org/am-i-rural

65. Rural Health Information Hub. What is Rural? Rural Health Information Hub. 2021. https://www.ruralhealthinfo.org/topics/what-is-rural 
66. Stetson B, Minges KE, Richardson CR. New directions for diabetes prevention and management in behavioral medicine. journal article. Journal of Behavioral Medicine.

2017;40(1):127-144. doi:10.1007/s10865-016-9802-2

67. Polonsky WH, Fisher L, Earles J, et al. Assessing Psychosocial Distress in Diabetes. 2005-03-01 2005;doi:10.2337/diacare.28.3.626

68. Morisky DE, Ang A, Krousel-Wood M, Ward HJ. Predictive Validity of a Medication Adherence Measure in an Outpatient Setting. The Journal of Clinical Hypertension. 2008;10(5):348-354. doi:https://doi.org/10.1111/j.1751-7176.2008.07572.x

69. Moon SJ, Lee W-Y, Hwang JS, Hong YP, Morisky DE. Accuracy of a screening tool for medication adherence: A systematic review and meta-analysis of the Morisky Medication Adherence Scale-8. PLoS One. 2017-11-02 2017;12(11):e0187139.

doi:10.1371/journal.pone.0187139

70. Yang A, Wang B, Zhu G, et al. Validation of Chinese version of the Morisky Medication Adherence Scale in patients with epilepsy. Seizure. 2014-04-01 2014;23(4):295-299. doi:10.1016/j.seizure.2014.01.003

71. Morisky DE, Green LW, Levine DM. Concurrent and predictive validity of a selfreported measure of medication adherence. Medical care. 1986:67-74.

72. Dashtidehkordi A, Shahgholian N, Attari F. "Exercise during hemodialysis and health promoting behaviors: a clinical trial". BMC Nephrology. 2019-12-01 2019;20(1)doi:10.1186/s12882-019-1276-3

73. Diaz-Godiño J, Fernández-Henriquez L, Peña-Pastor F, Alfaro-Flores P, ManriqueBorjas G, Mayta-Tovalino F. Lifestyles, Depression, Anxiety, and Stress as Risk Factors in Nursing Apprentices: A Logistic Regression Analysis of 1193 Students in Lima, Peru. Journal of environmental and public health. 2019/11/06 2019;2019:7395784. doi:10.1155/2019/7395784

74. Walker SN, Sechrist KR, Pender NJ. The Health-Promoting Lifestyle Profile: Development and Psychometric Characteristics. Nursing Research. 1987;36(2):76-81. 75. Harris PA, Taylor R, Thielke R, Payne J, Gonzalez N, Conde JG. Research electronic data capture (REDCap) — A metadata-driven methodology and workflow process for providing translational research informatics support. Journal of Biomedical Informatics. 2009/04/01/ 2009;42(2):377-381. doi:https://doi.org/10.1016/j.jbi.2008.08.010

76. Vanderbilt University. About REDCap. Vanderbilt University. 2019. https://projectredcap.org/about/

77. Microsoft Excel. Microsoft Corporation; 2016.

78. Wilson Van Voorhis CR, Morgan BL. Understanding Power and Rules of Thumb for Determining Sample Sizes. TQMP. 2007-09-01 2007;3(2):43-50. IN FILE.

doi:10.20982/tqmp.03.2.p043

79. Miller DE, Kunce JT. Prediction and Statistical Overkill Revisited. research-article.

https://doiorg/101080/00256307197312022590. 16 Jul 2018

2018;doi:10.1080/00256307.1973.12022590

80. Detry M, Ma Y. Analyzing Repeated Measurements Using Mixed Models. JAMA. 2016;315(4):407-408. doi:10.1001/jama.2015.19394

81. Deana Z. Main Effects. In: Salkind N, editor. Encyclopedia of Research Design. Thousand Oaks, CA: SAGE Publications, Inc.; 2010.

82. IBM SPSS Statistics for Windows. Version 27. IBM Corp; 2015.

83. Akoglu H. User's guide to correlation coefficients. Turk J Emerg Med. 2018;18(3):91-93. doi:10.1016/j.tjem.2018.08.001 
84. Dancey CP, Reidy J. Statistics without maths for psychology. Pearson education; 2007. 85. Mathiesen AS, Egerod I, Jensen T, Kaldan G, Langberg H, Thomsen T. Psychosocial interventions for reducing diabetes distress in vulnerable people with type 2 diabetes mellitus: a systematic review and meta-analysis. Diabetes, metabolic syndrome and obesity: targets and therapy. 12/17/2018 2018;12doi:10.2147/DMSO.S179301

86. Dubois SK, Lehrer HM, Whyne EZ, Steinhardt MA. A Resilience Intervention for Adults with Type 2 Diabetes: Proof-of-Concept in Community Health Centers. OriginalPaper. International Journal of Behavioral Medicine. 2020-06-15 2020;27(5):565-575. doi:doi:10.1007/s12529-020-09894-5

87. Wagner JA, Bermudez-Millan A, Damio G, et al. A randomized, controlled trial of a stress management intervention for Latinos with type 2 diabetes delivered by community health workers: Outcomes for psychological wellbeing, glycemic control, and cortisol. Diabetes Res Clin Pract. Oct 2016;120:162-70. doi:10.1016/j.diabres.2016.07.022

88. Davies MJ, Heller S, Skinner TC, et al. Effectiveness of the diabetes education and self management for ongoing and newly diagnosed (DESMOND) programme for people with newly diagnosed type 2 diabetes: cluster randomised controlled trial. 2008-02-28

2008;doi:10.1136/bmj.39474.922025.BE

89. Adams AS, Banerjee S, Ku CJ. Medication adherence and racial differences in diabetes in the USA: an update. Diabetes Management. 2015;5(2):79.

90. Kochanek K, Xu J, Arias E. Mortality in the United States. 2020. 2021-05-11T05:53:26Z. https://www.cdc.gov/nchs/products/databriefs/db395.htm

91. Delahanty LM, Grant RW, Wittenberg E, et al. Association of diabetes-related emotional distress with diabetes treatment in primary care patients with Type 2 diabetes. Diabet Med. Jan 2007;24(1):48-54. doi:10.1111/j.1464-5491.2007.02028.x

92. Misra R, Fitch C, Roberts D, Wright D. Community-Based Diabetes Screening and Risk Assessment in Rural West Virginia. J Diabetes Res. 2016;2016doi:10.1155/2016/2456518

93. Tessaro I, Smith SL, Rye S. Knowledge and perceptions of diabetes in an Appalachian population. Preventing chronic disease. 2005;2(2):A13-A13.

94. Fisher L, Mullan J, Skaff M, Glasgow R, Arean P, Hessler D. Predicting diabetes distress in patients with Type 2 diabetes: a longitudinal study. Diabetic medicine : a journal of the British Diabetic Association. 2009 Jun 2009;26(6)doi:10.1111/j.1464-5491.2009.02730.x 95. Fisher L, Hessler D, Glasgow RE, et al. REDEEM: A Pragmatic Trial to Reduce Diabetes Distress. 2013-09-01 2013;doi:10.2337/dc12-2493

96. Mizokami-Stout K, Choi H, Richardson CR, Piatt G, Heisler M. Diabetes Distress and Glycemic Control in Type 2 Diabetes: Mediator and Moderator Analysis of a Peer Support Intervention. JMIR Diabetes. 2021-01-11 2021;6(1):e21400. doi:10.2196/21400

97. Schmitt A, Reimer A, Kulzer B, Haak T, Gahr A, Hermanns N. Negative association between depression and diabetes control only when accompanied by diabetes-specific distress. Journal of behavioral medicine. 2015 Jun 2015;38(3)doi:10.1007/s10865-014-9604-3

98. Dennick K, Sturt J, Speight J. What is diabetes distress and how can we measure it? A narrative review and conceptual model. J Diabetes Complications. May 2017;31(5):898-911. doi:10.1016/j.jdiacomp.2016.12.018

99. Sturt J, Mccarthy K, Dennick K, Narasimha M, Sankar S, Kumar S. What characterises diabetes distress and its resolution? A documentary analysis. International Diabetes Nursing. 2015-08-01 2015;12(2):56-62. doi:10.1179/2057332415y.0000000002 
100. Hirano T. Pathophysiology of Diabetic Dyslipidemia. Journal of Atherosclerosis and Thrombosis. 2018-09-01 2018;25(9):771-782. doi:10.5551/jat.rv17023

101. Chait A, Ginsberg HN, Vaisar T, Heinecke JW, Goldberg IJ, Bornfeldt KE. Remnants of the Triglyceride-Rich Lipoproteins, Diabetes, and Cardiovascular Disease. Diabetes. 2020-04-01 2020;69(4):508-516. doi:10.2337/dbi19-0007

102. American Diabetes Association. 10. Cardiovascular Disease and Risk Management: Standards of Medical Care in Diabetes-2021. Diabetes Care. 2021-01-01 2021;44(Supplement 1):S125-S150. doi:10.2337/dc21-s010

103. Schwertner HA, Troxler RG, Uhl GS, Jackson WG. Relationship between cortisol and cholesterol in men with coronary artery disease and type A behavior. Arteriosclerosis: An Official Journal of the American Heart Association, Inc. 1984-01-01 1984;4(1):59-64. doi:10.1161/01.atv.4.1.59

104. Colorado State University. Steroidogenesis. Colorado State University. 2021. http://www.vivo.colostate.edu/hbooks/pathphys/endocrine/basics/steroidogenesis.html 105. Berg JM, Tymoczko JL, Stryer L. Important Derivatives of Cholesterol Include Bile Salts and Steroid Hormones. Text. W H Freeman; 2002. Accessed 2002.

https://www.ncbi.nlm.nih.gov/pubmed/

106. Pickup JC, Crook MA. Is Type II diabetes mellitus a disease of the innate immune system? Diabetologia. 1998-09-18 1998;41(10):1241-1248. doi:10.1007/s001250051058

107. Aglaia GS-C, Guzmán-Saldaña R, Castillo-Arreol Ad, Pineda-Sánchez JE, Paz-Bautista JC. Cortisol, stress and diabetes: a dangerous relationship. Universidad Autónoma del Estado de Hidalgo. 2018;

108. Chiodini I, Adda G, Scillitani A, et al. Cortisol secretion in patients with type 2 diabetes: relationship with chronic complications. Diabetes Care. Jan 2007;30(1):83-8. doi:10.2337/dc061267

109. Molarius A, Granström F. Educational differences in psychological distress? Results from a population-based sample of men and women in Sweden in 2012. BMJ Open. 2018-04-01 2018;8(4):e021007. doi:10.1136/bmjopen-2017-021007

110. Wong E, Backholer K, Gearon E, et al. Diabetes and risk of physical disability in adults: a systematic review and meta-analysis. The Lancet Diabetes \& Endocrinology. 2013;1(2):106114. doi:10.1016/s2213-8587(13)70046-9

111. National Institute of Meantal Health. Depression. National Institute of Meantal Health. 2021. https://www.ncbi.nlm.nih.gov/pubmed/

112. Lavrakas PJ. Encyclopedia of Survey Research Methods. In: Lavrakas PJ, editor. Encyclopedia of Survey Research Methods. Thousand Oaks, California2008. 


\subsection{Appendix B}

Table 1. Descriptive analysis of demographic variables at baseline

\begin{tabular}{|c|c|c|c|c|c|c|c|c|c|c|}
\hline Variables & \multicolumn{3}{|c|}{ Total } & \multicolumn{3}{|c|}{ Intervention } & \multicolumn{3}{|c|}{ Control group } & \multirow[b]{2}{*}{ p-values } \\
\hline & $\mathrm{N}$ & Mean \pm SD & $\begin{array}{c}\text { Median } \\
(\mathrm{IQR})\end{array}$ & $\mathrm{N}$ & Mean \pm SD. & Median & $\mathrm{N}$ & Mean \pm SD & $\begin{array}{c}\text { Median } \\
(\mathrm{IQR})\end{array}$ & \\
\hline $\operatorname{Age}^{\mathrm{k}}$ & 89 & $60.82 \pm 12.16$ & & 44 & $\begin{array}{c}62.55 \pm \\
10.64\end{array}$ & & 45 & $59.66 \pm 12.75$ & & 0.249 \\
\hline \multicolumn{11}{|l|}{ Gender $^{1}$} \\
\hline Male & 32 & $35.96 \%$ & & 11 & $25.00 \%$ & & 21 & $46.67 \%$ & & 0.033 \\
\hline Female & 57 & $64.04 \%$ & & 33 & $75.00 \%$ & & 24 & $53.33 \%$ & & \\
\hline $\mathrm{BMI}^{\mathrm{j}}$ & 89 & & $\begin{array}{l}35.40 \\
(8.38) \\
\end{array}$ & 44 & & $\begin{array}{l}36.59 \\
(8.92) \\
\end{array}$ & 45 & & $\begin{array}{l}34.34 \\
(8.09) \\
\end{array}$ & 0.325 \\
\hline \multirow{4}{*}{$\begin{array}{l}\text { BMI } \\
\text { (categorical) }^{\mathrm{k}} \\
\text { Normal } \\
\text { Overweight } \\
\text { Obese }\end{array}$} & & & & & & & & & & 0.021 \\
\hline & 4 & $4.6 \%$ & & 2 & $4.7 \%$ & & 2 & $4.5 \%$ & & \\
\hline & 13 & $13.8 \%$ & & 2 & $4.7 \%$ & & 10 & $22.7 \%$ & & \\
\hline & 72 & $81.6 \%$ & & 39 & $90.7 \%$ & & 32 & $72.7 \%$ & & \\
\hline $\begin{array}{l}\text { Hypertension } \\
\text { duration }^{\text {a }}\end{array}$ & 89 & & $\begin{array}{c}14.83 \\
(22.28)\end{array}$ & 41 & & $\begin{array}{c}15.61 \\
(24.21) \\
\end{array}$ & 37 & & $\begin{array}{c}13.34 \\
(22.51)\end{array}$ & 0.774 \\
\hline $\begin{array}{l}\text { Diabetes } \\
\text { duration }\end{array}$ & 89 & & $\begin{array}{c}10.63 \\
(13.93)\end{array}$ & 41 & & $\begin{array}{c}10.62 \\
(13.96)\end{array}$ & 37 & & $\begin{array}{c}10.90 \\
(14.31)\end{array}$ & 0.191 \\
\hline $\begin{array}{l}\text { Education } \\
\text { level }^{\text {c }}\end{array}$ & & & & & & & & & & 0.277 \\
\hline $\begin{array}{l}\text { High school } \\
\text { or less than } \\
\text { high school }\end{array}$ & 16 & $18.8 \%$ & & 11 & $25.0 \%$ & & 5 & $12.2 \%$ & & \\
\hline $\begin{array}{l}\text { some college } \\
\text { education or } \\
\text { associate } \\
\text { degree }\end{array}$ & 27 & $31.8 \%$ & & 14 & $31.8 \%$ & & 13 & $31.7 \%$ & & \\
\hline $\begin{array}{l}\text { college } \\
\text { graduate, }\end{array}$ & 42 & $49.4 \%$ & & 19 & $43.2 \%$ & & 23 & $56.1 \%$ & & \\
\hline
\end{tabular}




\begin{tabular}{|c|c|c|c|c|c|c|c|c|c|c|}
\hline \multicolumn{11}{|l|}{$\begin{array}{c}\text { post-graduate } \\
\text { or } \\
\text { professional } \\
\text { degree }\end{array}$} \\
\hline \multirow{3}{*}{$\begin{array}{l}\text { Race }^{\mathrm{d}} \\
\text { Non-White } \\
\text { White }\end{array}$} & & & & & & & & & & 0.715 \\
\hline & 8 & $9.8 \%$ & & 6 & $11.6 \%$ & & 4 & $7.7 \%$ & & \\
\hline & 74 & $90.2 \%$ & & 38 & $84.4 \%$ & & 36 & $92.3 \%$ & & \\
\hline $\begin{array}{l}\text { Number of } \\
\text { household } \\
\text { members }\end{array}$ & 89 & & $1.0(1.0)$ & 44 & & $\begin{array}{c}1.00 \\
(1.00)\end{array}$ & 45 & & $\begin{array}{c}1.00 \\
(1.00)\end{array}$ & 0.099 \\
\hline \multirow{3}{*}{$\begin{array}{l}\text { Rural or } \\
\text { Urban }^{\text {f }} \\
\text { Rural } \\
\text { Urban }\end{array}$} & & & & & & & & & & 0.764 \\
\hline & 27 & $30.34 \%$ & & 14 & $31.82 \%$ & & 13 & $28.89 \%$ & & \\
\hline & 62 & $69.66 \%$ & & 30 & $68.18 \%$ & & 32 & $71.11 \%$ & & \\
\hline \multirow{3}{*}{$\begin{array}{l}\text { Family } \\
\text { history of } \\
\text { diabetes } \\
\text { Yes } \\
\text { No }\end{array}$} & & & & & & & & & & 0.563 \\
\hline & 77 & $86.52 \%$ & & 39 & $88.63 \%$ & & 38 & $84.44 \%$ & & \\
\hline & 12 & $13.48 \%$ & & 5 & $11.36 \%$ & & 7 & $15.56 \%$ & & \\
\hline \multirow{3}{*}{$\begin{array}{l}\text { Family } \\
\text { history of } \\
\text { hypertension }^{\text {h }} \\
\text { Yes } \\
\text { No }\end{array}$} & & & & & & & & & & 0.798 \\
\hline & 76 & $85.39 \%$ & & 38 & $86.36 \%$ & & 38 & $84.44 \%$ & & \\
\hline & 13 & $14.61 \%$ & & 6 & $13.64 \%$ & & 7 & $15.56 \%$ & & \\
\hline $\begin{array}{l}\text { Access to } \\
\text { health } \\
\text { insurance }^{\mathrm{i}}\end{array}$ & & & & & & & & & & 0.053 \\
\hline Yes & 82 & $92.13 \%$ & & 43 & $97.73 \%$ & & 39 & $86.67 \%$ & & \\
\hline No & 7 & $7.87 \%$ & & 1 & $2.27 \%$ & & 6 & $13.33 \%$ & & \\
\hline
\end{tabular}

Note:

IQR: Interquartile range.

${ }^{\mathrm{k}}$ Age: measured in years.

${ }^{1}$ Gender: responses were categorized as male, and female. 
${ }^{a}$ Diabetes duration: indicates how many years the participants have been living with diabetes; measured in years.

${ }^{\mathrm{b}}$ Hypertension duration: indicates how many years the participants have been living with hypertension; measured in years. ${ }^{c}$ Education level: indicated the highest academic degree achieved by the participant.

${ }^{\mathrm{d}}$ Race of participants was recategorized into two categories: Non-white, and White.

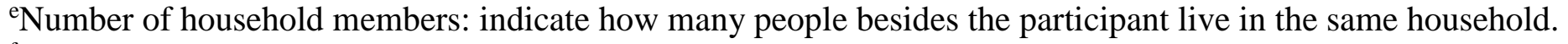

${ }^{f}$ Rural or Urban: indicates the location of the participants' residence based on their zip code.

${ }^{g}$ Family history of diabetes: indicates whether the participants have any family members diagnosed with diabetes. Answer response was yes, and no.

${ }^{h}$ Family history of hypertension: indicates whether the participants have any family members diagnosed with hypertension. Answer response was yes, and no.

${ }^{i}$ Access to health insurance: indicates whether the participants have any type of health insurance. The answer response was yes, and no.

jBMI was calculated in $\mathrm{kg} / \mathrm{m}^{2}$

kBMI (categorical) was categorized into three options: normal, overweight, and obese. 
Table 2. Descriptive statistics of the dependent and clinical variables at baseline

\begin{tabular}{|c|c|c|c|c|c|c|c|c|c|c|}
\hline Clinical Variables & $\mathrm{N}$ & Mean \pm SD & $\begin{array}{l}\text { Median } \\
\text { (IQR) }\end{array}$ & $\mathrm{N}$ & Mean \pm SD & $\begin{array}{c}\text { Median } \\
\text { (IQR) }\end{array}$ & $\mathrm{N}$ & Mean \pm SD & $\begin{array}{c}\text { Median } \\
\text { (IQR) }\end{array}$ & $\mathrm{p}$-value \\
\hline Total diabetes distress ${ }^{\mathrm{a}}$ & 89 & & $\begin{array}{l}1.76 \\
(1.04)\end{array}$ & 44 & & $\begin{array}{l}1.79 \\
(1.19)\end{array}$ & 45 & & $\begin{array}{c}1.74 \\
(0.96)\end{array}$ & 0.686 \\
\hline Emotional distress $^{\mathrm{b}}$ & 89 & & $\begin{array}{c}1.60 \\
(1.40)\end{array}$ & 44 & & $\begin{array}{c}1.70 \\
(1.75)\end{array}$ & 45 & & $\begin{array}{c}1.40 \\
(1.40)\end{array}$ & 0.479 \\
\hline Interpersonal distress $^{b}$ & 88 & & $\begin{array}{c}1.33 \\
(1.25)\end{array}$ & 44 & & $\begin{array}{c}1.33 \\
(1.33)\end{array}$ & 44 & & $\begin{array}{c}1.17 \\
(1.00)\end{array}$ & 0.536 \\
\hline $\begin{array}{c}\text { Physician related } \\
\text { distress }^{\text {b }}\end{array}$ & 89 & & $\begin{array}{l}1.00 \\
(0.50)\end{array}$ & 44 & & $\begin{array}{l}1.00 \\
(0.50)\end{array}$ & 45 & & $\begin{array}{c}1.00 \\
(0.44)\end{array}$ & 0.909 \\
\hline $\begin{array}{l}\text { Regimen related } \\
\text { distress }^{\mathrm{b}}\end{array}$ & 88 & $2.61 \pm 1.27$ & & 44 & $2.58 \pm 1.40$ & & 44 & $2.63 \pm 1.13$ & & 0.848 \\
\hline Serum cortisol $^{\mathrm{i}}$ & 87 & $\begin{array}{l}13.20 \pm \\
4.14\end{array}$ & & 44 & $\begin{array}{c}13.28 \pm \\
4.22\end{array}$ & & 43 & $\begin{array}{c}13.12 \pm \\
4.10\end{array}$ & & 0.857 \\
\hline $\operatorname{Diet}^{c}$ & 89 & $2.85 \pm 0.07$ & & 44 & $2.91 \pm 0.93$ & & 45 & $2.75 \pm 0.13$ & & 0.085 \\
\hline $\mathrm{PA}^{\mathrm{d}}$ & 89 & $2.06 \pm 0.09$ & & 44 & $2.18 \pm 0.72$ & & 32 & $1.90 \pm 0.76$ & & 0.115 \\
\hline Medication adherence & 85 & $6.39 \pm 0.21$ & & 43 & $6.51 \pm 0.26$ & & 42 & $6.20 \pm 0.35$ & & 0.172 \\
\hline
\end{tabular}




\begin{tabular}{|c|c|c|c|c|c|c|c|c|c|c|}
\hline $\mathrm{HbA} 1 \mathrm{c}^{\mathrm{f}}$ & 73 & $7.29 \pm 0.19$ & & 44 & $7.33 \pm 1.38$ & & 29 & $7.40 \pm 1.89$ & & 0.867 \\
\hline $\mathrm{LDL}^{\mathrm{g}}$ & 89 & $\begin{array}{c}94.23 \pm \\
4.58\end{array}$ & & 44 & $\begin{array}{c}91.95 \pm \\
5.11\end{array}$ & & 45 & $\begin{array}{l}98.04 \pm \\
8.85\end{array}$ & & 0.451 \\
\hline VLDL $^{g}$ & 89 & & $\begin{array}{c}25.00 \\
(20.75)\end{array}$ & 44 & & $\begin{array}{c}25.00 \\
(18.25)\end{array}$ & 45 & & $\begin{array}{c}29.00 \\
(27.00)\end{array}$ & 0.600 \\
\hline Systolic blood pressure $^{\mathrm{h}}$ & 90 & $\begin{array}{c}136.47 \pm \\
18.88\end{array}$ & & 44 & $\begin{array}{c}135.81 \pm \\
20.50\end{array}$ & & 46 & $\begin{array}{c}137.10 \pm \\
17.39\end{array}$ & & 0.748 \\
\hline $\begin{array}{l}\text { Diastolic blood } \\
\text { pressure }^{\mathrm{h}}\end{array}$ & 90 & $\begin{array}{c}83.06 \pm \\
11.29\end{array}$ & & 44 & $\begin{array}{c}82.03 \pm \\
10.75\end{array}$ & & 46 & $\begin{array}{c}84.03 \pm \\
11.82\end{array}$ & & 0.404 \\
\hline $\begin{array}{l}\text { Note: } \\
\text { IQR: Interquartile range. } \\
\text { a,b Diabetes distress (total } \\
\text { scale questions. Response } \\
\text { fHbA1c or glycosylated h } \\
\text { f }{ }^{\mathrm{c}} \text { Diet score was calculatec } \\
\text { never = 1, sometimes = 2, } \\
{ }^{\mathrm{d}} \mathrm{PA} \text { (physical activity) sc } \\
\text { options included never = } \\
\text { e Medication adherence w } \\
\text { questions. Score range: } 0 \\
\text { gSerum cholesterol (LDL, } \\
\text { 'Serum cortisol was meas } \\
\text { iSerum (systolic } \\
{ }^{\mathrm{h}} \text { Blood pressure }\end{array}$ & $\begin{array}{l}\text { core } \\
\text { optic } \\
\text { mog } \\
\text { from } \\
\text { ofter } \\
\text { re w } \\
\text {, son } \\
\text { s cal } \\
3 \text {. } \\
\text { VLD } \\
\text { red i }\end{array}$ & $\begin{array}{l}\text { Ind subscores } \\
\text { included fro } \\
\text { obin was mea } \\
\text { the Lifestyle } \\
=3 \text {, and rout } \\
\text { s calculated } \mathrm{f} \\
\text { etimes }=2 \text {, o } \\
\text { ulated using } \\
\text { ) was measu } \\
\text { mcg/dL. } \\
\text { astolic blood }\end{array}$ & $\begin{array}{l}\text { was calc } \\
\mathrm{m} 1=\text { not } \\
\text { sured in } \mathrm{p} \\
\text { Profile II } \\
\text { nely }=4 \text {. } \\
\text { om the } \mathrm{Li} \\
\text { ten }=3 \text {, at } \\
\text { lorisky M } \\
\text { ed in } \mathrm{mg} /\end{array}$ & $\begin{array}{l}\text { late } \\
\text { a pro } \\
\text { ercen } \\
\text { cale } \\
\text { score } \\
\text { festy } \\
\text { d ro } \\
\text { edic } \\
\text { dL. }\end{array}$ & $\begin{array}{l}\text { using the Dia } \\
\text { lem to } 6=\mathrm{a} \\
\text { age. } \\
\text { sing nine Lik } \\
\text { range: } 9-36 \text {. } \\
\text { e Profile II sc } \\
\text { tinely }=4 . \mathrm{Sc} \\
\text { tion Adheren }\end{array}$ & $\begin{array}{l}\text { betes Dist } \\
\text { Jery seriol } \\
\text { ert scale q } \\
\text { le using } \\
\text { re range: } \\
\text { e Scale } 8\end{array}$ & $\begin{array}{l}\text { ress } \\
\text { us pro } \\
\text { uesti } \\
\text { ight } \\
8-32 \\
\text { (MM }\end{array}$ & $\begin{array}{l}\text { urvey (DDS) } \\
\text { blem. Score } \\
\text { nikert Response } \\
\text { AS8) that had }\end{array}$ & $\begin{array}{l}\text { which ha } \\
\text { ange: } 1-6 . \\
\text { options in } \\
\text { estions. R } \\
\text { a total of }\end{array}$ & $\begin{array}{l}7 \text { Likert } \\
\text { ponse } \\
\text { ided }\end{array}$ \\
\hline
\end{tabular}


Table 3. Bivariate relationship between dependent variables and continuous predictor variables

\begin{tabular}{|c|c|c|c|c|c|c|c|c|c|c|c|c|c|c|c|c|c|c|}
\hline Variable & $\begin{array}{l}\text { 1.To } \\
\text { tal } \\
\text { diab } \\
\text { etes } \\
\text { distr } \\
\text { ess }^{\mathrm{a}}\end{array}$ & $\begin{array}{l}2 . \\
\text { Emo } \\
\text { tiona } \\
1 \\
\text { distr } \\
\text { ess }^{b}\end{array}$ & $\begin{array}{l}3 . \\
\text { Phys } \\
\text { ician } \\
\text { relat } \\
\text { ed } \\
\text { distr } \\
\text { ess }\end{array}$ & $\begin{array}{l}4 . \\
\text { Regi } \\
\text { men } \\
\text { relat } \\
\text { ed } \\
\text { distr } \\
\text { ess }\end{array}$ & $\begin{array}{l}5 . \\
\text { Inter } \\
\text { pers } \\
\text { onal } \\
\text { distr } \\
\text { ess }^{\text {b }}\end{array}$ & $\begin{array}{l}6 . \\
\text { Seru } \\
\mathrm{m} \\
\text { cortis } \\
\text { ol }^{\mathrm{i}}\end{array}$ & $\begin{array}{l}7 . \\
\mathrm{Ag} \\
\mathrm{e}\end{array}$ & $\begin{array}{l}8 . \\
\text { Diab } \\
\text { etes } \\
\text { dura } \\
\text { tion }\end{array}$ & $\begin{array}{l}09 . \\
\text { Hyperte } \\
\text { nsion } \\
\text { duration }\end{array}$ & $\begin{array}{l}10 . \\
\text { Num } \\
\text { ber of } \\
\text { house } \\
\text { hold } \\
\text { mem } \\
\text { bers }\end{array}$ & $\begin{array}{l}11 . \\
\text { Tota } \\
1 \\
\text { chol } \\
\text { ester } \\
\text { ol }\end{array}$ & LDL & $\begin{array}{l}\text { VLD } \\
\mathrm{L}\end{array}$ & $\begin{array}{l}12 . \\
\text { Medi } \\
\text { cation } \\
\text { adher } \\
\text { ence }\end{array}$ & $\begin{array}{l}13 . \\
\mathrm{HbA} 1 \\
c^{f}\end{array}$ & $\begin{array}{l}14 . \\
\mathrm{PA}^{\mathrm{d}}\end{array}$ & 15. Diet & $\begin{array}{l}16 . \\
\text { Systoli } \\
\mathrm{c} \mathrm{BP}^{\mathrm{h}}\end{array}$ \\
\hline $\begin{array}{l}\text { 1. Total } \\
\text { diabetes } \\
\text { distress }^{\text {a }} \\
\end{array}$ & 1 & & & & & & & & & & & & & & & & & \\
\hline $\begin{array}{l}\text { 2. Emotional } \\
\text { distress }^{b}\end{array}$ & $\begin{array}{l}.874 \\
* *\end{array}$ & 1 & & & & & & & & & & & & & & & & \\
\hline $\begin{array}{l}\text { 3. Physician } \\
\text { related } \\
\text { distress }^{\mathrm{c}}\end{array}$ & $\begin{array}{l}.445 \\
* *\end{array}$ & $\begin{array}{l}.269 \\
*\end{array}$ & 1 & & & & & & & & & & & & & & & \\
\hline $\begin{array}{l}\text { 4. Regimen } \\
\text { related } \\
\text { distress }^{d}\end{array}$ & $\begin{array}{l}.904 \\
* *\end{array}$ & $\begin{array}{l}.684 \\
* *\end{array}$ & $\begin{array}{l}.327 \\
* *\end{array}$ & 1 & & & & & & & & & & & & & & \\
\hline $\begin{array}{l}5 . \\
\text { Interpersonal } \\
\text { distress }^{\mathrm{e}} \\
\end{array}$ & $\begin{array}{l}.648 \\
* *\end{array}$ & $\begin{array}{l}.573 \\
* *\end{array}$ & $\begin{array}{l}.436 \\
* *\end{array}$ & $\begin{array}{l}.501 \\
* *\end{array}$ & 1 & & & & & & & & & & & & & \\
\hline $\begin{array}{l}\text { 6. Serum } \\
\text { cortisol }\end{array}$ & $\begin{array}{l}0.05 \\
5\end{array}$ & $\begin{array}{l}0.07 \\
1\end{array}$ & $\begin{array}{l}0.06 \\
5\end{array}$ & $\begin{array}{l}- \\
0.03 \\
3\end{array}$ & $\begin{array}{l}0.04 \\
6\end{array}$ & 1 & & & & & & & & & & & & \\
\hline 7. Age & $\begin{array}{l}- \\
0.15 \\
4\end{array}$ & $\begin{array}{l}- \\
0.17 \\
9\end{array}$ & $\begin{array}{l}0.03 \\
0\end{array}$ & $\begin{array}{l}- \\
0.12 \\
8\end{array}$ & $\begin{array}{l}0.00 \\
8\end{array}$ & 0.052 & 1 & & & & & & & & & & & \\
\hline
\end{tabular}


Table 3. Bivariate relationship between dependent variables and continuous predictor variables

\begin{tabular}{|c|c|c|c|c|c|c|c|c|c|c|c|c|c|c|c|c|c|c|}
\hline Variable & $\begin{array}{l}\text { 1.To } \\
\text { tal } \\
\text { diab } \\
\text { etes } \\
\text { distr } \\
\text { ess }^{\text {a }}\end{array}$ & $\begin{array}{l}2 . \\
\text { Emo } \\
\text { tiona } \\
1 \\
\text { distr } \\
\text { ess }^{b}\end{array}$ & $\begin{array}{l}3 . \\
\text { Phys } \\
\text { ician } \\
\text { relat } \\
\text { ed } \\
\text { distr } \\
\text { ess }^{\mathrm{b}}\end{array}$ & $\begin{array}{l}4 . \\
\text { Regi } \\
\text { men } \\
\text { relat } \\
\text { ed } \\
\text { distr } \\
\text { ess }\end{array}$ & $\begin{array}{l}5 . \\
\text { Inter } \\
\text { pers } \\
\text { onal } \\
\text { distr } \\
\text { ess }^{b}\end{array}$ & $\begin{array}{l}6 . \\
\text { Seru } \\
\mathrm{m} \\
\text { cortis } \\
\text { ol }^{\mathrm{i}}\end{array}$ & $\begin{array}{l}7 . \\
\mathrm{Ag} \\
\mathrm{e}\end{array}$ & $\begin{array}{l}8 . \\
\text { Diab } \\
\text { etes } \\
\text { dura } \\
\text { tion }\end{array}$ & $\begin{array}{l}09 . \\
\text { Hyperte } \\
\text { nsion } \\
\text { duration }\end{array}$ & $\begin{array}{l}10 . \\
\text { Num } \\
\text { ber of } \\
\text { house } \\
\text { hold } \\
\text { mem } \\
\text { bers }\end{array}$ & $\begin{array}{l}11 . \\
\text { Tota } \\
1 \\
\text { chol } \\
\text { ester } \\
\text { ol }\end{array}$ & LDL & $\begin{array}{l}\text { VLD } \\
\mathrm{L}\end{array}$ & $\begin{array}{l}12 . \\
\text { Medi } \\
\text { cation } \\
\text { adher } \\
\text { ence }\end{array}$ & $\begin{array}{l}13 . \\
\mathrm{HbA} 1 \\
c^{f}\end{array}$ & $\begin{array}{l}14 . \\
\mathrm{PA}^{\mathrm{d}}\end{array}$ & 15. Diet & $\begin{array}{l}16 . \\
\text { Systoli } \\
\mathrm{c} \mathrm{BP}^{\mathrm{h}}\end{array}$ \\
\hline $\begin{array}{l}\text { 8. Diabetes } \\
\text { duration }\end{array}$ & $\begin{array}{l}0.03 \\
3\end{array}$ & $\begin{array}{l}0.00 \\
6\end{array}$ & $\begin{array}{l}0.03 \\
3\end{array}$ & $\begin{array}{l}0.02 \\
4\end{array}$ & $\begin{array}{l}- \\
0.02 \\
3\end{array}$ & 0.059 & $\begin{array}{l}.21 \\
8 *\end{array}$ & 1 & & & & & & & & & & \\
\hline $\begin{array}{l}09 . \\
\text { Hypertension } \\
\text { duration }\end{array}$ & $\begin{array}{l}- \\
0.19 \\
6\end{array}$ & $\begin{array}{l}- \\
0.19 \\
7\end{array}$ & $\begin{array}{l}- \\
0.16 \\
9\end{array}$ & $\begin{array}{l}- \\
0.15 \\
3\end{array}$ & $\begin{array}{l}- \\
0.12 \\
1\end{array}$ & $\begin{array}{l}- \\
0.036\end{array}$ & $\begin{array}{l}.43 \\
1 * *\end{array}$ & $\begin{array}{l}.291 \\
* *\end{array}$ & 1 & & & & & & & & & \\
\hline $\begin{array}{l}\text { 10. Number } \\
\text { of household } \\
\text { members }\end{array}$ & $\begin{array}{l}- \\
0.09 \\
6\end{array}$ & $\begin{array}{l}- \\
0.05 \\
0\end{array}$ & $\begin{array}{l}- \\
0.06 \\
4\end{array}$ & $\begin{array}{l}- \\
0.16 \\
6\end{array}$ & $\begin{array}{l}0.00 \\
6\end{array}$ & $.275 *$ & $\begin{array}{l}- \\
.33 \\
6^{* *}\end{array}$ & $\begin{array}{l}- \\
0.09 \\
1\end{array}$ & $-.247 *$ & 1 & & & & & & & & \\
\hline $\begin{array}{l}\text { 11. Total } \\
\text { cholesterol }\end{array}$ & $\begin{array}{l}0.22 \\
1\end{array}$ & $\begin{array}{l}0.16 \\
1\end{array}$ & $\begin{array}{l}0.19 \\
2\end{array}$ & .222 & $\begin{array}{l}0.12 \\
2\end{array}$ & 0.059 & $\begin{array}{l}- \\
0.0 \\
41\end{array}$ & $\begin{array}{l}0.05 \\
8\end{array}$ & -0.120 & $\begin{array}{l}- \\
0.024\end{array}$ & 1 & & & & & & & \\
\hline LDL & $\begin{array}{l}0.18 \\
2\end{array}$ & $\begin{array}{l}0.17 \\
6\end{array}$ & $\begin{array}{l}.236 \\
*\end{array}$ & $\begin{array}{l}0.17 \\
4\end{array}$ & $\begin{array}{l}0.10 \\
7\end{array}$ & 0.025 & $\begin{array}{l}- \\
0.1 \\
02 \\
\end{array}$ & $\begin{array}{l}0.00 \\
1\end{array}$ & -0.144 & $\begin{array}{l}- \\
0.038\end{array}$ & $\begin{array}{l}0.93 \\
4 * *\end{array}$ & 1 & & & & & & \\
\hline VLDL & $\begin{array}{l}0.17 \\
9\end{array}$ & $\begin{array}{l}0.16 \\
1\end{array}$ & $\begin{array}{l}- \\
0.17 \\
7\end{array}$ & $\begin{array}{l}0.24 \\
2\end{array}$ & $\begin{array}{l}0.00 \\
2\end{array}$ & $\begin{array}{l}0.251 \\
*\end{array}$ & $\begin{array}{l}- \\
0.0 \\
56\end{array}$ & $\begin{array}{l}- \\
0.02 \\
7\end{array}$ & 0.044 & $\begin{array}{l}- \\
0.154\end{array}$ & $\begin{array}{l}0.37 \\
1 * *\end{array}$ & 0.277 & 1 & & & & & \\
\hline
\end{tabular}


Table 3. Bivariate relationship between dependent variables and continuous predictor variables

\begin{tabular}{|c|c|c|c|c|c|c|c|c|c|c|c|c|c|c|c|c|c|c|}
\hline Variable & $\begin{array}{l}\text { 1.To } \\
\text { tal } \\
\text { diab } \\
\text { etes } \\
\text { distr } \\
\text { ess }^{\text {a }}\end{array}$ & $\begin{array}{l}2 . \\
\text { Emo } \\
\text { tiona } \\
1 \\
\text { distr } \\
\text { ess }\end{array}$ & $\begin{array}{l}3 . \\
\text { Phys } \\
\text { ician } \\
\text { relat } \\
\text { ed } \\
\text { distr } \\
\text { ess }^{\text {b }}\end{array}$ & $\begin{array}{l}4 . \\
\text { Regi } \\
\text { men } \\
\text { relat } \\
\text { ed } \\
\text { distr } \\
\text { ess }^{b}\end{array}$ & $\begin{array}{l}5 . \\
\text { Inter } \\
\text { pers } \\
\text { onal } \\
\text { distr } \\
\text { ess }^{b}\end{array}$ & $\begin{array}{l}6 . \\
\text { Seru } \\
\mathrm{m} \\
\text { cortis } \\
\text { ol }^{\mathrm{i}}\end{array}$ & $\begin{array}{l}7 . \\
\mathrm{Ag} \\
\mathrm{e}\end{array}$ & $\begin{array}{l}8 . \\
\text { Diab } \\
\text { etes } \\
\text { dura } \\
\text { tion }\end{array}$ & $\begin{array}{l}09 . \\
\text { Hyperte } \\
\text { nsion } \\
\text { duration }\end{array}$ & $\begin{array}{l}10 . \\
\text { Num } \\
\text { ber of } \\
\text { house } \\
\text { hold } \\
\text { mem } \\
\text { bers }\end{array}$ & $\begin{array}{l}11 . \\
\text { Tota } \\
1 \\
\text { chol } \\
\text { ester } \\
\text { ol }\end{array}$ & LDL & $\begin{array}{l}\text { VLD } \\
\mathrm{L}\end{array}$ & $\begin{array}{l}12 . \\
\text { Medi } \\
\text { cation } \\
\text { adher } \\
\text { ence }\end{array}$ & $\begin{array}{l}13 . \\
\mathrm{HbA} 1 \\
\mathrm{c}^{\mathrm{f}}\end{array}$ & $\mathrm{PA}^{\mathrm{d}}$ & 15. Diet & $\begin{array}{l}16 . \\
\text { Systoli } \\
\text { c BPh }\end{array}$ \\
\hline $\begin{array}{l}12 . \\
\text { Medication }^{\text {adherence }}\end{array}$ & $\begin{array}{l}- \\
.337 \\
*\end{array}$ & $\begin{array}{l}- \\
.315 \\
* *\end{array}$ & $\begin{array}{l}- \\
0.22 \\
4\end{array}$ & $\begin{array}{l}- \\
.448 \\
* *\end{array}$ & $\begin{array}{l}- \\
0.00 \\
7\end{array}$ & 0.094 & $\begin{array}{l}.36 \\
7 * *\end{array}$ & $\begin{array}{l}- \\
0.01 \\
8\end{array}$ & 0.101 & 0.048 & $\begin{array}{l}- \\
0.20 \\
1\end{array}$ & $\begin{array}{l}- \\
0.221\end{array}$ & $\begin{array}{l}- \\
0.142\end{array}$ & 1 & & & & \\
\hline 13. $\mathrm{HbAl}^{\mathrm{g}} \mathrm{c}^{\mathrm{g}}$ & $\begin{array}{l}0.19 \\
8\end{array}$ & $\begin{array}{l}0.16 \\
6\end{array}$ & $\begin{array}{l}- \\
0.14 \\
0\end{array}$ & $\begin{array}{l}.367 \\
* *\end{array}$ & $\begin{array}{l}- \\
0.10 \\
3 \\
\end{array}$ & $\begin{array}{l}- \\
0.018\end{array}$ & $\begin{array}{l}- \\
0.1 \\
80\end{array}$ & $\begin{array}{l}0.21 \\
9\end{array}$ & -0.126 & $\begin{array}{l}- \\
0.136\end{array}$ & $\begin{array}{l}0.18 \\
0\end{array}$ & 0.103 & $\begin{array}{l}0.366 \\
* *\end{array}$ & $\begin{array}{l}- \\
.366^{*} \\
*\end{array}$ & 1 & & & \\
\hline 14. $\mathrm{PA}^{\mathrm{h}}$ & $\begin{array}{l}- \\
.232 \\
*\end{array}$ & $\begin{array}{l}- \\
0.15 \\
2\end{array}$ & $\begin{array}{l}0.10 \\
2\end{array}$ & $\begin{array}{l}- \\
.311 \\
* *\end{array}$ & $\begin{array}{l}- \\
0.17 \\
8\end{array}$ & 0.108 & $\begin{array}{l}0.0 \\
28\end{array}$ & $\begin{array}{l}- \\
0.04 \\
7\end{array}$ & 0.052 & 0.183 & $\begin{array}{l}- \\
0.04 \\
1\end{array}$ & $\begin{array}{l}- \\
0.008\end{array}$ & $\begin{array}{l}- \\
0.284 \\
*\end{array}$ & .198 & $\begin{array}{l}- \\
0.046\end{array}$ & 1 & & \\
\hline 15. Diet $^{\mathrm{i}}$ & $\begin{array}{l}- \\
0.19 \\
1 \\
\end{array}$ & $\begin{array}{l}- \\
0.09 \\
6 \\
\end{array}$ & $\begin{array}{l}0.01 \\
5\end{array}$ & $\begin{array}{l}- \\
0.37 \\
4 * * \\
\end{array}$ & $\begin{array}{l}- \\
0.07 \\
0\end{array}$ & $\begin{array}{l}- \\
0.037\end{array}$ & $\begin{array}{l}0.1 \\
94\end{array}$ & $\begin{array}{l}- \\
0.16 \\
0 \\
\end{array}$ & 0.110 & 0.032 & $\begin{array}{l}- \\
0.10 \\
2 \\
\end{array}$ & $\begin{array}{l}- \\
0.091\end{array}$ & $\begin{array}{l}- \\
0.299 \\
*\end{array}$ & $\begin{array}{l}.321 * \\
*\end{array}$ & - & $\begin{array}{l}.478 \\
* *\end{array}$ & 1 & \\
\hline $\begin{array}{l}\text { 16. Systolic } \\
\text { BP }\end{array}$ & $\begin{array}{l}0.17 \\
6\end{array}$ & $\begin{array}{l}0.14 \\
8\end{array}$ & $\begin{array}{l}0.06 \\
9\end{array}$ & $\begin{array}{l}0.16 \\
7\end{array}$ & $\begin{array}{l}0.11 \\
7\end{array}$ & $\begin{array}{l}- \\
0.145\end{array}$ & $\begin{array}{l}0.2 \\
02\end{array}$ & $\begin{array}{l}0.00 \\
6\end{array}$ & $.270 *$ & $\begin{array}{l}- \\
0.217\end{array}$ & $\begin{array}{l}.402 \\
* *\end{array}$ & $\begin{array}{l}0.381 \\
* *\end{array}$ & $\begin{array}{l}0.343 \\
* *\end{array}$ & $\begin{array}{l}- \\
0.040\end{array}$ & 0.112 & $\begin{array}{l}- \\
0.12 \\
5\end{array}$ & -0.152 & 1 \\
\hline
\end{tabular}


Table 3. Bivariate relationship between dependent variables and continuous predictor variables

\begin{tabular}{|c|c|c|c|c|c|c|c|c|c|c|c|c|c|c|c|c|c|c|}
\hline Variable & $\begin{array}{l}\text { 1.To } \\
\text { tal } \\
\text { diab } \\
\text { etes } \\
\text { distr } \\
\text { ess }^{\text {a }}\end{array}$ & $\begin{array}{l}2 . \\
\text { Emo } \\
\text { tiona } \\
1 \\
\text { distr } \\
\text { ess }^{b}\end{array}$ & $\begin{array}{l}3 . \\
\text { Phys } \\
\text { ician } \\
\text { relat } \\
\text { ed } \\
\text { distr } \\
\text { ess }^{\text {b }}\end{array}$ & $\begin{array}{l}4 . \\
\text { Regi } \\
\text { men } \\
\text { relat } \\
\text { ed } \\
\text { distr } \\
\text { ess }\end{array}$ & $\begin{array}{l}5 . \\
\text { Inter } \\
\text { pers } \\
\text { onal } \\
\text { distr } \\
\text { ess }{ }^{b}\end{array}$ & $\begin{array}{l}6 . \\
\text { Seru } \\
\text { m } \\
\text { cortis } \\
\text { ol }^{\mathrm{i}}\end{array}$ & $\begin{array}{l}7 . \\
\mathrm{Ag} \\
\mathrm{e}\end{array}$ & $\begin{array}{l}8 . \\
\text { Diab } \\
\text { etes } \\
\text { dura } \\
\text { tion }\end{array}$ & $\begin{array}{l}09 . \\
\text { Hyperte } \\
\text { nsion } \\
\text { duration }\end{array}$ & $\begin{array}{l}10 . \\
\text { Num } \\
\text { ber of } \\
\text { house } \\
\text { hold } \\
\text { mem } \\
\text { bers }\end{array}$ & $\begin{array}{l}11 . \\
\text { Tota } \\
1 \\
\text { chol } \\
\text { ester } \\
\text { ol }\end{array}$ & LDL & $\begin{array}{l}\text { VLD } \\
\mathrm{L}\end{array}$ & $\begin{array}{l}12 . \\
\text { Medi } \\
\text { cation } \\
\text { adher } \\
\text { ence }\end{array}$ & $\begin{array}{l}13 . \\
\mathrm{HbA} 1 \\
\mathrm{c}^{\mathrm{f}}\end{array}$ & $\begin{array}{l}14 . \\
P^{d}\end{array}$ & 15. Diet & $\begin{array}{l}16 . \\
\text { Systoli } \\
\text { c BPh }\end{array}$ \\
\hline
\end{tabular}

\section{Note:}

$* * \mathrm{p}$ value $\leq 0.01$

$* p$ value $\leq 0.05$.

${ }^{\mathrm{a}, \mathrm{b}}$ Diabetes distress (total score and subscores) was calculated using the Diabetes Distress Survey (DDS), which had 17 Likert scale questions. Response option included from $1=$ not a problem to $6=$ a very serious problem. Score range: $1-6$.

${ }^{\mathrm{f}} \mathrm{HbA1c}$ or glycosylated hemoglobin was measured in percentage.

${ }^{c}$ Diet score was calculated from the Lifestyle Profile II scale using nine Likert scale questions. Response options included never $=1$, sometimes $=2$, often $=3$, and routinely $=4$. Score range: $9-36$.

${ }^{\mathrm{d}}$ PA (physical activity) score was calculated from the Lifestyle Profile II scale using eight Likert scale questions. Response options included never $=1$, sometimes $=2$, often $=3$, and routinely $=4$. Score range: 8-32.

${ }^{\mathrm{e}}$ Medication adherence was calculated using Morisky Medication Adherence Scale 8 (MMAS8) that had a total of eight questions. Score range: 0-8.

${ }^{\mathrm{g}}$ Serum cholesterol (LDL, VLDL) was measured in $\mathrm{mg} / \mathrm{dL} .{ }^{\mathrm{e}}$ Serum cholesterol (LDL, VLDL) was measured in $\mathrm{mg} / \mathrm{dL}$.

${ }^{\mathrm{h}}$ Blood pressure (systolic BP) was measured in $\mathrm{mm} \mathrm{Hg}$.

${ }^{i}$ Serum cortisol was measured in mcg/dL. 
Table 4: Bivariate relationship between dependent variables and categorical predictor variables

\begin{tabular}{|c|c|c|c|c|c|}
\hline \multicolumn{6}{|c|}{ For nonparametric dependent variables } \\
\hline Predictor variable & $\begin{array}{c}\text { Mean } \\
\text { rank }\end{array}$ & $\begin{array}{l}\text { Standard } \\
\text { deviation }\end{array}$ & Median & $\begin{array}{c}\text { Mann- } \\
\text { Whitney } \\
\text { U/ } \\
\text { Kruskal- } \\
\text { Wallis H }\end{array}$ & $\begin{array}{c}\begin{array}{c}\text { p-value } \\
\text { (Mann- } \\
\text { Whitney test/ } \\
\text { Kruskal- } \\
\text { Wallis test) }\end{array}\end{array}$ \\
\hline \multicolumn{6}{|c|}{ Total diabetes distress } \\
\hline Gender $^{\mathrm{a}}$ & & & & 581.00 & 0.459 \\
\hline Male & 40.48 & & 1.88 & & \\
\hline Female & 36.60 & & 1.64 & & \\
\hline Education level $^{\mathrm{b}}$ & & & & 7.754 & $0.021 *$ \\
\hline $\begin{array}{l}\text { less than or equal } \\
\text { to high school }\end{array}$ & 39.43 & & 1.97 & & \\
\hline $\begin{array}{l}\text { some college } \\
\text { education or }\end{array}$ & 27.74 & & 1.47 & & \\
\hline $\begin{array}{l}\text { associate degree } \\
\text { college graduate, } \\
\text { post-graduate or } \\
\text { professional degree }\end{array}$ & 43.68 & & 1.97 & & \\
\hline Annual salary ${ }^{\mathrm{C}}$ & & & & 1.84 & 0.765 \\
\hline Less than $\$ 25,000$ & 39.74 & & 1.94 & & \\
\hline$\$ 25,000-50,000$ & 36.54 & & 1.64 & & \\
\hline$\$ 50,000-75,000$ & 34.97 & & 1.59 & & \\
\hline$\$ 75,000-100,000$ & 43.75 & & 1.85 & & \\
\hline $\begin{array}{c}\text { Greater than } \\
\$ 100,000\end{array}$ & 27.50 & & 1.52 & & \\
\hline Rural/Urband & & & & 619.00 & 0.951 \\
\hline Rural & 38.22 & & 2.00 & & \\
\hline Urban & 37.89 & & 1.73 & & \\
\hline Race $^{\mathrm{e}}$ & & & & 283.00 & 0.558 \\
\hline Non-white & 33.80 & & 1.44 & & \\
\hline White & 38.07 & & 1.76 & & \\
\hline Health insurance ${ }^{f}$ & & & & 59.00 & 0.670 \\
\hline No & 31.00 & & 1.71 & & \\
\hline Yes & 38.19 & & 1.76 & & \\
\hline $\begin{array}{l}\text { Family history of } \\
\text { diabetes }^{\mathrm{g}}\end{array}$ & & & & 308.50 & 0.514 \\
\hline No & 41.95 & & 1.76 & & \\
\hline Yes & 37.32 & & 1.73 & & \\
\hline $\begin{array}{l}\text { Family history of } \\
\text { hypertension }^{\mathrm{h}}\end{array}$ & & & & 341.00 & 0.593 \\
\hline No & 34.92 & & 1.56 & & \\
\hline Yes & 38.59 & & 1.76 & & \\
\hline
\end{tabular}




\begin{tabular}{|c|c|c|c|c|}
\hline \multicolumn{5}{|c|}{ Emotional distress } \\
\hline Gender $^{\mathrm{a}}$ & & & 564.00 & 0.348 \\
\hline Male & 41.11 & 1.80 & & \\
\hline Female & 36.25 & 1.40 & & \\
\hline Education level $^{\mathrm{b}}$ & & & 3.099 & 0.212 \\
\hline $\begin{array}{l}\text { less than or equal } \\
\text { to high school }\end{array}$ & 39.79 & 1.80 & & \\
\hline & 31.48 & 1.20 & & \\
\hline $\begin{array}{l}\text { associate degree } \\
\text { college graduate, } \\
\text { post-graduate or } \\
\text { professional degree }\end{array}$ & 41.29 & 1.70 & & \\
\hline Annual salary $^{\mathrm{c}}$ & & & 1.03 & 0.905 \\
\hline Less than $\$ 25,000$ & 38.57 & 1.60 & & \\
\hline$\$ 25,000-50,000$ & 35.02 & 1.40 & & \\
\hline$\$ 50,000-75,000$ & 39.62 & 1.80 & & \\
\hline$\$ 75,000-100,000$ & 40.50 & 1.50 & & \\
\hline $\begin{array}{c}\text { Greater than } \\
\$ 100,000\end{array}$ & 30.67 & 1.60 & & \\
\hline Rural/Urban $^{\mathrm{d}}$ & & & 562.00 & 0.473 \\
\hline Rural & 40.52 & 1.60 & & \\
\hline Urban & 36.74 & 1.50 & & \\
\hline Race $^{\mathrm{e}}$ & & & 271.00 & 0.433 \\
\hline Non-white & 32.60 & 1.00 & & \\
\hline White & 38.27 & 1.60 & & \\
\hline Health insurance $^{f}$ & & & 65.00 & 0.809 \\
\hline No & 42.00 & 1.90 & & \\
\hline Yes & 37.89 & 1.60 & & \\
\hline $\begin{array}{l}\text { Family history of } \\
\text { diabetes }^{\mathrm{g}}\end{array}$ & & & 278.50 & 0.265 \\
\hline No & 44.68 & 1.80 & & \\
\hline Yes & 36.85 & 1.60 & & \\
\hline $\begin{array}{l}\text { Family history of } \\
\text { hypertension }\end{array}$ & & & 376.50 & 0.982 \\
\hline No & 37.88 & 1.40 & & \\
\hline Yes & 38.59 & 1.60 & & \\
\hline \multicolumn{5}{|c|}{ Physician-related distress } \\
\hline Gender $^{\mathrm{a}}$ & & & 613.00 & 0.649 \\
\hline Male & 36.70 & 1.0 & & \\
\hline Female & 38.73 & 1.0 & & \\
\hline $\begin{array}{l}\text { Education level }^{\mathrm{b}} \\
\text { less than or equal } \\
\text { to high school }\end{array}$ & 38.07 & 1.00 & 0.714 & 0.700 \\
\hline
\end{tabular}




\begin{tabular}{|c|c|c|c|c|}
\hline $\begin{array}{l}\text { some college } \\
\text { education or } \\
\text { associate degree } \\
\text { college graduate, } \\
\text { post-graduate or } \\
\text { professional degree }\end{array}$ & 39.54 & 1.00 & & \\
\hline Annual salary ${ }^{c}$ & & & 8.364 & 0.079 \\
\hline Less than $\$ 25,000$ & 42.50 & 1.00 & & \\
\hline$\$ 25,000-50,000$ & 37.84 & 1.00 & & \\
\hline$\$ 50,000-75,000$ & 28.91 & 1.00 & & \\
\hline$\$ 75,000-100,000$ & 45.88 & 1.25 & & \\
\hline $\begin{array}{c}\text { Greater than } \\
\$ 100,000\end{array}$ & 26.00 & 1.00 & & \\
\hline Rural/Urban $^{\mathrm{d}}$ & & & 570.00 & 0.466 \\
\hline Rural & 35.80 & 1.00 & & \\
\hline Urban & 39.10 & 1.00 & & \\
\hline Race $^{\mathrm{e}}$ & & & 319.50 & 0.993 \\
\hline Non-white & 37.45 & 1.00 & & \\
\hline White & 37.51 & 1.00 & & \\
\hline Health insurance ${ }^{f}$ & & & 49.00 & 0.468 \\
\hline No & 26.00 & 1.00 & & \\
\hline Yes & 38.33 & 1.00 & & \\
\hline $\begin{array}{l}\text { Family history of } \\
\text { diabetes }^{g}\end{array}$ & & & 339.00 & 0.818 \\
\hline No & 36.82 & 1.00 & & \\
\hline Yes & 38.20 & 1.00 & & \\
\hline $\begin{array}{l}\text { Family history of } \\
\text { hypertension }^{\mathrm{h}}\end{array}$ & & & 0.11 & 0.753 \\
\hline No & 39.54 & 1.00 & & \\
\hline Yes & 37.71 & 1.00 & & \\
\hline \multicolumn{5}{|c|}{ Interpersonal distress } \\
\hline Gender $^{\mathrm{a}}$ & & & 625.00 & 0.791 \\
\hline Male & 38.85 & 1.33 & & \\
\hline Female & 37.52 & 1.33 & & \\
\hline Education level $^{\mathrm{b}}$ & & & 7.132 & $0.028^{*}$ \\
\hline $\begin{array}{l}\text { less than or equal } \\
\text { to high school }\end{array}$ & 38.86 & 1.33 & & \\
\hline some college & 28.65 & 1.00 & & \\
\hline $\begin{array}{l}\text { education or } \\
\text { associate degree } \\
\text { college graduate, } \\
\text { post-graduate or } \\
\text { professional degree }\end{array}$ & 43.34 & 1.67 & & \\
\hline Annual salary $^{\mathrm{c}}$ & & & 1.416 & 0.841 \\
\hline Less than $\$ 25,000$ & 36.21 & 1.33 & & \\
\hline$\$ 25,000-50,000$ & 40.10 & 1.33 & & \\
\hline
\end{tabular}




\begin{tabular}{|c|c|c|c|c|}
\hline$\$ 50,000-75,000$ & 34.32 & 1.33 & & \\
\hline$\$ 75,000-100,000$ & 41.56 & 1.50 & & \\
\hline $\begin{array}{c}\text { Greater than } \\
\$ 100,000\end{array}$ & 32.00 & 1.00 & & \\
\hline Rural/Urban $^{\mathrm{d}}$ & & & 602.50 & 0.792 \\
\hline Rural & 37.10 & 1.33 & & \\
\hline Urban & 38.45 & 1.33 & & \\
\hline Race $^{\mathrm{e}}$ & & & 219.50 & 0.098 \\
\hline Non white & 27.45 & 1.00 & & \\
\hline White & 39.07 & 1.33 & & \\
\hline Health insurance $\mathrm{f}^{\mathrm{f}}$ & & & 66.00 & 0.833 \\
\hline No & 41.50 & 1.00 & & \\
\hline Yes & 37.90 & 1.00 & & \\
\hline $\begin{array}{c}\text { Family history of } \\
\text { diabetes }^{\mathrm{g}}\end{array}$ & & & 265.00 & 0.173 \\
\hline No & 45.91 & 1.67 & & \\
\hline Yes & 36.64 & 1.33 & & \\
\hline $\begin{array}{l}\text { Family history of } \\
\text { hypertension }^{\text {h }}\end{array}$ & & & 356.00 & 0.740 \\
\hline No & 39.83 & 1.33 & & \\
\hline Yes & 37.65 & 1.33 & & \\
\hline
\end{tabular}

For parametric dependent variables

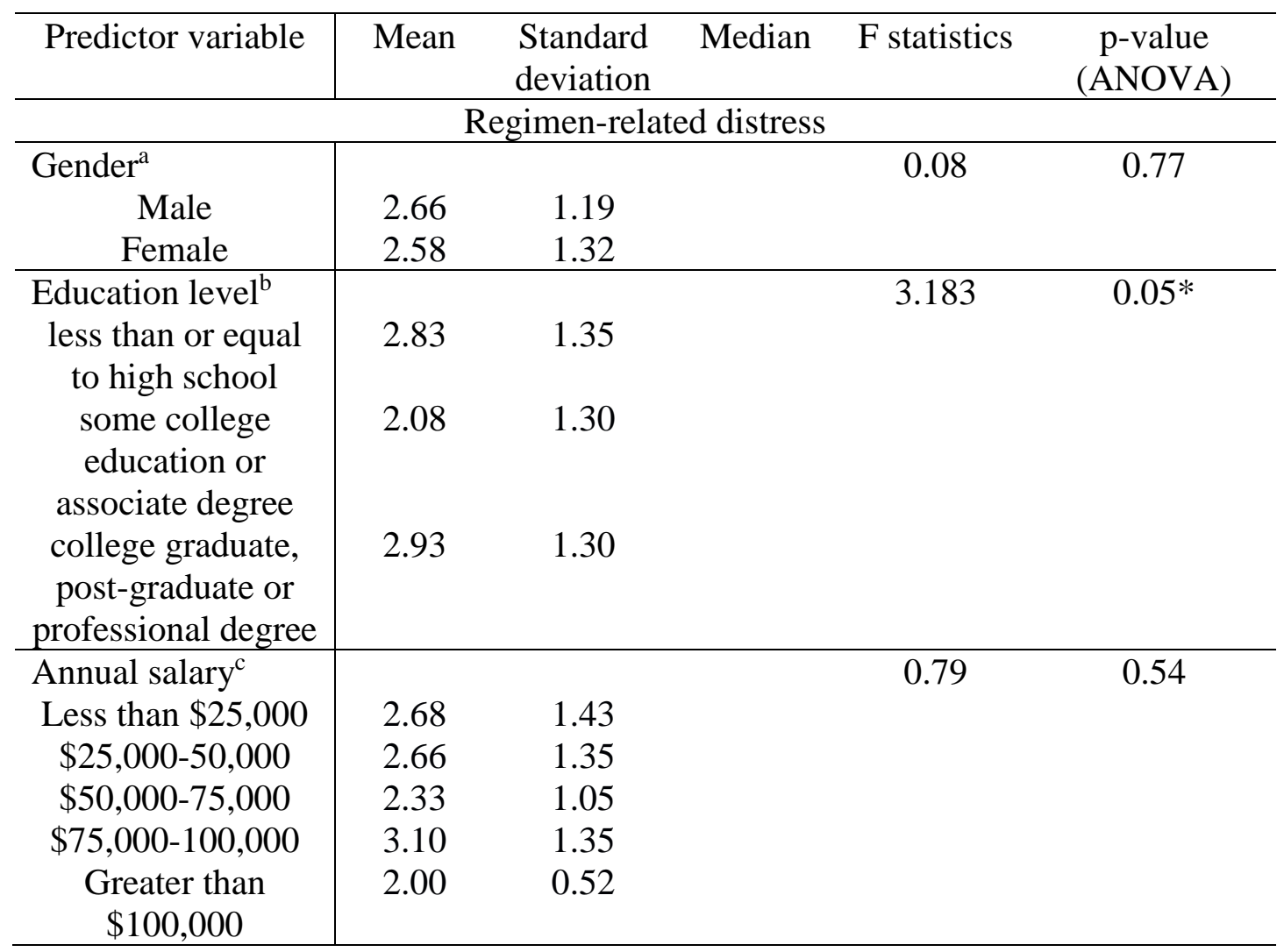




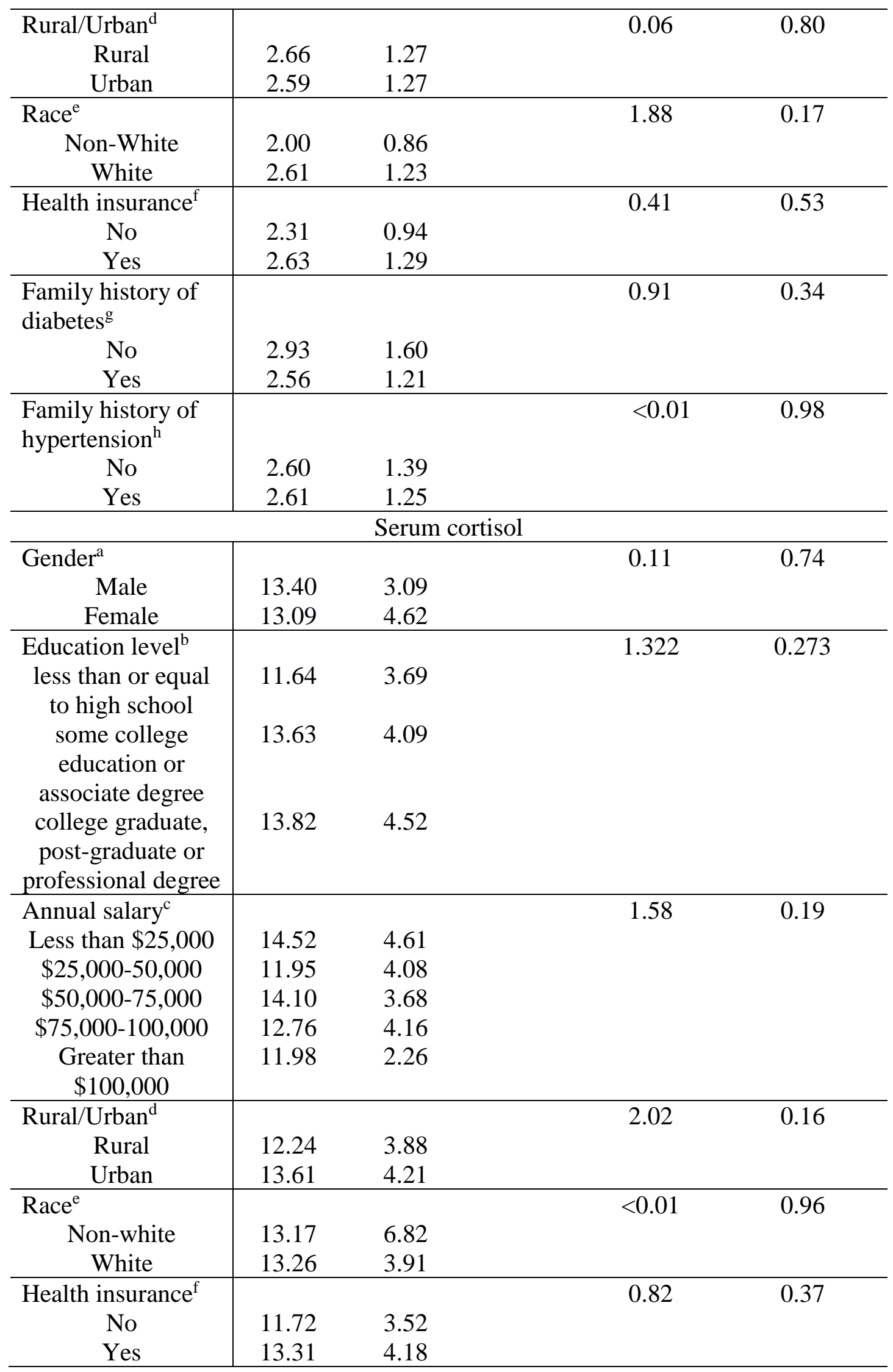




\begin{tabular}{c|rrrr}
\hline $\begin{array}{l}\text { Family history of } \\
\text { diabetes }^{\mathrm{g}}\end{array}$ & & & 1.14 & 0.29 \\
No & 14.38 & 4.46 & & \\
Yes & 13.01 & 4.08 & 3.91 & $0.05^{*}$ \\
\hline $\begin{array}{c}\text { Family history of } \\
\text { hypertension }\end{array}$ & & & & \\
No & 15.46 & 5.03 & & \\
Yes & 12.87 & 3.92 & \\
\hline
\end{tabular}

Note:

$* p$ value $\leq 0.05$.

${ }^{a}$ Gender: a categorical variable with two categories (male, female).

bEducation level: a categorical variable with three categories (less than or equal to high school, some college education or associate degree, and college graduate, post-graduate or professional degree.

'Annual salary: a categorical variable with five categories (less than $\$ 25,500$, $\$ 25000-50,000, \$ 50,000-75,000, \$ 75,000-100,000$, greater than $\$ 100,000)$.

${ }^{\mathrm{d}}$ Rural/Urban: a categorical variable with two categories (rural, urban).

${ }^{\mathrm{e}}$ Race: a categorical variable which was recategorized into two categories (Nonwhite, white).

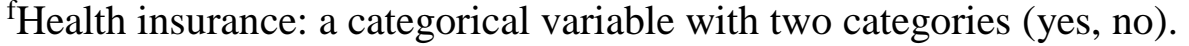

${ }^{g}$ Family history of diabetes: a categorical variable with two categories (yes, no).

${ }^{\mathrm{h}}$ Family history of BP: a categorical variable with two categories (yes, no). 
Table 5. Linear mixed model on diabetes distress and it's domains

\begin{tabular}{|c|c|c|c|c|c|}
\hline \multicolumn{6}{|c|}{ Total diabetes distress } \\
\hline \multirow{2}{*}{ Covariates } & \multirow{2}{*}{$\begin{array}{c}\text { Coefficient }(\text { effect }) / \\
\text { Slope }\end{array}$} & \multirow{2}{*}{$\begin{array}{l}\text { Std Error } \\
\qquad(\mathrm{SE})\end{array}$} & \multirow{2}{*}{$\mathrm{p}$-value } & \multicolumn{2}{|c|}{$95 \% \mathrm{CI}$} \\
\hline & & & & Lower & Upper \\
\hline Diabetes duration & -0.002 & 0.009 & 0.80 & -0.020 & 0.015 \\
\hline $\begin{array}{c}\text { Number of } \\
\text { household members }\end{array}$ & -0.025 & 0.078 & 0.75 & -0.180 & 0.131 \\
\hline $\begin{array}{l}\text { Medication } \\
\text { adherence }^{b}\end{array}$ & -0.109 & 0.046 & $0.02 *$ & -0.201 & -0.017 \\
\hline Physical activity ${ }^{\mathrm{c}}$ & 0.065 & 0.109 & 0.55 & -0.151 & 0.281 \\
\hline $\operatorname{Diet}^{\mathrm{d}}$ & -0.353 & 0.157 & $0.03 *$ & -0.663 & -0.043 \\
\hline Program attendance ${ }^{a}$ & -0.024 & 0.012 & $0.05 *$ & -0.049 & -0.001 \\
\hline $\begin{array}{l}\text { Education level } \\
\text { (Some college } \\
\text { education or } \\
\text { associate degree) }\end{array}$ & 0.276 & 0.253 & 0.28 & -0.228 & 0.781 \\
\hline $\begin{array}{c}\text { Education level } \\
\text { (College graduate, } \\
\text { post-graduate or } \\
\text { professional degree })^{\mathrm{e}}\end{array}$ & -0.088 & 0.270 & 0.75 & -0.625 & 0.450 \\
\hline
\end{tabular}

Emotional distress

\begin{tabular}{|c|c|c|c|c|c|}
\hline \multirow{2}{*}{ Covariates } & \multirow{2}{*}{$\begin{array}{c}\text { Coefficient (effect) } \\
\text { / Slope }\end{array}$} & \multirow{2}{*}{$\begin{array}{l}\text { Std Error } \\
\qquad(\mathrm{SE})\end{array}$} & \multirow{2}{*}{ p-value } & \multicolumn{2}{|c|}{$95 \% \mathrm{CI}$} \\
\hline & & & & Lower & Lower \\
\hline Diabetes duration & 0.003 & 0.012 & 0.78 & -0.021 & 0.028 \\
\hline $\begin{array}{c}\text { Number of } \\
\text { household members }\end{array}$ & 0.050 & 0.109 & 0.65 & -0.167 & 0.266 \\
\hline $\begin{array}{l}\text { Medication } \\
\text { adherence }^{\mathrm{b}}\end{array}$ & -0.152 & 0.063 & $0.02 *$ & -0.276 & -0.028 \\
\hline Physical activity ${ }^{\mathrm{c}}$ & 0.156 & 0.145 & 0.28 & -0.131 & 0.444 \\
\hline $\operatorname{Diet}^{\mathrm{d}}$ & -0.380 & 0.210 & 0.07 & -0.796 & 0.036 \\
\hline
\end{tabular}




\begin{tabular}{c|c|c|c|c|c}
\hline Program attendance $^{\mathrm{a}}$ & -0.019 & 0.016 & 0.22 & -0.051 & 0.012 \\
\hline $\begin{array}{c}\text { Education level } \\
\text { (Some college }_{\text {education or }}\end{array}$ & 0.286 & 0.357 & 0.43 & -0.424 & 0.997 \\
$\begin{array}{c}\text { associate degree) } \\
\text { e }\end{array}$ & 0.040 & 0.381 & 0.93 & -0.717 & 0.798 \\
\hline $\begin{array}{c}\text { Education level } \\
(\text { College graduate, } \\
\text { post-graduate or } \\
\text { professional degree) }\end{array}$ & & & & & \\
\hline
\end{tabular}

Physician-related distress

\begin{tabular}{|c|c|c|c|c|c|}
\hline \multirow{2}{*}{ Covariates } & \multirow{2}{*}{$\begin{array}{l}\text { Coefficient (effect) } \\
\text { / Slope }\end{array}$} & \multirow{2}{*}{$\begin{array}{l}\text { Std Error } \\
\quad(\mathrm{SE})\end{array}$} & \multirow{2}{*}{$\mathrm{p}$-value } & \multicolumn{2}{|c|}{$95 \% \mathrm{CI}$} \\
\hline & & & & Lower & Lower \\
\hline Diabetes duration & -0.004 & 0.008 & 0.63 & -0.021 & 0.013 \\
\hline $\begin{array}{c}\text { Number of } \\
\text { household members }\end{array}$ & -0.059 & 0.074 & 0.43 & -0.206 & 0.089 \\
\hline $\begin{array}{l}\text { Medication } \\
\text { adherence }^{b}\end{array}$ & -0.014 & 0.048 & 0.77 & -0.108 & 0.080 \\
\hline Physical activity $^{\mathrm{c}}$ & 0.103 & 0.111 & 0.36 & -0.117 & 0.322 \\
\hline $\operatorname{Diet}^{\mathrm{d}}$ & -0.045 & 0.158 & 0.78 & -0.358 & 0.268 \\
\hline Program attendance $^{a}$ & -0.001 & 0.013 & 0.92 & -0.027 & 0.025 \\
\hline LDL & 0.005 & 0.002 & $0.02 *$ & 0.001 & 0.010 \\
\hline $\begin{array}{l}\text { Education level } \\
\text { (Some college } \\
\text { education or } \\
\text { associate degree) }^{\mathrm{e}}\end{array}$ & 0.393 & 0.247 & 0.15 & -0.098 & 0.884 \\
\hline $\begin{array}{c}\text { Education level } \\
\text { (College graduate, } \\
\text { post-graduate or } \\
\text { professional degree) }\end{array}$ & 0.048 & 0.257 & 0.85 & -0.463 & 0.559 \\
\hline \multicolumn{6}{|c|}{ Regimen-related distress } \\
\hline \multirow{2}{*}{ Covariates } & \multirow{2}{*}{$\begin{array}{l}\text { Coefficient (effect) } \\
\text { / Slope }\end{array}$} & \multirow{2}{*}{$\begin{array}{l}\text { Std Error } \\
\quad(\mathrm{SE})\end{array}$} & \multirow{2}{*}{$\mathrm{p}$-value } & \multicolumn{2}{|c|}{$95 \% \mathrm{CI}$} \\
\hline & & & & Lower & Lower \\
\hline
\end{tabular}




\begin{tabular}{c|c|c|c|c|c}
\hline Diabetes duration & -0.008 & 0.012 & 0.51 & -0.031 & 0.015 \\
\hline $\begin{array}{c}\text { Number of } \\
\text { household members }\end{array}$ & -0.057 & 0.103 & 0.58 & -0.262 & 0.148 \\
\hline $\begin{array}{c}\text { Medication } \\
\text { adherence }\end{array}$ & -0.129 & 0.063 & $0.04 *$ & -0.254 & -0.003 \\
\hline $\begin{array}{c}\text { Physical activity } \\
\text { Diet }\end{array}$ & -0.102 & 0.149 & 0.50 & -0.397 & 0.194 \\
\hline $\begin{array}{c}\text { d } \\
\text { Program attendance }\end{array}$ & -0.430 & 0.217 & $0.05^{\mathrm{a}}$ & -0.860 & $<-0.001$ \\
\hline $\begin{array}{c}\text { Glycosylated } \\
\text { hemoglobin }\end{array}$ & -0.043 & 0.017 & $0.01 *$ & -0.077 & -0.010 \\
\hline $\begin{array}{c}\text { Education level } \\
(\text { Some college } \\
\text { education or } \\
\text { associate degree) }\end{array}$ & 0.224 & 0.070 & $<0.01^{*}$ & 0.086 & 0.363 \\
\hline $\begin{array}{c}\text { Education level } \\
\left(\begin{array}{c}\text { College graduate, } \\
\text { post-graduate or } \\
\text { professional degree) }\end{array}\right.\end{array}$ & -0.282 & 0.353 & 0.43 & -0.987 & 0.422 \\
\hline
\end{tabular}

Interpersonal distress

\begin{tabular}{c|c|c|c|c|c}
\hline Covariates & $\begin{array}{c}\text { Coefficient (effect) } \\
\text { / Slope }\end{array}$ & $\begin{array}{c}\text { Std Error } \\
(\text { SE) }\end{array}$ & p-value & \multicolumn{2}{|c}{$95 \%$ CI } \\
\cline { 4 - 6 } & -0.002 & 0.011 & 0.86 & -0.023 & 0.020 \\
\hline Diabetes duration & 0.015 & 0.095 & 0.87 & -0.174 & 0.205 \\
\hline $\begin{array}{c}\text { Number of } \\
\text { household members }\end{array}$ & -0.089 & 0.060 & 0.14 & -0.209 & 0.031 \\
\hline $\begin{array}{c}\text { Medication } \\
\text { adherence }\end{array}$ & -0.049 & 0.145 & 0.74 & -0.336 & 0.239 \\
\hline $\begin{array}{c}\text { Physical activity } \\
\text { phiet }\end{array}$ & -0.163 & 0.206 & 0.43 & -0.570 & 0.245 \\
\hline Did & -0.010 & 0.017 & 0.57 & -0.044 & 0.025 \\
\hline $\begin{array}{c}\text { Program attendance } \\
\text { a }\end{array}$ & 0.567 & 0.309 & 0.07 & -0.047 & 1.181 \\
\hline $\begin{array}{c}\text { Education level } \\
\text { (Some college }\end{array}$ & & & & & \\
\hline
\end{tabular}




\begin{tabular}{c|c|c|c|c|c}
\hline $\begin{array}{c}\text { education or } \\
\text { associate degree) }\end{array}$ & & & & & \\
\hline $\begin{array}{c}\text { Education level } \\
\text { (College graduate, } \\
\text { post-graduate or } \\
\text { professional degree) }\end{array}$ & 0.011 & 0.328 & 0.97 & -0.643 & 0.664 \\
\hline
\end{tabular}

Serum cortisol

\begin{tabular}{|c|c|c|c|c|c|}
\hline \multirow{2}{*}{ Covariates } & \multirow{2}{*}{$\begin{array}{l}\text { Coefficient (effect) } \\
\text { / Slope }\end{array}$} & \multirow{2}{*}{$\begin{array}{l}\text { Std Error } \\
\text { (SE) }\end{array}$} & \multirow{2}{*}{$\mathrm{p}$-value } & \multicolumn{2}{|c|}{$95 \% \mathrm{CI}$} \\
\hline & & & & Lower & Lower \\
\hline Diabetes duration & -0.006 & 0.042 & 0.88 & -0.089 & 0.076 \\
\hline $\begin{array}{c}\text { Number of } \\
\text { household members }\end{array}$ & -0.741 & 0.360 & $0.04 *$ & -1.461 & -0.022 \\
\hline $\begin{array}{l}\text { Medication } \\
\text { adherence }^{\mathrm{b}}\end{array}$ & 0.032 & 0.261 & 0.90 & -0.486 & 0.550 \\
\hline Physical activity $^{\mathrm{c}}$ & 0.858 & 0.603 & 0.16 & -0.336 & 2.053 \\
\hline $\operatorname{Diet}^{\mathrm{d}}$ & -0.430 & 0.865 & 0.62 & -2.143 & 1.284 \\
\hline Program attendance $^{\mathrm{a}}$ & -0.078 & 0.084 & 0.36 & -0.247 & 0.090 \\
\hline VLDL & 0.058 & 0.027 & $0.03 *$ & 0.005 & 0.111 \\
\hline $\begin{array}{c}\text { Education level } \\
\text { (Some college } \\
\text { education or } \\
\text { associate degree) }^{\mathrm{e}}\end{array}$ & 2.403 & 1.236 & 0.06 & -0.056 & 4.863 \\
\hline $\begin{array}{c}\text { Education level } \\
\text { (College graduate, } \\
\text { post-graduate or } \\
\text { professional degree })^{\mathrm{e}}\end{array}$ & 1.915 & 1.298 & 0.14 & -0.673 & 4.502 \\
\hline
\end{tabular}

Note:

$* p$ value $\leq 0.05$

CI: Confidence interval.

aProgram attendance: number of days a participant attended educational sessions. Range 0-12.

${ }^{\mathrm{b}}$ Medication adherence was calculated using Morisky Medication Adherence Scale 8 (MMAS8) that had total of eight questions. Score range: $0-8$.

${ }^{\mathrm{c}} \mathrm{PA}$ (physical activity) score was calculated from the Lifestyle Profile 
II scale using eight Likert scale questions. Response options included never $=1$, sometimes $=2$, often $=3$, and routinely $=4$. Score range: 8 32.

${ }^{\mathrm{d}}$ Diet score was calculated from the Lifestyle Profile II scale using nine Likert scale questions. Response options included never $=1$, sometimes $=2$, often $=3$, and routinely $=4$. Score range: 8-32.

eEducation level was categorized into three categories: less than or equal to high school, some college education or associate degree, and college graduate, post-graduate or professional degree eSerum cholesterol (LDL, VLDL) was measured in $\mathrm{mg} / \mathrm{dL}$. 


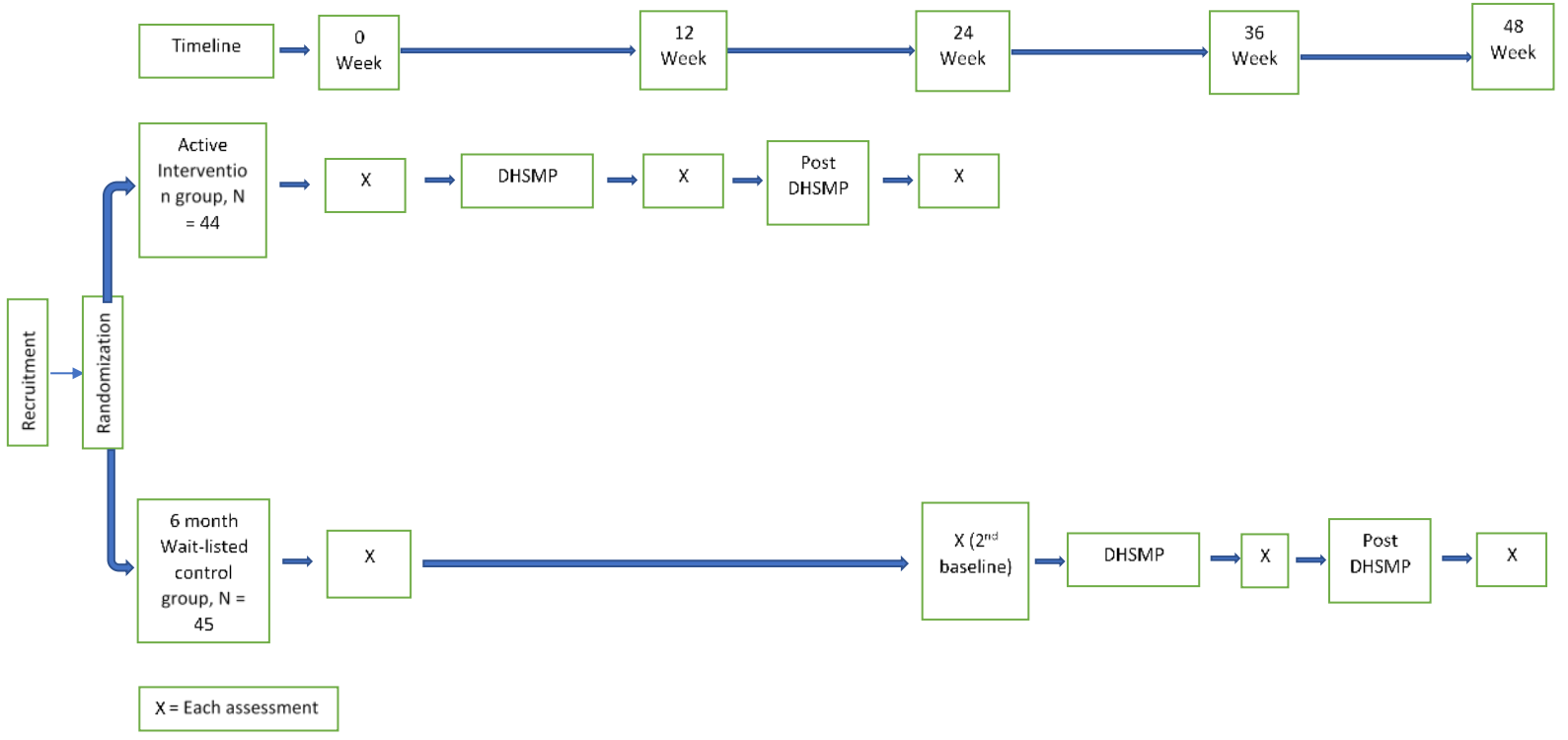

Figure 1. Study design schema. 
Supplementary data analysis

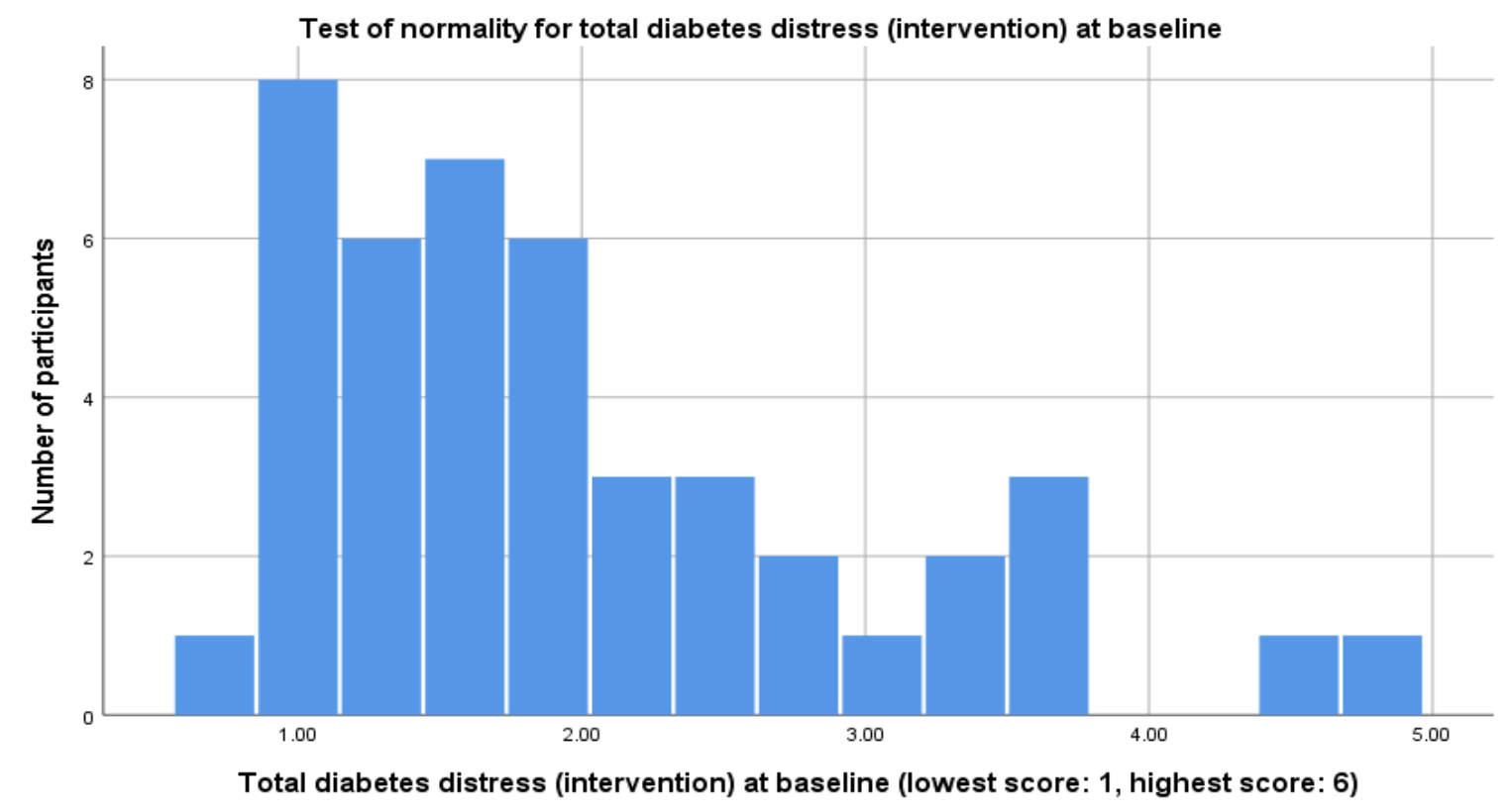

Figure $2 \mathrm{a}$. Test of normality for total diabetes distress (intervention) at baseline. 


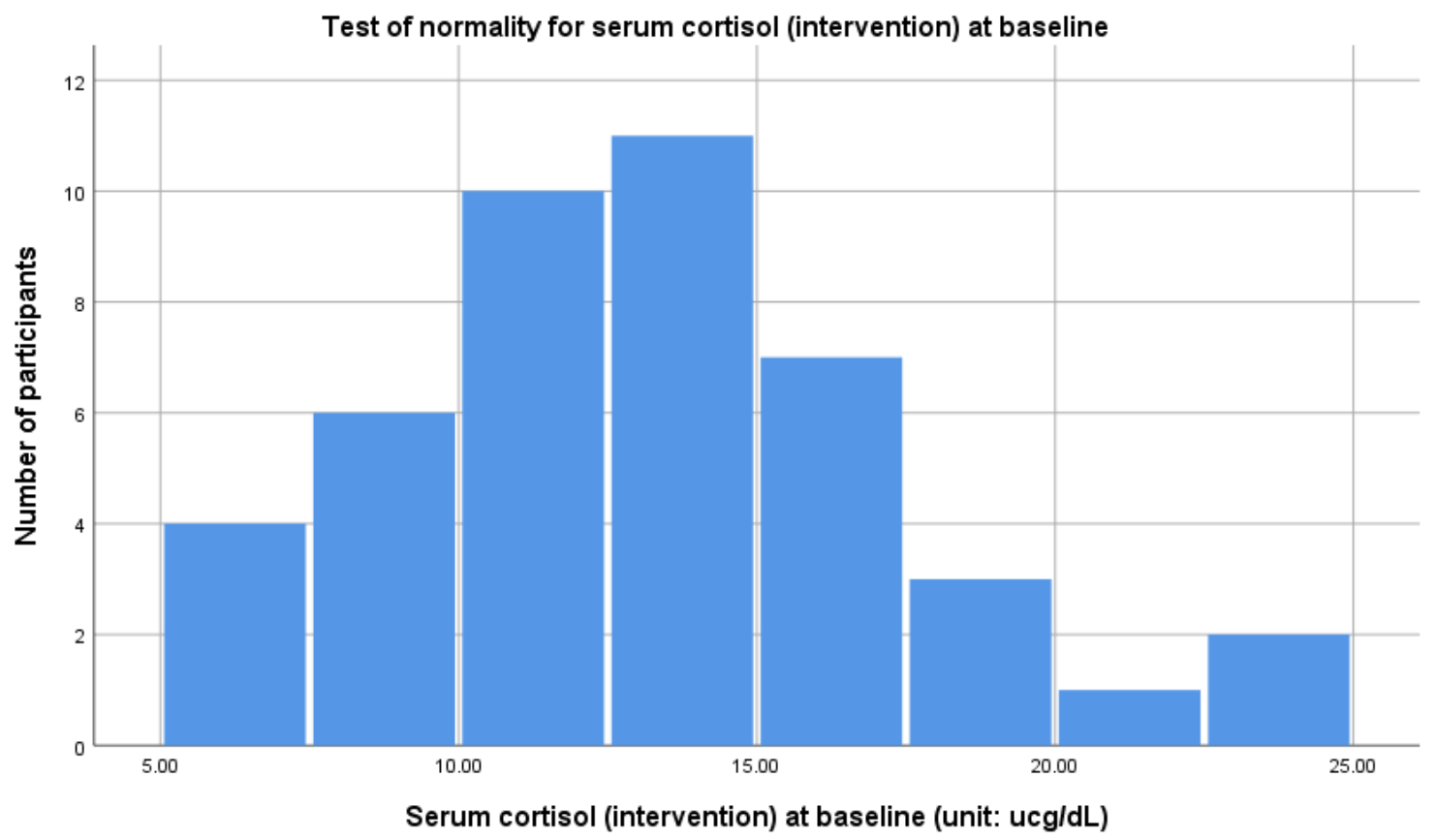

Figure $2 b$. Test of normality for serum cortisol (intervention) at baseline. 


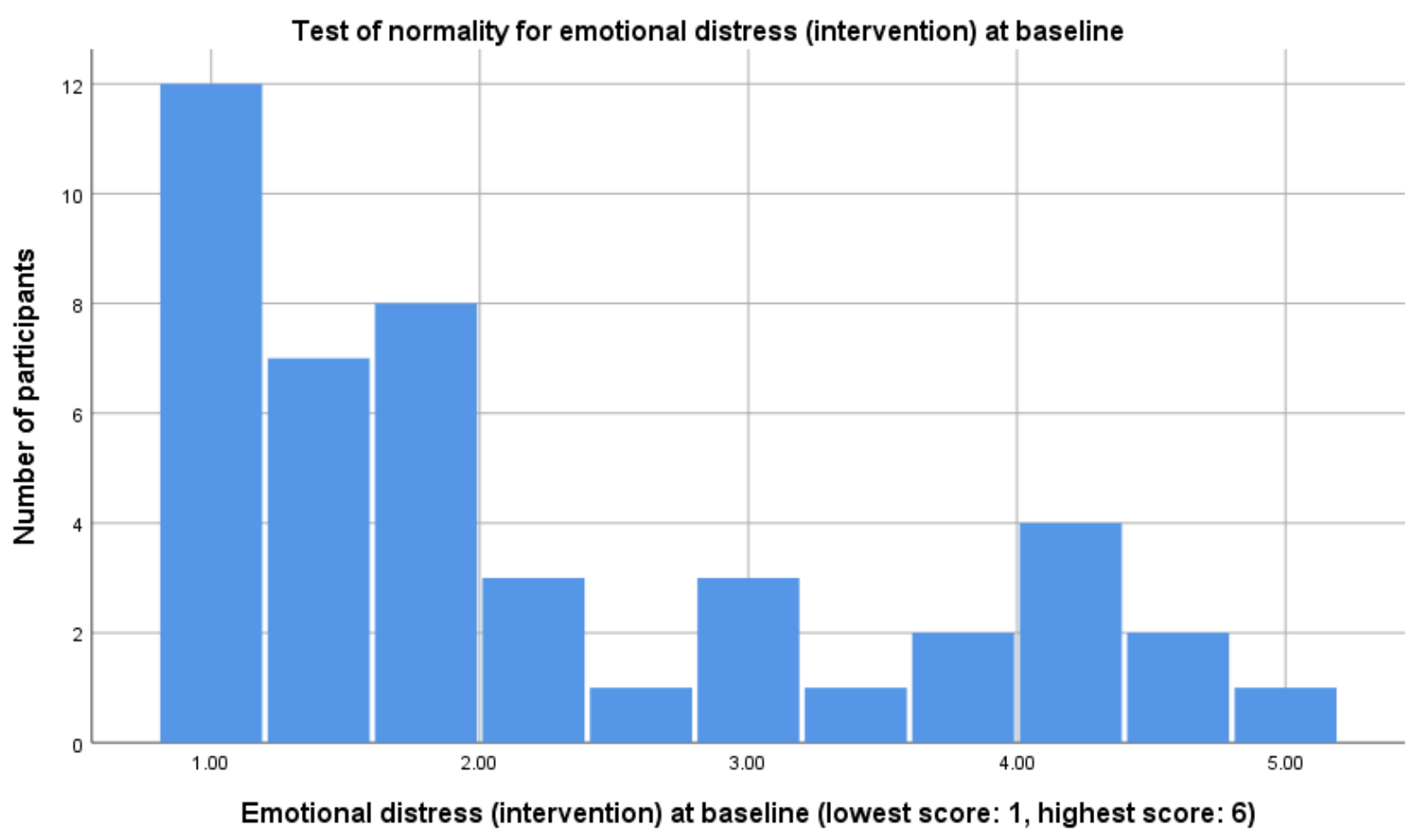

Figure 2c. Test of normality for emotional distress (intervention) at baseline. 


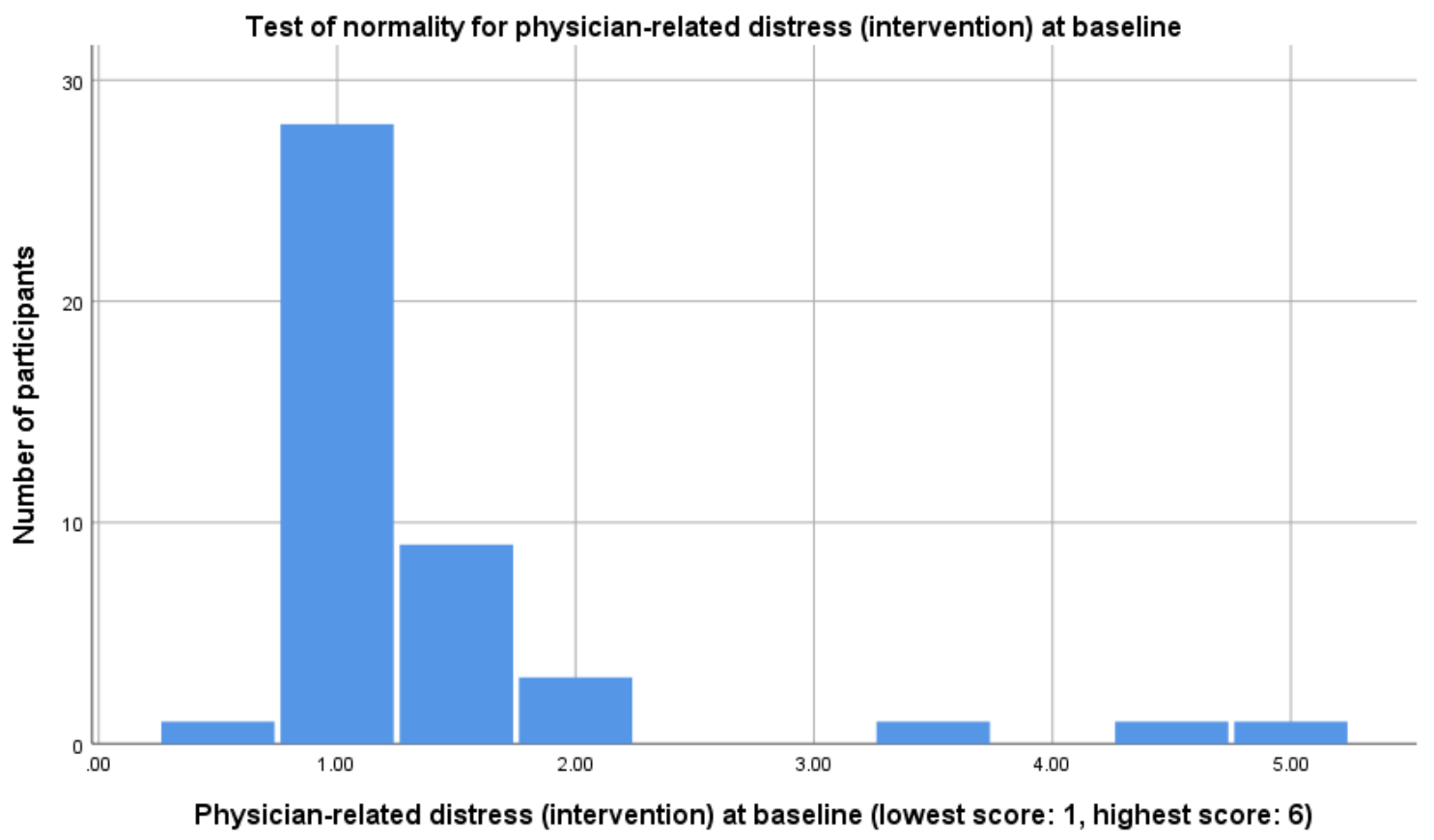

Figure 2d. Test of normality for physician-related distress (intervention) at baseline. 


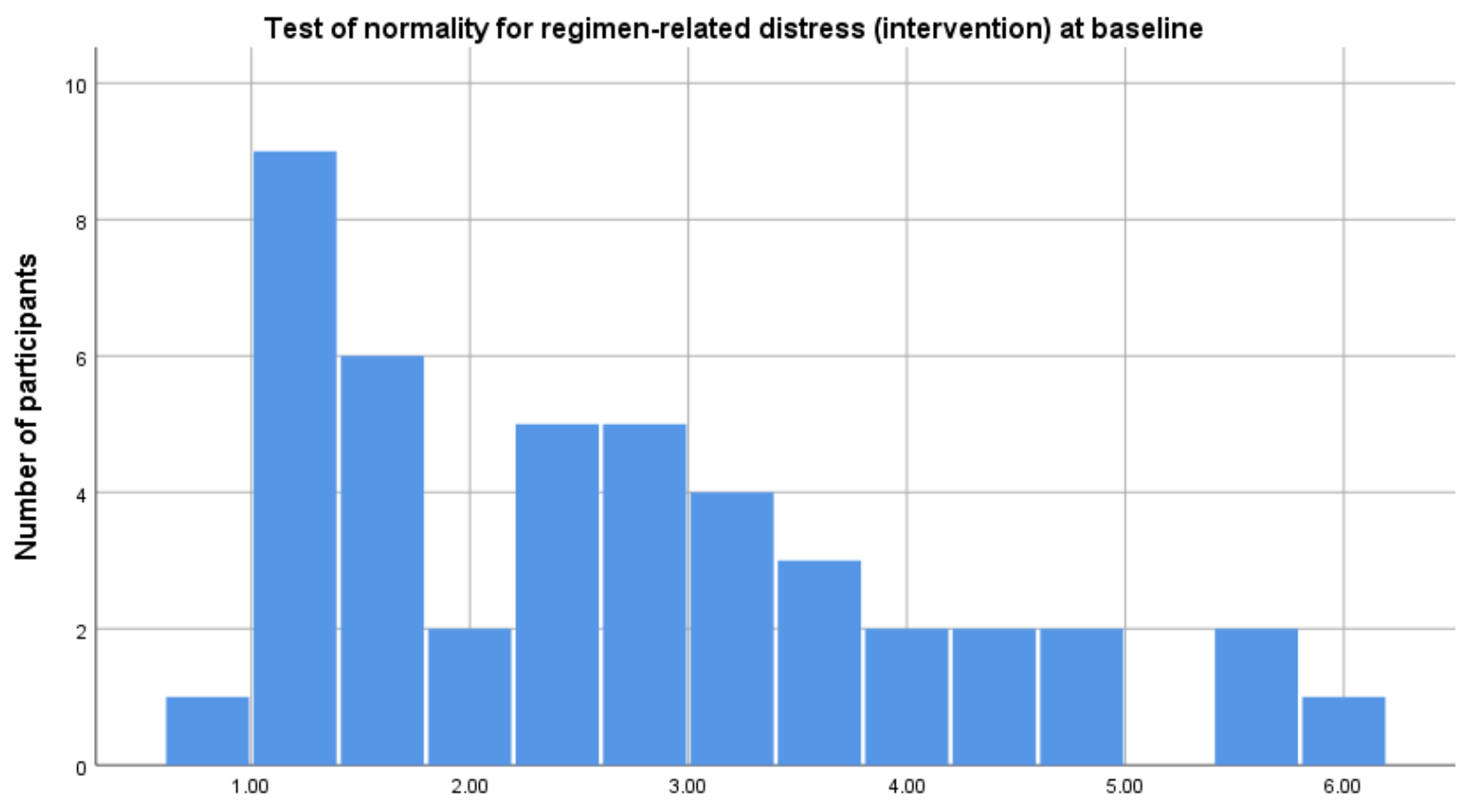

Regimen-related distress (intervention) at baseline (lowest score: 1, highest score: 6)

Figure 2e. Test of normality for regimen-related distress (intervention) at baseline. 


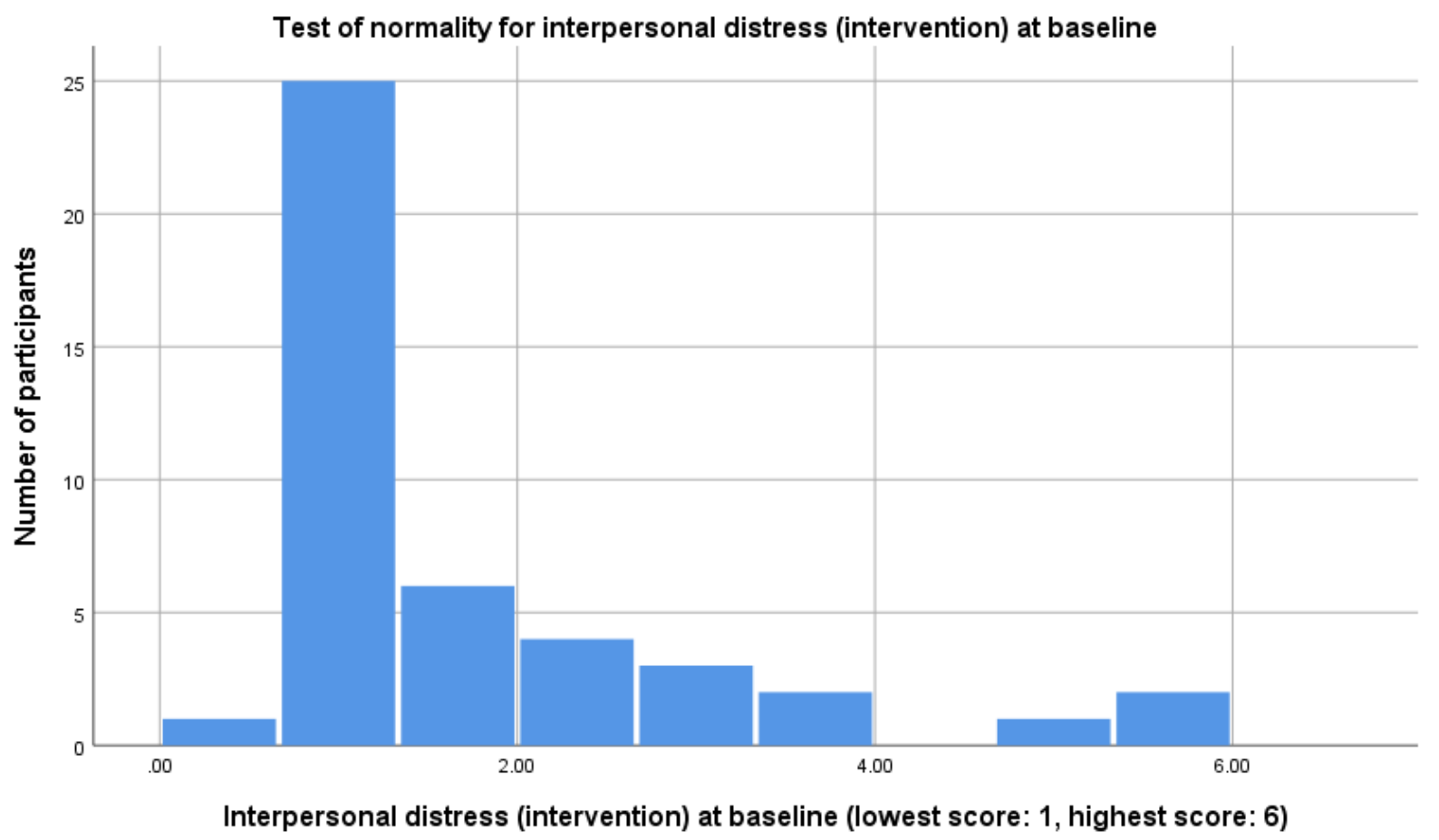

Figure 2f. Test of normality for interpersonal distress (intervention) at baseline. 


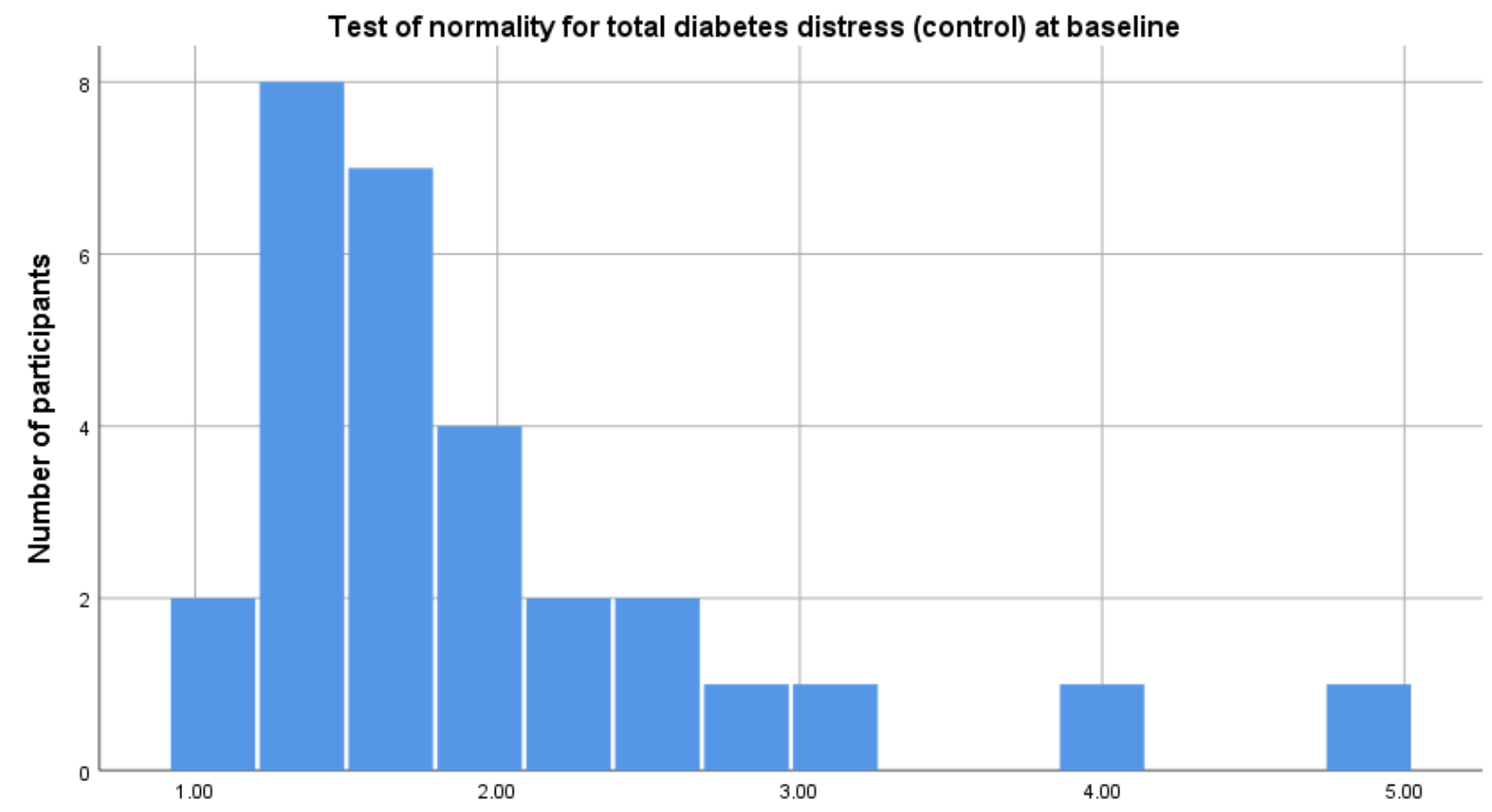

Total diabetes distress (wait-listed control) at baseline (lowest score: 1, highest score: 6)

Figure 2g. Test of normality for total diabetes distress (wait-listed control) at baseline. 


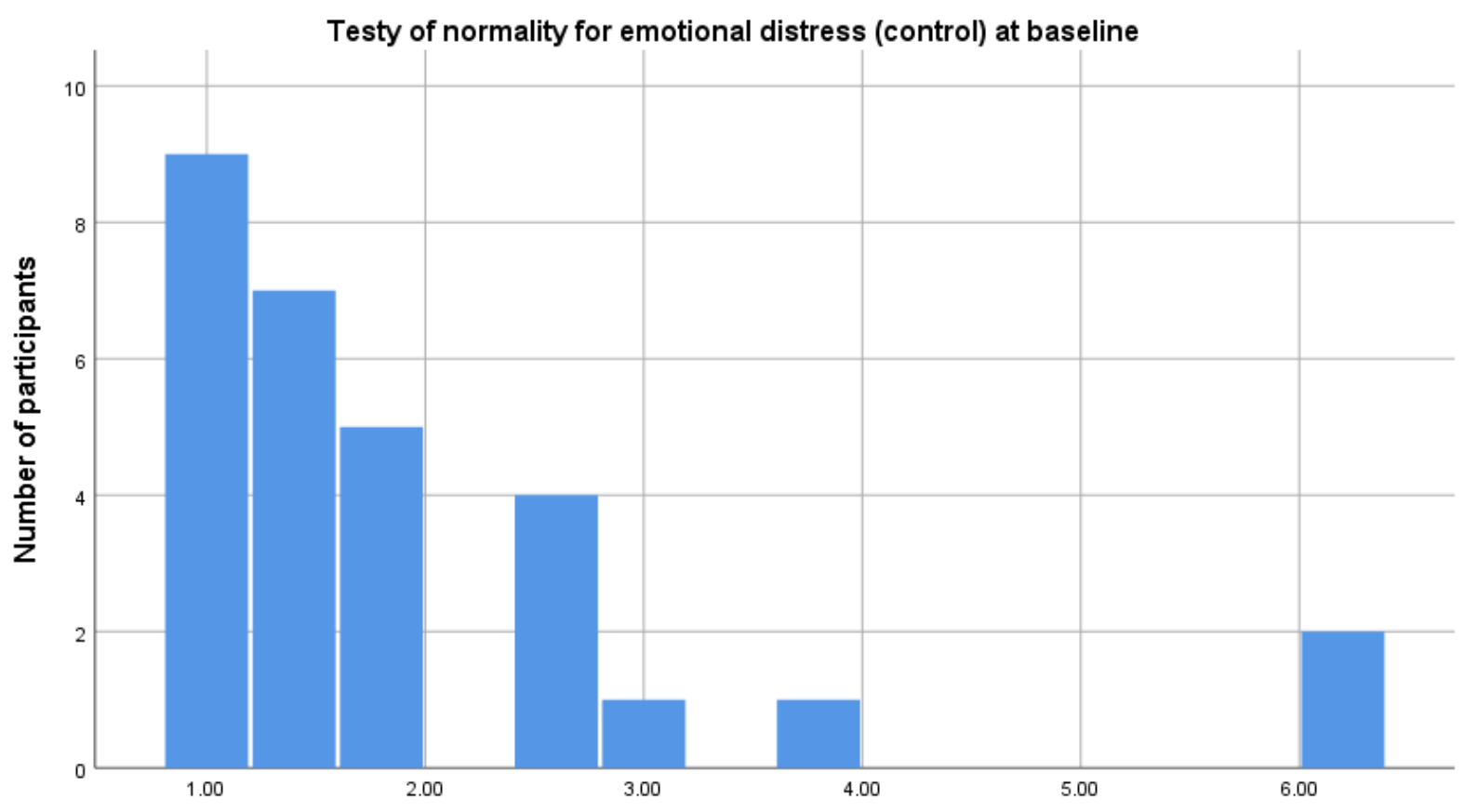

Emotional distress (wait-listed control) at baseline (lowest score: 1, highest score: 6)

Figure $2 \mathrm{~h}$. Test of normality for emotional distress (wait-listed control) at baseline. 


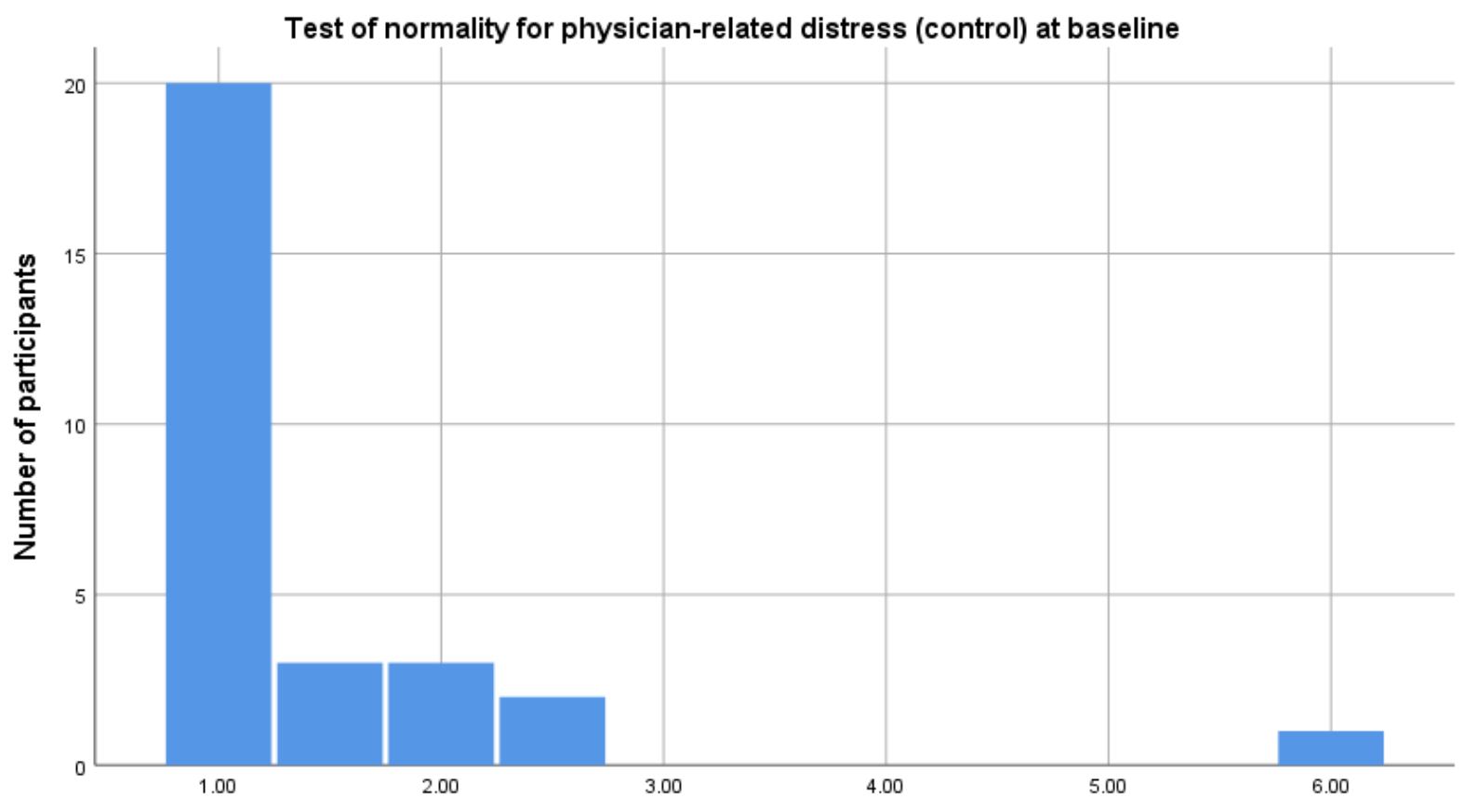

Physician-related distress (wait-listed control) at baseline (lowest score: 1, highest score: 6)

Figure 2i. Test of normality for physician-related distress (wait-listed control) at baseline. 


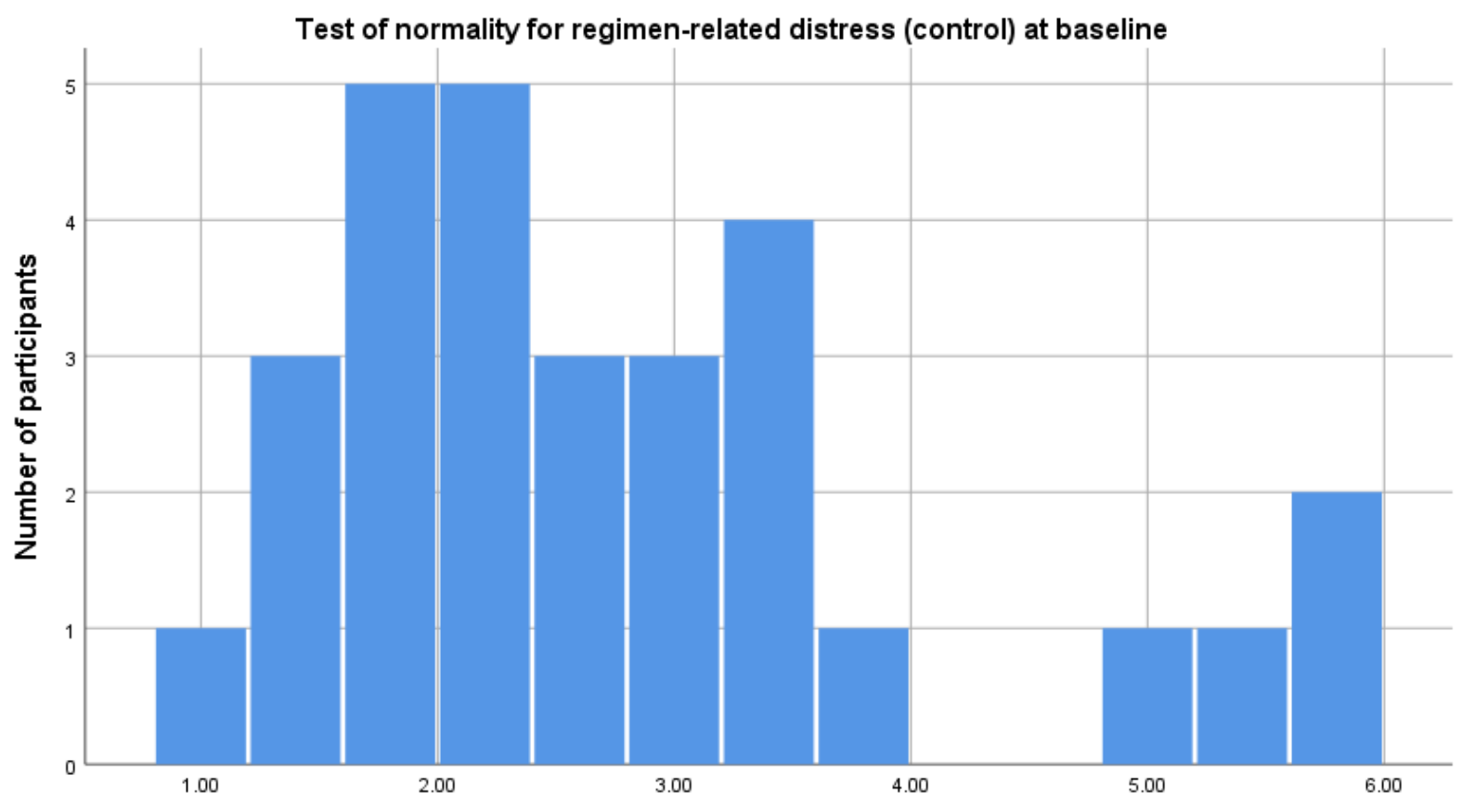

Regimen-related distress (wait-listed control) at baseline (lowest score: 1, highest score: 6)

Figure 2j. Test of normality for regimen-related distress (wait-listed control) at baseline. 


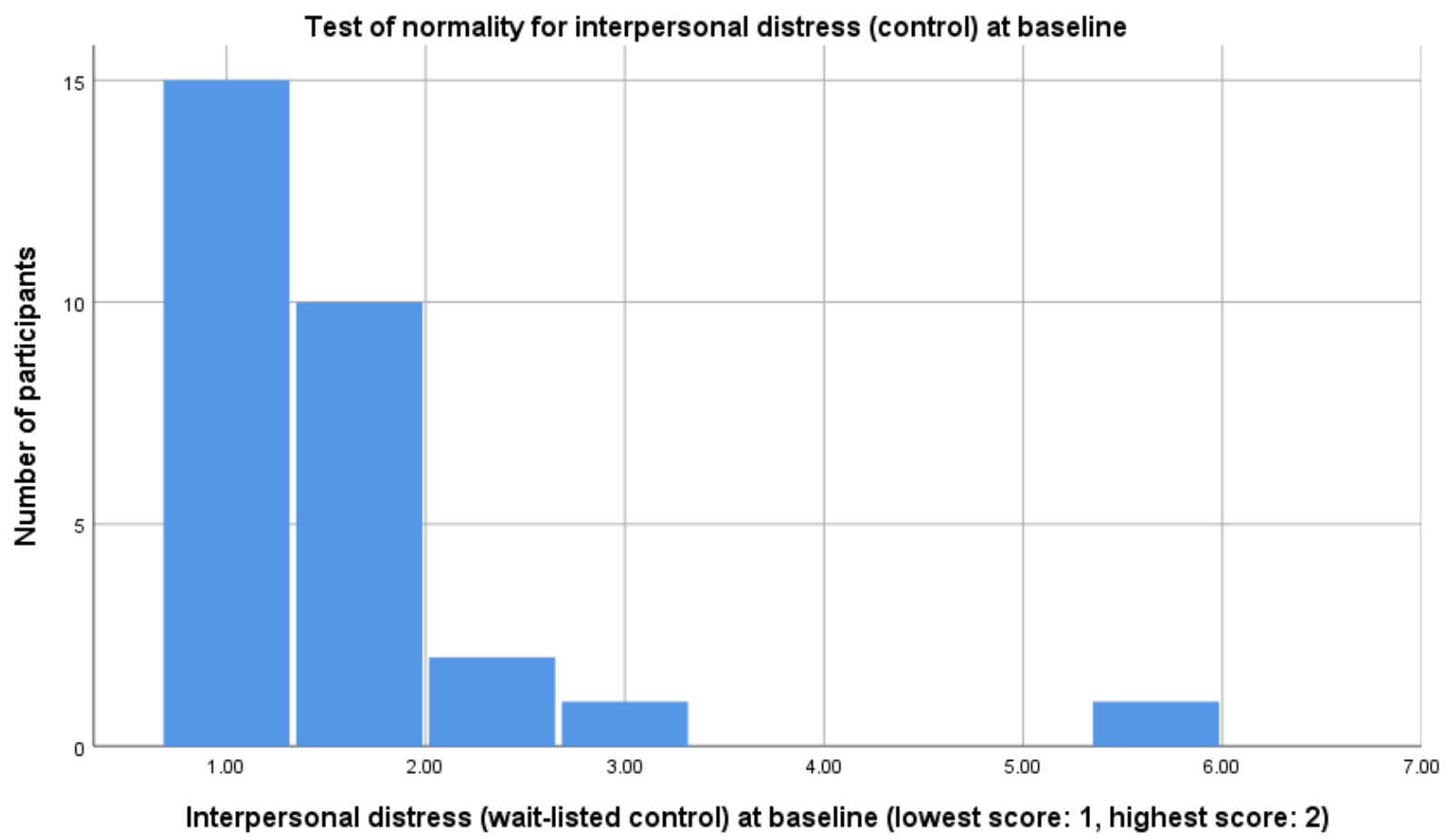

Figure 2k. Test of normality for interpersonal distress (wait-listed control) at baseline. 


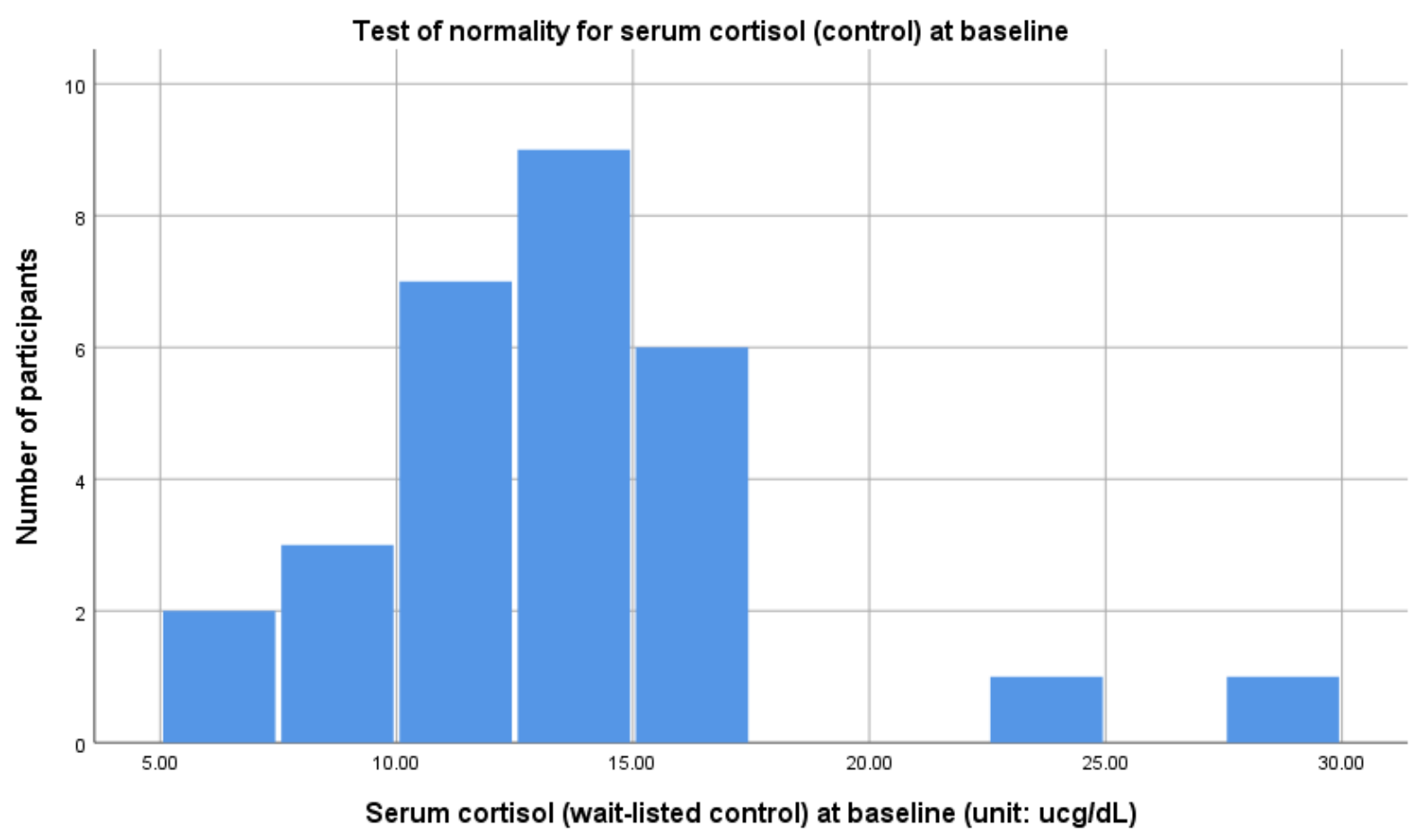

Figure 21. Test of normality for serum cortisol (wait-listed control) at baseline. 
Supplementary Table 1 . Test of homogeneity of variances

\begin{tabular}{c|c|c}
\hline Variable & Levene statistic & p-value \\
\hline Total diabetes distress & 1.96 & 0.166 \\
\hline Emotional distress & 0.39 & 0.534 \\
\hline Physician-related distress & 0.01 & 0.917 \\
\hline Regimen-related distress & 0.59 & 0.444 \\
\hline Interpersonal distress & 1.93 & 0.169 \\
\hline Serum cortisol & 0.06 & 0.246 \\
\hline
\end{tabular}

Note:

$* \mathrm{p}$ value $\leq 0.05$ 


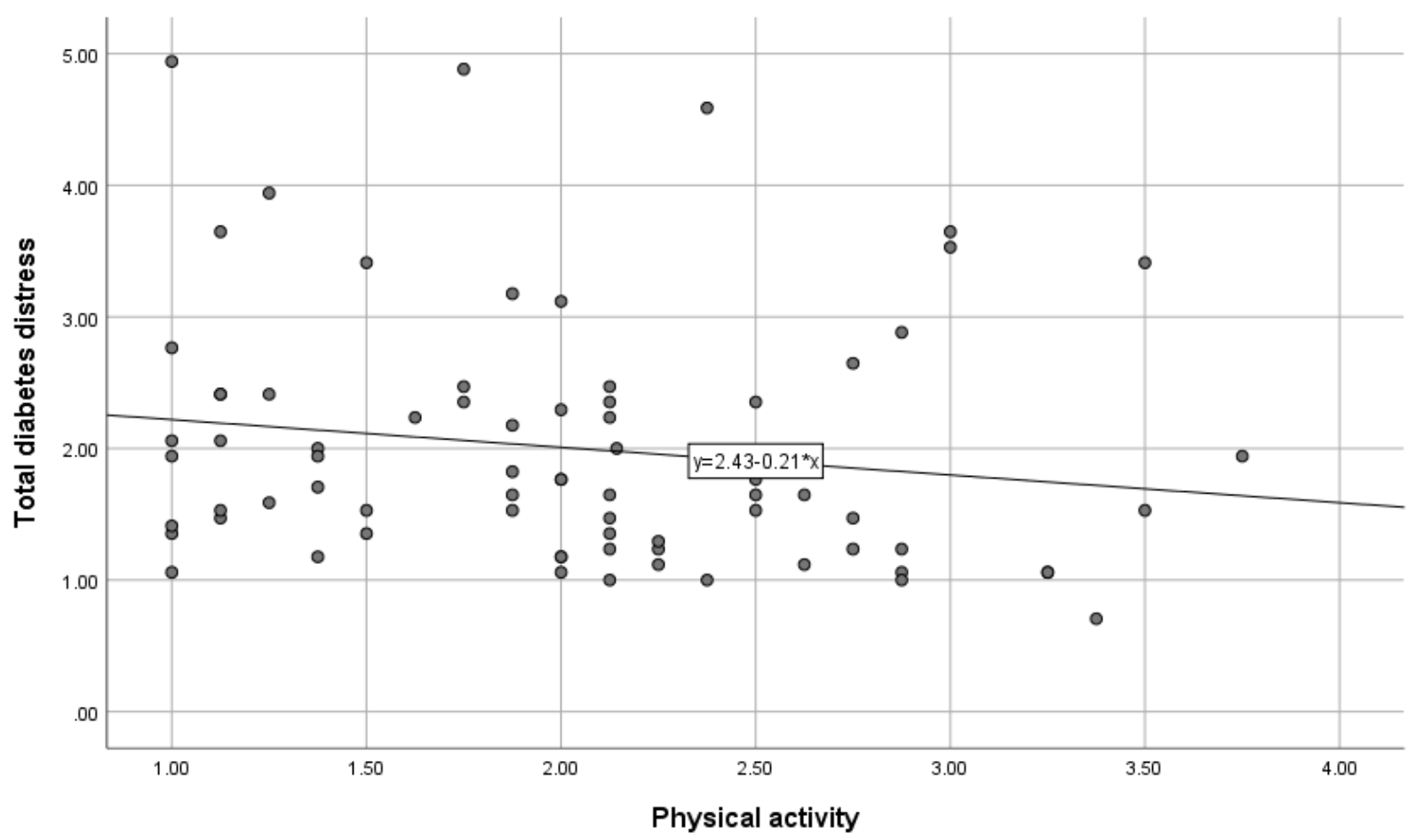

Figure 3a. Scatterplot to show relationships between physical activity and total diabetes distress. 


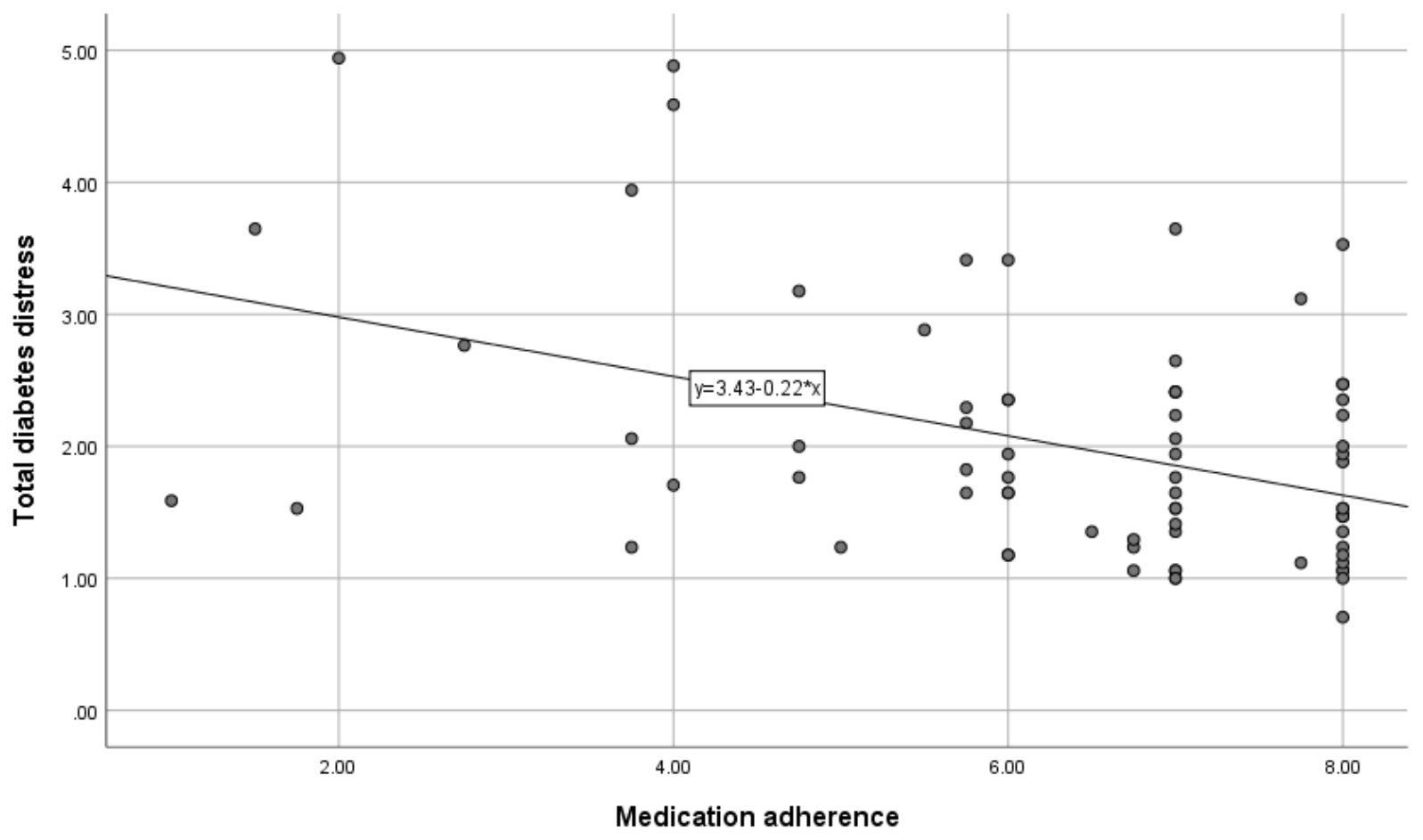

Figure 3b. Scatterplot to show relationships between medication adherence and total diabetes distress. 


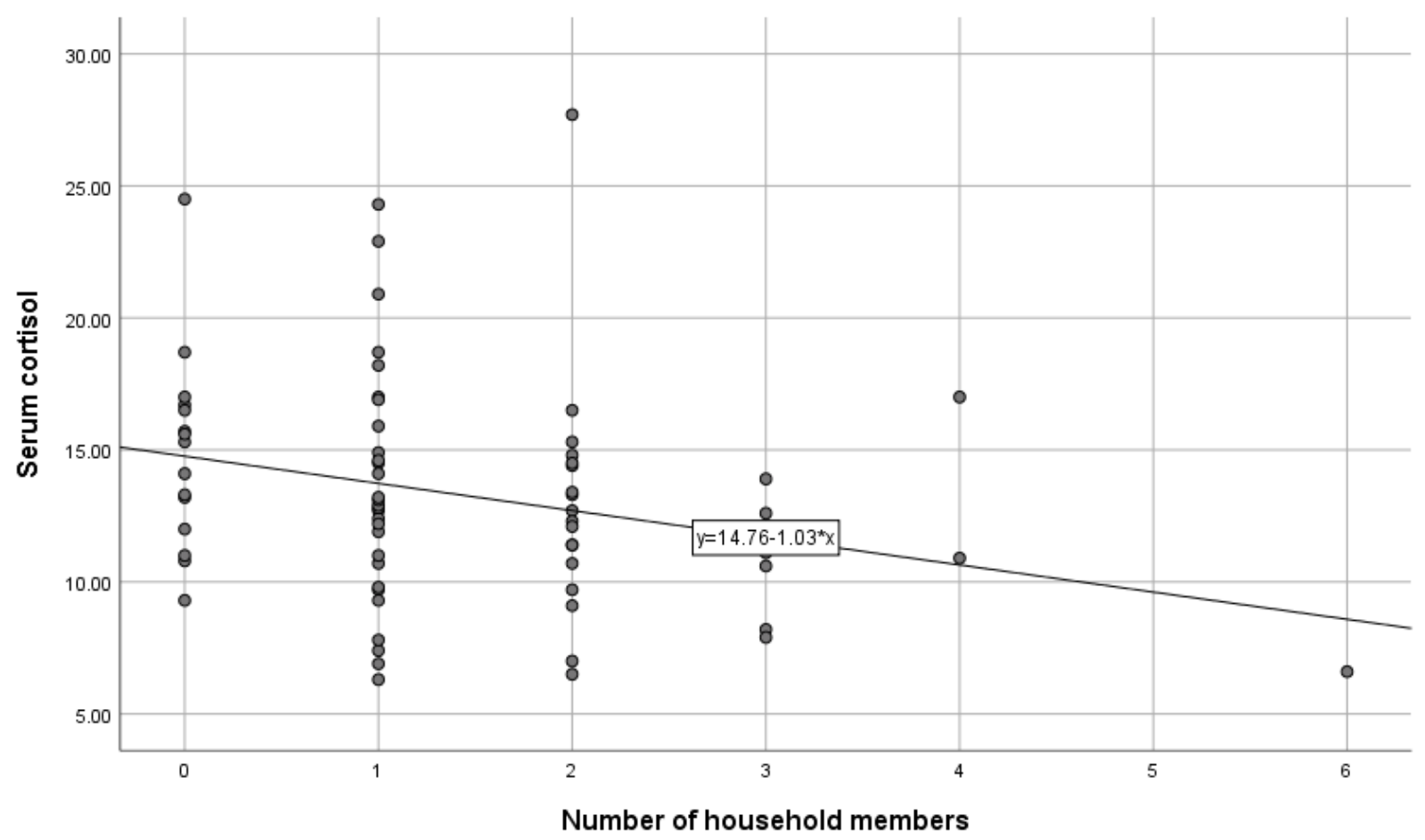

Figure 3c. Scatterplot to show relationships between number of household members and serum cortisol. 


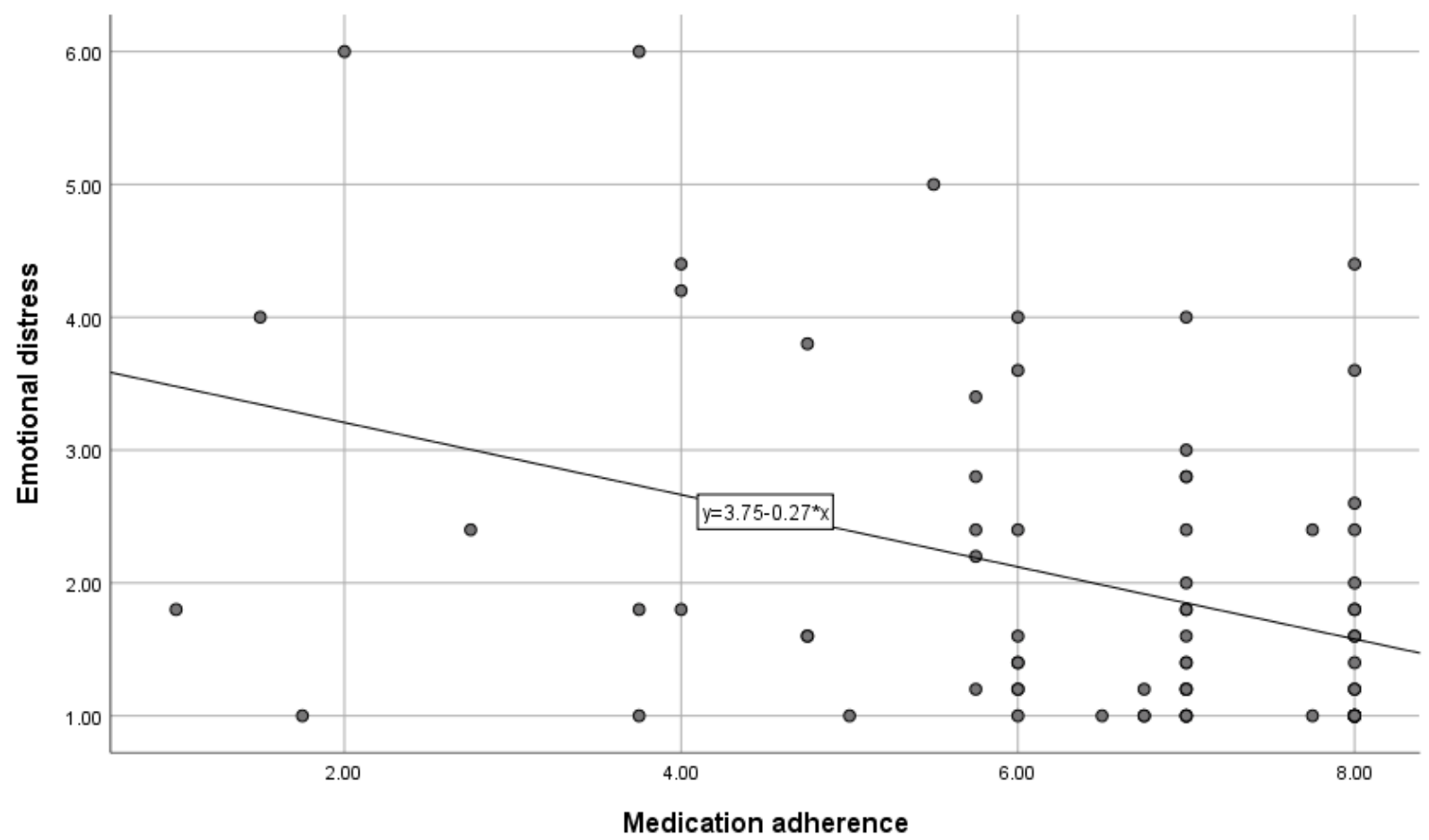

Figure 3d. Scatterplot to show relationships between medication adherence and emotional distress. 


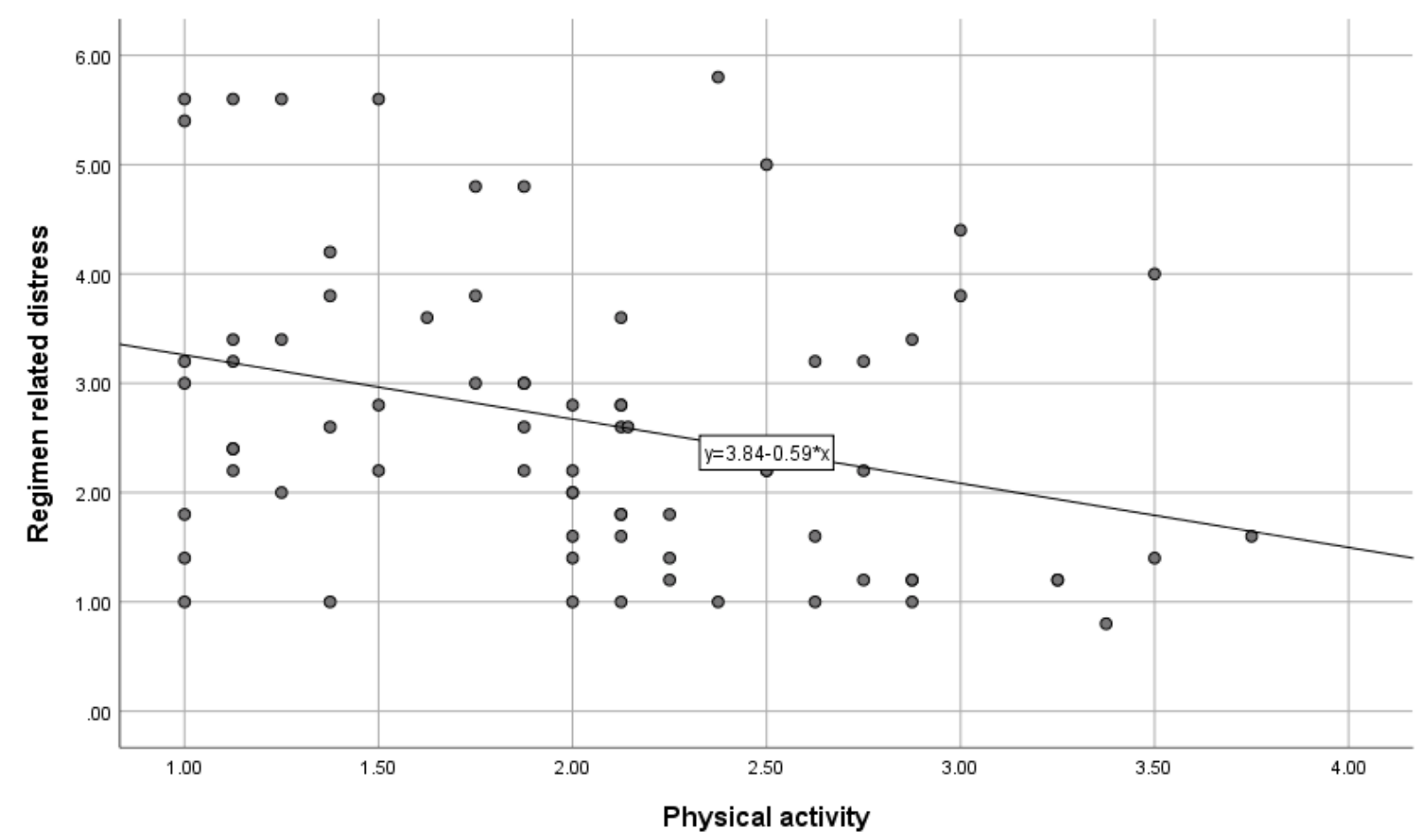

Figure 3e. Scatterplot to show relationships between physical activity and regimen-related distress. 


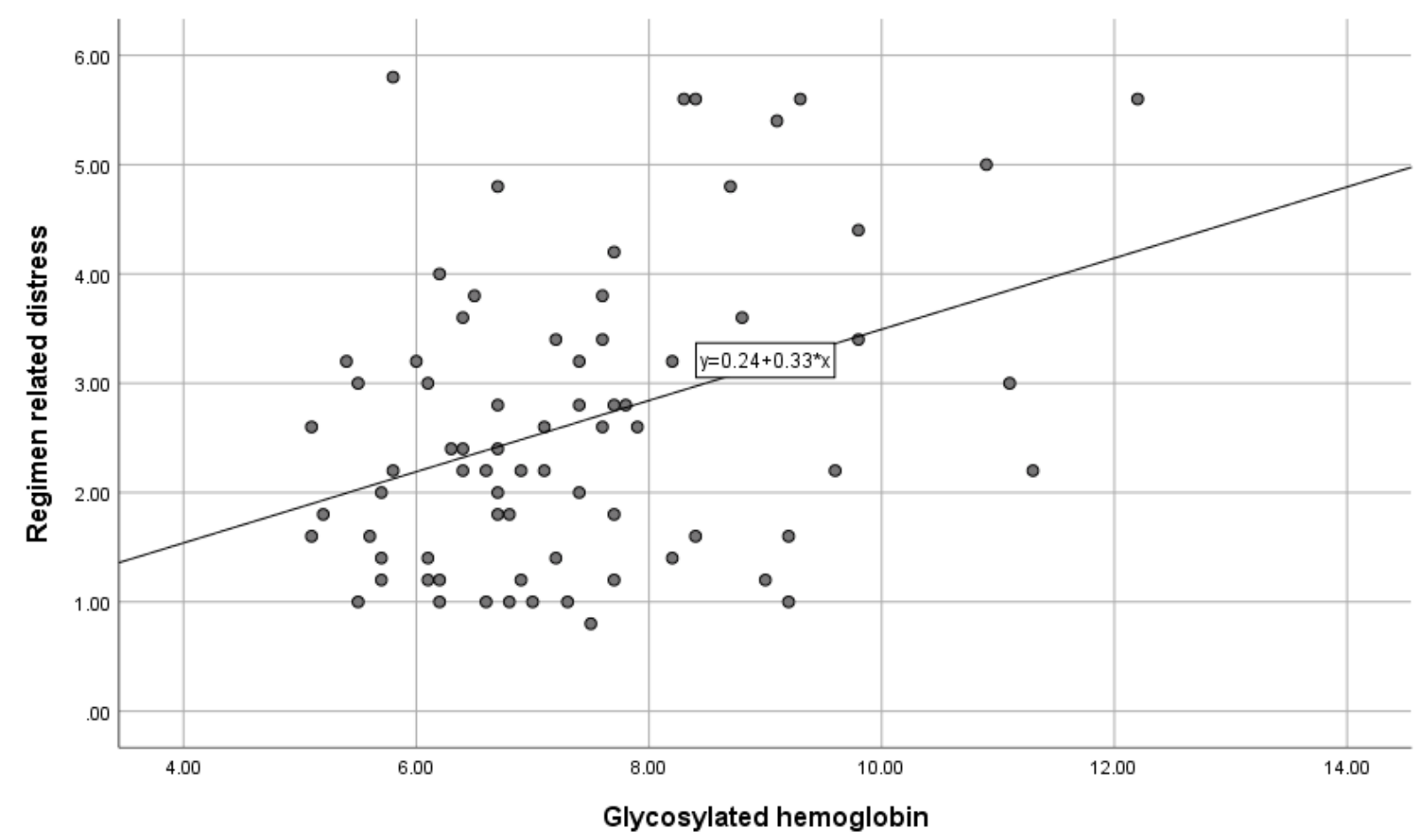

Figure 3f. Scatterplot to show relationships between glycosylated hemoglobin and regimenrelated distress. 


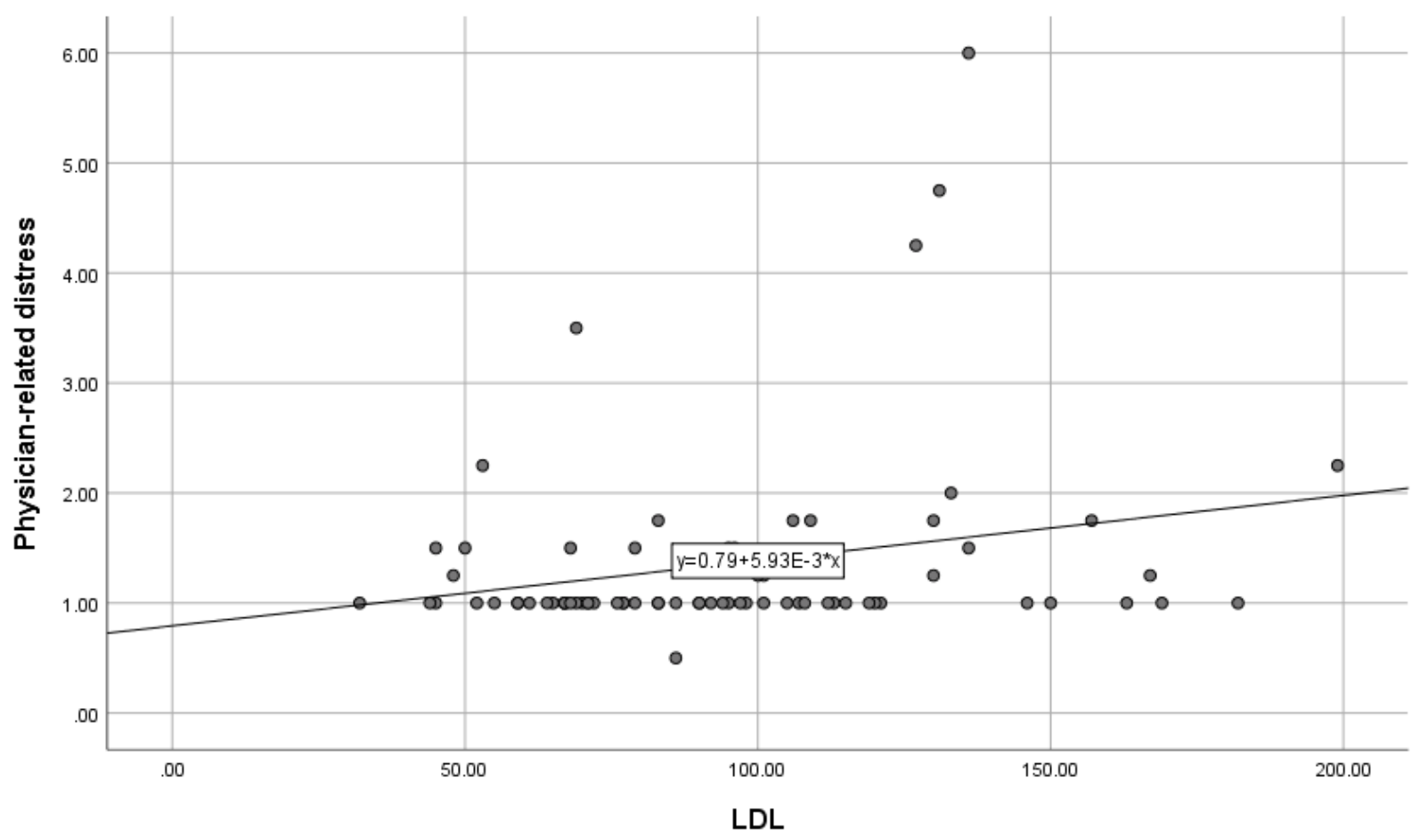

Figure 3g. Scatterplot to show relationships between LDL and physician-related distress. 


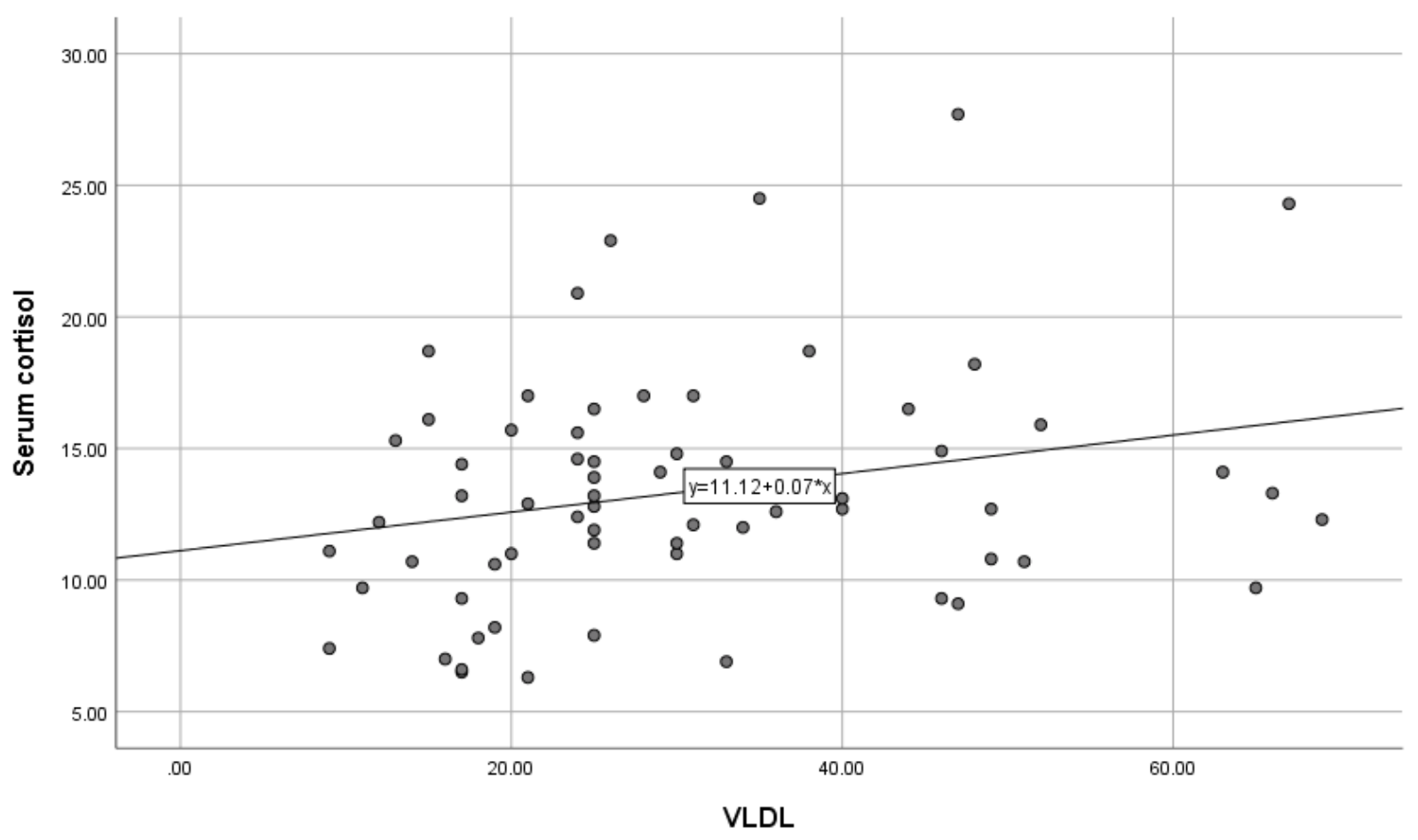

Figure 3h. Scatterplot to show relationship between VLDL and serum cortisol. 


\section{Chapter 3}

\section{Aim 2: To evaluate the impact of clinical variables (HbA1c, blood pressure, serum cholesterol) and behavioral variables (diet, physical activity, and medication adherence) on change in diabetes distress among participants of the DHSMP at 12 weeks and 24 weeks}

\subsection{Introduction}

Type 2 diabetes (T2DM) is a highly prevalent chronic metabolic disease. It is the $7^{\text {th }}$ leading cause of death both in the US and globally. ${ }^{1,2}$ The estimated global prevalence of diabetes in 2019 was $9.3 \%$ (463 million). ${ }^{3}$ Approximately $9.4 \%$ of the total US population (30.3 million) have T2DM. ${ }^{4}$ West Virginia (WV) is one of the economically disadvantaged states burdened with chronic diseases. ${ }^{5-8}$ The prevalence of diabetes-related comorbidities such as obesity and hypertension is higher among the population in WV. ${ }^{9}$ It is the third most rural state in the US and the only state entirely within the Appalachian region. ${ }^{10}$ Such regions are distinctively characterized by the rural population who live in low socio-economic situations. This rural population has poor health status and a high prevalence of chronic diseases. ${ }^{10-12}$ Approximately $51 \%$ of WV population live in medically underserved areas (MUAs). ${ }^{13-15}$ More than $90 \%$ of WV counties are officially designated as MUAs. ${ }^{16}$ Individuals with T2DM in MUAs lack selfmanagement knowledge and suffer from higher diabetes-related complications. ${ }^{17-20}$

Hypertension is a common comorbid condition frequently found in individuals with T2DM (ref).

${ }^{21}$ According to the Centers for Disease Control and Prevention (CDC), $68.4 \%$ of US adults with diagnosed diabetes also have hypertension. ${ }^{4} \mathrm{~A}$ large retrospective study using the Quintiles Electronic Medical Record (EMR) research database (Q-EMR) found that approximately $82.1 \%$ of diagnosed T2DM individuals had comorbid hypertension. ${ }^{21}$ In the US, $32.3 \%$ of adults have diagnosed hypertension. ${ }^{7}$ The prevalence of hypertension in $\mathrm{WV}$ is $43.8 \%$, the highest in the 
nation. ${ }^{7}$ Individuals with diabetes and comorbid hypertension are at four times higher risk of having cardiovascular disease than those with either diabetes or hypertension. ${ }^{22}$ Furthermore, individuals with uncontrolled diabetes who do not take antihypertensive medication are at a higher risk of having T2DM later in their lives. ${ }^{22}$

Chronic diseases are frequently associated with psychological stress in individuals (e.g., stress, depression). ${ }^{23,24}$ Diabetes distress is psychological stress prevalent in individuals with T2DM ${ }^{25-}$ ${ }^{30}$, which is the burden of emotional stress and worry related to the diagnosis, self-management, and complications on a day-to-day basis. ${ }^{25,26,31}$ It also includes their challenges of interacting with health care providers and communicating with families and friends. ${ }^{25,26,32}$ Fisher et al. classified diabetes distress into four domains: emotional distress, physician-related distress, interpersonal distress, and regimen-related distress. ${ }^{33}$ Previous studies have reported diabetes distress impacts glycemic status, diabetes self-care (e.g., diet and exercise behaviors), and selfefficacy among adults with T2DM. ${ }^{30,34-36}$

Chronic psychological stress in T2DM individuals can affect their bodies' homeostasis or metabolic equilibrium. ${ }^{37}$ Change in homeostasis alters the hypothalamic-pituitary-adrenal (HPA) axis or pathway to overproduce glucocorticoid hormones such as cortisol. ${ }^{37,}{ }^{38}$ Research has shown that individuals' serum cortisol levels remain high under chronic stress. ${ }^{37}$ This high cortisol level results from a damaged feedback mechanism due to the presence of chronic stress. ${ }^{37}$ Individuals with T2DM often have elevated serum cortisol levels. ${ }^{38-40}$ T2DM individuals with high cholesterol levels have a higher risk of atherosclerosis due to hyperglycemia and insulin resistance. ${ }^{41}$ Oxidative stress due to hyperglycemia and insulin resistance in T2DM individuals leads to activation of the diacylglycerol-protein kinase C (DAGPKC) pathway, promoting vascular damage that leads to atherosclerosis. ${ }^{41}$ For example, a large 
population-based study reported an increased risk of developing T2DM among individuals with a high cholesterol level. ${ }^{42}$ Prior clinical studies also reported a link between high cholesterol level and hyperglycemia, thereby leading to the onset of T2DM. ${ }^{43,44}$

Medication adherence, i.e., individuals following a prescribed medication regimen, ${ }^{45}$ has been linked to multiple health outcomes in individuals with diabetes and hypertension. ${ }^{45,46}$ Medication adherence is inversely associated with diabetes distress. ${ }^{47-50}$ In other words, individuals with medication nonadherence tend to have higher diabetes distress. ${ }^{51,52} \mathrm{~T} 2 \mathrm{DM}$ individuals with higher medication adherence also have a better quality of life. ${ }^{53}$ Medication nonadherence is frequently found among individuals with hypertension. ${ }^{46}$ Steiner et al.'s retrospective study of hypertensive individuals found that only $36 \%$ adhered to their medication regimen. ${ }^{54}$

Lifestyle behaviors such as physical activity and a healthy diet are important components of T2DM individuals' self-care. Adequate physical activity can help to prevent and alleviate diabetes-related complications. ${ }^{55}$ Prior studies have also shown that regular physical activity can reduce the progression of prediabetes to T2DM and complications related to poor glycemic control. ${ }^{56,57}$ The importance of a healthy diet in diabetes management is well-known. ${ }^{58}$ Multiple studies have shown that a healthy diet improves the glycemic status of T2DM individuals. ${ }^{58-61}$ Healthy diet and adequate physical activity improve psychological well-being as well among these individuals. ${ }^{62-65}$ A healthy lifestyle, including adequate physical activity and a healthy diet, is also important in managing hypertension. The American Association of Family Physicians recommends a combination of a healthy diet and a minimum of 150 minutes of moderateintensity or 75 minutes of vigorous physical activity per week to reduce hypertension-related complications. ${ }^{66}$ In a recent randomized controlled trial, researchers reported that regular physical activity for 9 months reduced systolic blood pressure among hypertensive individuals. ${ }^{67}$ 
Behavioral interventions such as diabetes self-management education (DSME) programs have recently become popular intervention strategies. ${ }^{68-70}$ DSME programs are scientifically proven methods in helping individuals with T2DM manage their diabetes, including improvement in glycemic status, diabetes knowledge, and psychological and behavioral outcomes. ${ }^{71-73} \mathrm{~A}$ randomized controlled trial by Vermunt and team reported that DSME program participation helped reduce diabetes risk factors. ${ }^{74} \mathrm{~A}$ meta-analysis reported that individuals with T2DM could benefit from reduced hypertension, serum cholesterol, and improved glycemic status if they follow DSME program guidelines. ${ }^{75}$ DSME interventions in faith-based settings, such as churches, have been used by public health researchers ${ }^{76}$, although mostly utilized by African Americans and other minority communities in the US. ${ }^{16,17}$ Faith-based health intervention programs can be highly effective in rural Appalachian states such as WV because of trust in and affinity for faith-based settings. ${ }^{77-79}$ However, very few community-based DSME intervention studies have been conducted in WV using faith-based settings, where the majority of the population (97\%) is non-Hispanic White and live in MUAs. ${ }^{13-15,78,80}$ Hence, the aim of the study was to evaluate the effect of clinical and behavioral variables on change in diabetes distress among participants of the Diabetes and Hypertension Self-Management Program (DHSMP) at 12 weeks and 24 weeks.

The hypotheses related to the aims were as follows.

Hypothesis 2.a: Glycosylated hemoglobin will have a positive association with diabetes distress [measured by the validated 17-item diabetes distress scale (DDS)] and serum cortisol at 12 weeks and 24 weeks. 
Hypothesis 2.b: Blood pressure will have a positive association with diabetes distress [measured by the validated 17-item diabetes distress scale (DDS)] and serum cortisol at 12 weeks and 24 weeks.

Hypothesis 2.c: Serum cholesterol will have a positive association with diabetes distress [measured by the validated 17-item diabetes distress scale (DDS)] and serum cortisol at 12 weeks and 24 weeks.

Hypothesis 2.d: Diet will have a negative association with diabetes distress [measured by the validated 17-item diabetes distress scale (DDS)] and serum cortisol at 12 weeks and 24 weeks.

Hypothesis 2.e: Physical activity will have a negative association with diabetes distress [measured by the validated 17-item diabetes distress scale (DDS)] and serum cortisol at 12 weeks and 24 weeks.

Hypothesis 2.f: Medication adherence will have a negative association with diabetes distress [measured by the validated 17-item diabetes distress scale (DDS)] and serum cortisol at 12 weeks and 24 weeks.

\subsection{Methods}

Data collected from the Diabetes and Hypertension Self-Management Program (DHSMP) were utilized to identify the association of clinical and behavioral variables with diabetes distress at 12 weeks and 24 weeks. The study was approved by the institutional review board of West Virginia University (WVU). 


\subsubsection{Study Design and Sample Selection}

\subsubsection{Diabetes and Hypertension Self-Management Program}

The Diabetes and Hypertension Self-Management Program (DHSMP) was one of the first multicomponent, randomized controlled trials implemented in two churches in Charleston and Morgantown, WV. The DHSMP was adapted from evidenced-based programs and tailored for Appalachian culture for adults with T2DM and comorbid hypertension. ${ }^{81,82}$ The DHSMP was a 12-week intervention program conducted during 2018-2019. Program participants were randomly assigned to the intervention and wait-listed control group. Participants from both the intervention and wait-listed control group attended educational sessions once a week for 12 consecutive weeks. Wait-listed control group participants waited six months (24 weeks) to attend their education sessions. The curriculum of DHSMP was developed using two evidence-based diabetes self-management guidelines from the National Diabetes Prevention Program (DPP), the Association of Diabetes Care \& Education Specialists' (previously known as the American Association of Diabetes Educators) ADCES7 self-care behaviors, and the Eighth Joint National Committee (JNC8) guideline on hypertension management developed by the American Family Physicians (AFP) ${ }^{83-85}$ Trained health coaches along with the experts conducted and delivered DHSMP education sessions. Undergraduate and graduate students at WVU were recruited and trained as health coaches. Health coaches received two days of training on the DHSMP curriculum, assessments, and content related to comorbid diabetes and hypertension and lifestyle modifications by the experts. The training also included practice sessions to familiarize the health coaches with the DHSMP educational sessions and assessments. The study design schema is provided in the appendix (Appendix C Figure 1). 


\subsubsection{Participant Recruitment}

Adults 21 years or older with diagnosed T2DM and hypertension were recruited using newsletters and flyers distributed in their communities. Exclusion criteria included pregnant or breastfeeding women, individuals with normal BMI (body mass index), and restrictions for any physical activity. Participants were randomly assigned to the intervention and wait-listed control groups. Both groups attended weekly educational sessions on diabetes and hypertension selfmanagement for 12 consecutive weeks. The intervention group participants attended the first 12 weeks of educational sessions, and wait-listed control group participants waited six months (24 weeks) to begin their 12 weeks of educational sessions. The duration of each session was 75 minutes. During each session, the participants received educational material on selfmanagement, including information on nutrition, physical activity, and medication adherence. Participants also received training on light exercise, stress management, and cooking healthy meals. Weekly sessions also included group discussions, reviews of the previous week's activities, and discussion of future action plans.

\subsubsection{Data Collection}

A total of 89 adults with comorbid T2DM and hypertension participated in the DHSMP program. The subjects were randomized to active intervention $(\mathrm{N}=44)$ and 6-month, wait-listed, control group participants $(\mathrm{N}=45)$. Data collection was conducted at the two study locations (churches) where the weekly educational sessions took place. The assessment timeline for the active intervention participants included three time points (baseline, 12 weeks, and 24 weeks) and four time points for the wait-listed control group (baseline, 24 weeks (or $2^{\text {nd }}$ baseline), 36 weeks (post-program), and 48 weeks (24-week post program) (see Appendix C Figure 1). At each time point, participants' fasting serum samples were collected by trained phlebotomists on the assessment day and sent to a clinical laboratory affiliated with WVU for further evaluation. 
Validated surveys were utilized to collect data on demographic information, diabetes distress, medication adherence, diet, and physical activity. The Diabetes Distress Scale (DDS) ${ }^{86}$ was utilized to measure diabetes distress and its four domains (emotional distress, physician-related distress, regimen-related distress, and interpersonal distress). For medication adherence, the Morisky Medication Adherence Scale (MMAS) ${ }^{87}$ survey was utilized, and for diet and physical activity, the Health-Promoting Lifestyle Profile II (HPLPII ${ }^{88}$ survey was utilized.

\subsubsection{Measures}

\subsubsection{Demographic variables}

Demographic variables were age, gender, Body Mass Index (BMI), race, level of education, number of household members, diabetes duration, hypertension duration, family history of diabetes, family history of hypertension, and access to health insurance. The participants' dates of birth were used to calculate their ages. The participants' height and weight were used to calculate their BMIs. The race was a categorical variable, and responses included African American, American Indian or Alaskan Native, White, and other (including Hispanic or Latino and two or more races). Responses to the race variable were recategorized into non-White and White because there were very few non-White participants in the program and also because nonHispanic Whites are the largest population group (92\%) in $\mathrm{WV} .{ }^{80}$ The education level was a categorical variable with multiple categories (less than or equal to high school, some college, associate's degree, college graduate, and graduate degree). Responses to education levels were recategorized into three categories: less than or equal to high school, some college education or associate degree, and college graduate, post-graduate or professional degree. Participants' selfreported zip codes were utilized to calculate whether they lived in rural or urban places using an online tool maintained by the Federal Office of Rural Health Policy (FORHP). ${ }^{89}$ To designate a rural or urban location, FORHP considers the eligibility criteria set up by three government 
agencies: the U.S. Census Bureau, the Office of Management and Budget (OMB), and the Economic Research Service, U.S. Department of Agriculture (USDA-ERS). ${ }^{90}$ Rural areas are outside an urbanized area (UA) or urban cluster (UC). A UA consists of an urban nucleus of 50,000 or more population, and a UC consists of the nucleus of a UA and a total land area of less than two square miles with a population density of 1,000 per square mile. ${ }^{90}$ The number of household members was a continuous variable self-reported by the participants. Access to health insurance was a categorical variable with seven response options (uninsured, dual eligible, Medicaid, Medicare, Medicare plus supplemental, Medicare only, third party, and unknown). It was recoded into two options (yes or no) (Appendix C Table 1). Diabetes duration and hypertension duration were two continuous variables self-reported by the participants. Family history of diabetes and hypertension were two categorical variables, each including the chronic condition among family members: siblings (brother, sister), parents (father, mother), and other family members (grandparents, uncles, aunts). The response options were summed and recategorized into two options (yes or no).

\subsubsection{Dependent and Predictor Variables}

\subsubsection{Dependent Variable}

\section{Diabetes Distress and Serum Cortisol}

The current study utilized the DDS, which is one of the widely accepted and commonly used survey instruments for measuring diabetes distress. ${ }^{86}$ DDS is a 17 -item self-reported Likert questionnaire in which response options for each question were $1=$ not a problem to $6=$ a very serious problem. DDS is used to measure four domains of diabetes distress: emotional distress, physician-/provider- related distress, regimen-related distress, and interpersonal distress.

Responses were summed to calculate the total score and the four domains (range 0-6). A higher score indicates a higher distress. A score between 2.0-2.9 indicates moderate distress, and a score 
$\geq 3.0$ indicates high distress. ${ }^{86}$ Internal consistency (Cronbach's alpha) of the DDS reported in the validation study was $0.93 .{ }^{91}$ DDS was significantly associated with the Center for Epidemiological Studies Depression (CESD) scale $(\mathrm{r}=0.55)$, disease management such as meal planning $(r=0.30)$, exercise $(r=0.13)$, and metabolic variables such as total cholesterol $(r$ $=0.20) .{ }^{92}$ Cronbach's alphas of total distress, emotional distress, physician-related distress, regimen-related distress, and interpersonal distress were $0.96,0.94,0.93,0.94$, and 0.93 , respectively for the current study. Serum cortisol was measured in mcg/dL.

\subsubsection{Predictor Variables}

Clinical Variables: Glycosylated hemoglobin (HbA1c) was measured in percentage (\%) of total hemoglobin in the blood, and serum cholesterol was measured in $\mathrm{mg} / \mathrm{dL}$. All clinical tests were conducted by the laboratory affiliated with West Virginia University (WVU) Medicine.

Medication adherence: The Morisky Medication Adherence Scale (MMAS) was utilized to measure medication adherence among the participants. MMAS uses 8 questions to determine the person's medication adherence, including behaviors related to medication use that may be unintentional (e.g., forgetfulness) or intentional (e.g., not taking medications because of side effects). Response choices were "yes" or "no" for items 1 through 7. Participant's responses were rated as 1 and 0 for each "no" and "yes" response, respectively, except for item 5, which was reverse coded. The response option for item 8 is a five-point Likert response scale. Responses for item 8 were "never", "once in a while", "sometimes", "usually", and "all the time", and these responses were scored $1,0.75,0.50,0.25$, and $0 .{ }^{93}$ The lowest and highest scores of each question are 0 and 8 , respectively, where $8=$ high adherence, 6 to $<8=$ medium adherence, and $<6=$ low adherence. ${ }^{87}$ MMAS is widely used by health researchers because of 
good reliability (Cronbach's alpha $=0.83)^{94}$, and psychometric property of the scale. ${ }^{93,95}$ Cronbach's alpha for the MMAS was 0.70 in the current study.

Lifestyle factors: The Health Promoting Lifestyle Profile II (HPLPII) scale was utilized to measure diet and physical activity. ${ }^{88}$ HPLPII has a total of 52 question, and each statement has four Likert-scale-based response options (never $=1$, sometimes $=2$, often $=3$, and routinely $=$ 4). Nine questions were used to measure scores for physical activity (lowest $=9$, highest $=36$ ), and 8 questions were used to measure scores for diet (lowest $=8$, highest $=32$ ). For the diet subscale, responses of one of the items that assessed the intake of carbohydrates (item 14) (statement: Eat 6-11 servings of bread, cereal, rice and pasta each day) were reverse coded. Healthy dietary habit was measured by the mean diet score calculated by summing the 9 diet questions and dividing by 9 . Physical activity score was measured by the mean physical activity score, calculated by summing the 8 physical activity questions and dividing by. A higher score indicated higher engagement in a healthy lifestyle, i.e., healthy diet and physical activity. ${ }^{88}$ HPLPII scale is widely used by researchers to investigate health-promoting lifestyle factors and the effects of health interventions for lifestyle improvement show good overall reliability (Cronbach's alpha $=0.92) .{ }^{88,96,97}$ In the current study, Cronbach's alpha for the physical activity and diet scale were 0.89 and 0.76 , respectively.

\subsection{Data Analysis}

Research Electronic Data Capture (REDCap) ${ }^{98,99}$ was utilized as the repository to record participants' data. Trained program personnel double-entered the data and reviewed them for any discrepancies. Data from REDCap were transferred to Microsoft Excel ${ }^{100}$ for data cleaning and data analysis was conducted using IBM Statistical Package for Social Sciences (SPSS) for Windows, version 27.0. ${ }^{101}$ Simple descriptive analysis of the demographic variables included the 
participant's age, gender, BMI, race, diabetes and hypertension duration, family history of diabetes and hypertension, level of education, rural/urban residence, number of household members, and health insurance. Mean, standard deviations (SD) were calculated for normally distributed continuous variables \& median and interquartile range (IQR) were calculated for nonparametric continuous variables. Percentages were calculated for the categorical variables. Mean and $\mathrm{SD}$ are presented as mean $\pm \mathrm{SD}$, and median and IQR are presented as median (IQR) in this manuscript. Histogram was used to test for assumptions of normality, Levene's test was utilized to test for homogeneity of variance (supplementary Table 1 in chapter 2).

Bivariate relationships were assessed between the dependent variables and predictor variables. Dependent variables included total distress score, and its 4 domains (emotional distress, physician-related distress, regimen-related distress, interpersonal distress), and serum cortisol. Predictor variables included age, gender, race, education level, diabetes and hypertension duration, family history of diabetes and hypertension, number of household members, medication adherence, physical activity, diet, glycosylated hemoglobin, systolic blood pressure, and serum cholesterol levels (total cholesterol, low-density lipoprotein or LDL, very low-density lipoprotein or VLDL). Pearson's correlation and one-way ANOVA were utilized for parametric dependent variables. Spearman's correlation, Mann-Whitney U test, and Kruskal-Wallis test were utilized for nonparametric dependent variables. To describe the strength of the correlation coefficient, Dancey and Reidy's categorization of strengths was used (details provided in chapter 2 manuscript). ${ }^{102,103}$ To interpret the strength of the relationships between the dependent and continuous independent variables, scatter plots were prepared and are included in the supplementary data analysis section (please see chapter 2 Appendix B Figure 3a to Figure 3h)(only significant relationships are shown). A weak correlation coefficient indicates a large 
variation in the spread of values of the dependent variables from the fitted line in the scatterplot, and a moderate correlation coefficient indicates a moderate spread of dependent variable values from the fitted line in the scatterplot. Multivariate models were used to assess the association between the dependent and predictor variables. For multivariate analysis, predictor variables were selected based on the hypotheses of the study, significant bivariate relationships, and limited to 8 predictors in a model considering the sample size was 89 participants and a minimum of 10 samples for each predictor variable recommended in multivariate regression models ). ${ }^{104,105}$ Predictor variables in the regression analysis included glycosylated hemoglobin, blood pressure (systolic), serum cholesterol (LDL for total diabetes distress, and it's 4 domains, VLDL for serum cortisol), medication adherence, physical activity, diet, and education level of participants.

To handle the repeated measurements over time from the same participants, a repeated measure linear mixed model with main effect was utilized to determine the association of predictor variables with the dependent variables. Total distress and four domains (emotional distress, physician-related distress, regimen-related distress, and interpersonal distress) and serum cortisol level were dependent variables. Three time points of data collection (baseline or 0 week, 12 weeks or 2 months, and 24 weeks or 6 months) were included in the analysis as the repeated measure. The repeated measure linear mixed model was considered appropriate since the analysis included repeated time points ( 0,3 , and 6 months) to assess differences in diabetes distress over time; participants were treated as a random effect in the model while time was treated as a repeated measure. A separate analysis was conducted for each dependent variable, and only the main effects of the independent variables in each model were considered. The mixed model analysis considered the missingness of data as "missing at random."106 The 
significance level was set to $\mathrm{p}<0.05$. Regression analysis was conducted using IBM SPSS

Statistics for Windows, Version 27.0. ${ }^{101}$

\subsection{Results}

Descriptive statistics of the demographic variables (Appendix C Table 1) show that, on average, the participants were 60.82 [mean \pm SD $60.82 \pm 12.16$ ] years old, and more than half of them were females (64\%). The majority of the participants were Non-Hispanic Whites (90\%), which resembles the demographics of $\mathrm{WV}$, where $92 \%$ of the population are Non-Hispanic Whites. ${ }^{107}$ Among the participants, $81.6 \%$ were obese, and $13.8 \%$ were overweight. Together, these two groups constituted $95.4 \%$ of the entire sample size. The remaining $4.6 \%$ had normal BMI. Median (IQR) for diabetes and hypertension duration was 10.63 (13.93) years and 14.83 (22.28) years, respectively. This suggests that DHSMP participants had onset of T2DM and comorbid hypertension when they were in their mid to late 40s. Furthermore, more than two-thirds of the participants had a family history of diabetes (86.52\%) and hypertension (85.39\%). Approximately $70 \%$ of the participants reported being urban dwellers, and $30 \%$ lived in rural areas. This supports the fact that the two study locations (Charleston and Morgantown) were the two largest urban areas in WV. Approximately $49 \%$ of the participants were educated with a bachelor, graduate, or professional degree. The majority had access to health insurance (92.13\%) and similar to that of the general US population $(91.2 \%){ }^{108}$

Appendix C Table 2 presents descriptive statistics of the dependent variables (total distress, emotional distress, physician-related distress, regimen-related distress, interpersonal distress, and serum cortisol), and clinical variables (glycosylated hemoglobin, serum cholesterol, systolic and diastolic blood pressure, medication adherence, physical activity, and diet). There was no significant difference between the active intervention and wait-listed control group participants 
in the dependent variables (total diabetes distress and its domains, and serum cortisol), and predictor variables (clinical and behavioral variables) at baseline. Overall, the study participants had mild total diabetes distress [median (IQR) 1.76 (1.04)]. They also had mild emotional distress [median (IQR) 1.60 (1.40)], physician-related distress [median (IQR) $1.00(0.50)$ ], and interpersonal distress [median (IQR) 1.33 (1.25)]. However, participants had moderate regimenrelated distress [mean \pm SD $2.61 \pm 1.27$ ]. Overall, the participants' serum cortisol level was within the normal range [median (IQR) 12.75 (4.75)] (morning range $5-25 \mathrm{mcg} / \mathrm{dL}$ ). ${ }^{109} \mathrm{The}$ participants' median (IQR) glycosylated hemoglobin was $6.90(1.92) \%$, which falls under the recommended level for T2DM individuals $(<7 \%) .{ }^{110}$ Mean physical activity score, and diet score were $2.06 \pm 0.09$, and $2.85 \pm 0.07$, respectively. This showed that, on average, the participants reported they followed a healthy diet "often" ( $1=$ never to $4=$ always), and were physically active "sometimes" in a typical week. The participants' adherence to medication regimen (range 0-8) was at medium level [median (IQR) $7.00(2.25)]$ at baseline.

Appendix C Table 3 presents the bivariate relationships (correlations) between the dependent (total distress, emotional distress, physician-related distress, regimen-related distress, interpersonal distress, and serum cortisol) and predictor variables (age, medication adherence, physical activity, diet, diabetes and hypertension duration, number of household members, glycosylated hemoglobin, systolic blood pressure, and serum cholesterol levels (total cholesterol, LDL, VLDL). Medication adherence had a significant but negative weak correlation with total diabetes distress $(\rho=-0.337, p<0.01)$ and emotional distress $(\rho=-0.315, p<0.01)$. The negative correlation between medication adherence and regimen-related distress was significant and moderate $(r=-0.448, p<0.01)$. In other words, participants who adhered to their medication regimen were more likely to have reduced total diabetes distress, emotional distress, and regime- 
related distress than those who did follow their medication guidelines. There was a significant negative correlation of physical activity with total diabetes distress $(\rho=-0.232, p=0.05)$, and regimen-related distress $(r=-0.311, \mathrm{p}<0.01)$. Hence, a physically active lifestyle resulted in the likelihood of having lower total diabetes distress and regimen-related distress. Similarly, diet had a significant negative and weak correlation with regimen-related distress $(r=-0374, p<0.01)$, indicating that individuals with a healthy diet had lower regimen-related distress as compared to those with an unhealthy diet.

Individuals with lower glycosylated hemoglobin levels were more likely to have lower regimenrelated distress. Glycosylated hemoglobin had a significant positive but weak correlation with regimen-related distress $(\mathrm{r}=0.367, \mathrm{p}=0.01)$. A significant (weak) positive correlation was also noted between LDL levels and physician-related distress $(\rho=0.236, p=0.04)$, and between VLDL and serum cortisol $(r=0.251, p=0.04)$, respectively. This showed that participants with higher levels of LDL and VLDL were more likely to have higher physician-related distress and higher stress (serum cortisol levels). Participants living with household members had lower serum cortisol levels than living alone; the number of household members was negatively correlated (weak) with serum cortisol $(\mathrm{r}=-0.275, \mathrm{p}=0.02)$.

Appendix C Table 4 shows the bivariate relationship between the dependent variables (total diabetes distress, emotional distress, physician-related distress, regimen-related distress, and serum cortisol), and the categorical predictor variables (gender, education level, rural/urban residence, race, health insurance, diabetes and hypertension duration, family history of diabetes and hypertension). Total diabetes distress was significantly different for participants in the three categories of education level $(H=7.754, \mathrm{p}=0.021)$. The mean rank of total diabetes distress was highest among participants with the highest education level (bachelor, graduate, or professional 
degree) (43.68). Interestingly, participants with the lowest education level (less than or equal to high school) had a mean total diabetes distress score of 39.43 , which was higher than those with some college education or associate degree (27.74). Similarly, patients with some college education or associate degree had the lowest levels of interpersonal distress (mean rank $=28.65)$ $(H=7.132, \mathrm{p}=0.028)$ than those with less than or equal to high school (mean rank $=38.86)$, and with a college degree (college graduate, post-graduate or professional degree; mean rank = 43.34). This indicates that interpersonal distress was higher among participants in the highest and lowest educational categories. Significant differences in regimen-related distress was noted among the three categories of education level variable, $F(2,72)=3.183, \mathrm{p}=0.05$. A similar pattern was observed for regimen-related distress with the highest distress among the educated participants (bachelor, graduate or professional degrees) $(2.93 \pm 1.30)$, and the lowest distress with an associate degree or some college education $(2.08 \pm 1.30)$.

Participants with a family history of hypertension had significantly lower serum cortisol levels $(12.87 \pm 3.92)$ than those without a family history of hypertension $(15.46 \pm 5.03), \mathrm{F}(1,72)=$ 3.91, $\mathrm{p}=0.05$. No other demographic variable (gender, race. rural or urban residence, health insurance, family history of diabetes) had any significant bivariate relationship with the dependent variables. Although Non-Hispanic White participants had higher interpersonal distress (mean rank $=39.07)$ than the non-White participants (mean rank $=27.45)$, it approached statistical significance $(\mathrm{U}=219.50, \mathrm{p}=0.098)$. The distribution of mean ranks of the physicianrelated distress by annual salary also approached significance $(\mathrm{H}=\mathrm{s} 8.364, \mathrm{p}=0.079)$. Physicianrelated distress was highest among participants whose annual income was between $\$ 75,000$ to 100,000 (mean rank = 45.88), followed by participants with the lowest income level, i.e., $<\$ 25,000$ annual income (mean rank $=42.50$ ). Physician-related distress among these two groups 
of participants was higher than those with an annual income level of $\$ 25,000$ to 50,000 (mean rank $=37.84$ ) and $\$ 50,000$ to $\$ 75,000$ (mean rank =28.91). Participants in the highest income group (i.e., over $\$ 100,000$ ) reported having the lowest physician-related distress (mean rank = 26.00).

Appendix C Table 5 presents the results of the linear mixed model analysis to assess which variables best predict diabetes distress (total, four domains and serum cortisol) after the DHSMP intervention. In these models, predictor variables included glycosylated hemoglobin, systolic blood pressure, serum cholesterol (LDL, VLDL), medication adherence, physical activity, diet, education level and program effect on changes in dependent variables were examined. Participation in the DHSMP reduced individuals' total diabetes distress by 0.16 point from baseline to 24 weeks (coefficient $=-0.157, \mathrm{SE}=0.08, \mathrm{p}=0.04$ ). Medication adherence, diet, and glycosylated hemoglobin had a significant main effect on participants' total diabetes distress at post-program. The coefficients for medication adherence $($ coefficient $=-0.083, \mathrm{SE}=0.03, \mathrm{p}=$ $0.01)$, diet $($ coefficient $=-0.246, \mathrm{SE}=0.11, \mathrm{p}=0.02)$, and glycosylated hemoglobin $($ coefficient $=0.124, \mathrm{SE}=0.04, \mathrm{p}<0.01)$ showed that, on average, for one-point increase in medication adherence score (0-8) and diet score (1-4), total diabetes distress declined by 0.08 and 0.25 , respectively. For one unit increase in glycosylated hemoglobin levels, participants' total diabetes distress also increased by 0.12 . In general, participants who adhered to their medication regimen, followed dietary guidelines, and reduced glycosylated hemoglobin had a greater reduction in their total diabetes distress.

Medication adherence, diet, and glycosylated hemoglobin predicted changes in emotional distress among program participants. Medication adherence $($ coefficient $=-0.109, \mathrm{SE}=0.05, \mathrm{p}=$ 0.02), diet (coefficient $=-0.334, \mathrm{SE}=0.15, \mathrm{p}=0.03)$, and glycosylated hemoglobin $($ coefficient 
$=0.131, \mathrm{SE}=0.06, \mathrm{p}=0.04)$ had a significant main effect on emotional distress. On average, with one-point increase in medication adherence score (0-8) and diet score (1-4), emotional distress declined by 0.11 and 0.33 , respectively. One unit increase in glycosylated hemoglobin level increased participants' emotional distress by 0.13 . Adherence to dietary guidelines and medication regimen, and glycemic control reduced emotional distress.

Higher LDL levels (coefficient $=0.005, \mathrm{SE}<0.01, \mathrm{p}=0.01$ ) had a significant main effect on physician-related distress. For every unit increase in LDL levels, on average, participants' physician-related distress increased by 0.005 . This implies that program participants who had lower LDL levels also saw a reduction in their physician-related distress.

Medication adherence, diet, glycosylated hemoglobin, and post-program time period (12w and $24 \mathrm{w})$ predicted regimen-related distress in the model. Participant's regimen-related distress declined by 0.30 and 0.34 from baseline to 12 weeks assessment $($ coefficient $=-0.301, \mathrm{SE}=$ $0.11, \mathrm{p}=0.01)$ and 24 weeks assessment (coefficient $=-0.337, \mathrm{SE}=0.12, \mathrm{p}<0.01)$, respectively. Medication adherence $($ coefficient $=-0.127, \mathrm{SE}=0.05, \mathrm{p}=0.01)$, diet $($ coefficient $=-0.374, \mathrm{SE}=$ $0.15, \mathrm{p}=0.02)$, and glycosylated hemoglobin (coefficient $=0.239, \mathrm{SE}=0.06, \mathrm{p}<0.01)$ had a significant main effect on the participants' regimen-related distress. On average, with one-point increase in medication adherence score (0-8) and diet score (1-4), regimen-related distress declined by 0.13 and 0.37 , respectively. Increase in glycosylated hemoglobin levels increased regimen related distress by 0.24 . For participants who completed the program, adherence to their medication regimen, healthy diet, and glycemic control resulted in a greater reduction in their regimen-related distress.

Both medication adherence and education level had significant associations with interpersonal distress. Medication adherence (coefficient $=-0.108, \mathrm{SE}=0.05, \mathrm{p}=0.03$ ), and higher education 
level (i.e., college graduate, post-graduate or professional degree; coefficient $=0.613, \mathrm{SE}=0.28$, $p=0.03$ ), had a significant main effect on interpersonal distress. It implies that, for a one-point increase in medication adherence score (0-8), interpersonal distress declined by 0.11 , on average. Also, educated participants had a significant increase ( 0.61 point $)$ in regimen-related distress than those with high school education.

For serum cortisol, only poor cholesterol level i.e., VLDL was a significant predictor (coefficient $=0.076, \mathrm{SE}=0.03, \mathrm{p}<0.01)$. This showed that for every unit increase in VLDL level, participants' serum cortisol level also increased by 0.08 . Participants with higher VLDL levels had higher serum cortisol levels.

\subsection{Discussion}

Limited number of diabetes self-management studies have assessed lifestyle program changes in diabetes distress, its domains, and serum cortisol among T2DM individuals in rural Appalachia. The current study identified that greater adherence to medication and dietary guidelines and reduction in glycosylated hemoglobin, and serum cholesterol levels can help T2DM individuals reduce their diabetes distress. Furthermore, this study shows that participation in DHSMP enabled the participants to reduce their diabetes-related distress over time. Findings indicate the importance of community-based diabetes self-management programs, such as the DHSMP in managing diabetes distress in rural populations, especially in rural Appalachia.

Participation in DHSMP reduced diabetes distress among T2DM individuals. Some of the program educational sessions focused on stress management education, coping strategies as well as peer support during the program. Participants shared their experiences in dealing with diabetes with fellow participants during program sessions. They also worked one on one with their designated health coach to manage diabetes-related physical and psychological issues. Prior 
research supports the use of health coaches for diabetes self-management, where participants learn problem-solving and coping skills that improve disease acceptance and manage their diabetes-related stress, anger, and anxiety. ${ }^{111-113}$ The group education format enabled the participants to share experiences and ideas with other participants that might have also helped to reduce diabetes distress. ${ }^{112}$ Similar successful strategies by health-coach-mediated DSME intervention studies have shown a reduction in diabetes distress by helping participants learn and apply self-management strategies. ${ }^{112,114,115}$ However, program duration has varied from a few weeks to one-year. For example, Zagarins' and Dubois' intervention study was for 24 weeks. ${ }^{112,}$ ${ }^{115}$ Generally speaking, behavioral intervention duration should be 12 weeks to see a change in glycemic status. The 12-week duration of DSME programs such as DHSMP can help individuals with T2DM manage diabetes distress.

Better medication adherence and a healthier diet helped participants reduce diabetes distress. Participants learned the value of following adherence guidelines for medications prescribed by their doctors and the importance of maintaining a healthy diet. Nutrition education focused on how to read food labels, count their daily fat, sugar and calorie intake, log that information in the food logs, as well as learn from food demonstrations of healthy meal preparation during sessions. They also received helpful information from the health coaches about healthy recipes and preparing healthy meals. Dispelling myths and education included the importance of taking medicine and insulin on time, and testing blood sugar regularly, and following their health care providers' advice. In two separate studies, Fisher et al. observed that reduced diabetes distress was associated with adopting a healthier diet. ${ }^{36,116}$ Similar to the current study's findings, an inverse relationship between medication adherence and diabetes distress has also been reported by several studies. ${ }^{26,53,117,118}$ 
Improved glycemic status reduced diabetes distress. By incorporating and practicing lifestyle modifications encouraged during the DHSMP sessions, participants improved glycemic status may have also reduced their distress. Several studies have shown that improved glycemic status was associated with lower distress among individuals with T2DM. ${ }^{29,118-120}$ Fisher reported a positive association between glycemic status and diabetes distress and theorized that this relationship was bidirectional, ${ }^{29}$ explaining that higher distress could negatively influence medication adherence and other self-management activities and thus lead to deteriorated glycemic status. ${ }^{29}$ Individuals with poor self-management have higher diabetes distress. ${ }^{29}$

Elevated serum cholesterol (LDL and VLDL) levels were found to elevate diabetes distress and serum cortisol levels in participants. These bad cholesterols (LDL and VLDL) are linked to cardiovascular complications in T2DM individuals. ${ }^{121,122}$ Furthermore, increased serum cholesterol levels can also increase serum cortisol level ${ }^{123,124}$, indicating higher psychological stress in individuals. American Diabetes Association recommends cholesterol reduction as part of diabetes management guidelines. ${ }^{125}$ Self-management education help participants make positive lifestyle changes (i.e., improved diet, physical activity) that might help reduce cholesterol levels. Moreover, stress reduction techniques shared during DHSMP sessions helped participants reduce their serum cortisol, which is an indicator of psychological stress. Thus, this study shows the importance of lifestyle changes not only for cholesterol management but also for reduced diabetes distress in T2DM individuals. Future intervention programs should consider including education on diabetes distress-specific stress reduction techniques.

One interesting finding was that individuals with the highest education level (bachelor, graduate, or professional degree) had higher diabetes distress than those with the lowest education level (high school or less). Although some prior studies have shown that individuals with lower 
education levels tend to have worse diabetes outcomes and higher diabetes distress ${ }^{126-128}$, the current study's results are contrary to those results. One assumption is that educated individuals have some knowledge on diabetes self-management even prior to enrolling in DHSMP. On the other hand, those with a lower education level (high school or less than high school) learned selfmanagement strategies during DHSMP educational sessions. Learning self-management strategies for the first time might have inspired them to apply the coping strategies to reduce their diabetes distress more than their educated peers. Grzywacz and colleagues reported that individuals with lower education tend to report less psychological stress than their counterparts with higher education. ${ }^{129}$ Molarius and Granstrom also reported that individuals with higher education levels had higher psychological stress. ${ }^{130}$ However, they measured psychological stress as the overall stress in daily life, which is different from diabetes distress. ${ }^{130}$ Another important factor that needs to be considered is that the rural Appalachian population is culturally and socioeconomically different from other parts of the US. ${ }^{8,129,131}$ Thus, the effect of education level on diabetes distress in the rural Appalachian population requires further evaluation. Since rural Appalachia has a low literacy rate ${ }^{132,133}$, referrals to DSME programs and/or adoption of DHSMP in clinical settings by health care providers can have a significant impact in reducing diabetes distress among T2DM individuals in this region.

Results from this study are also important for diabetes specialists and primary-care health care providers. They can utilize screening tools such as DDS to measure distress among their patients with T2DM, provide hands-on skills and knowledge about diabetes self-management to help their patients improve their glycemic status, medication adherence, follow healthy behaviors (diet and physical activity). This is especially important for providers in rural MUAs such as rural Appalachia, where only a few providers serve a population with a higher prevalence of 
chronic diseases such as T2DM. ${ }^{13,134,135}$ Provider education on diabetes distress and training in stress-reduction techniques and coping mechanisms will be helpful for implementing their DSME knowledge to practice. ${ }^{136}$

Although this study identified clinical and behavioral predictors of diabetes distress using a RCT study design, it is not without limitations. Several demographic variables were self-reported by the participants, including family history of diabetes and family history of high blood pressure, years living with diabetes, and years living with high blood pressure. Due to self-reporting, these variables might have recall bias. Surveys completed by the participants might suffer from social desirability bias. The participants could misunderstand some of the questions in the surveys, and the responses may be incorrect, although the participants were properly instructed by the health coaches before they completed those surveys. The independent effect of gender on the dependent variables was not assessed, although there was a significant difference in gender between the intervention and wait-listed control groups at baseline. Since DHSMP participants were randomized, the gender difference was considered to be by chance. Also, due to small sample size, the number of variables in the multivariate models was limited. There were some missing responses in the surveys, and some participants did not attend all sessions, dropped out, or did not complete clinical assessments at 12 weeks and 24 weeks, thus reducing the sample size in the mixed-model analysis.

\subsection{Conclusion}

The current study aimed at improving diabetes distress among adults with T2DM. Results showed that program participation reduced diabetes distress over time, higher medication adherence, improved glycemic status, and a healthy diet was associated with reduced diabetes distress among rural WV adults, especially with lower education levels who participate in DSME 
programs such as the DHSMP. For participants who fully engage, knowledge of diabetes selfmanagement, including medication adherence, the importance of maintaining improved glycemic status, and a healthy diet can facilitate necessary lifestyle modifications to reduce diabetes distress over time. Our RCT design support causal conclusions, and the program may be a useful adjunct to DSME programs available in West Virginia and beyond.

Results from this study will be useful for healthcare providers, especially primary-care providers in rural Appalachia, who frequently manage T2DM patients. Knowledge of the relationship between behavioral and clinical factors with diabetes distress will help providers understand the complex physical and psychological issues related to their patients' diabetes status. Healthcare providers can benefit from routine screening of their T2DM patients for diabetes distress so that education on diabetes self-management can be tailored to achieve a healthy lifestyle, including management of psychological stress such as diabetes distress prevalent in T2DM individuals. 


\section{References}

1. American Diabetes Association. Economic Costs of Diabetes in the U.S. in 2017. Diabetes Care. 2018;41(5):917. doi:10.2337/dci18-0007

2. World Health Organization. The top 10 causes of death. 2020. https://www.who.int/news-room/fact-sheets/detail/the-top-10-causes-of-death

3. Saeedi P, Petersohn I, Salpea P, et al. Global and regional diabetes prevalence estimates for 2019 and projections for 2030 and 2045: Results from the International Diabetes Federation Diabetes Atlas, 9 th edition. Diabetes research and clinical practice. 2019 Nov 2019;157doi:10.1016/j.diabres.2019.107843

4. Center for Disease Control and Prevention. National Diabetes Statistics Report, 2020. 2020. https://www.cdc.gov/diabetes/pdfs/data/statistics/national-diabetes-statistics-report.pdf

5. Perent of total population in poverty (US Department of Agriculture) (2018).

6. American Diabetes Association. The Burden of Diabetes in West Virginia. American Diabetes Association. 2020. https://www.diabetes.org/resources/statistics/statistics-by-state 7. Center for Disease Control and Prevention. BRFSS Prevalence \& Trends Data. Accessed 2020/12/15. https://www.cdc.gov/brfss/brfssprevalence/

8. Appalachian Regional Commission. About the Appalachian Region. Appalachian Regional Commission. 2020. https://www.arc.gov/about-the-appalachian-region/

9. WV Department of Health and Human Resources. West Virginia Behavioral Risk Factor Surveillance System Report. 2017.

http://www.wvdhhr.org/bph/hsc/pubs/brfss/2017/BRFSS2017.pdf

10. West Virginia Bureau for Public Health. Creating a Culture of Health in Rural West Virginia: State Rural Health Plan 2018-2022. 2018. Accessed 2020. https://www.wvrha.org/wpcontent/uploads/2017/08/2018-State-Rural-Health-Plan-Final.pdf

11. Coben JH, Tiesman HM, Bossarte RM, Furbee PM. Rural-Urban Differences in Injury Hospitalizations in the U.S., 2004. American journal of preventive medicine. 2009-01-01 2009;36(1):49-55. doi:10.1016/j.amepre.2008.10.001

12. Auchincloss AH, Hadden W. The Health Effects of Rural-Urban Residence and Concentrated Poverty. The Journal of Rural Health. 2002-03-01 2002;18(2):319-336. doi:10.1111/j.1748-0361.2002.tb00894.x

13. Health Resources \& Services Administration. Medically Underserved Areas/Populations (MUA/P) Dashboard Health Resources \& Services Administration. 2020.

https://data.hrsa.gov/topics/health-workforce/shortage-areas

14. Rural Health Information Hub. Rural Health for West Virginia. Rural Health Information Hub. 2020. https://www.ruralhealthinfo.org/states/west-virginia

15. Alkadry MG, Wilson C, Nicholas D. Stroke Awareness Among Rural Residents. Social Work in Health Care. 2006-02-08 2006;42(2):73-92. doi:10.1300/j010v42n02_05

16. Misra R, Sambamoorthi U. Five-year Trend in Diabetes Clinical Care and SelfManagement among Adults with Diabetes in West Virginia: 2010-2014. Journal of Health Disparities Research \& Practice. 2019;12(1)

17. Jackson BM, Gutierrez ML, Relyea GE, et al. Unmet Primary Care Needs in Diabetic Patients with Multimorbidity in a Medically Underserved Area. Health services research and managerial epidemiology. 05/11/2017 2017;4doi:10.1177/2333392817702760

18. Boren SA. A review of health literacy and diabetes: opportunities for technology. Journal of diabetes science and technology. 2009 Jan 2009;3(1)doi:10.1177/193229680900300124 
19. Chew L, Griffin J, Partin M, et al. Validation of screening questions for limited health literacy in a large VA outpatient population. Journal of general internal medicine. 2008 May 2008;23(5)doi:10.1007/s11606-008-0520-5

20. Cavanaugh K. Health literacy in diabetes care: explanation, evidence and equipment.

Diabetes management (London, England). 2011 Mar 2011;1(2)doi:10.2217/dmt.11.5

21. Iglay K, Hannachi H, Joseph Howie P, et al. Prevalence and co-prevalence of comorbidities among patients with type 2 diabetes mellitus. Current Medical Research and Opinion. 2016-07-02 2016;32(7):1243-1252. doi:10.1185/03007995.2016.1168291

22. Cryer MJ, Horani T, DiPette DJ. Diabetes and Hypertension: A Comparative Review of Current Guidelines. The Journal of Clinical Hypertension. 2016/02/01 2015;18(2):95-100. doi:10.1111/jch.12638

23. Ralston S, Penman ID, Strachan MWJ, Hobson RP, Britton R, Davidson SS. Davidson's principles and practice of medicine. 23rd edition. ed. Elsevier; 2018.

24. Turner J, Kelly B. Emotional dimensions of chronic disease. West J Med.

2000;172(2):124-128. doi:10.1136/ewjm.172.2.124

25. Fisher L. Expert Interview, Diabetes Distress: A real and normal part of diabetes. In: Snouffer E, editor. Diabetes Voice: International Diabetes Federation; 2016. p. 29-34.

26. Chew B-H, Vos RC, Pouwer F, Rutten GEHM. The associations between diabetes distress and self-efficacy, medication adherence, self-care activities and disease control depend on the way diabetes distress is measured: Comparing the DDS-17, DDS-2 and the PAID-5.

Diabetes Research and Clinical Practice. 2018/08/01/ 2018;142:74-84.

doi:https://doi.org/10.1016/j.diabres.2018.05.021

27. Hackett RA, Steptoe A. Type 2 diabetes mellitus and psychological stress - a modifiable risk factor. Nature reviews Endocrinology. Sep 2017;13(9):547-560.

doi:10.1038/nrendo.2017.64

28. Nicolucci A, Kovacs Burns K, Holt RIG, et al. Diabetes Attitudes, Wishes and Needs second study (DAWN2 ${ }^{\mathrm{TM}}$ ): cross-national benchmarking of diabetes-related psychosocial outcomes for people with diabetes. Diabetic medicine : a journal of the British Diabetic Association. 2013 Jul 2013;30(7)doi:10.1111/dme.12245

29. Fisher L, Mullan JT, Arean P, Glasgow RE, Hessler D, Masharani U. Diabetes Distress but Not Clinical Depression or Depressive Symptoms Is Associated With Glycemic Control in Both Cross-Sectional and Longitudinal Analyses. 2010-01-01 2010;doi:10.2337/dc09-1238

30. Young-Hyman D, De Groot M, Hill-Briggs F, Gonzalez JS, Hood K, Peyrot M. Psychosocial Care for People With Diabetes: A Position Statement of the American Diabetes Association. Diabetes care. 2016 Dec 2016;39(12)doi:10.2337/dc16-2053

31. Beverly L, Hughes A, Nelson L, Loyola M, Vela A. What is Diabetes Distress? Society of Behavioral Medicine. 2021. https://www.sbm.org/healthy-living/what-is-diabetes-distress

32. Kuniss N, Kramer G, Muller N, et al. Diabetes-Related Burden and Distress is Low in Peoplewith Diabetes at Outpatient Tertiary Care Level. Exp Clin Endocrinol Diabetes. 2016; 124:307-312.

33. Fisher L, Glasgow RE, Mullan JT, Skaff MM, Polonsky WH. Development of a brief diabetes distress screening instrument. Ann Fam Med. May-Jun 2008;6(3):246-52.

doi:10.1370/afm.842

34. Fisher L, Hessler DM, Polonsky WH, Mullan J. When is diabetes distress clinically meaningful?: establishing cut points for the Diabetes Distress Scale. Diabetes Care. Feb 2012;35(2):259-64. doi:10.2337/dc11-1572 
35. Aikens JE. Prospective Associations Between Emotional Distress and Poor Outcomes in Type 2 Diabetes. 2012-12-01 2012;doi:10.2337/dc12-0181

36. Fisher L, Hessler D, Glasgow RE, et al. REDEEM: A Pragmatic Trial to Reduce Diabetes Distress. 2013-09-01 2013;doi:10.2337/dc12-2493

37. Lee DY, Kim E, Choi MH. Technical and clinical aspects of cortisol as a biochemical marker of chronic stress. BMB Rep. 2015;48(4):209-16. doi:10.5483/BMBRep.2015.48.4.275

38. Joseph JJ, Wang X, Spanakis E, et al. Diurnal salivary cortisol, glycemia and insulin resistance: The multi-ethnic study of atherosclerosis. Psychoneuroendocrinology. Dec 2015;62:327-35. doi:10.1016/j.psyneuen.2015.08.021

39. Bellastella G, Maiorino MI, De Bellis A, et al. Serum but not salivary cortisol levels are influenced by daily glycemic oscillations in type 2 diabetes. Endocrine. Jul 2016;53(1):220-6. doi:10.1007/s12020-015-0777-5

40. Duong M, Cohen JI, Convit A. High cortisol levels are associated with low quality food choice in type 2 diabetes. Endocrine. Feb 2012;41(1):76-81. doi:10.1007/s12020-011-9527-5

41. Giacco F, Brownlee M. Oxidative Stress and Diabetic Complications. Circulation Research. 2010-10-29 2010;107(9):1058-1070. doi:10.1161/circresaha.110.223545

42. Rhee E-J, Han K, Ko S-H, Ko K-S, Lee W-Y. Increased risk for diabetes development in subjects with large variation in total cholesterol levels in 2,827,950 Koreans: A nationwide population-based study. PLoS One. 2017-05-18 2017;12(5):e0176615. doi:10.1371/journal.pone.0176615

43. Wada M, Yano S, Hamano T, Nabika T, Kumakura S. Effect of Serum Cholesterol on Insulin Secretory Capacity: Shimane CoHRE Study. Text. 2016 2016; doi:10.1371/journal.pone.0149452

44. Seo MH, Bae JC, Park SE, et al. Association of Lipid and Lipoprotein Profiles with Future Development of Type 2 Diabetes in Nondiabetic Korean Subjects: A 4-Year Retrospective, Longitudinal Study. The Journal of Clinical Endocrinology \& Metabolism. 201112-01 2011;96(12):E2050-E2054. doi:10.1210/jc.2011-1857

45. Ho PM, Bryson CL, Rumsfeld JS. Medication Adherence. Circulation. 2009-06-16 2009;119(23):3028-3035. doi:10.1161/circulationaha.108.768986

46. Ritchey M, Chang A, Powers C, et al. Vital Signs: Disparities in Antihypertensive Medication Nonadherence Among Medicare Part D Beneficiaries — United States, 2014. MMWR Morbidity and Mortality Weekly Report. 2016-09-16 2016;65(36):967-976. doi:10.15585/mmwr.mm6536e1

47. Kumar N, Unnikrishnan B, Thapar R, et al. Distress and Its Effect on Adherence to Antidiabetic Medications Among Type 2 Diabetes Patients in Coastal South India. J Nat Sci Biol Med. 2017;8(2):216-20. doi:10.4103/0976-9668.210008

48. Chew B-C, Mohd-Sidik S, Sharif-Ghazali S. Negative effects of diabetes-related distress on health-related quality of life: an evaluation among the adult patients with type 2 diabetes mellitus in three primaryhealthcare clinics in Malaysia. Health and Quality of Life Outcomes. 2016;13(187)

49. Piette JD. Interactive voice response systems in the diagnosis and management of chronic disease. The American journal of managed care. Jul 2000;6(7):817-27.

50. Piette JD, Weinberger M, Kraemer FB, McPhee SJ. Impact of automated calls with nurse follow-up on diabetes treatment outcomes in a Department of Veterans Affairs Health Care System: a randomized controlled trial. Diabetes Care. Feb 2001;24(2):202-8. doi:10.2337/diacare.24.2.202 
51. Zhang Z, Premikha M, Luo M, Venkataraman K. Diabetes distress and peripheral neuropathy are associated with medication non-adherence in individuals with type 2 diabetes in primary care. Acta diabetologica. 11/19/2020 2020;doi:10.1007/s00592-020-01609-2

52. Kretchy I, Koduah A, Ohene-Agyei T, Boima V, Appiah B. The Association between Diabetes-Related Distress and Medication Adherence in Adult Patients with Type 2 Diabetes Mellitus: A Cross-Sectional Study. Journal of diabetes research. 03/01/2020 2020;2020doi:10.1155/2020/4760624

53. Jannoo Z, Wah YB, Lazim AM, Hassali MA. Examining diabetes distress, medication adherence, diabetes self-care activities, diabetes-specific quality of life and health-related quality of life among type 2 diabetes mellitus patients. J Clin Transl Endocrinol. 2017;9:48-54. doi:10.1016/j.jcte.2017.07.003

54. Steiner JF, Ho PM, Beaty BL, et al. Sociodemographic and Clinical Characteristics Are Not Clinically Useful Predictors of Refill Adherence in Patients With Hypertension. Circulation: Cardiovascular Quality and Outcomes. 2009-09-01 2009;2(5):451-457.

doi:10.1161/circoutcomes.108.841635

55. Zinman B, Ruderman N, Campaigne BN, Devlin JT SS, American Diabetes Association. Physical Activity/Exercise and Diabetes Mellitus. 10.2337/diacare.26.2007.S73. Diabetes Care. 2003;26(suppl 1):s73.

56. Tuomilehto J, Lindstrom J, Eriksson JG, et al. Prevention of type 2 diabetes mellitus by changes in lifestyle among subjects with impaired glucose tolerance. $N$ Engl J Med. May 3 2001;344(18):1343-50. doi:10.1056/nejm200105033441801

57. Knowler WC, Barrett-Connor E, Fowler SE, et al. Reduction in the incidence of type 2 diabetes with lifestyle intervention or metformin. N Engl J Med. Feb 7 2002;346(6):393-403. doi:10.1056/NEJMoa012512

58. Ojo O. Dietary Intake and Type 2 Diabetes. Nutrients. 2019-09-11 2019;11(9):2177. doi:10.3390/nu11092177

59. Coppell KJ, Kataoka M, Williams SM, Chisholm AW, Vorgers SM, Mann JI. Nutritional intervention in patients with type 2 diabetes who are hyperglycaemic despite optimised drug treatment--Lifestyle Over and Above Drugs in Diabetes (LOADD) study: randomised controlled trial. BMJ. 2010-07-20 2010;341(jul20 2):c3337-c3337. doi:10.1136/bmj.c3337

60. Song S, Lee J. Dietary Patterns Related to Triglyceride and High-Density Lipoprotein Cholesterol and the Incidence of Type 2 Diabetes in Korean Men and Women. Nutrients. 201812-20 2018;11(1):8. doi:10.3390/nu11010008

61. Brandão-Lima P, Carvalho G, Santos R, et al. Intakes of Zinc, Potassium, Calcium, and Magnesium of Individuals with Type 2 Diabetes Mellitus and the Relationship with Glycemic Control. Nutrients. 2018-12-08 2018;10(12):1948. doi:10.3390/nu10121948

62. Strohle A. Physical activity, exercise, depression and anxiety disorders. Journal of neural transmission (Vienna, Austria : 1996). Jun 2009;116(6):777-84. doi:10.1007/s00702-008-0092-x 63. Fox KR. The influence of physical activity on mental well-being. Public health nutrition. 1999;2(3a):411-418. doi:10.1017/S1368980099000567

64. Josefsson T, Lindwall M, Archer T. Physical exercise intervention in depressive disorders: Meta-analysis and systematic review. Scandinavian Journal of Medicine \& Science in Sports. 2014/04/01 2013;24(2):259-272. doi:10.1111/sms.12050

65. Mammen G, Faulkner G. Physical Activity and the Prevention of Depression: A Systematic Review of Prospective Studies. American journal of preventive medicine. 2013/11/01/ 2013;45(5):649-657. doi:https://doi.org/10.1016/j.amepre.2013.08.001 
66. Lanier JB, Bury DC, Richardson SW. Diet and Physical Activity for Cardiovascular Disease Prevention. Am Fam Physician. Jun 1 2016;93(11):919-24.

67. Arija V, Villalobos F, Pedret R, et al. Physical activity, cardiovascular health, quality of life and blood pressure control in hypertensive subjects: randomized clinical trial. Health and Quality of Life Outcomes. 2018-12-01 2018;16(1)doi:10.1186/s12955-018-1008-6

68. Xiaoqin He JLBW, Qiuming Yao, Ling Li, Ronghua Song, Xiaohong Shi, Jin-an

Zhang. Diabetes self-management education reduces risk of all-cause mortality in type 2 diabetes patients: a systematic review and meta-analysis | SpringerLink. 2018;doi:10.1007/s12020-016$1168-2$

69. Harris J, Graue M, Dunning T, et al. Involving people with diabetes and the wider community in diabetes research: a realist review protocol. Systematic reviews. Nov 04 2015;4:146. doi:10.1186/s13643-015-0127-y

70. Khan RK, Misra R. Community-Based Participatory Research in Diabetes Prevention Programs. Review Article. Social Determinants of Health. 2020-07-14 2019;5(4):273-288. doi:https://doi.org/10.22037/sdh.v5i4.28286

71. Norris SL, Engelgau MM, Narayan KMV. Effectiveness of Self-Management Training in Type 2 Diabetes. 2001-03-01 2001;doi:10.2337/diacare.24.3.561

72. Amagyei A, Meal A, Shaw I, Adams GG. Effectiveness of Community Health Workerled Diabetes Self-Management Education on Type 2 diabetes patients: A Systematic Review and Meta-Analysis. International Journal of Diabetes. 2020;1(2)

73. Werfalli M, Raubenheimer PJ, Engel M, et al. The effectiveness of peer and community health worker-led self-management support programs for improving diabetes health-related outcomes in adults in low- and-middle-income countries: a systematic review. OriginalPaper. Systematic reviews. 2020-06-06 2020;9(1):1-19. doi:doi:10.1186/s13643-020-01377-8

74. Vermunt PW, Milder IE, Wielaard F, et al. A lifestyle intervention to reduce Type 2 diabetes risk in Dutch primary care: 2.5-year results of a randomized controlled trial. Diabet Med. Aug 2012;29(8):e223-31. doi:10.1111/j.1464-5491.2012.03648.x

75. Anderson JW, Kendall CW, Jenkins DJ. Importance of weight management in type 2 diabetes: review with meta-analysis of clinical studies. Journal of the American College of Nutrition. Oct 2003;22(5):331-9.

76. Levin J. Partnerships between the faith-based and medical sectors: Implications for preventive medicine and public health. Prev Med Rep. 2016;4:344-50.

doi:10.1016/j.pmedr.2016.07.009

77. Coyne CA, Demian-Popescu C, Friend D. Social and cultural factors influencing health in southern West Virginia: a qualitative study. Preventing chronic disease. 2006;3(4):A124A124.

78. Campbell MK, Hudson MA, Resnicow K, Blakeney N, Paxton A, Baskin M. ChurchBased Health Promotion Interventions: Evidence and Lessons Learned. Annual review of public health. 2007-04-01 2007;28(1):213-234. doi:10.1146/annurev.publhealth.28.021406.144016

79. Paskett ED, Baltic RD, Young GS, et al. A Group Randomized Trial to Reduce Obesity among Appalachian Church Members: The Walk by Faith Study. Cancer Epidemiology Biomarkers \& Prevention. 2018-11-01 2018;27(11):1289-1297. doi:10.1158/1055-9965.epi-171085

80. United States Census Bureau. QuickFacts: West Virginia. United States Census Bureau. 2020. https://www.census.gov/quickfacts/WV 
81. Misra R. Community-based diabetes AND hypertension self-management program in West Virginia. West Virginia: National Institute of Health; 2017.

82. Misra R, Sambamoorthi U. Community-Based Diabetes and Hypertension SelfManagement Program in West Virginia. National Institute of Health; 2017.

83. Center for Disease Control and Prevention. What Is the National DPP? 2018-0116T04:06:36Z 2018;

84. Tomky D, Tomky D, Cypress M, et al. AADE Position Statement. The Diabetes educator. 2008/05/01 2008;34(3):445-449. doi:10.1177/0145721708316625

85. James PA, University of Iowa IC, Oparil S, et al. 2014 Evidence-Based Guideline for the Management of High Blood Pressure in Adults: Report From the Panel Members Appointed to the Eighth Joint National Committee (JNC 8). JAMA. 2018;311(5):507-520.

doi:10.1001/jama.2013.284427

86. Behavioral Diabetes Institure. Diabetes Distress Scale (DDS). Behavioral Diabetes Institure,. 2020. https://behavioraldiabetes.org/scales-and-measures/\#1448434304099-9078f27c$\underline{4106}$

87. Morisky DE, Green LW, Levine DM. Concurrent and predictive validity of a selfreported measure of medication adherence. Medical care. 1986:67-74.

88. Walker SN, Sechrist KR, Pender NJ. The Health-Promoting Lifestyle Profile:

Development and Psychometric Characteristics. Nursing Research. 1987;36(2):76-81.

89. Rural Health Information Hub. Am I Rural? Rural Health Information Hub. 2020.

https://www.ruralhealthinfo.org/am-i-rural

90. Rural Health Information Hub. What is Rural? Rural Health Information Hub. 2021.

https://www.ruralhealthinfo.org/topics/what-is-rural

91. Polonsky WH, Fisher L, Earles J, et al. Assessing Psychosocial Distress in Diabetes. 2005-03-01 2005;doi:10.2337/diacare.28.3.626

92. Stetson B, Minges KE, Richardson CR. New directions for diabetes prevention and management in behavioral medicine. journal article. Journal of Behavioral Medicine. 2017;40(1):127-144. doi:10.1007/s10865-016-9802-2

93. Yang A, Wang B, Zhu G, et al. Validation of Chinese version of the Morisky Medication Adherence Scale in patients with epilepsy. Seizure. 2014-04-01 2014;23(4):295-299.

doi:10.1016/j.seizure.2014.01.003

94. Morisky DE, Ang A, Krousel-Wood M, Ward HJ. Predictive Validity of a Medication Adherence Measure in an Outpatient Setting. The Journal of Clinical Hypertension. 2008;10(5):348-354. doi:https://doi.org/10.1111/j.1751-7176.2008.07572.x

95. Moon SJ, Lee W-Y, Hwang JS, Hong YP, Morisky DE. Accuracy of a screening tool for medication adherence: A systematic review and meta-analysis of the Morisky Medication Adherence Scale-8. PLoS One. 2017-11-02 2017;12(11):e0187139.

doi:10.1371/journal.pone.0187139

96. Dashtidehkordi A, Shahgholian N, Attari F. "Exercise during hemodialysis and health promoting behaviors: a clinical trial". BMC Nephrology. 2019-12-01

2019;20(1)doi:10.1186/s12882-019-1276-3

97. Diaz-Godiño J, Fernández-Henriquez L, Peña-Pastor F, Alfaro-Flores P, ManriqueBorjas G, Mayta-Tovalino F. Lifestyles, Depression, Anxiety, and Stress as Risk Factors in Nursing Apprentices: A Logistic Regression Analysis of 1193 Students in Lima, Peru. Journal of environmental and public health. 2019/11/06 2019;2019:7395784. doi:10.1155/2019/7395784 
98. Harris PA, Taylor R, Thielke R, Payne J, Gonzalez N, Conde JG. Research electronic data capture (REDCap) - A metadata-driven methodology and workflow process for providing translational research informatics support. Journal of Biomedical Informatics. 2009/04/01/ 2009;42(2):377-381. doi:https://doi.org/10.1016/j.jbi.2008.08.010

99. Vanderbilt University. About REDCap. Vanderbilt University. 2019. https://projectredcap.org/about/

100. Microsoft Excel. Microsoft Corporation; 2016.

101. IBM SPSS Statistics for Windows. Version 27. IBM Corp; 2015.

102. Akoglu H. User's guide to correlation coefficients. Turk J Emerg Med. 2018;18(3):91-93. doi:10.1016/j.tjem.2018.08.001

103. Dancey CP, Reidy J. Statistics without maths for psychology. Pearson education; 2007.

104. Wilson Van Voorhis CR, Morgan BL. Understanding Power and Rules of Thumb for Determining Sample Sizes. TQMP. 2007-09-01 2007;3(2):43-50. IN FILE. doi:10.20982/tqmp.03.2.p043

105. Miller DE, Kunce JT. Prediction and Statistical Overkill Revisited. research-article. https://doiorg/101080/00256307197312022590. $16 \mathrm{Jul} 2018$

2018; doi:10.1080/00256307.1973.12022590

106. Detry M, Ma Y. Analyzing Repeated Measurements Using Mixed Models. JAMA. 2016;315(4):407-408. doi:10.1001/jama.2015.19394

107. US Census Bureau. QuickFacts: West Virginia. US Census Bureau. 2020. //www.census.gov/quickfacts/fact/table/WV/PST045219

108. Berchick ER, Hood E, Barnett JC. Health insurance coverage in the United States: 2017. 2018. Current Population Reports.

109. WVUMedicine. Cortisol, Free and Total, Serum. Mayo Foundation for Medical Education and Research. 2021. https://uh.testcatalog.org/show/CORTO

110. American Diabetes Association. Glycemic Targets: Standards of Medical Care in Diabetes-2020. Diabetes Care. 2020-01-01 2020;43(Supplement 1):S66-S76. doi: $10.2337 / \mathrm{dc} 20$-s006

111. Solowiejczyk J. Diabetes and Depression: Some Thoughts to Think About. 2010-01-21 2010;doi:10.2337/diaspect.23.1.11

112. Zagarins SE, Allen NA, Garb JL, Welch G. Improvement in glycemic control following a diabetes education intervention is associated with change in diabetes distress but not change in depressive symptoms. OriginalPaper. Journal of Behavioral Medicine. 2011-06-21 2011;35(3):299-304. doi:doi:10.1007/s10865-011-9359-z

113. Glasgow, RE., Toobert D, Barrera M, Strycker L. Assessment of problem-solving: a key to successful diabetes self-management. Journal of behavioral medicine. 2004 Oct 2004;27(5)doi:10.1023/b:jobm.0000047611.81027.71

114. Wagner JA, Bermudez-Millan A, Damio G, et al. A randomized, controlled trial of a stress management intervention for Latinos with type 2 diabetes delivered by community health workers: Outcomes for psychological wellbeing, glycemic control, and cortisol. Diabetes Res Clin Pract. Oct 2016;120:162-70. doi:10.1016/j.diabres.2016.07.022

115. Dubois SK, Lehrer HM, Whyne EZ, Steinhardt MA. A Resilience Intervention for Adults with Type 2 Diabetes: Proof-of-Concept in Community Health Centers. OriginalPaper. International Journal of Behavioral Medicine. 2020-06-15 2020;27(5):565-575. doi:doi:10.1007/s12529-020-09894-5 
116. Fisher L, Mullan J, Skaff M, Glasgow R, Arean P, Hessler D. Predicting diabetes distress in patients with Type 2 diabetes: a longitudinal study. Diabetic medicine : a journal of the British Diabetic Association. 2009 Jun 2009;26(6)doi:10.1111/j.1464-5491.2009.02730.x 117. Delahanty LM, Grant RW, Wittenberg E, et al. Association of diabetes-related emotional distress with diabetes treatment in primary care patients with Type 2 diabetes. Diabet Med. Jan 2007;24(1):48-54. doi:10.1111/j.1464-5491.2007.02028.x

118. Cummings DM, Lutes L, Littlewood K, et al. Regimen-Related Distress, Medication Adherence, and Glycemic Control in Rural African American Women With Type 2 Diabetes Mellitus. Annals of Pharmacotherapy. 2014-08-01 2014;48(8):970-977.

doi:10.1177/1060028014536532

119. Mora Pablo, Buskirk Ann, Lyden Maureen, G. PC, Borsa Lena, Petersen Bettina. Use of a Novel, Remotely Connected Diabetes Management System Is Associated with Increased Treatment Satisfaction, Reduced Diabetes Distress, and Improved Glycemic Control in Individuals with Insulin-Treated Diabetes: First Results from the Personal Diabetes Management Study. research-article. https://homeliebertpubcom/dia. 2017-12-01

2017;doi:10.1089/dia.2017.0206

120. Van Bastelaar K, Pouwer F, Geelhoed-Duijvestijn P, et al. Diabetes-specific emotional distress mediates the association between depressive symptoms and glycaemic control in Type 1 and Type 2 diabetes. Diabetic medicine : a journal of the British Diabetic Association. $2010 \mathrm{Jul}$ 2010;27(7)doi:10.1111/j.1464-5491.2010.03025.x

121. Hirano T. Pathophysiology of Diabetic Dyslipidemia. Journal of Atherosclerosis and Thrombosis. 2018-09-01 2018;25(9):771-782. doi:10.5551/jat.rv17023

122. Chait A, Ginsberg HN, Vaisar T, Heinecke JW, Goldberg IJ, Bornfeldt KE. Remnants of the Triglyceride-Rich Lipoproteins, Diabetes, and Cardiovascular Disease. Diabetes. 2020-04-01 2020;69(4):508-516. doi:10.2337/dbi19-0007

123. Schwertner HA, Troxler RG, Uhl GS, Jackson WG. Relationship between cortisol and cholesterol in men with coronary artery disease and type A behavior. Arteriosclerosis: An Official Journal of the American Heart Association, Inc. 1984-01-01 1984;4(1):59-64. doi:10.1161/01.atv.4.1.59

124. Pickup JC, Crook MA. Is Type II diabetes mellitus a disease of the innate immune system? Diabetologia. 1998-09-18 1998;41(10):1241-1248. doi:10.1007/s001250051058

125. American Diabetes Association. 10. Cardiovascular Disease and Risk Management: Standards of Medical Care in Diabetes-2021. Diabetes Care. 2021-01-01 2021;44(Supplement 1):S125-S150. doi:10.2337/dc21-s010

126. Kleinman NJ, Shah A, Shah S, Phatak S, Viswanathan V. Improved Medication Adherence and Frequency of Blood Glucose Self-Testing Using an m-Health Platform Versus Usual Care in a Multisite Randomized Clinical Trial Among People with Type 2 Diabetes in India. Telemedicine journal and e-health : the official journal of the American Telemedicine Association. Sep 2017;23(9):733-740. doi:10.1089/tmj.2016.0265

127. Sperl-Hillen J, Beaton S, Fernandes O, et al. Are benefits from diabetes self-management education sustained? The American journal of managed care. Feb 2013;19(2):104-12.

128. Mathiesen AS, Egerod I, Jensen T, Kaldan G, Langberg H, Thomsen T. Psychosocial interventions for reducing diabetes distress in vulnerable people with type 2 diabetes mellitus: a systematic review and meta-analysis. Diabetes, Metabolic Syndrome and Obesity: Targets and Therapy. 2018-12-01 2018;Volume 12:19-33. doi:10.2147/dmso.s179301 
129. Grzywacz JG, Almeida DM, Neupert SD, Ettner SL. Socioeconomic Status and Health: A Micro-level Analysis o Exposure and Vulnerability to Daily Stressors. Journal of Health and Social Behavior. 2004-03-01 2004;45(1):1-16. doi:10.1177/002214650404500101

130. Molarius A, Granström F. Educational differences in psychological distress? Results from a population-based sample of men and women in Sweden in 2012. BMJ Open. 2018-04-01 2018;8(4):e021007. doi:10.1136/bmjopen-2017-021007

131. Della LJ. Exploring Diabetes Beliefs in At-Risk Appalachia. The Journal of Rural Health. 2011-01-01 2011;27(1):3-12. doi:10.1111/j.1748-0361.2010.00311.x 132. Lester L. Putting Rural Readers on the Map: Strategies for Rural Literacy. The Reading Teacher. 2012-03-01 2012;65(6):407-415. doi:10.1002/trtr.01062

133. National Assessment of Adult Literacy. State and County Literacy Estimates - State Estimates. National Assessment of Adult Literacy. 2021. https://nces.ed.gov/naal/estimates/StateEstimates.aspx

134. Health Resources \& Services Administration. Medically Underserved Areas/Populations (MUA/P) Dashboard. Health Resources \& Services Administration. 2020.

https://data.hrsa.gov/topics/health-workforce/shortage-areas

135. Rural Health Information Hub. Chronic Disease in Rural America. Rural Health Information Hub. 2020. https://www.ruralhealthinfo.org/topics/chronic-disease

136. Reyes J, Tripp-Reimer T, Parker E, Muller B, Laroche H. Factors Influencing Diabetes Self-Management Among Medically Underserved Patients With Type II Diabetes. Global qualitative nursing research. 06/14/2017 2017;4doi:10.1177/2333393617713097 


\subsection{Appendix C}

Table 1. Descriptive analysis of demographic variables at baseline

\begin{tabular}{|c|c|c|c|c|c|c|c|c|c|c|}
\hline Variables & \multicolumn{3}{|c|}{ Total } & \multicolumn{3}{|c|}{ Intervention } & \multicolumn{3}{|c|}{ Control group } & \multirow[b]{2}{*}{ p-values } \\
\hline & $\mathrm{N}$ & Mean \pm SD & $\begin{array}{c}\text { Median } \\
(\mathrm{IQR})\end{array}$ & $\mathrm{N}$ & Mean \pm SD. & Median & $\mathrm{N}$ & Mean \pm SD & $\begin{array}{c}\text { Median } \\
(\mathrm{IQR})\end{array}$ & \\
\hline $\operatorname{Age}^{\mathrm{k}}$ & 89 & $60.82 \pm 12.16$ & & 44 & $\begin{array}{c}62.55 \pm \\
10.64\end{array}$ & & 45 & $59.66 \pm 12.75$ & & 0.249 \\
\hline \multicolumn{11}{|l|}{ Gender $^{1}$} \\
\hline Male & 32 & $35.96 \%$ & & 11 & $25.00 \%$ & & 21 & $46.67 \%$ & & 0.033 \\
\hline Female & 57 & $64.04 \%$ & & 33 & $75.00 \%$ & & 24 & $53.33 \%$ & & \\
\hline $\mathrm{BMI}^{\mathrm{j}}$ & 89 & & $\begin{array}{l}35.40 \\
(8.38) \\
\end{array}$ & 44 & & $\begin{array}{l}36.59 \\
(8.92) \\
\end{array}$ & 45 & & $\begin{array}{l}34.34 \\
(8.09) \\
\end{array}$ & 0.325 \\
\hline \multirow{4}{*}{$\begin{array}{l}\text { BMI } \\
\text { (categorical) }^{\mathrm{k}} \\
\text { Normal } \\
\text { Overweight } \\
\text { Obese }\end{array}$} & & & & & & & & & & 0.049 \\
\hline & 4 & $4.6 \%$ & & 2 & $4.7 \%$ & & 2 & $4.5 \%$ & & \\
\hline & 12 & $13.8 \%$ & & 2 & $4.7 \%$ & & 10 & $22.7 \%$ & & \\
\hline & 71 & $81.6 \%$ & & 39 & $90.7 \%$ & & 32 & $72.7 \%$ & & \\
\hline $\begin{array}{l}\text { Hypertension } \\
\text { duration }^{\text {a }}\end{array}$ & 78 & & $\begin{array}{c}14.83 \\
(22.28) \\
\end{array}$ & 41 & & $\begin{array}{c}15.61 \\
(24.21) \\
\end{array}$ & 37 & & $\begin{array}{c}13.34 \\
(22.51)\end{array}$ & 0.774 \\
\hline $\begin{array}{l}\text { Diabetes } \\
\text { duration }^{\mathrm{b}}\end{array}$ & 78 & & $\begin{array}{c}10.63 \\
(13.93)\end{array}$ & 41 & & $\begin{array}{c}10.62 \\
(13.96)\end{array}$ & 37 & & $\begin{array}{c}10.90 \\
(14.31)\end{array}$ & 0.191 \\
\hline $\begin{array}{l}\text { Education } \\
\text { levelc }\end{array}$ & & & & & & & & & & 0.277 \\
\hline $\begin{array}{l}\text { High school } \\
\text { or less than } \\
\text { high school }\end{array}$ & 16 & $18.8 \%$ & & 11 & $25.0 \%$ & & 5 & $12.2 \%$ & & \\
\hline $\begin{array}{l}\text { some college } \\
\text { education or } \\
\text { associate } \\
\text { degree }\end{array}$ & 27 & $31.8 \%$ & & 14 & $31.8 \%$ & & 13 & $31.7 \%$ & & \\
\hline $\begin{array}{l}\text { college } \\
\text { graduate, }\end{array}$ & 42 & $49.4 \%$ & & 19 & $43.2 \%$ & & 23 & $56.1 \%$ & & \\
\hline
\end{tabular}




\begin{tabular}{|c|c|c|c|c|c|c|c|c|c|c|}
\hline \multicolumn{11}{|l|}{$\begin{array}{c}\text { post-graduate } \\
\text { or } \\
\text { professional } \\
\text { degree }\end{array}$} \\
\hline \multirow{3}{*}{$\begin{array}{l}\text { Race }^{\mathrm{d}} \\
\text { Non-White } \\
\text { White }\end{array}$} & & & & & & & & & & 0.607 \\
\hline & 10 & $9.8 \%$ & & 6 & $11.6 \%$ & & 4 & $7.7 \%$ & & \\
\hline & 74 & $90.2 \%$ & & 38 & $84.4 \%$ & & 36 & $92.3 \%$ & & \\
\hline $\begin{array}{l}\text { Number of } \\
\text { household } \\
\text { members }\end{array}$ & 89 & & $1.0(1.0)$ & 44 & & $\begin{array}{c}1.00 \\
(1.00)\end{array}$ & 45 & & $\begin{array}{c}1.00 \\
(1.00)\end{array}$ & 0.099 \\
\hline \multirow{3}{*}{$\begin{array}{l}\text { Rural or } \\
\text { Urban }^{\text {f }} \\
\text { Rural } \\
\text { Urban }\end{array}$} & & & & & & & & & & 0.764 \\
\hline & 27 & $30.34 \%$ & & 14 & $31.82 \%$ & & 13 & $28.89 \%$ & & \\
\hline & 62 & $69.66 \%$ & & 30 & $68.18 \%$ & & 32 & $71.11 \%$ & & \\
\hline \multirow{3}{*}{$\begin{array}{l}\text { Family } \\
\text { history of } \\
\text { diabetes } \\
\text { Yes } \\
\text { No }\end{array}$} & & & & & & & & & & 0.563 \\
\hline & 77 & $86.52 \%$ & & 39 & $88.63 \%$ & & 38 & $84.44 \%$ & & \\
\hline & 12 & $13.48 \%$ & & 5 & $11.36 \%$ & & 7 & $15.56 \%$ & & \\
\hline \multirow{3}{*}{$\begin{array}{l}\text { Family } \\
\text { history of } \\
\text { hypertension }^{\mathrm{h}} \\
\text { Yes } \\
\text { No }\end{array}$} & & & & & & & & & & 0.798 \\
\hline & 76 & $85.39 \%$ & & 38 & $86.36 \%$ & & 38 & $84.44 \%$ & & \\
\hline & 13 & $14.61 \%$ & & 6 & $13.64 \%$ & & 7 & $15.56 \%$ & & \\
\hline $\begin{array}{l}\text { Access to } \\
\text { health } \\
\text { insurance }^{\mathrm{i}}\end{array}$ & & & & & & & & & & 0.053 \\
\hline Yes & 82 & $92.13 \%$ & & 43 & $97.73 \%$ & & 39 & $86.67 \%$ & & \\
\hline No & 7 & $7.87 \%$ & & 1 & $2.27 \%$ & & 6 & $13.33 \%$ & & \\
\hline
\end{tabular}

Note:

IQR: Interquartile range.

${ }^{\mathrm{k}}$ Age: measured in years.

${ }^{1}$ Gender: responses were categorized as male, and female. 
${ }^{a}$ Diabetes duration: indicates how many years the participants have been living with diabetes; measured in years.

${ }^{\mathrm{b}}$ Hypertension duration: indicates how many years the participants have been living with hypertension; measured in years. ${ }^{c}$ Education level: indicated the highest academic degree achieved by the participant.

${ }^{\mathrm{d}}$ Race of participants was recategorized into two categories: Non-white, and White.

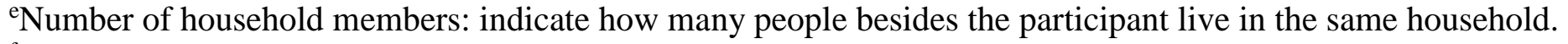

${ }^{f}$ Rural or Urban: indicates the location of the participants' residence based on their zip code.

${ }^{g}$ Family history of diabetes: indicates whether the participants have any family members diagnosed with diabetes. Answer response was yes, and no.

${ }^{h}$ Family history of hypertension: indicates whether the participants have any family members diagnosed with hypertension. Answer response was yes, and no.

${ }^{i}$ Access to health insurance: indicates whether the participants have any type of health insurance. The answer response was yes, and no.

${ }_{\mathrm{j} B M I}$ was calculated in $\mathrm{kg} / \mathrm{m}^{2}$

${ }^{\mathrm{k}}$ BMI (categorical) was categorized into three options: normal, overweight, and obese. 
Table 2. Descriptive statistics of the dependent and clinical variables at baseline

\begin{tabular}{|c|c|c|c|c|c|c|c|c|c|c|}
\hline Clinical Variables & $\mathrm{N}$ & Mean \pm SD & $\begin{array}{l}\text { Median } \\
\text { (IQR) }\end{array}$ & $\mathrm{N}$ & Mean \pm SD & $\begin{array}{c}\text { Median } \\
\text { (IQR) }\end{array}$ & $\mathrm{N}$ & Mean \pm SD & $\begin{array}{c}\text { Median } \\
\text { (IQR) }\end{array}$ & $\mathrm{p}$-value \\
\hline Total diabetes distress ${ }^{\mathrm{a}}$ & 89 & & $\begin{array}{c}1.76 \\
(1.04)\end{array}$ & 44 & & $\begin{array}{l}1.79 \\
(1.19)\end{array}$ & 45 & & $\begin{array}{c}1.74 \\
(0.96)\end{array}$ & 0.686 \\
\hline Emotional distress $^{\mathrm{b}}$ & 89 & & $\begin{array}{c}1.60 \\
(1.40)\end{array}$ & 44 & & $\begin{array}{c}1.70 \\
(1.75)\end{array}$ & 45 & & $\begin{array}{c}1.40 \\
(1.40)\end{array}$ & 0.479 \\
\hline Interpersonal distress $^{\mathrm{b}}$ & 88 & & $\begin{array}{c}1.33 \\
(1.25)\end{array}$ & 44 & & $\begin{array}{c}1.33 \\
(1.33)\end{array}$ & 44 & & $\begin{array}{c}1.17 \\
(1.00)\end{array}$ & 0.536 \\
\hline $\begin{array}{c}\text { Physician related } \\
\text { distress }^{\text {b }}\end{array}$ & 89 & & $\begin{array}{l}1.00 \\
(0.50)\end{array}$ & 44 & & $\begin{array}{l}1.00 \\
(0.50)\end{array}$ & 45 & & $\begin{array}{c}1.00 \\
(0.44)\end{array}$ & 0.909 \\
\hline $\begin{array}{l}\text { Regimen related } \\
\text { distress }^{\mathrm{b}}\end{array}$ & 88 & $2.61 \pm 1.27$ & & 44 & $2.58 \pm 1.40$ & & 44 & $2.63 \pm 1.13$ & & 0.848 \\
\hline Serum cortisol $^{\mathrm{i}}$ & 87 & $\begin{array}{l}13.20 \pm \\
4.14\end{array}$ & & 44 & $\begin{array}{c}13.28 \pm \\
4.22\end{array}$ & & 43 & $\begin{array}{l}13.12 \pm \\
4.10\end{array}$ & & 0.857 \\
\hline $\operatorname{Diet}^{c}$ & 89 & $2.85 \pm 0.07$ & & 44 & $2.91 \pm 0.93$ & & 45 & $2.75 \pm 0.13$ & & 0.085 \\
\hline $\mathrm{PA}^{\mathrm{d}}$ & 89 & $2.06 \pm 0.09$ & & 44 & $2.18 \pm 0.72$ & & 32 & $1.90 \pm 0.76$ & & 0.115 \\
\hline Medication adherence & 85 & $6.39 \pm 0.21$ & & 43 & $6.51 \pm 0.26$ & & 42 & $6.20 \pm 0.35$ & & 0.172 \\
\hline
\end{tabular}




\begin{tabular}{|c|c|c|c|c|c|c|c|c|c|c|}
\hline $\mathrm{HbA} 1 \mathrm{c}^{\mathrm{f}}$ & 73 & $7.29 \pm 0.19$ & & 44 & $7.33 \pm 1.38$ & & 29 & $7.40 \pm 1.89$ & & 0.867 \\
\hline $\mathrm{LDL}^{\mathrm{g}}$ & 89 & $\begin{array}{c}94.23 \pm \\
4.58\end{array}$ & & 44 & $\begin{array}{c}91.95 \pm \\
5.11\end{array}$ & & 45 & $\begin{array}{c}98.04 \pm \\
8.85\end{array}$ & & 0.451 \\
\hline VLDL $^{g}$ & 89 & & $\begin{array}{c}25.00 \\
(20.75)\end{array}$ & 44 & & $\begin{array}{c}25.00 \\
(18.25)\end{array}$ & 45 & & $\begin{array}{c}29.00 \\
(27.00)\end{array}$ & 0.600 \\
\hline Systolic blood pressure ${ }^{\mathrm{h}}$ & 90 & $\begin{array}{c}136.47 \pm \\
18.88\end{array}$ & & 44 & $\begin{array}{c}135.81 \pm \\
20.50\end{array}$ & & 46 & $\begin{array}{c}137.10 \pm \\
17.39\end{array}$ & & 0.748 \\
\hline $\begin{array}{l}\text { Diastolic blood } \\
\text { pressure }^{\mathrm{h}}\end{array}$ & 90 & $\begin{array}{c}83.06 \pm \\
11.29\end{array}$ & & 44 & $\begin{array}{c}82.03 \pm \\
10.75\end{array}$ & & 46 & $\begin{array}{c}84.03 \pm \\
11.82\end{array}$ & & 0.404 \\
\hline 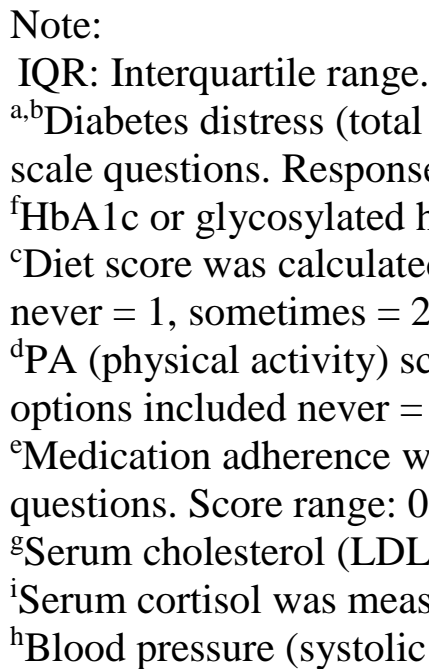 & $\begin{array}{l}\text { core } \\
\text { optic } \\
\text { mog } \\
\text { from } \\
\text { ofter } \\
\text { re w } \\
\text {, son } \\
\text { s cal } \\
3 \text {. } \\
\text { VLD } \\
\text { red i } \\
\text { nd d }\end{array}$ & $\begin{array}{l}\text { Ind subscores } \\
\text { included fro } \\
\text { obin was mea } \\
\text { the Lifestyle } \\
=3 \text {, and rout } \\
\text { s calculated } \mathrm{f} \\
\text { etimes }=2, \mathrm{o} \\
\text { ulated using } \\
\text { L) was measu } \\
\text { mcg/dL. } \\
\text { astolic blood }\end{array}$ & $\begin{array}{l}\text { was calc } \\
\mathrm{m} 1=\text { not } \\
\text { sured in } \mathrm{p} \\
\text { Profile II } \\
\text { nely }=4 \text {. } \\
\text { om the } \mathrm{Li} \\
\text { ten }=3 \text {, al } \\
\text { Morisky } \mathrm{M} \\
\text { ed in } \mathrm{mg} \text { ( }\end{array}$ & $\begin{array}{l}\text { latec } \\
\text { a pro } \\
\text { rcen } \\
\text { cale } \\
\text { core } \\
\text { festy } \\
\text { d rot } \\
\text { edica } \\
\text { lL. }\end{array}$ & $\begin{array}{l}\text { using the Dia } \\
\text { lem to } 6=\mathrm{a} \\
\text { age. } \\
\text { sing nine Lik } \\
\text { range: } 9-36 \text {. } \\
\text { e Profile II sc } \\
\text { tinely = 4. Sc } \\
\text { tion Adheren }\end{array}$ & $\begin{array}{l}\text { betes Dist } \\
\text { very seriou } \\
\text { ert scale q } \\
\text { le using } \\
\text { ore range: } \\
\text { e Scale } 8\end{array}$ & $\begin{array}{l}\text { ress } \\
\text { is pr } \\
\text { uesti } \\
\text { ight } \\
8-32 \\
\text { (MM }\end{array}$ & $\begin{array}{l}\text { urvey (DDS) } \\
\text { blem. Score } 1 \\
\text { Aikert scale q } \\
\text { AS8) that hac }\end{array}$ & $\begin{array}{l}\text { which ha } \\
\text { nge: } 1-6 . \\
\text { options in } \\
\text { estions. R } \\
\text { a total of }\end{array}$ & $\begin{array}{l}7 \text { Likert } \\
\text { honse } \\
\text { ht }\end{array}$ \\
\hline
\end{tabular}


Table 3. Bivariate relationship between dependent variables and continuous predictor variables

\begin{tabular}{|c|c|c|c|c|c|c|c|c|c|c|c|c|c|c|c|c|c|c|}
\hline Variable & $\begin{array}{l}\text { 1.To } \\
\text { tal } \\
\text { diab } \\
\text { etes } \\
\text { distr } \\
\text { ess }^{\mathrm{a}}\end{array}$ & $\begin{array}{l}2 . \\
\text { Emo } \\
\text { tiona } \\
1 \\
\text { distr } \\
\text { ess }^{b}\end{array}$ & $\begin{array}{l}3 . \\
\text { Phys } \\
\text { ician } \\
\text { relat } \\
\text { ed } \\
\text { distr } \\
\text { ess }\end{array}$ & $\begin{array}{l}4 . \\
\text { Regi } \\
\text { men } \\
\text { relat } \\
\text { ed } \\
\text { distr } \\
\text { ess }^{b}\end{array}$ & $\begin{array}{l}5 . \\
\text { Inter } \\
\text { pers } \\
\text { onal } \\
\text { distr } \\
\text { ess }^{b}\end{array}$ & $\begin{array}{l}6 . \\
\text { Seru } \\
\mathrm{m} \\
\text { cortis } \\
\text { ol }^{\mathrm{i}}\end{array}$ & $\begin{array}{l}7 . \\
\mathrm{Ag} \\
\mathrm{e}\end{array}$ & $\begin{array}{l}8 . \\
\text { Diab } \\
\text { etes } \\
\text { dura } \\
\text { tion }\end{array}$ & $\begin{array}{l}09 . \\
\text { Hyperte } \\
\text { nsion } \\
\text { duration }\end{array}$ & $\begin{array}{l}10 . \\
\text { Num } \\
\text { ber of } \\
\text { house } \\
\text { hold } \\
\text { mem } \\
\text { bers }\end{array}$ & $\begin{array}{l}11 . \\
\text { Tota } \\
1 \\
\text { chol } \\
\text { ester } \\
\text { ol }\end{array}$ & LDL & $\begin{array}{l}\text { VLD } \\
\mathrm{L}\end{array}$ & $\begin{array}{l}12 . \\
\text { Medi } \\
\text { cation } \\
\text { adher } \\
\text { ence }\end{array}$ & $\begin{array}{l}13 . \\
\mathrm{HbA} 1 \\
\mathrm{c}^{\mathrm{f}}\end{array}$ & $\begin{array}{l}14 . \\
P^{d}\end{array}$ & 15. Diet & $\begin{array}{l}16 . \\
\text { Systoli } \\
\mathrm{c} \mathrm{BP}^{\mathrm{h}}\end{array}$ \\
\hline $\begin{array}{l}\text { 1. Total } \\
\text { diabetes } \\
\text { distress }^{\text {a }}\end{array}$ & 1 & & & & & & & & & & & & & & & & & \\
\hline $\begin{array}{l}\text { 2. Emotional } \\
\text { distress }^{b}\end{array}$ & $\begin{array}{l}.874 \\
* *\end{array}$ & 1 & & & & & & & & & & & & & & & & \\
\hline $\begin{array}{l}\text { 3. Physician } \\
\text { related } \\
\text { distress }^{\mathrm{c}}\end{array}$ & $\begin{array}{l}.445 \\
* *\end{array}$ & $\begin{array}{l}.269 \\
*\end{array}$ & 1 & & & & & & & & & & & & & & & \\
\hline $\begin{array}{l}\text { 4. Regimen } \\
\text { related } \\
\text { distress }^{\mathrm{d}}\end{array}$ & $\begin{array}{l}.904 \\
* *\end{array}$ & $\begin{array}{l}.684 \\
* *\end{array}$ & $\begin{array}{l}.327 \\
* *\end{array}$ & 1 & & & & & & & & & & & & & & \\
\hline $\begin{array}{l}5 . \\
\text { Interpersonal } \\
\text { distress }^{\mathrm{e}} \\
\end{array}$ & $\begin{array}{l}.648 \\
* *\end{array}$ & $\begin{array}{l}.573 \\
* *\end{array}$ & $\begin{array}{l}.436 \\
* *\end{array}$ & $\begin{array}{l}.501 \\
* *\end{array}$ & 1 & & & & & & & & & & & & & \\
\hline $\begin{array}{l}\text { 6. Serum } \\
\text { cortisol }\end{array}$ & $\begin{array}{l}0.05 \\
5\end{array}$ & $\begin{array}{l}0.07 \\
1\end{array}$ & $\begin{array}{l}0.06 \\
5\end{array}$ & $\begin{array}{l}- \\
0.03 \\
3 \\
\end{array}$ & $\begin{array}{l}0.04 \\
6\end{array}$ & 1 & & & & & & & & & & & & \\
\hline 7. Age & $\begin{array}{l}- \\
0.15 \\
4\end{array}$ & $\begin{array}{l}- \\
0.17 \\
9\end{array}$ & $\begin{array}{l}0.03 \\
0\end{array}$ & $\begin{array}{l}- \\
0.12 \\
8\end{array}$ & $\begin{array}{l}0.00 \\
8\end{array}$ & 0.052 & 1 & & & & & & & & & & & \\
\hline
\end{tabular}


Table 3. Bivariate relationship between dependent variables and continuous predictor variables

\begin{tabular}{|c|c|c|c|c|c|c|c|c|c|c|c|c|c|c|c|c|c|c|}
\hline Variable & $\begin{array}{l}\text { 1.To } \\
\text { tal } \\
\text { diab } \\
\text { etes } \\
\text { distr } \\
\text { ess }^{\text {a }}\end{array}$ & $\begin{array}{l}2 . \\
\text { Emo } \\
\text { tiona } \\
1 \\
\text { distr } \\
\text { ess }^{b}\end{array}$ & $\begin{array}{l}3 . \\
\text { Phys } \\
\text { ician } \\
\text { relat } \\
\text { ed } \\
\text { distr } \\
\text { ess }^{b}\end{array}$ & $\begin{array}{l}4 . \\
\text { Regi } \\
\text { men } \\
\text { relat } \\
\text { ed } \\
\text { distr } \\
\text { ess }^{b}\end{array}$ & $\begin{array}{l}5 . \\
\text { Inter } \\
\text { pers } \\
\text { onal } \\
\text { distr } \\
\text { ess }^{b}\end{array}$ & $\begin{array}{l}6 . \\
\text { Seru } \\
\text { m } \\
\text { cortis } \\
\text { ol }^{\mathrm{i}}\end{array}$ & $\begin{array}{l}7 . \\
\mathrm{Ag} \\
\mathrm{e}\end{array}$ & $\begin{array}{l}8 . \\
\text { Diab } \\
\text { etes } \\
\text { dura } \\
\text { tion }\end{array}$ & $\begin{array}{l}09 . \\
\text { Hyperte } \\
\text { nsion } \\
\text { duration }\end{array}$ & $\begin{array}{l}10 . \\
\text { Num } \\
\text { ber of } \\
\text { house } \\
\text { hold } \\
\text { mem } \\
\text { bers }\end{array}$ & $\begin{array}{l}11 . \\
\text { Tota } \\
1 \\
\text { chol } \\
\text { ester } \\
\text { ol }\end{array}$ & LDL & $\begin{array}{l}\text { VLD } \\
\mathrm{L}\end{array}$ & $\begin{array}{l}12 . \\
\text { Medi } \\
\text { cation } \\
\text { adher } \\
\text { ence }\end{array}$ & $\begin{array}{l}13 . \\
\mathrm{HbA} 1 \\
\mathrm{c}^{\mathrm{f}}\end{array}$ & $P^{14 .}$ & $\begin{array}{l}\text { 15.Diet } \\
\mathrm{c}\end{array}$ & $\begin{array}{l}16 . \\
\text { Systoli } \\
\mathrm{c} \mathrm{BP}^{\mathrm{h}}\end{array}$ \\
\hline $\begin{array}{l}\text { 8. Diabetes } \\
\text { duration }\end{array}$ & $\begin{array}{l}0.03 \\
3\end{array}$ & $\begin{array}{l}0.00 \\
6\end{array}$ & $\begin{array}{l}0.03 \\
3\end{array}$ & $\begin{array}{l}0.02 \\
4\end{array}$ & $\begin{array}{l}- \\
0.02 \\
3\end{array}$ & 0.059 & $\begin{array}{l}.21 \\
8^{*}\end{array}$ & 1 & & & & & & & & & & \\
\hline $\begin{array}{l}09 . \\
\text { Hypertension } \\
\text { duration }\end{array}$ & $\begin{array}{l}- \\
0.19 \\
6\end{array}$ & $\begin{array}{l}- \\
0.19 \\
7\end{array}$ & $\begin{array}{l}- \\
0.16 \\
9\end{array}$ & $\begin{array}{l}- \\
0.15 \\
3\end{array}$ & $\begin{array}{l}- \\
0.12 \\
1\end{array}$ & $\begin{array}{l}- \\
0.036\end{array}$ & $\begin{array}{l}.43 \\
1 * *\end{array}$ & $\begin{array}{l}.291 \\
* *\end{array}$ & 1 & & & & & & & & & \\
\hline $\begin{array}{l}\text { 10. Number } \\
\text { of household } \\
\text { members }\end{array}$ & $\begin{array}{l}- \\
0.09 \\
6\end{array}$ & $\begin{array}{l}- \\
0.05 \\
0\end{array}$ & $\begin{array}{l}- \\
0.06 \\
4\end{array}$ & $\begin{array}{l}- \\
0.16 \\
6\end{array}$ & $\begin{array}{l}0.00 \\
6\end{array}$ &.- & $\begin{array}{l}- \\
.33 \\
6 * *\end{array}$ & $\begin{array}{l}- \\
0.09 \\
1\end{array}$ & $-.247 *$ & 1 & & & & & & & & \\
\hline $\begin{array}{l}\text { 11. Total } \\
\text { cholesterol }\end{array}$ & $\begin{array}{l}0.22 \\
1\end{array}$ & $\begin{array}{l}0.16 \\
1\end{array}$ & $\begin{array}{l}0.19 \\
2\end{array}$ & .222 & $\begin{array}{l}0.12 \\
2\end{array}$ & 0.059 & $\begin{array}{l}- \\
0.0 \\
41 \\
\end{array}$ & $\begin{array}{l}0.05 \\
8\end{array}$ & -0.120 & $\begin{array}{l}- \\
0.024\end{array}$ & 1 & & & & & & & \\
\hline LDL & $\begin{array}{l}0.18 \\
2\end{array}$ & $\begin{array}{l}0.17 \\
6\end{array}$ & $\begin{array}{l}.236 \\
*\end{array}$ & $\begin{array}{l}0.17 \\
4\end{array}$ & $\begin{array}{l}0.10 \\
7\end{array}$ & 0.025 & $\begin{array}{l}- \\
0.1 \\
02 \\
\end{array}$ & $\begin{array}{l}0.00 \\
1\end{array}$ & -0.144 & $\begin{array}{l}- \\
0.038\end{array}$ & $\begin{array}{l}0.93 \\
4 * *\end{array}$ & 1 & & & & & & \\
\hline VLDL & $\begin{array}{l}0.17 \\
9\end{array}$ & $\begin{array}{l}0.16 \\
1\end{array}$ & $\begin{array}{l}- \\
0.17 \\
7\end{array}$ & $\begin{array}{l}0.24 \\
2\end{array}$ & $\begin{array}{l}0.00 \\
2\end{array}$ & $\begin{array}{l}0.251 \\
*\end{array}$ & $\begin{array}{l}- \\
0.0 \\
56\end{array}$ & $\begin{array}{l}- \\
0.02 \\
7 \\
\end{array}$ & 0.044 & $\begin{array}{l}- \\
0.154\end{array}$ & $\begin{array}{l}0.37 \\
1 * *\end{array}$ & 0.277 & 1 & & & & & \\
\hline
\end{tabular}


Table 3. Bivariate relationship between dependent variables and continuous predictor variables

\begin{tabular}{|c|c|c|c|c|c|c|c|c|c|c|c|c|c|c|c|c|c|c|}
\hline Variable & $\begin{array}{l}\text { 1.To } \\
\text { tal } \\
\text { diab } \\
\text { etes } \\
\text { distr } \\
\text { ess }^{\text {a }}\end{array}$ & $\begin{array}{l}2 . \\
\text { Emo } \\
\text { tiona } \\
1 \\
\text { distr } \\
\text { ess }^{b}\end{array}$ & $\begin{array}{l}3 . \\
\text { Phys } \\
\text { ician } \\
\text { relat } \\
\text { ed } \\
\text { distr } \\
\text { ess }^{\text {b }}\end{array}$ & $\begin{array}{l}4 . \\
\text { Regi } \\
\text { men } \\
\text { relat } \\
\text { ed } \\
\text { distr } \\
\text { ess }^{b}\end{array}$ & $\begin{array}{l}5 . \\
\text { Inter } \\
\text { pers } \\
\text { onal } \\
\text { distr } \\
\text { ess }^{b}\end{array}$ & $\begin{array}{l}6 . \\
\text { Seru } \\
\text { m } \\
\text { cortis } \\
\text { ol }^{\mathrm{i}}\end{array}$ & $\begin{array}{l}7 . \\
\mathrm{Ag} \\
\mathrm{e}\end{array}$ & $\begin{array}{l}8 . \\
\text { Diab } \\
\text { etes } \\
\text { dura } \\
\text { tion }\end{array}$ & $\begin{array}{l}09 . \\
\text { Hyperte } \\
\text { nsion } \\
\text { duration }\end{array}$ & $\begin{array}{l}10 . \\
\text { Num } \\
\text { ber of } \\
\text { house } \\
\text { hold } \\
\text { mem } \\
\text { bers }\end{array}$ & $\begin{array}{l}11 . \\
\text { Tota } \\
1 \\
\text { chol } \\
\text { ester } \\
\text { ol }\end{array}$ & LDL & $\begin{array}{l}\text { VLD } \\
\mathrm{L}\end{array}$ & $\begin{array}{l}12 . \\
\text { Medi } \\
\text { cation } \\
\text { adher } \\
\text { ence }\end{array}$ & $\begin{array}{l}13 . \\
\mathrm{HbA} 1 \\
\mathrm{c}^{\mathrm{f}}\end{array}$ & $\mathrm{PA}^{\mathrm{d}}$ & 15. Diet & $\begin{array}{l}16 . \\
\text { Systoli } \\
\mathrm{c} \mathrm{BP}^{\mathrm{h}}\end{array}$ \\
\hline $\begin{array}{l}12 . \\
\text { Medication }^{\text {adherence }}\end{array}$ & $\begin{array}{l}- \\
.337 \\
*\end{array}$ & $\begin{array}{l}- \\
.315 \\
* *\end{array}$ & $\begin{array}{l}- \\
0.22 \\
4\end{array}$ & $\begin{array}{l}- \\
.448 \\
* *\end{array}$ & $\begin{array}{l}- \\
0.09 \\
5\end{array}$ & 0.094 & $\begin{array}{l}.36 \\
7 * *\end{array}$ & $\begin{array}{l}- \\
0.01 \\
8\end{array}$ & 0.101 & 0.048 & $\begin{array}{l}- \\
0.20 \\
1\end{array}$ & $\begin{array}{l}- \\
0.221\end{array}$ & $\begin{array}{l}- \\
0.142\end{array}$ & 1 & & & & \\
\hline 13. $\mathrm{HbA} 1 \mathrm{c}^{\mathrm{g}}$ & $\begin{array}{l}0.19 \\
8\end{array}$ & $\begin{array}{l}0.16 \\
6\end{array}$ & $\begin{array}{l}- \\
0.14 \\
0\end{array}$ & $\begin{array}{l}.367 \\
* *\end{array}$ & $\begin{array}{l}- \\
0.10 \\
3\end{array}$ & $\begin{array}{l}- \\
0.018\end{array}$ & $\begin{array}{l}- \\
0.1 \\
80\end{array}$ & $\begin{array}{l}0.21 \\
9\end{array}$ & -0.126 & $\begin{array}{l}- \\
0.136\end{array}$ & $\begin{array}{l}0.18 \\
0\end{array}$ & 0.103 & $\begin{array}{l}0.366 \\
* *\end{array}$ & $\begin{array}{l}- \\
.366^{*} \\
*\end{array}$ & 1 & & & \\
\hline 14. $\mathrm{PA}^{\mathrm{h}}$ & $\begin{array}{l}- \\
.232 \\
*\end{array}$ & $\begin{array}{l}- \\
0.15 \\
2 \\
\end{array}$ & $\begin{array}{l}0.10 \\
2\end{array}$ & $\begin{array}{l}- \\
.311 \\
* *\end{array}$ & $\begin{array}{l}- \\
0.17 \\
8 \\
\end{array}$ & 0.108 & $\begin{array}{l}0.0 \\
28\end{array}$ & $\begin{array}{l}- \\
0.04 \\
7 \\
\end{array}$ & 0.052 & 0.183 & $\begin{array}{l}- \\
0.04 \\
1 \\
\end{array}$ & $\begin{array}{l}- \\
0.008\end{array}$ & $\begin{array}{l}- \\
0.284 \\
*\end{array}$ & .198 & $\begin{array}{l}- \\
0.046\end{array}$ & 1 & & \\
\hline 15. Diet $^{\mathrm{i}}$ & $\begin{array}{l}- \\
0.19 \\
1 \\
\end{array}$ & $\begin{array}{l}- \\
0.09 \\
6 \\
\end{array}$ & $\begin{array}{l}0.01 \\
5\end{array}$ & $\begin{array}{l}- \\
0.37 \\
4 * *\end{array}$ & $\begin{array}{l}- \\
0.07 \\
0 \\
\end{array}$ & $\begin{array}{l}- \\
0.037\end{array}$ & $\begin{array}{l}0.1 \\
94\end{array}$ & $\begin{array}{l}- \\
0.16 \\
0\end{array}$ & 0.110 & 0.032 & $\begin{array}{l}- \\
0.10 \\
2 \\
\end{array}$ & $\begin{array}{l}- \\
0.091\end{array}$ & $\begin{array}{l}- \\
0.299 \\
*\end{array}$ & $\begin{array}{l}.321 * \\
*\end{array}$ & 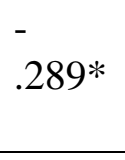 & $\begin{array}{l}.478 \\
* *\end{array}$ & 1 & \\
\hline $\begin{array}{l}\text { 16. Systolic } \\
\text { BP }\end{array}$ & $\begin{array}{l}0.17 \\
6\end{array}$ & $\begin{array}{l}0.14 \\
8\end{array}$ & $\begin{array}{l}0.06 \\
9\end{array}$ & $\begin{array}{l}0.16 \\
7\end{array}$ & $\begin{array}{l}0.11 \\
7\end{array}$ & $\begin{array}{l}- \\
0.145\end{array}$ & $\begin{array}{l}0.2 \\
02\end{array}$ & $\begin{array}{l}0.00 \\
6\end{array}$ & $.270 *$ & $\begin{array}{l}- \\
0.217\end{array}$ & $\begin{array}{l}.402 \\
* *\end{array}$ & $\begin{array}{l}0.381 \\
* *\end{array}$ & $\begin{array}{l}0.343 \\
* *\end{array}$ & $\begin{array}{l}- \\
0.040\end{array}$ & 0.112 & $\begin{array}{l}- \\
0.12 \\
5\end{array}$ & -0.152 & 1 \\
\hline
\end{tabular}


Table 3. Bivariate relationship between dependent variables and continuous predictor variables

\begin{tabular}{|c|c|c|c|c|c|c|c|c|c|c|c|c|c|c|c|c|c|c|}
\hline Variable & $\begin{array}{l}\text { 1.To } \\
\text { tal } \\
\text { diab } \\
\text { etes } \\
\text { distr } \\
\text { ess }^{\text {a }}\end{array}$ & $\begin{array}{l}2 . \\
\text { Emo } \\
\text { tiona } \\
1 \\
\text { distr } \\
\text { ess }^{b}\end{array}$ & $\begin{array}{l}3 . \\
\text { Phys } \\
\text { ician } \\
\text { relat } \\
\text { ed } \\
\text { distr } \\
\text { ess }\end{array}$ & $\begin{array}{l}4 . \\
\text { Regi } \\
\text { men } \\
\text { relat } \\
\text { ed } \\
\text { distr } \\
\text { ess }\end{array}$ & $\begin{array}{l}5 . \\
\text { Inter } \\
\text { pers } \\
\text { onal } \\
\text { distr } \\
\text { ess }^{b}\end{array}$ & $\begin{array}{l}6 . \\
\text { Seru } \\
\mathrm{m} \\
\text { cortis } \\
\text { ol }^{\mathrm{i}}\end{array}$ & $\begin{array}{l}7 . \\
\mathrm{Ag} \\
\mathrm{e}\end{array}$ & $\begin{array}{l}8 . \\
\text { Diab } \\
\text { etes } \\
\text { dura } \\
\text { tion }\end{array}$ & $\begin{array}{l}09 . \\
\text { Hyperte } \\
\text { nsion } \\
\text { duration }\end{array}$ & $\begin{array}{l}10 . \\
\text { Num } \\
\text { ber of } \\
\text { house } \\
\text { hold } \\
\text { mem } \\
\text { bers }\end{array}$ & $\begin{array}{l}11 . \\
\text { Tota } \\
1 \\
\text { chol } \\
\text { ester } \\
\text { ol }\end{array}$ & LDL & $\begin{array}{l}\text { VLD } \\
\mathrm{L}\end{array}$ & $\begin{array}{l}12 . \\
\text { Medi } \\
\text { cation } \\
\text { adher } \\
\text { ence }\end{array}$ & $\begin{array}{l}13 . \\
\mathrm{HbA} 1 \\
\mathrm{c}^{\mathrm{f}}\end{array}$ & $\mathrm{PA}^{\mathrm{d}}$ & ${ }_{c}^{15 . D i e t}$ & $\begin{array}{l}16 . \\
\text { Systoli } \\
\mathrm{c} \mathrm{BP}^{\mathrm{h}}\end{array}$ \\
\hline
\end{tabular}

Note:

$* *$ p value $\leq 0.01$

$* p$ value $\leq 0.05$

${ }^{\mathrm{a}, \mathrm{b}}$ Diabetes distress (total score and subscores) was calculated using the Diabetes Distress Survey (DDS), which had 17 Likert scale questions. Response option included from $1=$ not a problem to $6=$ a very serious problem. Score range: $1-6$.

${ }^{\mathrm{f}} \mathrm{HbA1c}$ or glycosylated hemoglobin was measured in percentage.

${ }^{c}$ Diet score was calculated from the Lifestyle Profile II scale using nine Likert scale questions. Response options included never $=1$, sometimes $=2$, often $=3$, and routinely $=4$. Score range: 9-36.

${ }^{\mathrm{d}} \mathrm{PA}$ (physical activity) score was calculated from the Lifestyle Profile II scale using eight Likert scale questions. Response options included never $=1$, sometimes $=2$, often $=3$, and routinely $=4$. Score range: $8-32$.

${ }^{\mathrm{e}}$ Medication adherence was calculated using Morisky Medication Adherence Scale 8 (MMAS8) that had a total of eight questions. Score range: 0-8.

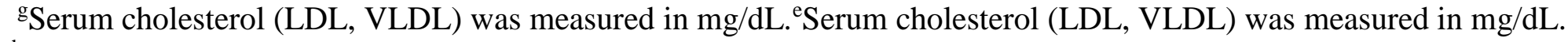

${ }^{\mathrm{h}}$ Blood pressure (systolic BP) was measured in $\mathrm{mm} \mathrm{Hg}$.

${ }^{i}$ Serum cortisol was measured in $\mathrm{mcg} / \mathrm{dL}$. 


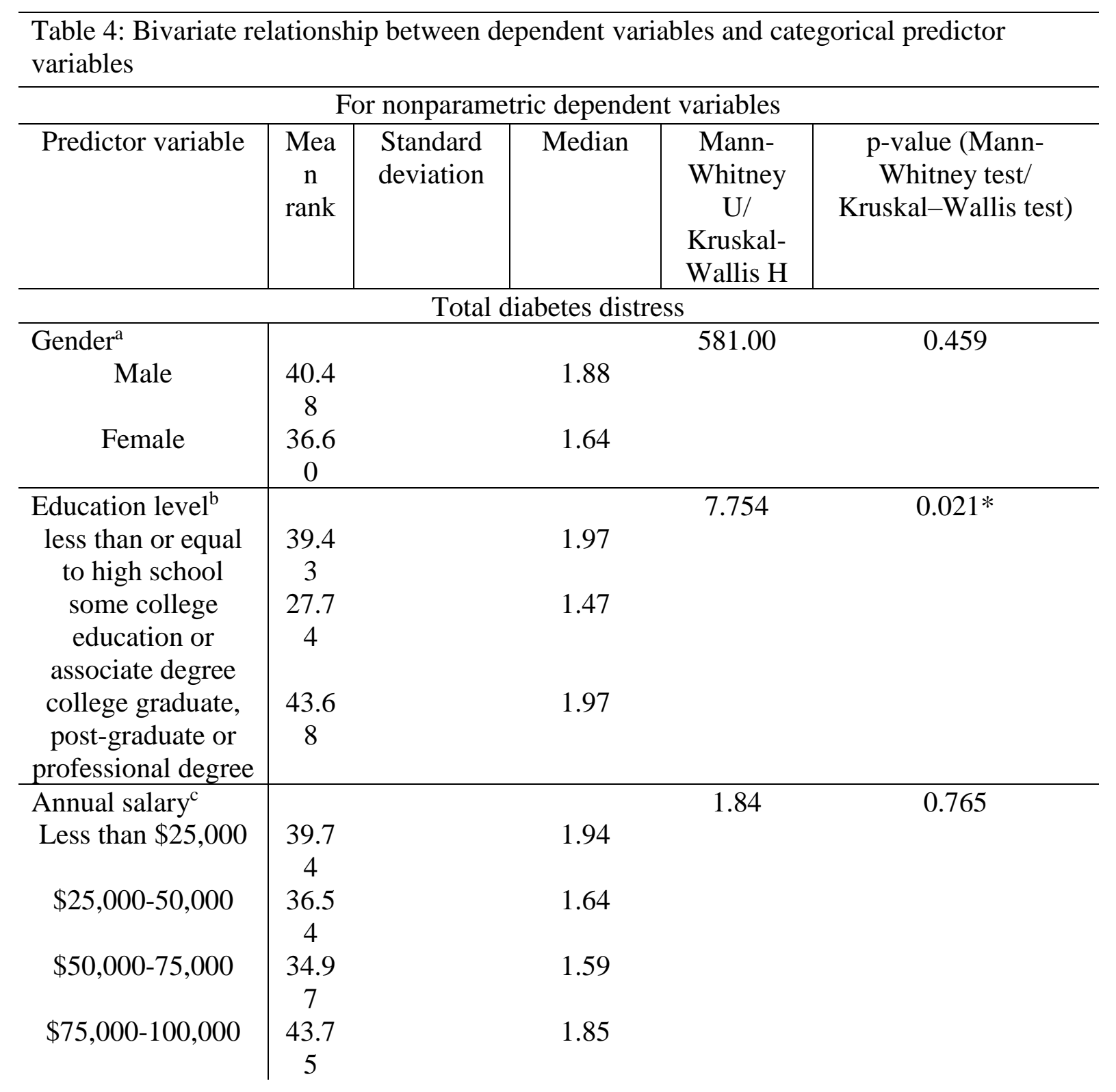




\begin{tabular}{|c|c|c|c|c|}
\hline $\begin{array}{c}\text { Greater than } \\
\$ 100,000\end{array}$ & $\begin{array}{c}27.5 \\
0 \\
\end{array}$ & 1.52 & & \\
\hline $\begin{array}{r}\text { Rural/Urban }^{\mathrm{d}} \\
\text { Rural }\end{array}$ & 38.2 & 2.00 & 619.00 & 0.951 \\
\hline Urban & $\begin{array}{c}2 \\
37.8 \\
9\end{array}$ & 1.73 & & \\
\hline Race $^{\mathrm{e}}$ & & & 283.00 & 0.558 \\
\hline Non-white & $\begin{array}{c}33.8 \\
0\end{array}$ & 1.44 & & \\
\hline White & $\begin{array}{c}38.0 \\
7\end{array}$ & 1.76 & & \\
\hline $\begin{array}{l}\text { Health insurance } \\
\text { No }\end{array}$ & $\begin{array}{c}31.0 \\
0\end{array}$ & 1.71 & 59.00 & 0.670 \\
\hline Yes & $\begin{array}{c}38.1 \\
9\end{array}$ & 1.76 & & \\
\hline $\begin{array}{l}\text { Family history of } \\
\text { diabetes }^{\mathrm{g}}\end{array}$ & & & 308.50 & 0.514 \\
\hline No & $\begin{array}{c}41.9 \\
5\end{array}$ & 1.76 & & \\
\hline Yes & $\begin{array}{c}37.3 \\
2\end{array}$ & 1.73 & & \\
\hline $\begin{array}{l}\text { Family history of } \\
\text { hypertension }\end{array}$ & & & 341.00 & 0.593 \\
\hline No & $\begin{array}{c}34.9 \\
2\end{array}$ & 1.56 & & \\
\hline Yes & $\begin{array}{c}38.5 \\
9\end{array}$ & 1.76 & & \\
\hline \multicolumn{5}{|c|}{ Emotional distress } \\
\hline $\begin{array}{r}\text { Gender }^{\mathrm{a}} \\
\text { Male }\end{array}$ & $\begin{array}{c}41.1 \\
1\end{array}$ & 1.80 & 564.00 & 0.348 \\
\hline
\end{tabular}




\begin{tabular}{|c|c|c|c|c|}
\hline Female & $\begin{array}{c}36.2 \\
5\end{array}$ & 1.40 & & \\
\hline $\begin{array}{l}\text { Education level } \\
\text { less than or equal } \\
\text { to high school } \\
\text { some college } \\
\text { education or } \\
\text { associate degree } \\
\text { college graduate, } \\
\text { post-graduate or } \\
\text { professional degree } \\
\end{array}$ & $\begin{array}{c}39.7 \\
9 \\
31.4 \\
8 \\
\\
41.2 \\
9\end{array}$ & $\begin{array}{l}1.80 \\
1.20\end{array}$ & 3.099 & 0.212 \\
\hline Annual salary ${ }^{\mathrm{c}}$ & & & 1.03 & 0.905 \\
\hline Less than $\$ 25,000$ & $\begin{array}{c}38.5 \\
7\end{array}$ & 1.60 & & \\
\hline$\$ 25,000-50,000$ & $\begin{array}{c}35.0 \\
2\end{array}$ & 1.40 & & \\
\hline$\$ 50,000-75,000$ & $\begin{array}{c}39.6 \\
2\end{array}$ & 1.80 & & \\
\hline$\$ 75,000-100,000$ & $\begin{array}{c}40.5 \\
0\end{array}$ & 1.50 & & \\
\hline $\begin{array}{c}\text { Greater than } \\
\$ 100,000\end{array}$ & $\begin{array}{c}30.6 \\
7\end{array}$ & 1.60 & & \\
\hline $\begin{array}{r}\text { Rural/Urban }^{\mathrm{d}} \\
\text { Rural }\end{array}$ & $\begin{array}{c}40.5 \\
2\end{array}$ & 1.60 & 562.00 & 0.473 \\
\hline Urban & $\begin{array}{c}36.7 \\
4 \\
\end{array}$ & 1.50 & & \\
\hline $\begin{array}{l}\text { Race }^{\mathrm{e}} \\
\quad \text { Non-white }\end{array}$ & $\begin{array}{c}32.6 \\
0\end{array}$ & 1.00 & 271.00 & 0.433 \\
\hline White & $\begin{array}{c}38.2 \\
7 \\
\end{array}$ & 1.60 & & \\
\hline Health insurance ${ }^{f}$ & & & 65.00 & 0.809 \\
\hline
\end{tabular}




\begin{tabular}{|c|c|c|c|c|}
\hline No & $\begin{array}{c}42.0 \\
0\end{array}$ & 1.90 & & \\
\hline Yes & $\begin{array}{c}37.8 \\
9\end{array}$ & 1.60 & & \\
\hline $\begin{array}{l}\text { Family history of } \\
\text { diabetes }^{\mathrm{g}}\end{array}$ & & & 278.50 & 0.265 \\
\hline No & $\begin{array}{c}44.6 \\
8\end{array}$ & 1.80 & & \\
\hline Yes & $\begin{array}{c}36.8 \\
5\end{array}$ & 1.60 & & \\
\hline $\begin{array}{l}\text { Family history of } \\
\text { hypertension }^{\mathrm{h}}\end{array}$ & & & 376.50 & 0.982 \\
\hline No & $\begin{array}{c}37.8 \\
8\end{array}$ & 1.40 & & \\
\hline Yes & $\begin{array}{c}38.5 \\
9\end{array}$ & 1.60 & & \\
\hline & & elated & & \\
\hline $\begin{array}{r}\text { Gender }^{\mathrm{a}} \\
\text { Male }\end{array}$ & $\begin{array}{c}36.7 \\
0\end{array}$ & 1.0 & 613.00 & 0.649 \\
\hline Female & $\begin{array}{c}38.7 \\
3\end{array}$ & 1.0 & & \\
\hline $\begin{array}{l}\text { Education level }^{\mathrm{b}} \\
\text { less than or equal } \\
\text { to high school }\end{array}$ & $\begin{array}{c}38.0 \\
7\end{array}$ & 1.00 & 0.714 & 0.700 \\
\hline $\begin{array}{l}\text { some college } \\
\text { education or }\end{array}$ & $\begin{array}{c}35.4 \\
1\end{array}$ & 1.00 & & \\
\hline $\begin{array}{l}\text { associate degree } \\
\text { college graduate, } \\
\text { post-graduate or } \\
\text { professional degree }\end{array}$ & $\begin{array}{c}39.5 \\
4\end{array}$ & 1.00 & & \\
\hline Annual salary ${ }^{\mathrm{c}}$ & & & 8.364 & 0.079 \\
\hline
\end{tabular}




\begin{tabular}{|c|c|c|c|c|}
\hline Less than $\$ 25,000$ & 42.5 & 1.00 & & \\
\hline$\$ 25,000-50,000$ & $\begin{array}{c}37.8 \\
4\end{array}$ & 1.00 & & \\
\hline$\$ 50,000-75,000$ & $\begin{array}{c}28.9 \\
1\end{array}$ & 1.00 & & \\
\hline$\$ 75,000-100,000$ & $\begin{array}{c}45.8 \\
8\end{array}$ & 1.25 & & \\
\hline $\begin{array}{c}\text { Greater than } \\
\$ 100,000\end{array}$ & $\begin{array}{c}26.0 \\
0\end{array}$ & 1.00 & & \\
\hline $\begin{array}{c}\text { Rural/Urban }^{\mathrm{d}} \\
\text { Rural }\end{array}$ & 35.8 & 1.00 & 570.00 & 0.466 \\
\hline & $\begin{array}{c}0 \\
39.1 \\
0\end{array}$ & 1.00 & & \\
\hline Race $^{\mathrm{e}}$ & & & 319.50 & 0.993 \\
\hline Non-white & $\begin{array}{c}37.4 \\
5\end{array}$ & 1.00 & & \\
\hline White & $\begin{array}{c}37.5 \\
1 \\
\end{array}$ & 1.00 & & \\
\hline $\begin{array}{c}\text { Health insurance } \\
\text { No }\end{array}$ & $\begin{array}{c}26.0 \\
0\end{array}$ & 1.00 & 49.00 & 0.468 \\
\hline Yes & $\begin{array}{c}38.3 \\
3\end{array}$ & 1.00 & & \\
\hline $\begin{array}{l}\text { Family history of } \\
\text { diabetes }^{\mathrm{g}}\end{array}$ & & & 339.00 & 0.818 \\
\hline No & $\begin{array}{c}36.8 \\
2\end{array}$ & 1.00 & & \\
\hline Yes & $\begin{array}{c}38.2 \\
0\end{array}$ & 1.00 & & \\
\hline $\begin{array}{l}\text { Family history of } \\
\text { hypertension }^{\text {h }}\end{array}$ & & & 0.11 & 0.753 \\
\hline
\end{tabular}




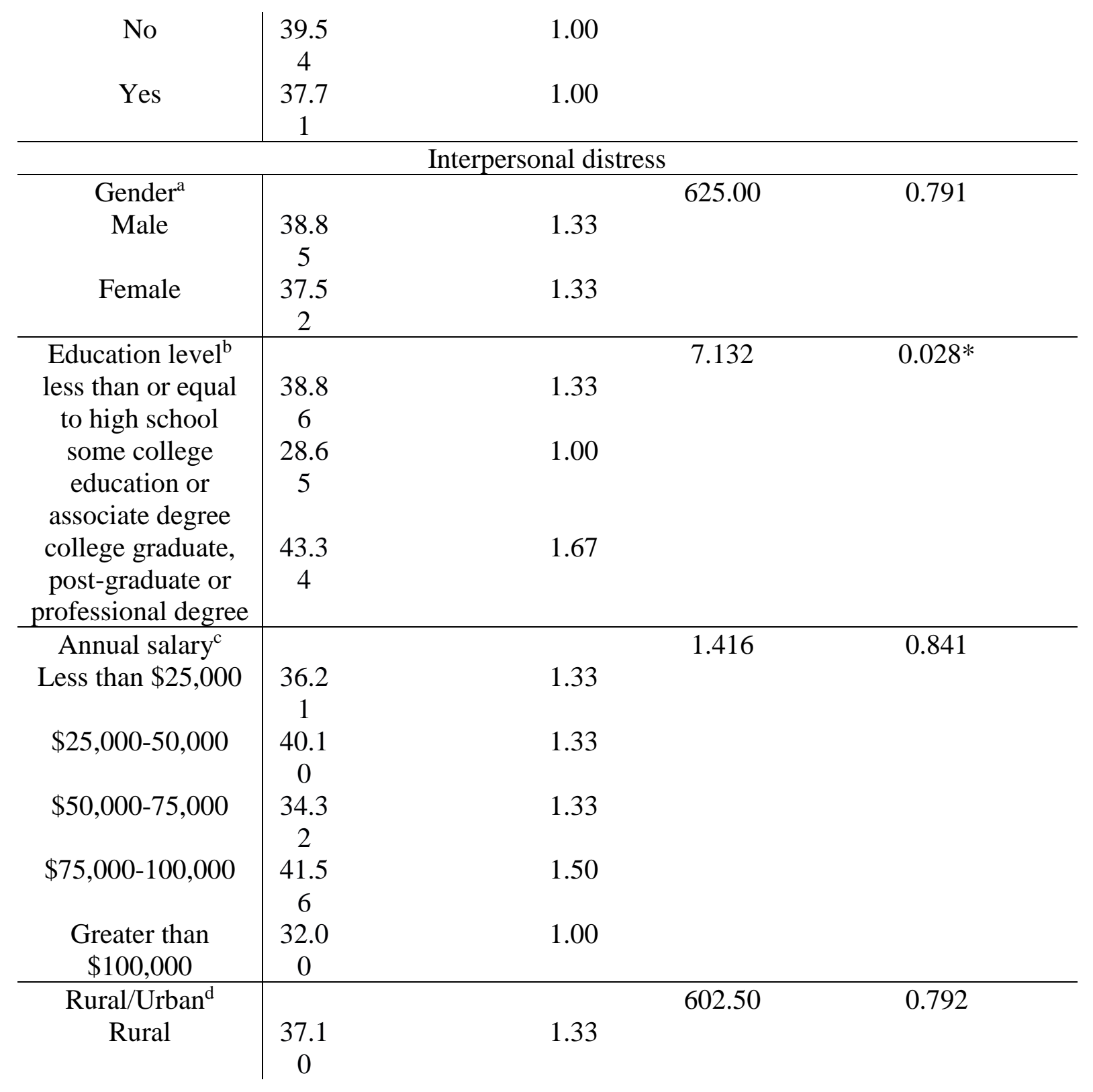




\begin{tabular}{|c|c|c|c|c|}
\hline Urban & $\begin{array}{c}38.4 \\
5\end{array}$ & 1.33 & & \\
\hline Race $^{\mathrm{e}}$ & & & \multirow[t]{5}{*}{219.50} & \multirow[t]{5}{*}{0.098} \\
\hline Non white & 27.4 & 1.00 & & \\
\hline & 5 & & & \\
\hline White & 39.0 & 1.33 & & \\
\hline & 7 & & & \\
\hline Health insurance ${ }^{f}$ & & & \multirow[t]{5}{*}{66.00} & \multirow[t]{5}{*}{0.833} \\
\hline No & 41.5 & 1.00 & & \\
\hline & 0 & & & \\
\hline Yes & 37.9 & 1.00 & & \\
\hline & 0 & & & \\
\hline Family history of & & & \multirow[t]{5}{*}{265.00} & \multirow[t]{5}{*}{0.173} \\
\hline diabetes ${ }^{2}$ & & & & \\
\hline No & $\begin{array}{c}45.9 \\
1\end{array}$ & 1.67 & & \\
\hline Yes & 36.6 & 133 & & \\
\hline & 4 & & & \\
\hline Family history of & & & \multirow[t]{6}{*}{356.00} & \multirow[t]{6}{*}{0.740} \\
\hline hypertension ${ }^{\mathrm{h}}$ & & & & \\
\hline No & 39.8 & 1.33 & & \\
\hline & 3 & & & \\
\hline \multirow[t]{2}{*}{ Yes } & 37.6 & 1.33 & & \\
\hline & 5 & & & \\
\hline
\end{tabular}

For parametric dependent variables

\begin{tabular}{c|ccccc}
\hline Predictor variable & $\begin{array}{c}\text { Mea } \\
\mathrm{n}\end{array}$ & $\begin{array}{c}\text { Standard } \\
\text { deviation }\end{array}$ & Median & F statistics & p-value (ANOVA) \\
\hline \multicolumn{5}{c}{ Regimen-related distress } \\
\hline Gender $^{\mathrm{a}}$ & & 0.08 & 0.77 \\
Male & 2.66 & 1.19 & & \\
Female & 2.58 & 1.32 & 3.183 & $0.05^{*}$
\end{tabular}




\begin{tabular}{|c|c|c|c|c|}
\hline $\begin{array}{l}\text { less than or equal } \\
\text { to high school } \\
\text { some college } \\
\text { education or } \\
\text { associate degree } \\
\text { college graduate, } \\
\text { post-graduate or } \\
\text { professional degree }\end{array}$ & $\begin{array}{l}2.83 \\
2.08\end{array}$ & $\begin{array}{l}1.35 \\
1.30\end{array}$ & & \\
\hline $\begin{array}{l}\text { Annual salary } \\
\text { Less than } \$ 25,000 \\
\$ 25,000-50,000 \\
\$ 50,000-75,000 \\
\$ 75,000-100,000 \\
\text { Greater than } \\
\$ 100,000\end{array}$ & $\begin{array}{l}2.68 \\
2.66 \\
2.33 \\
3.10 \\
2.00\end{array}$ & $\begin{array}{l}1.43 \\
1.35 \\
1.05 \\
1.35 \\
0.52\end{array}$ & 0.79 & 0.54 \\
\hline $\begin{array}{r}\text { Rural/Urban }^{\mathrm{d}} \\
\text { Rural } \\
\text { Urban } \\
\end{array}$ & $\begin{array}{l}2.66 \\
2.59 \\
\end{array}$ & $\begin{array}{l}1.27 \\
1.27 \\
\end{array}$ & 0.06 & 0.80 \\
\hline $\begin{array}{l}\text { Race }^{\mathrm{e}} \\
\text { Non-White } \\
\text { White }\end{array}$ & $\begin{array}{l}2.00 \\
2.61 \\
\end{array}$ & $\begin{array}{l}0.86 \\
1.23 \\
\end{array}$ & 1.88 & 0.17 \\
\hline $\begin{array}{c}\text { Health insurance }^{\mathrm{f}} \\
\text { No } \\
\text { Yes } \\
\end{array}$ & $\begin{array}{l}2.31 \\
2.63 \\
\end{array}$ & $\begin{array}{l}0.94 \\
1.29 \\
\end{array}$ & 0.41 & 0.53 \\
\hline $\begin{array}{c}\text { Family history of } \\
\text { diabetes }^{\mathrm{g}} \\
\text { No } \\
\text { Yes }\end{array}$ & $\begin{array}{l}2.93 \\
2.56\end{array}$ & $\begin{array}{l}1.60 \\
1.21\end{array}$ & 0.91 & 0.34 \\
\hline $\begin{array}{c}\text { Family history of } \\
\text { hypertension }^{\mathrm{h}} \\
\text { No } \\
\text { Yes }\end{array}$ & $\begin{array}{l}2.60 \\
2.61\end{array}$ & $\begin{array}{l}1.39 \\
1.25\end{array}$ & $<0.01$ & 0.98 \\
\hline
\end{tabular}




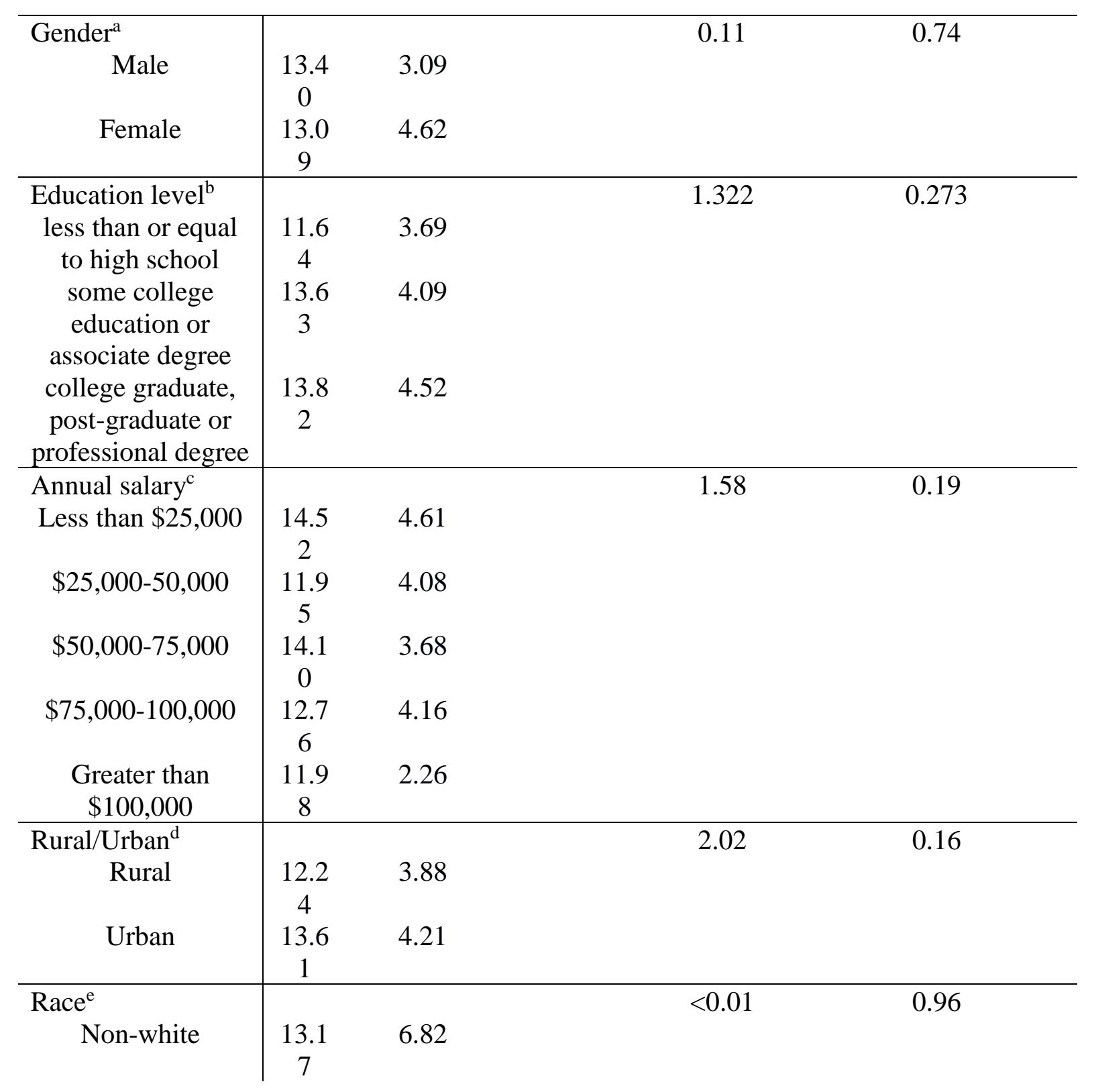




\begin{tabular}{c|cccc} 
White & 13.2 & 3.91 & 0.82 & 0.37 \\
\hline $\begin{array}{c}\text { Health insurance } \\
\text { No }\end{array}$ & $\begin{array}{c}11.7 \\
2\end{array}$ & 3.52 & & \\
Yes & 13.3 & 4.18 & & \\
& 1 & & & 0.29 \\
Family history of $_{\text {diabetes }}^{\text {g }}$ & & & & \\
No & 14.3 & 4.46 & & \\
Yes & 8 & & & \\
\hline $\begin{array}{c}\text { Family history of } \\
\text { hypertension }\end{array}$ & 13.0 & 4.08 & 3.91 & \\
No & 15.4 & 5.03 & & \\
Yes & 6 & & & \\
\hline
\end{tabular}

Note:

$*$ p value $\leq 0.05$

${ }^{\mathrm{a}}$ Gender: a categorical variable with two categories (male, female).

${ }^{b}$ Education level: a categorical variable with three categories (less than or equal to high school, some college education or associate degree, and college graduate, post-graduate or professional degree.

${ }^{c}$ Annual salary: a categorical variable with five categories (less than $\$ 25,500, \$ 25000$ $50,000, \$ 50,000-75,000, \$ 75,000-100,000$, greater than $\$ 100,000$ ).

${ }^{\mathrm{d}}$ Rural/Urban: a categorical variable with two categories (rural, urban).

${ }^{\text {e}}$ Race: a categorical variable which was recategorized into two categories (Non-white, white).

${ }^{\mathrm{f}}$ Health insurance: a categorical variable with two categories (yes, no).

${ }^{g}$ Family history of diabetes: a categorical variable with two categories (yes, no).

${ }^{\text {h}}$ Family history of BP: a categorical variable with two categories (yes, no). 
Table 5. Repeated measures linear mixed model to assess change in diabetes distress from baseline to 6-month follow-up for adults with diabetes and comorbid hypertension who participated in the DHSMP

\begin{tabular}{|c|c|c|c|c|c|}
\hline \multicolumn{6}{|c|}{ Total diabetes distress } \\
\hline \multirow{2}{*}{ Covariates } & \multirow{2}{*}{$\begin{array}{c}\text { Coefficient (effect)/ } \\
\text { Slope }\end{array}$} & \multirow{2}{*}{$\begin{array}{l}\text { Std Error } \\
\quad(\mathrm{SE})\end{array}$} & \multirow{2}{*}{ p-value } & \multicolumn{2}{|c|}{$95 \% \mathrm{CI}$} \\
\hline & & & & Lower & Upper \\
\hline $\begin{array}{l}\text { Glycosylated } \\
\text { hemoglobin }\end{array}$ & 0.124 & 0.04 & $<0.01 * *$ & 0.038 & 0.210 \\
\hline $\begin{array}{l}\text { Blood pressure } \\
\quad \text { (systolic) }\end{array}$ & $<0.001$ & $<0.01$ & 0.602 & -0.001 & 0.001 \\
\hline $\begin{array}{l}\text { Serum cholesterol } \\
\text { (LDL) }\end{array}$ & 0.003 & $<0.01$ & $0.04 *$ & $<0.001$ & 0.007 \\
\hline $\operatorname{Diet}^{\mathrm{d}}$ & -0.246 & 0.11 & $0.02 *$ & -0.455 & -0.037 \\
\hline Physical activity $^{\mathrm{c}}$ & -0.017 & 0.08 & 0.831 & -0.176 & 0.141 \\
\hline $\begin{array}{l}\text { Medication } \\
\text { adherence }^{b}\end{array}$ & -0.083 & 0.03 & $0.01 *$ & -0.148 & -0.018 \\
\hline $\begin{array}{l}\text { Education level } \\
\text { (Some college } \\
\text { education or } \\
\text { associate degree) }\end{array}$ & -0.119 & 0.23 & 0.606 & -0.576 & 0.338 \\
\hline $\begin{array}{l}\text { Education level } \\
\text { (College graduate, } \\
\text { post-graduate or } \\
\text { professional degree) }\end{array}$ & 0.331 & 0.22 & 0.133 & -0.103 & 0.765 \\
\hline
\end{tabular}




\begin{tabular}{|c|c|c|c|c|c|}
\hline Time $(12 w)$ & -0.033 & 0.08 & 0.664 & -0.183 & 0.117 \\
\hline Time $(24 w)$ & -0.157 & 0.08 & $0.04 *$ & -0.309 & -0.004 \\
\hline \multicolumn{6}{|c|}{ Emotional distress } \\
\hline \multirow{2}{*}{ Covariates } & \multirow{2}{*}{$\begin{array}{c}\text { Coefficient (effect) } \\
\text { / Slope }\end{array}$} & \multirow{2}{*}{$\begin{array}{l}\text { Std Error } \\
\quad(\mathrm{SE})\end{array}$} & \multirow{2}{*}{ p-value } & \multicolumn{2}{|c|}{$95 \% \mathrm{CI}$} \\
\hline & & & & Lower & Lower \\
\hline $\begin{array}{l}\text { Glycosylated } \\
\text { hemoglobin }\end{array}$ & 0.131 & 0.06 & $0.04 *$ & 0.010 & 0.253 \\
\hline $\begin{array}{l}\text { Blood pressure } \\
\text { (systolic) }\end{array}$ & -0.001 & $<0.01$ & 0.397 & -0.002 & 0.001 \\
\hline $\begin{array}{l}\text { Serum cholesterol } \\
\text { (LDL) }\end{array}$ & 0.002 & $<0.01$ & 0.385 & -0.003 & 0.007 \\
\hline $\operatorname{Diet}^{d}$ & -0.334 & 0.15 & $0.03 *$ & -0.629 & -0.039 \\
\hline Physical activity $^{\mathrm{c}}$ & 0.054 & 0.11 & 0.631 & -0.169 & 0.278 \\
\hline $\begin{array}{l}\text { Medication } \\
\text { adherence }^{b}\end{array}$ & -0.109 & 0.05 & $0.02 *$ & -0.201 & -0.018 \\
\hline $\begin{array}{l}\text { Education level } \\
\text { (Some college } \\
\text { education or } \\
\text { associate degree) })^{\mathrm{e}}\end{array}$ & -0.157 & 0.33 & 0.635 & -0.811 & 0.497 \\
\hline $\begin{array}{c}\text { Education level } \\
\text { (College graduate, } \\
\text { post-graduate or } \\
\text { professional degree })^{\mathrm{e}}\end{array}$ & 0.173 & 0.31 & 0.580 & -0.447 & 0.793 \\
\hline
\end{tabular}




\begin{tabular}{c|c|c|c|c|c}
\hline Time $(12 \mathrm{w})$ & 0.036 & 0.11 & 0.736 & -0.174 & 0.245 \\
\hline Time $(24 \mathrm{w})$ & -0.094 & 0.11 & 0.386 & -0.308 & 0.120 \\
\hline
\end{tabular}

Physician-related distress

\begin{tabular}{|c|c|c|c|c|c|}
\hline \multirow{2}{*}{ Covariates } & \multirow{2}{*}{$\begin{array}{c}\text { Coefficient (effect) } \\
\text { / Slope }\end{array}$} & \multirow{2}{*}{$\begin{array}{l}\text { Std Error } \\
\quad(\mathrm{SE})\end{array}$} & \multirow{2}{*}{$\mathrm{p}$-value } & \multicolumn{2}{|c|}{$95 \% \mathrm{CI}$} \\
\hline & & & & Lower & Lower \\
\hline $\begin{array}{l}\text { Glycosylated } \\
\text { hemoglobin }\end{array}$ & $<0.001$ & $<0.01$ & 0.842 & -0.001 & 0.001 \\
\hline $\begin{array}{l}\text { Blood pressure } \\
\text { (systolic) }\end{array}$ & $<0.001$ & $<0.01$ & 0.842 & -0.001 & 0.001 \\
\hline $\begin{array}{l}\text { Serum cholesterol } \\
\text { (LDL) }\end{array}$ & 0.005 & $<0.01$ & $0.01 *$ & 0.001 & 0.008 \\
\hline $\operatorname{Diet}^{\mathrm{d}}$ & -0.110 & 0.11 & 0.327 & -0.332 & 0.111 \\
\hline Physical activity $^{\mathrm{c}}$ & 0.105 & 0.08 & 0.214 & -0.061 & 0.272 \\
\hline $\begin{array}{l}\text { Medication } \\
\text { adherence }^{b}\end{array}$ & -0.001 & 0.03 & 0.985 & -0.069 & 0.068 \\
\hline $\begin{array}{l}\text { Education level } \\
\text { (Some college } \\
\text { education or } \\
\text { associate degree) }\end{array}$ & 0.004 & 0.23 & 0.985 & -0.460 & 0.469 \\
\hline $\begin{array}{c}\text { Education level } \\
\text { (College graduate, } \\
\text { post-graduate or } \\
\text { professional degree) }\end{array}$ & 0.335 & 0.22 & 0.133 & -0.105 & 0.776 \\
\hline
\end{tabular}




\begin{tabular}{|c|c|c|c|c|c|}
\hline Time $(12 w)$ & 0.046 & 0.08 & 0.567 & -0.113 & 0.206 \\
\hline Time $(24 w)$ & -0.112 & 0.08 & 0.175 & -0.275 & 0.051 \\
\hline \multicolumn{6}{|c|}{ Regimen-related distress } \\
\hline \multirow{2}{*}{ Covariates } & \multirow{2}{*}{$\begin{array}{c}\text { Coefficient (effect) } \\
\text { / Slope }\end{array}$} & \multirow{2}{*}{$\begin{array}{l}\text { Std Error } \\
\quad(\mathrm{SE})\end{array}$} & \multirow{2}{*}{ p-value } & \multicolumn{2}{|c|}{$95 \% \mathrm{CI}$} \\
\hline & & & & Lower & Lower \\
\hline $\begin{array}{l}\text { Glycosylated } \\
\text { hemoglobin }\end{array}$ & 0.239 & 0.06 & $<0.01 *$ & 0.125 & 0.353 \\
\hline $\begin{array}{l}\text { Blood pressure } \\
\text { (systolic) }\end{array}$ & -0.001 & $<0.01$ & 0.513 & -0.002 & 0.001 \\
\hline $\begin{array}{l}\text { Serum cholesterol } \\
\text { (LDL) }\end{array}$ & 0.004 & $<0.01$ & 0.051 & $<-0.001$ & 0.009 \\
\hline $\operatorname{Diet}^{\mathrm{d}}$ & -0.374 & 0.15 & $0.02 *$ & -0.674 & -0.074 \\
\hline Physical activity ${ }^{\mathrm{c}}$ & -0.115 & 0.11 & 0.31 & -0.335 & 0.106 \\
\hline $\begin{array}{l}\text { Medication } \\
\text { adherence }^{\mathrm{b}}\end{array}$ & -0.127 & 0.05 & $0.01 *$ & -0.218 & -0.035 \\
\hline $\begin{array}{c}\text { Education level } \\
\text { (Some college } \\
\text { education or } \\
\text { associate degree) }\end{array}$ & -0.199 & 0.27 & 0.46 & -0.732 & 0.333 \\
\hline $\begin{array}{l}\text { Education level } \\
\text { (College graduate, } \\
\text { post-graduate or } \\
\text { professional degree) }\end{array}$ & 0.291 & 0.25 & 0.25 & -0.214 & 0.797 \\
\hline
\end{tabular}




\begin{tabular}{|c|c|c|c|c|c|}
\hline Time $(12 w)$ & -0.301 & 0.11 & $0.01 *$ & -0.523 & -0.078 \\
\hline Time $(24 w)$ & -0.337 & 0.12 & $<0.01^{*}$ & -0.566 & -0.107 \\
\hline \multicolumn{6}{|c|}{ Interpersonal distress } \\
\hline \multirow{2}{*}{ Covariates } & \multirow{2}{*}{$\begin{array}{c}\text { Coefficient (effect) } \\
\text { / Slope }\end{array}$} & \multirow{2}{*}{$\begin{array}{l}\text { Std Error } \\
\quad(\mathrm{SE})\end{array}$} & \multirow{2}{*}{$\mathrm{p}$-value } & \multicolumn{2}{|c|}{$95 \% \mathrm{CI}$} \\
\hline & & & & Lower & Lower \\
\hline $\begin{array}{l}\text { Glycosylated } \\
\text { hemoglobin }\end{array}$ & 0.022 & 0.06 & 0.72 & -0.101 & 0.146 \\
\hline $\begin{array}{l}\text { Blood pressure } \\
\text { (systolic) }\end{array}$ & $<0.001$ & $<0.01$ & 0.96 & -0.002 & 0.002 \\
\hline $\begin{array}{l}\text { Serum cholesterol } \\
\text { (LDL) }\end{array}$ & 0.003 & $<0.01$ & 0.24 & -0.002 & 0.008 \\
\hline $\operatorname{Diet}^{\mathrm{d}}$ & -0.033 & 0.16 & 0.84 & -0.355 & 0.289 \\
\hline Physical activity $^{\mathrm{c}}$ & -0.136 & 0.12 & 0.26 & -0.373 & 0.102 \\
\hline $\begin{array}{l}\text { Medication } \\
\text { adherence }^{\text {b }}\end{array}$ & -0.108 & 0.05 & $0.03 *$ & -0.206 & -0.010 \\
\hline $\begin{array}{c}\text { Education level } \\
\text { (Some college } \\
\text { education or } \\
\text { associate degree) }\end{array}$ & 0.004 & 0.29 & 0.99 & -0.578 & 0.586 \\
\hline $\begin{array}{c}\text { Education level } \\
\text { (College graduate, } \\
\text { post-graduate or } \\
\text { professional degree) }^{\mathrm{e}}\end{array}$ & 0.613 & 0.28 & $0.03 *$ & 0.061 & 1.165 \\
\hline
\end{tabular}




\begin{tabular}{|c|c|c|c|c|c|}
\hline Time (12w) & 0.136 & 0.12 & 0.26 & -0.101 & 0.374 \\
\hline Time $(24 w)$ & -0.078 & 0.12 & 0.53 & -0.322 & 0.167 \\
\hline \multicolumn{6}{|c|}{ Serum cortisol } \\
\hline \multirow{2}{*}{ Covariates } & \multirow{2}{*}{$\begin{array}{c}\text { Coefficient (effect) } \\
\text { / Slope }\end{array}$} & \multirow{2}{*}{$\begin{array}{l}\text { Std Error } \\
\quad(\mathrm{SE})\end{array}$} & \multirow{2}{*}{$\mathrm{p}$-value } & \multicolumn{2}{|c|}{$95 \% \mathrm{CI}$} \\
\hline & & & & Lower & Lower \\
\hline $\begin{array}{l}\text { Glycosylated } \\
\text { hemoglobin }\end{array}$ & -0.378 & 0.25 & 0.14 & -0.883 & 0.127 \\
\hline $\begin{array}{l}\text { Blood pressure } \\
\text { (systolic) }\end{array}$ & -0.005 & $<0.01$ & 0.29 & -0.014 & 0.004 \\
\hline $\begin{array}{l}\text { Serum cholesterol } \\
\text { (VLDL) }\end{array}$ & 0.076 & 0.03 & $<0.01 *$ & 0.026 & 0.126 \\
\hline $\operatorname{Diet}^{\mathrm{d}}$ & -0.681 & 0.73 & 0.35 & -2.121 & 0.758 \\
\hline Physical activity ${ }^{\mathrm{c}}$ & 0.477 & 0.52 & 0.36 & -0.543 & 1.498 \\
\hline $\begin{array}{l}\text { Medication } \\
\text { adherence }^{\mathrm{b}}\end{array}$ & -0.112 & 0.21 & 0.60 & -0.535 & 0.311 \\
\hline $\begin{array}{l}\text { Education level } \\
\text { (Some college } \\
\text { education or } \\
\text { associate degree) }\end{array}$ & 1.028 & 1.02 & 0.32 & -1.003 & 3.059 \\
\hline $\begin{array}{c}\text { Education level } \\
\text { (College graduate, } \\
\text { post-graduate or } \\
\text { professional degree) }\end{array}$ & 1.318 & 0.96 & 0.17 & -0.597 & 3.233 \\
\hline
\end{tabular}




\begin{tabular}{c|c|c|c|c|c}
\hline Time $(12 \mathrm{w})$ & -0.046 & 0.61 & 0.94 & -1.242 & 1.149 \\
\hline Time $(24 \mathrm{w})$ & -0.761 & 0.62 & 0.22 & -1.990 & 0.468 \\
\hline
\end{tabular}

Note:

$* * p$ value $\leq 0.01$.

$* \mathrm{p}$ value $\leq 0.05$

CI: Confidence interval.

${ }^{\mathrm{b}}$ Medication adherence was calculated using Morisky Medication Adherence Scale 8

(MMAS8) that had total of eight questions. Score range: 0-8.

${ }^{\mathrm{c}} \mathrm{PA}$ (physical activity) score was calculated from the Lifestyle Profile II scale using eight

Likert scale questions. Response options included never $=1$, sometimes $=2$, often $=3$, and routinely $=4$. Score range: $8-32$.

${ }^{\mathrm{d}}$ Diet score was calculated from the Lifestyle Profile II scale using nine Likert scale questions.

Response options included never $=1$, sometimes $=2$, often $=3$, and routinely $=4$. Score

range: 9-36.

eEducation level was categorized into three categories: less than or equal to high school, some college education or associate degree, and college graduate, post-graduate or professional

degree.

eSerum cholesterol (LDL, VLDL) was measured in $\mathrm{mg} / \mathrm{dL}$.

fSystolic blood pressure was measured in $\mathrm{mm} / \mathrm{Hg}$.

gSerum cortisol was measured in $\mathrm{mcg} / \mathrm{dL}$.

gDiabetes distress (total score, and sub-scores) was calculated using Diabetes Distress Survey

17 (DDS17) which had total 17 Likert scale question. Response option included from $11=$ not

a problem to $6=$ a very serious problem. Score range: $1-6$. 
Table 6. Number of participants at each

assessment

\begin{tabular}{l|l|l|l}
\hline & Baseline & $\begin{array}{c}12 \\
\text { Weeks }\end{array}$ & 24 Weeks \\
\hline Intervention & 44 & 40 & 36 \\
\hline $\begin{array}{l}\text { Wait-listed } \\
\text { control group }\end{array}$ & 45 & 45 & 45 \\
\hline Total & 89 & 85 & 81 \\
\hline
\end{tabular}




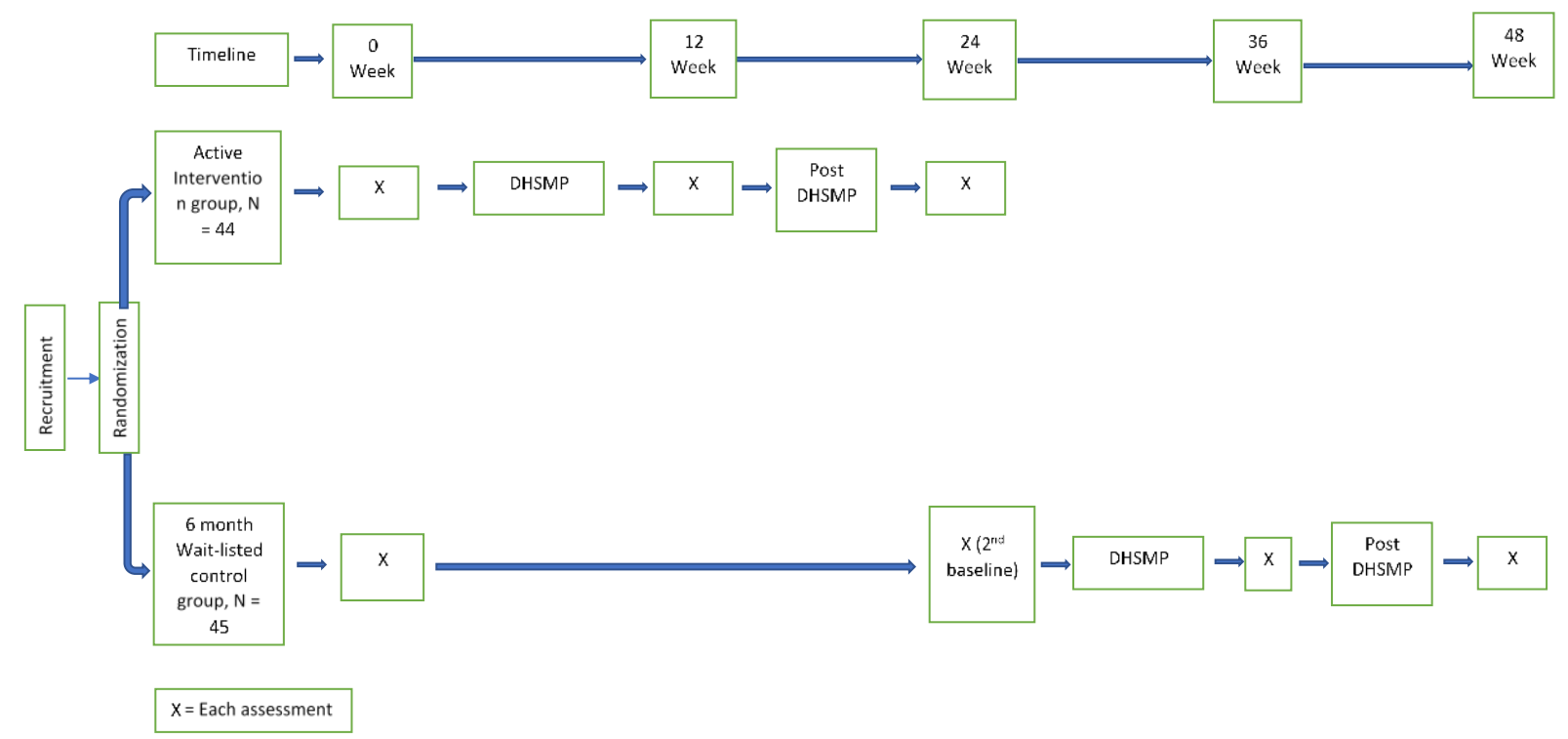

Figure 1. Study design schema. 


\section{Chapter 4}

\section{Aim 3a: To understanding everyday lived experiences and challenges to managing diabetes and its related distress among participants in a self- management program}

\section{Aim 3b: To explore the efficacy of DHSMP participation on the participants' reported improvement in diabetes self-management behaviors and reducing diabetes-related distress}

\subsection{Introduction/ Background}

Type 2 Diabetes Mellitus (T2DM) is a highly prevalent chronic disease. The global prevalence of diabetes among adults will increase from 460 million in 2019 to 700 million by $2045{ }^{1,2}$ In the USA, 34.1 million adults (13\% of the population) have T2DM. ${ }^{3,4}$ The majority $(\sim 90 \%)$ of individuals with diabetes in the United States have T2DM. ${ }^{1,2}$ In West Virginia, which has the highest prevalence of diabetes in the country, 219,000 individuals (15.7\% of the population) are diagnosed with diabetes. ${ }^{5,6}$ In addition, undiagnosed cases or 45,000 individuals are unaware of their diabetes status and comprise $3.2 \%$ of the cases in $\mathrm{WV} .{ }^{5} \mathrm{~T} 2 \mathrm{DM}$ has many micro and macrovascular health complications. It is the seventh $\left(7^{\text {th }}\right)$ leading cause of death in the USA. ${ }^{4}$ T2DM is associated with low health-related quality of life (HRQoL). ${ }^{7}$ The economic burden of diabetes in the United States, related to the total diabetes medication expenditure, is $\$ 327$ billion. ${ }^{8}$ Locally, the economic burden of diabetes is similarly high in WV; people with diabetes spent $\$ 1.7$ billion in 2017 for treatment. ${ }^{5,9,10}$

T2DM is defined as a condition when insulin production is ineffective along with a gradual deficiency of insulin and/or the body's inability to respond to insulin. ${ }^{11}$ Diabetes affects not only physical well-being but also the psychological well-being of an individual. The psychological 
stress of living with diabetes and the self-care necessary to manage the disease is different from anxiety and clinical depression. ${ }^{12}$ Diabetes distress is defined as an emotional response to the worries, concerns, fears, and threats that are associated with a demanding chronic disease over time, including its management, threats of complications, potential loss of functioning, and concerns about access to care. ${ }^{13}$

Diabetes distress can be measured using different patient-reported measures, such as Problem Areas in Diabetes Scale (PAID), Questionnaire on Stress in Patients with Diabetes-Revised (QSD-R), Diabetes Knowledge Scale (ATT39), Diabetes Distress Scale (DDS). ${ }^{14-18}$ While each of these measures assesses diabetes distress, some are reported to be confusing to patients (e.g., QSD-R) and do not include all the aspects of diabetes distress in detail (e.g., PAID). ${ }^{15}$ Furthermore, ATT39 and QSD-R measures are extensive and increase participant burden due to the time to complete. ${ }^{15}$ Hence, the validated Diabetes Distress Scale (DDS) measure, a 17-item Likert scale, is currently used in the literature. ${ }^{15}$ The DDS was developed by Polonsky et al, and includes four subtypes of distress that are commonly reported by T2DM individuals: emotional distress, interpersonal distress, physician-related distress, and regimen-related distress. ${ }^{15}$ Emotional distress includes the person's anxieties and worries related to the disease and associated complications. ${ }^{12}$ Interpersonal distress occurs due to a lack of support and understanding from family members and friends. ${ }^{12}$ Provider or physician-related distress includes the stress that is formed due to lack of communication between the patient and the health care provider and worries about access to adequate treatment, trust, and care from the health care provider. ${ }^{12}$ Regimen-related distress includes stress related to managing the disease, such as maintaining a healthy diet, adequate physical activity, regular blood glucose checkup, taking medicines, and insulin regularly as prescribed. ${ }^{12}$ Previous research has shown diabetes 
distress is negatively associated with patients' adherence to diabetes treatment and management strategy, quality of life, poor glycemic status, and mental health issues (e.g., depression) in T2DM individuals. ${ }^{19-25}$

Individuals with diabetes make self-management decisions on a daily basis and perform regular activities to manage their chronic conditions, including diabetes and its comorbidities. Diabetes self-management education (DSME) programs are created to help people with diabetes learn important skills and gain knowledge on their disease condition and management. ${ }^{26}$ DSME programs are found to be highly effective in improving health outcomes and reducing overall healthcare costs. ${ }^{27}$ Vermunt et al showed that people at risk of T2DM, who participated in a randomized controlled trial of DSME programs, significantly reduced fasting plasma glucose level, BMI, and total energy intake. ${ }^{28}$ Researchers in the United Kingdom found that participants of self-management programs who regularly monitored and managed their glycemic status reduced micro and macrovascular damages from diabetes. ${ }^{29,}{ }^{30}$ Participants of DSME programs also had reduced hospitalization rates and lowered their health care expenditure. ${ }^{31}$ In rural areas, T2DM individuals benefit from DSME program participation in improving their glycemic status. ${ }^{32}$ In a joint position statement, the American Diabetes Association, the American Association of Diabetes Educators, and the Academy of Nutrition and Dietetics mentioned that participation in DSME programs reduced diabetes distress. ${ }^{27}$ Although DSME programs have been successful in helping patients manage their diabetes and related complications ${ }^{33}$, however, challenges are noted for program participation. For example, most of these programs are for extended periods (up to 18 months) ${ }^{33}$ and require the participants' dedication and regularity towards the successful program completion, long-term management activities, and adherence to healthy lifestyle behaviors. ${ }^{33}$ 
Adherence and long-term management of healthy lifestyle behaviors and the disease create a burden of diabetes and can be highly stressful in many patients' everyday lives. Nascent literature exists on patients' everyday lived experiences and challenges. However, the existing literature focuses on the experience of older adults and urban populations living with T2DM..$^{33,34}$ For example, Hernandez and his colleagues observed challenging relationships with healthcare providers, fear, guilt, and forgetfulness among the geriatric population with T2DM. ${ }^{34}$ In another study, researchers noted an existing knowledge gap on the burden of diabetes among the rural population in the USA. ${ }^{35}$ In a qualitative study conducted by Pal and colleagues, participants shared concerns about their unmet needs for diabetes self-management and the effects of diabetes in their physical and psychological health and social life. ${ }^{36}$ In a study conducted among older urban Singaporean adults to explore their expectations, needs, and barriers related to diabetes self-management programs, the participants perceived self-management to be a difficult task and considered their health care providers as important facilitators of self-management. ${ }^{37}$

Social scientists and anthropologists use qualitative research to engage in naturalistic inquiry and studies in real-world settings to produce rich narrative descriptions. ${ }^{38,39}$ Through inductive analysis across cases, qualitative studies provide patterns and themes as the 'fruit' of qualitative research. ${ }^{38}$ While qualitative studies are different from epidemiological or quantitative studies; approaches are often complementary. ${ }^{40}$ Use of qualitative methods has become more mainstream in health sciences disciplines over the past several decades ${ }^{41}$ as they are well-grounded, full of detailed descriptions, and explain processes in identifiable local contexts. ${ }^{42}$ Qualitative approaches also allow for observation and understanding the chronological flow and relationships between key constructs to draw meaningful explanations based on real-world 
observations. ${ }^{41}$ Qualitative methods explain human behavior within the social context of where the behavior occurs. ${ }^{43}$

Qualitative description is a useful strategy for exploring T2DM individuals' experiences, their interactions, and the relationships with their health care providers, family members, friends, and their ideas on the health care system. ${ }^{44}$ Qualitative descriptive studies provide a clear, rich, and straightforward description of patient perspectives using their own words instead of a theoretical and interpretive summary of the data. ${ }^{44-46}$ Qualitative descriptive studies are widely utilized in health research where researchers seek to improve their understanding of the sophisticated experience, events, or processes embedded in the human context. ${ }^{47}$ According to Neergaard et al, qualitative descriptive studies are helpful and relevant in mixed methods research since they complement the quantitative information by letting researchers gain firsthand knowledge on the participants' experiences with a specific topic. ${ }^{44}$ Hence, this study will use a qualitative descriptive study methodology to provide T2DM individuals' perspectives of lived experiences and diabetes distress.

As noted earlier, diabetes distress has negative impacts on the physical and psychological health of T2DM individuals. ${ }^{19-25}$ Yet, very few studies have been conducted in rural Appalachian regions to explore the everyday lived experiences and challenges to managing diabetes and the effectiveness of DSME programs in reducing diabetes distress in T2DM individuals. To address this knowledge gap, the current study utilized fundamental qualitative description to explore the everyday lived experiences, struggles, and distress related to the management of diabetes and comorbidities among the patients with T2DM using semi-structured interviews and focus groups. Specifically, the two aims of the study were as follows: 
Aim 3a: To understand DHSMP participant's everyday lived experiences and challenges of managing diabetes and its related distress.

Aim 3b: To explore the efficacy of DHSMP participation on the participants' reported improvement in diabetes self-management behaviors and reducing diabetes-related distress.

\subsection{Methods}

A qualitative descriptive approach was utilized to explore the participants' experiences and challenges in managing their diabetes-related distress and the impact of the program participation on their self-management and associated diabetes distress. At the end of DHSMP, focus groups were conducted for quality improvement and program evaluation purpose. Two senior researchers (DD and $\mathrm{RM})$ prepared questions and probes related to the program evaluation and quality assessment. Interview guides and questions/probes specific to diabetes distress (Aim 3) for semi-structured interviews and focus groups were developed in consultation with two of the authors (DD and RM), who hold expertise in qualitative methods and diabetes self-management, respectively. Furthermore, two interview questions from a previous qualitative study on diabetes distress by Tanenbaum et al were incorporated. ${ }^{48}$ The questions prepared for the semi-structured interview and the focus group were open ended and included probing questions to clarify interviewees' responses. The questions were carefully constructed with familiar language to

maintain clarity and neutrality, and were devoid of jargon and leading languages. ${ }^{49}$ Based on the experts' (DD and RM) suggestions, questions were further revised and finalized. Finally, focus group questions and probes specific to diabetes distress were incorporated into the existing focus group questions and probes. Forty-two individuals participated in the qualitative study of which 33 completed a semi-structured interview and 23 individuals participated in four focus groups 
(please see Appendix D Figure 1). The study was approved by the institutional review board of West Virginia University.

\subsection{Diabetes and Hypertension Self-Management Program (DHSMP)}

The Diabetes and Hypertension Self-Management Program (DHSMP) was one of the first randomized controlled trials in WV to examine the effectiveness of a community-based, culturally appropriate diabetes self-management program among individuals living with T2DM and comorbid hypertension. ${ }^{50,51}$ The DHSMP program was implemented in two churches in Morgantown and Charleston WV. Participants were adults 21 years or older with diagnosed T2DM and hypertension. Participants were randomly assigned to the intervention and wait-listed control group. The 12- week educational sessions were delivered by trained health coaches and experts to both the intervention and control groups. Wait-listed control group participants waited six months (24 weeks) to attend the education sessions. The curriculum of DHSMP was adapted by combining curricula from two evidence-based diabetes self-management programs: the Centers for Disease Control and Prevention (CDC)'s National Diabetes Prevention Program (DPP) and the American Association of Diabetes Educators' AADE7 Self-Care Behaviors. ${ }^{52,53}$ It also included the Eighth Joint National Committee (JNC8) guideline developed by the American

Family Physicians (AFP) for management of hypertension. ${ }^{54}$ Health coaches were undergraduate and graduate students at WVU who received two days of training by the experts to familiarize them with the DHSMP curriculum and educational session materials.

\subsubsection{Data collection procedures}

Two methods were employed for this study: focus groups and semi-structured telephone interviews. These data collection methods allowed a dialogue between the researchers and participants, guided by a flexible interview protocol and follow-up questions, probes to achieve a 
reliable and in-depth understanding of diabetes and sensitive issues such as distress and lived experiences. The findings resulted in the identification of patient-centered themes and key information to understand participants' lived experiences with diabetes and related-distress.

Participants were invited to participate in a qualitative study (semi-structured phone interview and/or focus groups) at the end of the 6-month program completion. Participants were given a description of the overall objective and intended outcome of the study, process of the semistructured interview, and/or focus group session. They were also informed that the participation was voluntary. Interested participants signed up for the phone interview and focus group sessions separately, and some participants agreed to attend both the phone interview and focus group session. Participants also received follow-up phone calls as a reminder about their participation in the semi-structured interview and focus group session on confirming their attendance.

\subsubsection{Semi-structured telephone interviews}

All semi-structured phone interviews were conducted by a trained program coordinator. Interviews were scheduled at a prearranged time, based on the availability and convenience of the participant. Reminders were also sent prior to the interview by the program personnel and rescheduled if a participant was unable to attend the phone interview. Each phone interview lasted between 20-30 minutes. The interviewer kept notes during the interviews. The interviews were audio recorded and the recorded audio files were renamed according to a code assigned to each participant. Participants received a \$20 gift card as compensation for their time. A total of thirty-three (33) participants completed the semi-structured phone interviews (response rate $=$ $37.08 \%)$. The phone interview questions and prompts are included in the appendix section. 


\subsubsection{Focus group sessions}

A total of four focus groups $(\mathrm{N}=23)$ were conducted (response rate $=25.84 \%)$. One focus group ( $\mathrm{N}=5$ ) was conducted at Charleston, WV location, and 3 focus groups ( $\mathrm{N}=6$ for each groups) were conducted at Morgantown, WV location. The focus group sessions were conducted in a private room at the intervention sites that were familiar to the participants. Individuals who agreed to participate in focus groups were given a cover letter describing the study and their rights as participants and were debriefed on the audio recording procedures. Verbal informed consent, to participate in the focus group and permission to record the conversations, was obtained from the participants. To familiarize the group with one another, participants wrote their names on small size place cards and placed in front of them at the table. Focus group sessions were conducted by an expert facilitator (DD). Two student volunteers and the first author (RK) assisted DD by taking notes during the sessions. The facilitator (DD) instructed the notetakers to draw the sitting arrangement of the participants in the room during the focus group sessions. The participants were identified by their first name only in the diagram. The participants' names were matched with their code numbers for transcription and coding purposes. Two audio recorders were utilized to record each focus group session, placed on two sides of the table around which the participants and the facilitator, with a comfortable distance between them. Prior to the focus group session, audio recorders were tested by the note takers to ensure the clarity of the recorded audio for transcription. A focus group script was utilized by the facilitator to moderate the discussion. Participants were asked questions about their experience related to participating in DHSMP and how it helped them manage their diabetes and diabetes distress. They were also encouraged to share their opinions and suggestions and converse with one another on these issues. Note takers wrote notes during the focus group sessions. The duration of the focus group sessions was approximately 90-120 minutes. Participants received 
$\$ 20$ gift cards as compensation for their time. Focus group questions and prompts are included in the appendix section.

\subsubsection{Qualitative analysis}

Audio recordings of the focus group sessions and phone interviews were transcribed verbatim via a professional transcription service $(\operatorname{Rev})^{55}$, and all identifying information was removed. Prior to analysis, strategies for data coding and organization were identified. RK as the primary coder, and a doctoral student (BK) with interest and experience in intervention research related to diabetes as the second coder, independently cleaned, read, and open coded each transcript. ${ }^{56}$ Microsoft Excel ${ }^{57}$ and NVIVO 12.0 software was used to facilitate data management and analysis. ${ }^{58}$ Preliminary codes were established related to participants' experiences of managing life with diabetes, diabetes distress, and how the DHSMP impacted their diabetes selfmanagement and distress. After the initial round of open coding, the two coders met with researchers (DD and RM) to discuss the preliminary coding scheme and operational definitions, and a final set of codes was agreed upon. Codes were then grouped into categories, paired with illustrative quotes, and eventually aggregated into 4 domains. Each domain was summarized and select verbatim quotes that captured participants' lived experiences and their management of diabetes self-care and distress were included in each summary. Three meetings were completed to finalize and summarize the domains, and categories. Five team meetings were conducted to discuss areas of agreement and disagreement with the domains until consensus was reached.

\subsection{Results}

Forty-two individuals participated in the qualitative study. Among them, 33 participated in the semi-structured interviews, and 23 participated in focus groups. Fourteen (14) participants overlapped in their participation for both assessments. The mean age of the participants was 
$63.38 \pm 12.88$ years. The majority were non-Hispanic Whites $(97.56 \%)$, women $(58.54 \%)$, had a bachelor, graduate or professional degree (51.22\%), and resided in towns or cities (65.85\%), and indicated that they had a family history of diabetes (75.61\%). The mean duration of their diabetes was $12.91 \pm 10.00$ years. Most of the participants were overweight or obese $(95.12 \%)$. Most of the participants had low to moderate diabetes distress, especially related to regimenrelated and emotional distress for their chronic conditions. Appendix D Figure 1 provides a schematic representation of sample size for the qualitative assessments.

\subsubsection{Diabetes Distress Domains}

The analysis focused on the coding the four diabetes distress domains emerged from the analysis. These domains were: "emotional distress", "interpersonal distress", "provider or physicianrelated distress", and "regimen-related distress". For each domain, three categories were identified: 1) participants' lived experiences; 2) how individuals addressed and mitigated a particular type of distress; and 3) how participation in the DHSMP helped them to address and cope with their diabetes distress. The first category illustrated participants' emotions related to diabetes, and the specific diabetes distress, the second category focused on their management of diabetes distress prior to their participation in DHSMP, while the third category focused on DHSMP specific strategies they utilized to manage their specific diabetes distress.

\subsubsection{4.3.1.1 Domain: Emotional Distress}

The first domain, "emotional distress" discussed the participants' emotion towards diabetes and its complication, their actions to cope with it, and how DHSMP helped them manage emotional distress. Emotional distress is a person's emotions such as anger, frustration towards the disease, and management of life and health. When asked about emotional distress, the participants shared their perspectives on the impact of diabetes on their emotions. They were also asked to share 
how they tried to address and mitigate their emotional distress and how participating in DHSMP helped them manage it.

\section{Category 1: Lived Experiences with Emotional Distress}

The participants described having a lot of stress, frustration, anxiety, and worry related to diabetes. Some described experiencing anger, and self-blame as an emotional response to living with diabetes. One participant mentioned, "I've definitely had the anger, because I know from when I first was diagnosed that, I knew how I was raised ... I should say, it obviously wasn't forced on me, but I just think the lifestyle I lived, even up to that point was again, just a bunch of bad choices, and it just created a lot of anger in myself." Participants were worried about the complications of diabetes later in their life. One participant said, "I also worry about long term because I know it's kind of a slow killer." They shared frustration with the burden of daily lifestyle management, such as dietary changes, physical activity, and medication adherence for their diabetes. The participants revealed they get emotional and stressed when they have to visit health care professionals frequently or are hospitalized for diabetes-related complications. Emotional distress was described by a participant in the following way: "Hospitalization, very stressful for me, and when your blood sugar goes to 600 ...I have had to fight with my doctors not to put me in the hospital." The participants also expressed concern or fear of their children having a genetic predisposition to diabetes, as expressed by one participant, "I worry, the only really emotions is, because I feel mine's genetic as much as anything, that I'm passing it down to my daughter." 


\section{Category 2: How Individuals Addressed/Mitigated Emotional Distress}

Even prior to enrolling into DHSP, participants noted enhanced knowledge on diabetes-self management. Participants mentioned that improving their knowledge of diabetes and diabetes management helped them control anxiety related to diabetes. One of the participants mentioned, "I think knowledge helps best. If you understand more about it, then it helps with that." A clear understanding of the diabetes management activities and adhering to the proper guidelines was deemed to help reduce distress among the participants. According to another participant, “As long as I can do what I know to do to help the situation and that it's not getting any worse, then my anxiety level's probably going to maintain pretty relatively low." Regular visitation with a psychologist or counselor was also reported to be helpful to cope with emotional distress related to diabetes. Stress-reducing exercises, such as meditation, were suggested as beneficial by some participants to reduce stress. As one participant described, "I've involved myself in a meditation group, and that's been very helpful; becoming more mindful about every day, just normal things."

\section{Category 3: Impact of DHSMP on Addressing Emotional Distress \& Diabetes Self- Management}

The participants informed that learning stress-reducing techniques at the program session helped them. Techniques such as deep breathing, allocating times for relaxation, easy exercises were mentioned as helpful. One participant mentioned, "Just knowing the different ways to calm yourself down is very helpful. Sometimes when I'm at a stoplight, I just try breathing deeply. Those kinds of things really have helped me." Another participant had a similar statement who said, "It was stress relief. Some nice easy exercises." The health coaches and other program personnel were always ready to talk and help the participants. The support and information 
provided by health coaches helped many participants be aware of their situation and take control of their emotions. One participant shared, "I think that [name of health coach] was a very good person to talk with and ... so she would would've helped me with that if I'd expressed a whole lot of angst." The supportive attitude of the program staff helped the participants as well. In addition, peer support from other program participants was indicated as helpful as individuals shared their experiences and tips of managing emotions. As stated by one participant, "Everybody was supportive that had anything to say. Nobody was a Debbie downer. Nobody had any negative feedback at all."

\subsubsection{4.3.1.2 Domain: Interpersonal Distress}

The second domain, "interpersonal distress", explored the participants' experience on the distress caused by the interaction with their family members, friends, colleagues in managing diabetes, their coping strategy with this distress, and how participating in DHSMP helped them deal with interpersonal distress. Interpersonal distress occurs due to the lack of understanding and support from the family members and friends of an individual with T2DM. The participants were asked questions on their life with interpersonal distress, how individuals dealt with interpersonal distress, and how DHSMP helped them manage interpersonal distress in life.

\section{Category 1: Lived Experiences with Interpersonal Distress}

Participants described developing stress due to lack of support or due to lack of understanding of their situation by their partners/spouses. Participants described that their partners or spouses with unhealthy dietary habits sometimes tried to influence the diet of the participants. As one participant noted, "She's [participant's spouse] constantly, constantly got to have cookies, and pies, and ice cream, and everything, all the stuff in the house all the time. and candy. Just candy everywhere and stuff. So, it's emotionally a difficult situation for me to maintain and not eat 
these things that are all just hanging around me." Another participant added, "My probably biggest problem is dealing with my wife who was a nurse for 30 years but was raised on limited food so she became a food junkie. She ate nothing but crap her whole life and she still does." The participant described how food insecurity in early childhood influenced his wife to develop an unhealthy diet that stressed him significantly. Partners'/spouses' discouraging comments on the participants' management of diabetes negatively affected their emotions. As one participant expressed, "I told them (family members) and my husband's kind of sadistic fellow. He says, "What do you want to do that for?" I told him, I said, "I need some support,"

Participants mentioned receiving proper support and encouragement from their immediate and extended family members and from peers that helped manage their diabetes and stress. Some participants had helpful partners/spouses who supported them emotionally and helped them have healthy eating habits. One participant talked about her supportive husband, "My husband's also ... He's kind of newly diagnosed as a diabetic, so now we're fighting it together. Okay. We're a pretty good team." Another participant mentioned his supportive wife, "My wife's a lot of help to me with giving me my shots and stuff like that. Been really supportive, fixes the right kind of foods, and make sure," Did you take your medicine today?", and all that kind of things like that." Other individuals received support from relatives such as siblings, parents and in-laws. As one participant noted, "Well, I always tell my sister when I'm getting in these things. She'll ask what I've learned, and what's coming up. I guess she's really the person I have that is for support."

On the other hand, some participants mentioned experiencing stress because their family members were careful about their eating habits and continuously monitored their food intake. One participant described, 
My mother, I live away from her, she lives in [city], I live up here. When I got sick, my husband called her and she flew up here the next morning and was with me in the hospital the four days I was in there. She stayed at a hotel and so she was learning to. So now whenever I'm home, she's always like, "Have you checked your blood sugar? Have you eaten? Do you need to eat?" And that stresses me out a little bit too because I'm like, I've got this! I appreciate the uber-concern, but.

There were frustrations from the participants about the lack of support from colleagues on diabetes management. Not finding enough healthy food options at work was mentioned by the participants. As one participant shared, "Like when if they are planning a party, they don't plan anything, and the fact that there's two people there that have celiac, they don't care, they going to bring what they like, they're going to bring the Hawaiian King buns, and the sweet buns. They're going bring potato chips, they're going to bring junk.”

Some participants mentioned not receiving any support from family members, friends, or colleagues; as stated by one participant, "There's not that many people to tell. I really haven't even told much of my family. I honestly don't think they care."

\section{Category 2: How Individuals Addressed/Mitigated Interpersonal Distress}

The participants shared several strategies they tried to avoid interpersonal distress prior to enrolling into DHSP. Since the conversation with partners/spouses can quickly turn to arguments, some participants tried to avoid such confrontations. One participant mentioned, "even if you try to approach it calmly or whatever, it ends up being an argument when it's a spousal situation. I pretty much just try to ignore it, and try to do the best I can with what I can." Some individuals mentioned refusing politely to any unhealthy food in a party or family 
gathering. As one participant noted, "I get offered to sometimes by my aunt and I just told them no, I gotta watch my sugar." The participants also mentioned not eating at social gatherings or parties if no healthy food options were available unless they were repeatedly insisted by the hosts. In those situations, the individuals took small portion sizes. This tactic was mentioned by one participant, "If you're at some kind of event where people are eating they can think you ate before you got there. You don't have to eat in front of anybody and show them how much you liked what they made. They don't have to know that you didn't try it. If its something they're particularly proud of you could try a spoonful and make them happy unless you say you hate it." Similar strategy was mentioned by another participant who narrated, "I'm going to a birthday party tomorrow; I know there's going to be cake; ice cream there ... pizza, probably. All the things I can't eat. So I'll probably just go and not eat anything." Another participant mentioned not listening to others' requests to take food or others' attempts to influence their diabetes management as ways to stay out of stress. The participants also stated informing hosts of their diabetes status so that the hosts can understand their situation; as one of them noted, "I tell people I have diabetes. I'm not ashamed of the fact that I have diabetes." On the contrary, some participants mentioned being hesitant to share such information with others. As one such participant mentioned, "I don't go out of my way to tell people that I have diabetes. So, I guess you might say that I'm a little bit hesitant to talk about it, at least to people that aren't close."

\section{Category 3: Impact of DHSMP on Addressing Interpersonal Distress and Diabetes Self-}

\section{Management}

The participants informed that DHSMP educational sessions were judgment-free and full of similarly minded participants and program personnel, which helped them freely discuss their issues such as interpersonal distress. One participant mentioned the benefits of the program as, 
“...being in the classroom, listening to everybody and being able to talk openly and without any kind of criticism." The participants described receiving support from their health coaches on dealing with interpersonal distress. The participants mentioned having conversations with health coaches in person or over the phone or via text message to receive their suggestions and encouragement. The Participants also mentioned receiving support and suggestions from other program personnel that helped them manage their distress. One participant noted, "[name of the health coach] was great. I mean she's, yeah, she talked to me weekly and we texted back and forth. I liked that. the program was nice because it allows you to be in a group of people of similar issues and it did provide some advice and encouragement as a group that you don't normally get."

\subsubsection{4.3.1.3 Domain: Provider or Physician-Related Distress}

The third domain, "provider or physician-related distress" described the participants' stress they experience from the interactions with health care providers, how they tried to manage that distress, and how they received support from DHSMP to mitigate provider-related distress. Patients may experience health care provider-related distress when the providers are not as supportive as supposed to be or not skilled enough to share information helpful with the patients. Participants were asked questions on their experience in dealings with health care providers, how individuals managed any provider-related distress, and whether DHSMP was helpful in addressing such distress.

\section{Category 1: Lived Experiences with Provider or Physician-Related Distress}

Participants mentioned not receiving enough time to discuss health issues with their doctors. Inadequate time to deal with the doctor was a major distress for the individuals. This concern was voiced by one participant: 
To be honest here I'm on my own. Even though I go to my doctor after five, 10 minutes with my doctor, you're just a mystery after that. I'm sorry, you're just a number. So that's how I feel about the doctor situation. They're just doing their best with that 10 minutes or 15 minutes they're spending with you and then you're out of sight out of mind.

Also, visiting multiple doctors for multiple health issues was noted as stressful by the participants. As one participant stated, "Second level of distress is dealing with all the damn doctors. The nephrologist, pulmonologist, cardiologist, ophthalmologist. There's so many of them. Having to go see them is just a total pain."

Participants revealed difficulties getting the doctors to adjust diabetes medication according to their needs. One participant described doctors not thinking 'outside the box' when adjusting medication dosage, as demonstrated in the following statement, "I'm talking maybe a decade with medication, a medication regime where my sugars go up and down and my doctors aren't, none of them, are adjusting my medications correctly. ... because I think they were only trained to offer, "Let's start with metformin." They can't think outside the box." Some participants thought their doctors were more interested in reducing the "numbers" instead of treating the disease as a whole. One participant stated:

Doctors are way too worried about the numbers, and they feel they're doing a good job if they can get your blood sugar down to 100 , and A1C is five or something like that. ...They're all focused on the number, number, number, number. That's not the whole thing. It's insidious in fact of, like I said, the heart disease that goes with it, the kidney problems, the neuropathy, and these things. That's the real dealing with the disease. 
The Participants mentioned that sometimes the doctors did not explain the medication or disease status to the participants. Not being adequately informed on their disease status and medication regimen made the participants distressed. One participant mentioned:

I think, especially from the very beginning, I never got a definitive diagnosis that I had Syndrome X, or pre-diabetes to diabetes, and I basically was very proactive and the fact that I have polycystic ovaries, I went and got myself on metformin. I had taken it for years, so there was never any ... the doctors never explained it. I had to do my research myself.

Sometimes the distress came from the fear of visiting the doctor. Because of such fear, participants reported visiting their doctors less frequently. As one participant noted, "I hate doctors, I had almost like a phobia. So, I'm a procrastinator and ignore it."

The Participants complained of the diabetes education received from their health care providers as fast-paced and inadequate to meet their needs. Those classes were characterized as 'haphazardly' managed. One participant noted, "They were supposed to make out sample menu. The sample menu they gave me, the first breakfast, the breakfast, lunch and dinner, they had the sample, they were all sandwiches. I said, well that's what I said. I threw a fit about it, and I walked out and I went down to administration and complained about it.” There were disappointments among the participants with the dietitians they visited for their diabetes management. Dietary recommendations from dietitians were considered not enough and personalized. As one participant mentioned, “...you think dieticians would be good at this stuff but they really aren't. Well they just have this pressured diet, it doesn't seem to be their research. They do all this magical carb counting and crap but it doesn't really work in real life." 
Participants also shared their disappointment with their insurance providers. Some individuals had difficulty in getting reimbursed for a medication or glucose monitoring device. One of the participants shared concern in the following statement, “...my problems that I've found is insurance wise because I'm having problems getting my insulin and being able to pay for that because of the insurance wise... I'm worried about getting sores because it's the removal of the skin that my insurance won't help me with.”

\section{Category 2: How Individuals Addressed/Mitigated Provider or physician-Related Distress}

Participants shared how they mitigated provider or physician-related distress prior to enrolling into DHSP. The participants mentioned asking questions to get explanations on health issues from their doctors. Getting explanations from health care providers helped the individuals feel less stressed. One of the participants noted, "When I go to the doctors, I'm the one ... I ask the questions, and I make them explain to me what ... I don't have a problem with that. I usually take my sister with me just so that she's hearing the same things I am. And we both ask questions too."

Some participants mentioned conducting their own research to get more information on diabetes from various sources. One such participant stated, "I do my own research, and I'm thinking, why am I doing this?... I'm finding I've had to sort it out myself, and I should take responsibility for my disease and take care of it." By doing their own research, the participants took responsibility for their health issues, which helped them reduce diabetes stress.

The participants expressed that the doctors could be more proactive in recommending them to proper health care and advising them to join diabetes self-management programs. One concerned participant noted: 
I just think that there needs to be, I think the doctors need to take a different approach... I mean like a cardiac doctor, he has ideas where I can send you to cardiac rehab, I can send you here, I can send you there? Why doesn't when ... to an endocrinologist, one says hey I want to send you to a diabetes class. I want to send you to this DASH diet class, I want to send you to a registered dietician. I want to send you to somebody, a personal trainer. I mean, why not?

\section{Category 3: Impact of DHSMP on Addressing Provider or Physician-Related Distress \& Diabetes Self-Management}

Participants mentioned that the DHSMP was helpful in reducing provider-related distress. Health coaches and researchers shared helpful information with the participants that helped them manage appointments with healthcare providers. The participants were encouraged by health coaches to talk freely with their doctors about their concerns and request more information needed. One participant mentioned, "[Health coach] stressed and emphasized the importance of talking with your personal physician about any issues that you have with your care and management." During the educational sessions, the participants learned the importance of sharing health issues with their doctors to receive proper health advice. Some participants reported receiving more information and support from the DHSMP personnel about their diabetes than their healthcare providers. One of the participants stated, “...It took for me to pay out of pocket for the device and then ask my insurance and get with [employer] human resources to pay for it and to tell the insurance to pay for it. Then it took me to take it Dr. [DHSMP personnel] because my endocrinologist hasn't done anything." 


\subsubsection{Domain: Regimen-Related Distress}

The fourth and the last domain, "regimen-related distress" discussed the participants" distress related to the burden of diabetes-related treatment and self-management, how they tried to mitigate that distress, and how participating in DHSMP helped them address regimen-related distress. Regimen-related distress can occur in a person with T2DM due to the frustration arising from the burden of following the medications and lifestyle adjustments suggested by healthcare providers. Participants were asked questions on the experiences with regimen-related distress, how they addressed/mitigated regimen-related distress, and what were the impacts of DHSMP on addressing/mitigating regimen-related distress.

\section{Category 1: Lived Experiences with Regimen-Related Distress}

Participants reported that regular blood sugar monitoring was stressful. Pricking fingers to check blood sugar was both a physically and psychologically painful experience for the participants. As one of the participants noted, "Maybe there may be some subconscious stress that causes me both to do the finger stick. That's probably what it is. I probably be feel stressed having to do those finger sticks." Participants shared experiencing physical pain of taking insulin and the related psychological stress was shared by the participants. Also, maintaining a regular schedule to take insulin was cumbersome for some participants. One participant's statement illustrates these difficulties:

Just a hassle of having to keep taking the insulin. I can't take the medications, because I have chronic kidney disorder, and they're...they're not good for kidneys, and so I have to be ... and a hassle of having to keep doing that. Sometimes at night when I'm getting 
ready for bed and I happen to forget, and I'm so dead tired, and I have to go through testing my blood, and taking the insulin.

Frustration with taking medication regularly was a common complaint of the participants. One participant expressed, “...dealing with the medication and the shots. And taking the medication with me when I travel, and things like that." Individuals used to take multiple medications regularly, and the side effects of medicines and interaction between medicines and food items contributed to their stress, as one participant mentioned, "My biggest challenge, for me, is because I also am on Warfarin blood thinner. Which restricts my leafy greens. I have to avoid those and that's really hard sometimes. That's my biggest challenge."

Managing a healthy diet was a major cause of stress among the participants. Maintaining a healthy diet was not always easy for individuals. It was difficult for the participants to give up foods they had been used to eating from their childhood. Some individuals complained about not being able to eat their favorite foods. One participant shared, "I like sweets. I've struggled to not overdo it, and I'm addicted to the real Coca-Cola." Some participants were stressed about getting into the habit of eating healthy food such as green vegetables. One participant stated, "What I struggle with is ...get the more vegetables and the more, to eat the right things. It's a struggle to do that way."

Reducing and maintaining weight was another major stress for the participants as they grappled with regular physical activity due to disability or other health issues. The participants shared stressful experiences to maintain a healthy weight while battling other health issues. Since weight gain is a common side effect of insulin intake, some participants struggled with this issue. One participant expressed, 
The weight gain. Yeah. Just ever since I've been diagnosed with diabetes I just have gained weight and I cannot lose it. I've tried everything. I've been through so many different programs and I just can't lose and it's just like a big circle where I need more insulin because my sugar's going high and then I'm just gaining weight because I'm getting more insulin.

Participants informed managing weight was getting harder as the participants were getting older. One participant stated, "Mainly especially here lately is keeping my weight down, and I don't know if insulin has anything to do with not being able to lose weight. Like I did it one time or maybe it's just as you get older it's harder to do."

\section{Category 2: How Individuals Addressed/Mitigated Regimen-Related Distress}

When asked how they managed regimen-related distress prior to enrolling into DHSMP, the participants mentioned that following a routine was important for them to manage regimenrelated distress. The individuals checked blood sugar regularly and took their insulin at regular intervals. One participant shared, "I've got a routine, and I check my sugar at a certain time... so it's like I've just got this little routine going." Taking medicines according to the prescription was a very important task for the participants to reduce their stress in life. As one participant stated, "I just take the pill and I'm pretty faithful with that. I've got a pretty good system set up where I take my medications at certain times." Similarly, another participant shared, "I take my medications like it's a religion...".

To maintain a proper weight and healthy diet, the participants avoided certain foods to reduce regiment-related stress. According to one participant, "I totally cut off pretty much sodas. I'll, once in a while I'll treat myself, but not very often. Not even, not even diet soda.” The 
individuals also chose healthier alternative food items instead of eating food rich in carbohydrates and fat. One individual noted, "We buy that Ezekiel, that flourless bread. And we eat a lot." There was increased awareness to read labels on the food items before purchasing in order to choose healthier options. One participant said, "I actually read labels now. Pretty much everything I get. I read a label now. Sugar content, Carbo- carb pod content, calorie counts, salt content, stuff like that."

Regular physical exercise helped the participants reduce their stress. Although for some participants it was difficult to perform physical activity on a regular basis, they tried their best to follow the recommendations, which helped them cope with their stress. One participant mentioned, "So I kind of have congestive heart failure now, so I kind of don't have the endurance to walk on a treadmill or anything for a long time. I can only do that in little bits. I still exercise, but not like I'd like to exercise."

\section{Category 3: Impact of DHSMP on Addressing Regimen-Related Distress}

When asked how DHSMP helped the participants manage regimen-related distress, they praised the support received during the program. Information shared in each education session was carefully crafted so the participants could easily understand and follow those on a daily basis. Following easily understandable recommendations helped the participants manage their life and reduce stress. One participant stated, "Everything was broken down nicely, of what causes what, and what leads to what in your body, and the diabetes process. And the side effects of having too high a blood sugar, and how you get it. What foods cause it. Just all that helps you... Once you understand it, you can do more about it, I think." 
Participants became careful while shopping for their food after attending DHSMP. The individuals carefully read food labels and purchased healthy food options. The participants also followed the health coaches' and researchers' advice on maintaining a healthy diet that helped them reduce stress. One participant said, "I'm more aware that when I go to the grocery store, I read labels now and I put back things that I normally would have eaten. I'm much more aware of that. The visual demonstrations that they did in the class were really made an impression. I remember this pink packets...It helps me know what I need to do." Participants also mentioned receiving support from health coaches to maintain their body weight and have regular physical activity. As noted by one participant, "I've been walking a lot more..."

Attending DHSMP educational session helped the participants become more organized in managing a healthy lifestyle. The health coaches maintained regular communication with the participants, which helped the individuals stay organized in maintaining a food log and physical activity chart. One participant mentioned, "Yeah, it helped make it organized, it helped me get motivated, it helped me stay on track". Health coaches helped the participants learn and adopt new technologies to track their diet and physical activity. These supports helped the participants manage their regimen-related distress. One participant noted, "Now that does help me, to keep track of food that I'm eating. That still helps me. And I have tried to use the apps for my phone as far as tracking, like the Lose It app, and then on my iPhone, I use that health app that already comes on the phone."

In Appendix D, Table 2 lists domains and categories with description, table 3 lists the quotes included in the results section, and table 3 lists all quotes utilized for analysis. 


\subsection{Discussion}

West Virginians have low rates of participation in diabetes self-management education (DSME) programs despite a high prevalence of diabetes.$^{59}$ This qualitative study examined an individual's burden and distress related to the daily diabetes self-care regimen, their lived experiences, and how these may impact their psychological and physical wellbeing. The participants' narratives revealed an understanding of the interconnectedness of the various dimensions of diabetes distress as well as improvement in their coping strategies with knowledge/skills from participation in self-management programs. Participants found support from health coaches and peers that were helpful to improve their coping strategies and communications with family, friends, and healthcare providers. Participants were able to apply their knowledge to the various domains of diabetes distress, e.g., emotional, interpersonal, regimen, and physician-related issues, as the categories were different yet had many similarities and overlapped with each other. This study demonstrated participants' emotional challenges to living with diabetes. The frustration of deprivation (emotional distress) and deprivation related to dietary changes and the burden of regular physical activity (regimen-related distress) were described by the participants. Interpersonal distress resulted from either overbearing support or a lack of understanding/support from others. Individuals also identified challenges with providers' lack of understanding of their stressors.

Emotional Distress: Participants expressed negative emotions such as worries, anger, and frustrations related to having diabetes. Similar to prior studies, longer duration of the disease was associated with emotional stress and worries about the long-term complications of diabetes in their life and its implications in their family life. In a qualitative study, participants shared anger, frustration, and guilt over their diabetes status. ${ }^{36}$ In this study, participants blamed themselves for 
their poor lifestyle choices and perceived that contributed to their chronic condition. This was also noted by adults with diabetes who participated in another qualitative study by Tanenbaum and her colleagues. ${ }^{48}$ Both male and female participants unanimously expressed concern about their children having diabetes later in their life due to having a genetic predisposition and concurs with prior literature. ${ }^{48}$ Concern was also expressed on the impact of their diabetes on family members from other perspectives. ${ }^{60,61}$ For example, Arefin and colleagues noted individual's fear of not taking care of young children ${ }^{61}$, and being unable to plan for their children's weddings. ${ }^{60}$

Participants relied on their knowledge of managing diabetes to reduce emotional distress. They reported that visiting psychologists and regular meditation were helpful. Similar to participation in DSME programs ${ }^{62}$, participants reported that attending the DHSMP educational sessions was beneficial to understand how to manage their emotional distress. Relaxation techniques, such as deep breathing and easy exercises, were particularly described as beneficial. Similar to what Wolever and colleagues described in their study, one-on-one discussion with health coaches and program personnel was perceived as supportive and mediated educational sessions in improving individuals' overall diabetes stress.

Interpersonal Distress: Participants perceived a lack of support, especially from partners and spouses, about participants' diabetes self-management, which increased their interpersonal distress. Interestingly, overconcern and extra care by family members induced disease-related distress. Pal and colleagues also found T2DM individuals were blamed for their disease, although the relationships between the participants and those who blamed them were not identified in the study. ${ }^{36}$ The participants in the current study, however, specified relationships that caused interpersonal distress during the interviews. An evaluation of interpersonal distress 
among adults in Indonesia showed they felt unsupported due to their dietary restrictions and unable to consume the foods that family members eat, such as sweet and salty foods. ${ }^{61}$ The participants also described similar perceptions when their spouses insisted on continuing unhealthy dietary habits (e.g., eating carbohydrate-rich food) and were not adequately supportive of the lifestyle modifications needed for diabetes self-care. A few participants also reported avoiding conversations and/or not sharing issues with family members, relatives, and friends about their diabetes self-management to cope with confrontations and heated arguments that result in interpersonal distress. Similar avoidance strategies were also reported by Tanenbaum et al when individuals with diabetes concealed their health issues to avoid interpersonal distress due to a lack of understanding and support from family and friends. ${ }^{48}$ Our results further support these findings that T2DM individuals had reduced interpersonal distress when there is understanding and emotional support, encouragement in diabetes self-care activities such as healthy eating from their family members, especially the spouses ${ }^{63}$ Other studies also suggest the importance of social support in managing diabetes distress. ${ }^{64,65}$ A systematic review conducted by Pamungkas et al, showed that reduction in diabetes distress occurred if family support was integrated with self-management programs. ${ }^{66}$ Through weekly communication and discussion with health coaches and peers in the educational program regarding interpersonal distress and identification of possible solutions and strategies allowed the participants to cope with it. Group educational sessions also allowed individuals to discuss their interpersonal distress related issues in a judgment-free environment and supported by findings from research conducted by Due-Christensen and colleagues; discussion with individuals dealing with similar situations helped understand they are not the only ones with such problems and how to better manage interpersonal distress in their daily lives. ${ }^{67}$ 
Provider or Physician-Related Distress: Participants voiced their concern over receiving limited attention, proper guidance, and emotional support from their healthcare providers that caused provider-related distress. More specifically, participants mentioned not receiving adequate time to discuss their health issues with their doctors and concurs with a prior study on diabetes distress. ${ }^{48}$ Another study also confirmed that limited time with their doctors was a problem. ${ }^{61}$ Participants in this study were particularly distressed when their doctors failed to listen to their needs and preferences to tailor or modify their treatment strategies to fit their specific health issues and medication side effects. Emphasis on just lab values instead of giving attention to the patient's overall struggle with the disease and barriers to adherence behaviors were dissatisfaction faced by the participants, as reported earlier. ${ }^{34}$ According to the participants, the doctors do not think out of the box to adjust treatment strategy for each patient and reported by Tanenbaum et al's study when providers "treat everyone through the book" ${ }^{48}$ In Pal and colleagues' study, the participants addressed a similar phenomenon as "tick box" culture, where the doctors recorded the complaints but did not address those to help the individuals. ${ }^{36}$ Inadequate support from allied health care professionals, such as dietitians, to assist the participants in managing their diet had an adverse effect on distress. For example, in the prior study, participants voiced their frustration when they received complex information on nutritional guidelines by their providers without proper guidance on how to interpret and implement them. ${ }^{36}$

To mitigate provider-related distress, participants described developing proactive strategies (selfconducted research on health topics) of improving their knowledge of diabetes and complications and related management strategy. Similar to prior studies, improved knowledge of diabetes selfcare and patient-provider communication to ask questions and seek explanations of their disease 
status and treatment strategy helped them manage their provider-related distress. ${ }^{68-70}$ Complying with diabetes clinical care and self-management is a challenging task for participants, and explanation by health coaches on the importance of patient-provider communication (i.e., talking freely and requesting more information) for diabetes care was reported as being helpful to manage their anxiety and stress prior to visiting their healthcare providers. Prior studies support that health coaches help to improve individuals' self-empowerment to engage with their providers regarding their disease and ask questions and advocate for their needs that also improves their relationship. ${ }^{34,71,72}$ For example, Thom and his team found that working with health coaches helped participants build an interpersonal relationship and trust with their providers. ${ }^{71}$ In their subsequent qualitative study, Thom and the team also identified that working with health coaches helped participants having better communication with their providers and understand their recommendations. ${ }^{72}$ Distress was also reported to the fear or anxiety of visiting the healthcare providers and dealing with insurance providers for proper reimbursement of diabetes-related health care costs as described in similar studies. ${ }^{48,61}$

Regimen-Related Distress: Our qualitative data demonstrate that regimen-related distress was especially prevalent among the participants. Dietary changes were perceived as stressful for many individuals since they had to reduce or avoid consuming comfort foods and those they ate since their childhood. Participants felt particularly challenged and frustration when they had to confirm to a strict diabetic diet to maintain blood glucose levels. In addition, participants stated that maintaining a healthy diet was difficult during holiday seasons, family gatherings, and social events. Such frustrations were also reported in other studies. ${ }^{34,48}$ Daily physical activities also caused distress as many had other comorbid health conditions, including aging, that prevented them from getting a regular and adequate amount of daily activity and exercise. Participants were 
worried about monitoring their blood glucose levels and taking insulin shots since it caused physical pain. Distress due to other self-management activities such as adherence to their routine medications (pills and insulin) for blood sugar control has also been reported in prior studies. ${ }^{48,61}$ To manage regimen-related distress, participants in this study described routine checking of their blood glucose levels and taking insulin and/or medicines prescribed by their physicians. A healthy diet and regular physical activity were reported to improve weight loss by the participants in this study. In a previous study, Hessler and colleagues also reported a reduction in regimen-related distress due to regular diabetes self-management among T2DM individuals. ${ }^{73}$ Participants mentioned that health coaches explained several important aspects of diabetes selfmanagement (reading food labels, calorie counting, maintaining food logs, staying organized), which helped them to understand the need to manage their daily regimen and reduce regimenrelated distress. Improvement in regimen-related distress was also specified by individuals when they modified their dietary behavior and used calorie counting to track their intake, with the support received from trained health coaches. ${ }^{74}$ That was similar to this study where trained health coaches provided support to participants to track their diet, read food labels, reduce fat and simple sugars. They reviewed the participant's food logs, provided helpful suggestions and weekly feedback for dietary modifications, encouraged physical activity and stretching exercises, and helped the participants adhere to medication regimens with simple reminders. Other studies have also described that individuals perceived working with health coaches helped them with healthy dietary modification and increase physical activity. ${ }^{75}$ 


\subsection{Strengths and limitations}

\section{Strengths}

This study's strength lies in the detailed understanding of patients' perspective of diabetes distress and how coping strategies were used to deal with all four dimensions of distress, including information and knowledge gained by participating in DSME programs such as the DHSMP. This study was one of the first studies that looked at the rural Appalachian population living with T2DM and diabetes distress. Hence, it adds to the current knowledge of diabetes distress that was not previously discovered in other studies. In this study, participants identified various dimensions of distress that were addressed during the coaching sessions, not identified in the prior study.$^{76}$ The present study extends the existing literature by examining how peer support, education, and discussion with health coaches form such a bridge between improved self-efficacy for diabetes self-care, coping with disease-related distress, and patient-provider communication..$^{34,71,72,76}$ Our study showed a high participation rate for the two types of qualitative data collection strategies (semi-structured interviews and focus group sessions). It also enabled the researchers to compare the results for concordance between the two data sources. ${ }^{40,77}$ This triangulation of data also contributes to the credibility of the study. ${ }^{77,78}$ Furthermore, utilization of two coders (RK and BK) for the data analysis allowed for crosschecking of the codes and categories and improved overall reliability. Because intense peer debriefing and discussion were conducted by the coders and researchers to ensure reliability of the data coding, the formal Cohen's kappa to measure intercoder reliability was not necessary. ${ }^{79}$ Utilizing two coders to read the transcripts to prepare codes and categories, and multiple discussions with researchers (DD and RM) improved the overall quality of the qualitative data analysis. ${ }^{80-82,81}$ The use of multiple focus group sessions and diverse participants from both study sites provided a comprehensive and elaborate account of individuals' diabetes distress-related 
issues, as recommended by Colorafi and Evans. ${ }^{77}$ All procedures and data analysis techniques were included using elaborate descriptions to improve the credibility of the study. ${ }^{77,83}$ The findings were cross analyzed with published research findings to ensure the validity and credibility of this research study. ${ }^{78}$ We have also provided a detailed methodology that could be used for replication, as a recommended strategy for enhancing transferability in qualitative research. ${ }^{78}$

\section{Limitations}

Some limitations of this study that need to be acknowledged include the limited diversity of the participants for racial/ethnic and socioeconomic status. Thus, the experiences and perspectives shared by the participants may not be generalizable to other rural areas and the U.S. population. Further, the current analysis was unable to explore the difference in diabetes distress and lived experiences between the participants on insulin versus those on oral medication. Future studies should take this into consideration as lived experiences and burdens will be different among patients on insulin versus oral medication.

\subsection{Conclusion}

Our study showed that adults with diabetes in West Virginia were burdened by all four subcategories of diabetes distress. Distress was noted in their daily diabetes care regimen, frustration, anxiety, and worry related to their disease/complications, which impacted their relationships with family and friends and everyday lived experiences and challenges of communicating with their providers to manage diabetes. Furthermore, participants revealed developing positive coping strategies for their diabetes-related distress with improved knowledge and skills after participation in the DHSMP program. Furthermore, participation in DHSMP provided support from trained health coaches and peers to cope with regimen-related distress and 
strategies for improved communications with providers, family, and friends to reduce diabetesrelated distress.

Results from this study will be useful for the healthcare providers to attend to the psychological needs (such as distress) in addition to focusing on the treatment, medications, and lab values. A better understanding of the specific challenges and burdens faced by individuals with diabetes by their health care providers (doctors, nurses, and dietitians) can help improve patient-provider communication and potential coping strategies. Due to the qualitative nature of the study, and relatively small sample size, we did not look into gender; however, future exploration is required to examine the relationship between gender, diabetes duration, and diabetes distress. Finally, findings will be of interest for researchers and DSME programs to focus on diabetes distress and coping strategies for improving outcomes. 


\section{References}

1. Lascar N, Brown J, Pattison H, Barnett AH, Bailey CJ, Bellary S. Type 2 diabetes in adolescents and young adults. The lancet Diabetes \& endocrinology. Jan 2018;6(1):69-80. doi:10.1016/s2213-8587(17)30186-9

2. International Diabetes Federation. IDF Diabetes Atlas. 2019. https://www.diabetesatlas.org/en/resources/

3. World Health Organization. Diabetes Facts Sheet. https://www.who.int/news-room/factsheets/detail/diabetes

4. Center for Disease Control and Prevention. National Diabetes Statistics Report, 2020. 2020. https://www.cdc.gov/diabetes/pdfs/data/statistics/national-diabetes-statistics-report.pdf 5. American Diabetes Association. The Burden of Diabetes in West Virginia. American Diabetes Association. 2020. https://www.diabetes.org/resources/statistics/statistics-by-state

6. Center for Disease Control and Prevention. BRFSS Prevalence \& Trends Data. Accessed 2020/12/15. https://www.cdc.gov/brfss/brfssprevalence/

7. Cannon A, Handelsman Y, Heile M, Shannon M. Burden of Illness in Type 2 Diabetes Mellitus. J Manag Care Spec Pharm. Sep 2018;24(9-a Suppl):S5-s13. doi:10.18553/jmcp.2018.24.9-a.s5

8. American Diabetes Association. Economic Costs of Diabetes in the U.S. in 2017. Diabetes Care. 2018;41(5):917. doi:10.2337/dci18-0007

9. US Census Bureau. QuickFacts: West Virginia. US Census Bureau. 2020. //www.census.gov/quickfacts/fact/table/WV/PST045219

10. Marshall J, Thomas L, Lane N, et al. Health Disparities in Appalachia. 2020. https://f1stage-apprc.pantheonsite.io/report/press-release/

11. DeFronzo RA, Ferrannini E, Zimmet P, Alberti G. International Textbook of Diabetes Mellitus. John Wiley \& Sons, Incorporated; 2015.

12. Fisher L, Glasgow RE, Mullan JT, Skaff MM, Polonsky WH. Development of a brief diabetes distress screening instrument. Ann Fam Med. May-Jun 2008;6(3):246-52. doi:10.1370/afm. 842

13. Fisher L, Polonsky WH, Hessler D. Addressing diabetes distress in clinical care: a practical guide. Diabetic Medicine. 2019;doi:10.1111/dme.13967

14. Dennick K, Sturt J, Speight J. What is diabetes distress and how can we measure it? A narrative review and conceptual model. J Diabetes Complications. May 2017;31(5):898-911. doi:10.1016/j.jdiacomp.2016.12.018

15. Polonsky WH, Fisher L, Earles J, et al. Assessing Psychosocial Distress in Diabetes. 2005-03-01 2005;doi:10.2337/diacare.28.3.626

16. Herschbach P, Duran G, Waadt S, Zettler A, Amm C, Marten-Mittag B. Psychometric properties of the Questionnaire on Stress in Patients with Diabetes--Revised (QSD-R). Health psychology : official journal of the Division of Health Psychology, American Psychological Association. Mar 1997;16(2):171-4.

17. Dunn S, Smartt H, Beeney L, Turtle J. Measurement of emotional adjustment in diabetic patients: validity and reliability of ATT39. Diabetes care. Sep-Oct 1986 1986;9(5)doi:10.2337/diacare.9.5.480

18. Polonsky WH, Anderson BJ, Lohrer PA, et al. Assessment of diabetes-related distress. Diabetes Care. Jun 1995;18(6):754-60.

19. Schmitt A, Reime rA, Kulzer B, Haak T, Ehrmann D, Hermanns N. How to assess diabetes distress: comparison of the Problem Areas in Diabetes Scale (PAID) and the Diabetes 
Distress Scale (DDS). Diabetic medicine : a journal of the British Diabetic Association. 2016 Jun 2016;33(6)doi:10.1111/dme.12887

20. Joensen L, Tapager I, Willaing I. Diabetes distress in Type 1 diabetes--a new measurement fit for purpose. Diabetic medicine : a journal of the British Diabetic Association. 2013 Sep 2013;30(9)doi:10.1111/dme.12241

21. Gonzalez J, Shreck E, Psaros C, Safren S. Distress and type 2 diabetes-treatment adherence: A mediating role for perceived control. Health psychology : official journal of the Division of Health Psychology, American Psychological Association. 2015 May 2015;34(5)doi:10.1037/hea0000131

22. Strandberg R, Graue M, Wentzel-Larsen T, Peyrot M, Rokne B. Relationships of diabetes-specific emotional distress, depression, anxiety, and overall well-being with HbA1c in adult persons with type 1 diabetes. Journal of psychosomatic research. 2014 Sep 2014;77(3)doi:10.1016/j.jpsychores.2014.06.015

23. Fisher L, Mullan JT, Arean P, Glasgow RE, Hessler D, Masharani U. Diabetes Distress but Not Clinical Depression or Depressive Symptoms Is Associated With Glycemic Control in Both Cross-Sectional and Longitudinal Analyses. 2010-01-01 2010;doi:10.2337/dc09-1238 24. Schmitt A, Reimer A, Kulzer B, Haak T, Gahr A, Hermanns N. Negative association between depression and diabetes control only when accompanied by diabetes-specific distress. Journal of behavioral medicine. 2015 Jun 2015;38(3)doi:10.1007/s10865-014-9604-3

25. Pibernik-Okanovic M, Grgurevic M, Begic D, Szabo S, Metelko Z. Interaction of depressive symptoms and diabetes-related distress with glycaemic control in Type 2 diabetic patients. Diabetic medicine : a journal of the British Diabetic Association. 2008 Oct 2008;25(10)doi:10.1111/j.1464-5491.2008.02553.x

26. American Diabetes Association. Diabetes Self Management Education. https://www.professional.diabetes.org/diabetes-self-management-education

27. Powers MA, Bardsley J, Cypress M, et al. Diabetes Self-management Education and Support in Type 2 Diabetes: A Joint Position Statement of the American Diabetes Association, the American Association of Diabetes Educators, and the Academy of Nutrition and Dietetics. other. http://dxdoiorg/101177/0145721716689694. 2017-01-24

2017; doi:10.1177_0145721716689694

28. Vermunt PW, Milder IE, Wielaard F, et al. A lifestyle intervention to reduce Type 2 diabetes risk in Dutch primary care: 2.5 -year results of a randomized controlled trial. Diabet Med. Aug 2012;29(8):e223-31. doi:10.1111/j.1464-5491.2012.03648.x

29. Kela R, Davies MJ. Implications of UKPDS evidence. Practice Nursing. 2010;21(3):140142.

30. King P, Peacock I, Donnelly R. The UK Prospective Diabetes Study (UKPDS): clinical and therapeutic implications for type 2 diabetes. Br J Clin Pharmacol. Nov 1999;48(5):643-8. doi:10.1046/j.1365-2125.1999.00092.x

31. Robbins JM, Thatcher GE, Webb DA, Valdmanis VG. Nutritionist Visits, Diabetes Classes, and Hospitalization Rates and Charges. 2008-04-01 2008;doi:10.2337/dc07-1871

32. Lepard MG, Joseph AL, Agne AA, Cherrington AL. Diabetes Self-Management Interventions for Adults with Type 2 Diabetes Living in Rural Areas: A Systematic Literature Review. Curr Diab Rep. Jun 2015;15(6):608. doi:10.1007/s11892-015-0608-3

33. Carpenter R, DiChiacchio T, Barker K. Interventions for self-management of type 2 diabetes: An integrative review. Int J Nurs Sci. Jan 10 2019;6(1):70-91.

doi:10.1016/j.ijnss.2018.12.002 
34. Hernandez L, Leutwyler H, Cataldo J, Kanaya A, Swislocki A, Chesla C. The Lived Experience of Older Adults With Type 2 Diabetes Mellitus and Diabetes-Related Distress. $J$ Gerontol Nurs. Mar 1 2020;46(3):37-44. doi:10.3928/00989134-20200129-05

35. Dugani SB, Mielke MM, Vella A. Burden and management of type 2 diabetes in rural United States. Diabetes/Metabolism Research and Reviews. n/a(n/a):e3410. doi:https://doi.org/10.1002/dmrr.3410

36. Pal K, Dack C, Ross J, et al. Digital Health Interventions for Adults With Type 2 Diabetes: Qualitative Study of Patient Perspectives on Diabetes Self-Management Education and Support. Journal of medical Internet research. 2018;20(2)doi:10.2196/jmir.8439

37. Tan CCL, Cheng KKF, Sum CF, Shew JSH, Holydard E, Wang W. Perceptions of Diabetes Self-Care Management Among Older Singaporeans With Type 2 Diabetes: A Qualitative Study. J Nurs Res. Aug 2018;26(4):242-249. doi:10.1097/jnr.0000000000000226 38. Patton M. Qualitative Research. Encyclopedia of statistics in behavioral science. John Wiley \& Sons, Ltd; 2005.

39. Economic and Social Research Council. Qualitative research. Economic and Social Research Council. 2020. https://esrc.ukri.org/about-us/what-is-social-science/qualitativeresearch/

40. Carter SM, Centre for Values EatLiM, University of Sydney, School of Public Health UoS, et al. Doing good qualitative research in public health: not as easy as it looks. New South Wales Public Health Bulletin. 2018;20(8):105-111. doi:10.1071/NB09018

41. Austin Z, Sutton J. Qualitative Research: Getting Started. Can J Hosp Pharm. 2014:43640. vol. 6 .

42. Miles MB, Huberman AM, Huberman MA, Huberman M. Qualitative data analysis: An expanded sourcebook. sage; 1994.

43. Steinke I. A companion to qualitative research. Sage; 2005.

44. Neergaard MA, Olesen F, Andersen RS, Sondergaard J. Qualitative description - the poor cousin of health research? BriefCommunication. BMC Medical Research Methodology. 2009-07-16 2009;9(1):1-5. doi:doi:10.1186/1471-2288-9-52

45. Sandelowski M. Whatever happened to qualitative description? - Sandelowski - 2000 Research in Nursing \& Health - Wiley Online Library. 2018;doi:10.1002/1098240X(200008)23:4<334::AID-NUR9>3.0.CO;2-G

46. Magilvy JK, Thomas E. A first qualitative project: qualitative descriptive design for novice researchers. Journal for specialists in pediatric nursing : JSPN. Oct 2009;14(4):298-300. doi:10.1111/j.1744-6155.2009.00212.x

47. Sullivan-Bolyai S, Bova C, Harper D. Developing and refining interventions in persons with health disparities: the use of qualitative description. Nursing outlook. May-Jun 2005;53(3):127-33. doi:10.1016/j.outlook.2005.03.005

48. Tanenbaum ML, Kane NS, Kenowitz J, Gonzalez JS. Diabetes distress from the patient's perspective: Qualitative themes and treatment regimen differences among adults with type 2 diabetes. August 2016 2016;30(6):1060-1068. doi:10.1016/j.jdiacomp.2016.04.023

49. Dejonckheere M, Vaughn LM. Semistructured interviewing in primary care research: a balance of relationship and rigour. Family Medicine and Community Health. 2019-03-01 2019;7(2):e000057. doi:10.1136/fmch-2018-000057

50. Misra R. Community-based diabetes AND hypertension self-management program in West Virginia. West Virginia: National Institute of Health; 2017. 
51. Misra R, Sambamoorthi U. Community-Based Diabetes and Hypertension SelfManagement Program in West Virginia. National Institute of Health; 2017.

52. Center for Disease Control and Prevention. What Is the National DPP? 2018-0116T04:06:36Z 2018;

53. Tomky D, Tomky D, Cypress M, et al. AADE Position Statement. The Diabetes educator. 2008/05/01 2008;34(3):445-449. doi:10.1177/0145721708316625

54. James PA, University of Iowa IC, Oparil S, et al. 2014 Evidence-Based Guideline for the Management of High Blood Pressure in Adults: Report From the Panel Members Appointed to the Eighth Joint National Committee (JNC 8). JAMA. 2018;311(5):507-520.

doi:10.1001/jama.2013.284427

55. Rev. Rev.com; 2018. https://www.rev.com/

56. Khandkar SH. Open coding. University of Calgary. 2009;23:2009.

57. Microsoft Excel. Microsoft Corporation; 2016.

58. NVIVO. QSR International; 2020. https://www.qsrinternational.com/nvivo-qualitativedata-analysis-software

59. Misra R, Sambamoorthi U. Five-year Trend in Diabetes Clinical Care and SelfManagement among Adults with Diabetes in West Virginia: 2010-2014. Journal of Health Disparities Research \& Practice. 2019;12(1)

60. Mendenhall E, Shivashankar R, Tandon N, Ali MK, Venkat Narayan KM, Prabhakaran D. Stress and diabetes in socioeconomic context: A qualitative study of urban Indians. Social Science \& Medicine. 2012/12/01/ 2012;75(12):2522-2529.

doi:https://doi.org/10.1016/j.socscimed.2012.09.040

61. Arifin B, Probandari A, Purba AKR. Diabetes is a gift from god' a qualitative study coping with diabetes distress by Indonesian outpatients. Quality of life research : an international journal of quality of life aspects of treatment, care and rehabilitation. 29(2020):109-125. doi:10.1007/s11136-019-02299-2

62. Young-Hyman D, De Groot M, Hill-Briggs F, Gonzalez JS, Hood K, Peyrot M. Psychosocial Care for People With Diabetes: A Position Statement of the American Diabetes Association. Diabetes Care. 2016-12-01 2016;39(12):2126-2140. doi:10.2337/dc16-2053 63. Mathew R, Gucciardi E, Melo MD, Barata P. Self-management experiences among men and women with type 2 diabetes mellitus: a qualitative analysis. OriginalPaper. BMC Family Practice. 2012-12-19 2012;13(1):1-12. doi:doi:10.1186/1471-2296-13-122

64. Baek RN, Tanenbaum ML, Gonzalez JS. Diabetes burden and diabetes distress: the buffering effect of social support. Annals of behavioral medicine : a publication of the Society of Behavioral Medicine. Oct 2014;48(2):145-55. doi:10.1007/s12160-013-9585-4

65. McEwen M, Pasvogel A, Gallegos G, Barrera L. Type 2 diabetes self-management social support intervention at the U.S.-Mexico border. Public health nursing (Boston, Mass). Jul-Aug 2010 2010;27(4)doi:10.1111/j.1525-1446.2010.00860.x

66. Pamungkas RA, Chamroonsawasdi K, Vatanasomboon P. A Systematic Review: Family Support Integrated with Diabetes Self-Management among Uncontrolled Type II Diabetes Mellitus Patients. Review. Behavioral Sciences. 2017-09-15 2017;7(3):62. doi:10.3390/bs7030062

67. Due-Christensen M, Zoffmann V, Hommel E, Lau M. Can sharing experiences in groups reduce the burden of living with diabetes, regardless of glycaemic control? Diabetic Medicine. 2012-02-01 2012;29(2):251-256. doi:10.1111/j.1464-5491.2011.03521.x 
68. Skinner TC, Joensen L, Parkin T. Twenty-five years of diabetes distress research. Diabetic Medicine. 2019-10-31 2019;doi:10.1111/dme.14157

69. Peimani M, Nasli-Esfahani E, Sadeghi R. Patients' perceptions of patient-provider communication and diabetes care: A systematic review of quantitative and qualitative studies. Chronic Illness. 2020-03-01 2020;16(1):3-22. doi:10.1177/1742395318782378

70. Hajos TRS, Polonsky WH, Twisk JWR, Dain M-P, Snoek FJ. Do physicians understand Type 2 diabetes patients' perceptions of seriousness; the emotional impact and needs for care improvement? A cross-national survey. Patient Education and Counseling. 2011-11-01 2011;85(2):258-263. doi:10.1016/j.pec.2010.08.019

71. Thom DH, Hessler D, Willard-Grace R, et al. Does health coaching change patients' trust in their primary care provider? Patient Education and Counseling. 2014-07-01 2014;96(1):135138. doi:10.1016/j.pec.2014.03.018

72. Thom DH, Wolf J, Gardner H, et al. A Qualitative Study of How Health Coaches Support Patients in Making Health-Related Decisions and Behavioral Changes. The Annals of Family Medicine. 2016-11-01 2016;14(6):509-516. doi:10.1370/afm.1988

73. Hessler D, Fisher L, Glasgow RE, et al. Reductions in Regimen Distress Are Associated With Improved Management and Glycemic Control Over Time. 2014-03-01 2014;doi:10.2337/dc13-0762

74. Chima CC, Swanson B, Anikpezie N, Salemi JL. Alleviating diabetes distress and improving diabetes self-management through health coaching in a primary care setting. $B M J$ Case Reports. 2021-04-01 2021;14(4):e241759. doi:10.1136/bcr-2021-241759

75. Mcgloin H, Timmins F, Coates V, Boore J. A case study approach to the examination of a telephone-based health coaching intervention in facilitating behaviour change for adults with Type 2 diabetes. Journal of Clinical Nursing. 2015-05-01 2015;24(9-10):1246-1257. doi:10.1111/jocn.12692

76. Wolever RQ, Dreusicke M, Fikkan J, et al. Integrative health coaching for patients with type 2 diabetes: a randomized clinical trial. research-article. The Diabetes educator. Jul-Aug 2010;36(4):629-39. doi:10.1177/0145721710371523

77. Colorafi KJ, Evans B. Qualitative Descriptive Methods in Health Science Research:. research-article. HERD: Health Environments Research \& Design Journal. 2016-01-19 2016;doi:10.1177_1937586715614171

78. Shenton AK. Strategies for Ensuring Trustworthiness in Qualitative Research Projects. Education for Information. 2018;22(2):63-75.

79. Miles MB, Huberman AM, Saldaña J. Qualitative data analysis : a methods sourcebook. 3 ed. SAGE Publications, Inc.; 2014.

80. Tong A, School of Public Health UoS, NSW 2006, Australia, Centre for Kidney Research TCsHaW, NSW 2145, Australia, et al. Consolidated criteria for reporting qualitative research (COREQ): a 32-item checklist for interviews and focus groups. International Journal for Quality in Health Care. 2018;19(6):349-357. doi:10.1093/intqhc/mzm042

81. O'Connor C, Joffe H. Intercoder Reliability in Qualitative Research: Debates and Practical Guidelines. International Journal of Qualitative Methods. 2020;19:1609406919899220. doi:10.1177/1609406919899220

82. Mcdonald N, Schoenebeck S, Forte A. Reliability and Inter-rater Reliability in Qualitative Research. Proceedings of the ACM on Human-Computer Interaction. 2019-11-07 2019;3(CSCW):1-23. doi:10.1145/3359174 
83. Sandelowski M. Counting Cats in Zanzibar. Research in Nursing \& Health.

2004;27(4):215-216. doi:10.1002/nur.20027

84. Mommersteeg PM, Herr R, Zijlstra WP, Schneider S, Pouwer F. Higher levels of psychological distress are associated with a higher risk of incident diabetes during 18 year follow-up: results from the British household panel survey. journal article. BMC Public Health. December 23 2012;12(1):1109. doi:10.1186/1471-2458-12-1109 


\subsection{Appendix D}

\section{Focus Group Questions}

We recently became interested in the concept of diabetes distress. Diabetes distress is defined as the emotional response of an individual with diabetes to stressors that originate from diabetes related complications, daily hassles and management of the disease. ${ }^{84}$ Diabetes distress includes, emotional distress (your own emotion related to diabetes and management of this issue including anger, anxiety etc), regimen related distress (regimen is the prescribed course of your medical treatment, any set of rules about medications, diet and physical activity that you should follow) physician related distress (support from health care provider on diabetes related care and concerns and interpersonal distress (lack of support, or no support at all or too critical support from family and friends).

1. We would like to hear from you about any diabetes-related distress you may have (currently or in the past), specific to the four areas I described earlier due to your disease (emotional distress, regimen related distress, physician related distress, and interpersonal distress).

2. Also, we would like to hear from you about any impact (positive and negative) that this program has had on your diabetes-related distress.

3. Would you be able to share any of your thoughts or ideas on how we can improve this program to help you better cope with managing diabetes distress?

\section{Semi-structured interview questions and probes}

1. Please tell me what has been hard for you about having diabetes? What have you struggled with?

a. Probe:

i. Medical/Self-management (e.g. Glucose self-monitoring, taking medications, insulin)

ii. Emotional/personal. 
iii. Social (family, fear of poor outcomes based on experiences of other people with diabetes).

iv. Talking to your doctor or health care provider about diabetes care.

2. Many people with diabetes find that their emotions affect their diabetes. Do you think your diabetes and emotions are related? How?

a. Probe:

i. Please think about your positive emotions

ii. What about negative emotions?

iii. Do you think emotions can affect diabetes and self-management?

1. If yes, how?

iv. Do you think diabetes affects your mood?

1. If yes, how?

v. What do you think about the emotional aspects of diabetes? From friends, family, health care providers?

3. Many people with chronic disease e.g. diabetes use lifestyle and educational programs to deal with the disease self-management. How do you feel the diabetes and hypertension selfmanagement program helped you to address the following diabetes related distress?

a. Emotional/personal issues

b. Did the program give you information on how to talk to your doctor or health care provider about diabetes care?

i. If yes, how?

c. Do you think the program helped you to make changes in diet, physical activity, medication adherence, and stress?

i. If yes, how?

d. How do you think these changes helped you? 
e. Do you think this program helped you to deal with emotional aspects of diabetes? If yes, who did you receive support from?
e. Health coaches?
f. Dr. Misra or other program staffs?
g. Family and friends?
h. Doctor or health care providers?

4. What did you struggle the most in making changes during the program?

a. Probe:
i. Think about your diet, food $\log$ ?
ii. Your physical activities, step counts?
iii. Monitoring your blood sugar and blood pressure?
iv. Taking medications and insulin?
v. Weight? 
Table 1: Participant characteristics (qualitative study).

\begin{tabular}{|c|c|c|c|}
\hline Variable & $\mathrm{N}$ & Median/ Percent $(\%)$ & IQR \\
\hline Age & 34 & $63.38 \pm 12.88$ & \\
\hline \multicolumn{4}{|l|}{ Gender $^{\mathrm{a}}$} \\
\hline Male & 17 & $41.46 \%$ & \\
\hline Female & 24 & $58.54 \%$ & \\
\hline \multicolumn{4}{|l|}{ Race $^{\mathrm{b}}$} \\
\hline Non-White & 1 & $2.44 \%$ & \\
\hline White & 41 & $97.56 \%$ & \\
\hline \multicolumn{4}{|l|}{$\begin{array}{l}\text { Highest level of } \\
\text { education }^{c}\end{array}$} \\
\hline $\begin{array}{l}\text { High school or } \\
\text { less than high } \\
\text { school }\end{array}$ & 14 & $34.15 \%$ & \\
\hline $\begin{array}{l}\text { Associate } \\
\text { degree or some } \\
\text { college but did } \\
\text { not graduate }\end{array}$ & 7 & $17.07 \%$ & \\
\hline $\begin{array}{l}\text { Bachelor, } \\
\text { graduate, or } \\
\text { professional } \\
\text { degree }\end{array}$ & 21 & $51.22 \%$ & \\
\hline \multicolumn{4}{|l|}{$\begin{array}{l}\text { Family history of } \\
\text { diabetes }^{\mathrm{d}}\end{array}$} \\
\hline Yes & 31 & $75.61 \%$ & \\
\hline No & 10 & $24.39 \%$ & \\
\hline Duration of diabetes ${ }^{\mathrm{e}}$ & 34 & $12.91 \pm 10.00$ & \\
\hline \multicolumn{4}{|l|}{ Rural or Urban ${ }^{f}$} \\
\hline Rural & 14 & $34.15 \%$ & \\
\hline Urban & 28 & $65.85 \%$ & \\
\hline $\begin{array}{l}\text { Number of household } \\
\text { members }\end{array}$ & 34 & & $1.00(1.00)$ \\
\hline BMI & 34 & $34.54 \pm 7.21$ & \\
\hline \multicolumn{4}{|l|}{ BMI $\left(\right.$ categorical) ${ }^{\mathrm{h}}$} \\
\hline $\begin{array}{l}\text { Underweight or } \\
\text { Normal } \\
\end{array}$ & 2 & $4.88 \%$ & \\
\hline Overweight & 7 & $17.07 \%$ & \\
\hline Obese & 33 & $78.05 \%$ & \\
\hline $\mathrm{HbA} 1 \mathrm{c}^{\mathrm{i}}$ & 34 & & $6.90(1.35)$ \\
\hline $\begin{array}{l}\text { Diabetes distress (total } \\
\text { score) }\end{array}$ & 34 & & $1.71(1.07)$ \\
\hline Emotional distress ${ }^{\mathrm{k}}$ & 34 & & $1.70(1.60)$ \\
\hline Interpersonal distress ${ }^{\mathrm{k}}$ & 34 & & $1.33(1.42)$ \\
\hline $\begin{array}{l}\text { Physician related } \\
\text { distress }^{\mathrm{k}}\end{array}$ & 34 & & $1.00(0.50)$ \\
\hline
\end{tabular}


Table 1: Participant characteristics (qualitative study).

\begin{tabular}{l|c|c|c}
\hline \multicolumn{1}{c|}{ Variable } & $\mathrm{N}$ & Median/ Percent $(\%)$ & IQR \\
\hline $\begin{array}{l}\text { Regimen related } \\
\text { distress }^{\mathrm{k}}\end{array}$ & 34 & $2.65 \pm 1.31$ & \\
\hline Serum cortisol $^{\mathrm{l}}$ & 34 & $13.99 \pm 4.53$ & \\
\hline Diet $^{\mathrm{m}}$ & 34 & $2.95 \pm 0.58$ & \\
\hline Physical activity $^{\mathrm{n}}$ & 34 & $2.13 \pm 0.75$ & $7.0(2.06)$ \\
\hline Medication adherence $^{\mathrm{0}}$ & 34 & & \\
\hline
\end{tabular}

Note:

${ }^{a}$ Gender: Gender was categorized into two groups: male and female.

${ }^{b}$ Race of participants was categorized into four sub-categories: African American, American Indian or Alaskan Native, White, Other.

${ }^{c}$ Highest level of education: indicated the highest academic degree achieved by the participant. ${ }^{\mathrm{d}}$ Family history of diabetes: indicates whether the participants have any family members diagnosed with diabetes. Answer response was yes, and no.

e Duration of diabetes: indicates how many years the participants have been living with diabetes; measured in years.

${ }^{\text {f }}$ Rural or Urban: indicates the location of the particiapnts' residence based on their zip code. ${ }^{g}$ Number of household members: indicates how many people besides the participant live in the same household.

${ }^{\mathrm{h}}$ BMI (categorical): BMI was categorized into three categories: underweight or normal $(<18.5$ to 24.99), overweight (25 to 29.99), obese ( $\geq 30$ ).

${ }^{\mathrm{i}} \mathrm{HbAlc}$ or glycosylated hemoglobin was measured in percentage.

${ }^{\mathrm{j}, \mathrm{k}}$ Diabetes distress (total score and sub-scores) was calculated using the Diabetes Distress Survey (DDS), which had 17 Likert scale questions. Response option included from $1=$ not a problem to $6=$ a very serious problem. Score range: 1-6. ${ }^{1}$ Serum cortisol: Serum cortisol was measured in $\mathrm{mcg} / \mathrm{dL}$.

${ }^{\mathrm{m}}$ Diet score was calculated from the Lifestyle Profile II scale using eight Likert scale questions. Response options included never $=1$, sometimes $=2$, often $=3$, and routinely $=4$. Score range: 9-36.

${ }^{n}$ Physical activity score was calculated from the Lifestyle Profile II scale using eight Likert scale questions. Response options included never $=1$, sometimes $=2$, often $=3$, and routinely $=4$. Score range: 8-32.

${ }^{\circ}$ Medication adherence was calculated using Morisky Medication Adherence Scale 8 (MMAS8) that had a total of eight questions. Score range: 0-8. 
Table 2. Domains of diabetes distress and categories for each described in the qualitative study

\begin{tabular}{|c|c|c|}
\hline Diabetes distress domains & Categories & Description \\
\hline \multirow[t]{3}{*}{ Emotional distress } & $\begin{array}{l}\text { Lived Experiences with } \\
\text { Emotional Distress }\end{array}$ & $\begin{array}{l}\text { Participants' emotions } \\
\text { related to diabetes, and the } \\
\text { emotional distress }\end{array}$ \\
\hline & $\begin{array}{l}\text { How Individuals } \\
\text { Addressed/Mitigated Emotional } \\
\text { Distress }\end{array}$ & $\begin{array}{l}\text { Participants' management of } \\
\text { emotional distress prior to } \\
\text { their participation in } \\
\text { DHSMP }\end{array}$ \\
\hline & $\begin{array}{l}\text { Impact of DHSMP on } \\
\text { Addressing Emotional Distress } \\
\text { \& Diabetes Self-Management }\end{array}$ & $\begin{array}{l}\text { DHSMP specific strategies } \\
\text { participants utilized to } \\
\text { manage their emotional } \\
\text { distress }\end{array}$ \\
\hline \multirow[t]{3}{*}{ Intrapersonal distress } & $\begin{array}{l}\text { Lived Experiences with } \\
\text { Interpersonal Distress }\end{array}$ & $\begin{array}{l}\text { Participants' emotions } \\
\text { related to diabetes, and the } \\
\text { interpersonal distress }\end{array}$ \\
\hline & $\begin{array}{l}\text { How Individuals } \\
\text { Addressed/Mitigated } \\
\text { Interpersonal Distress }\end{array}$ & $\begin{array}{l}\text { Participants' management of } \\
\text { interpersonal distress prior } \\
\text { to their participation in } \\
\text { DHSMP }\end{array}$ \\
\hline & $\begin{array}{l}\text { Impact of DHSMP on } \\
\text { Addressing Interpersonal } \\
\text { Distress and Diabetes Self- } \\
\text { Management }\end{array}$ & $\begin{array}{l}\text { DHSMP specific strategies } \\
\text { participants utilized to } \\
\text { manage their interpersonal } \\
\text { distress }\end{array}$ \\
\hline \multirow[t]{3}{*}{$\begin{array}{l}\text { Provider-related/ Physician } \\
\text { distress }\end{array}$} & $\begin{array}{l}\text { Lived Experiences with } \\
\text { Provider-Related Distress }\end{array}$ & $\begin{array}{l}\text { Participants' emotions } \\
\text { related to diabetes, and the } \\
\text { provider-related distress }\end{array}$ \\
\hline & $\begin{array}{l}\text { How Individuals } \\
\text { Addressed/Mitigated Provider } \\
\text { Related Distress }\end{array}$ & $\begin{array}{l}\text { Participants' management of } \\
\text { provider-related distress } \\
\text { prior to their participation in } \\
\text { DHSMP }\end{array}$ \\
\hline & $\begin{array}{l}\text { Impact of DHSMP on } \\
\text { addressing provider/physician- } \\
\text { related distress \& diabetes self- } \\
\text { management }\end{array}$ & $\begin{array}{l}\text { DHSMP specific strategies } \\
\text { participants utilized to } \\
\text { manage their provider- } \\
\text { related distress }\end{array}$ \\
\hline \multirow[t]{3}{*}{ Regimen-related distress } & $\begin{array}{l}\text { Lived Experiences with } \\
\text { Regimen-Related Distress }\end{array}$ & $\begin{array}{l}\text { Participants' emotions } \\
\text { related to diabetes, and the } \\
\text { regimen-related distress }\end{array}$ \\
\hline & $\begin{array}{l}\text { How Individuals } \\
\text { Addressed/Mitigated Regimen- } \\
\text { Related Distress }\end{array}$ & $\begin{array}{l}\text { Participants' management of } \\
\text { regimen-related distress } \\
\text { prior to their participation in } \\
\text { DHSMP }\end{array}$ \\
\hline & $\begin{array}{l}\text { Impact of DHSMP on } \\
\text { Addressing Regimen-Related } \\
\text { Distress and Diabetes Self- } \\
\text { management }\end{array}$ & $\begin{array}{l}\text { DHSMP specific strategies } \\
\text { participants utilized to } \\
\text { manage their regimen- } \\
\text { related distress }\end{array}$ \\
\hline
\end{tabular}


Table 3. Quotes included in the manuscript

\section{Emotional distress}

\begin{tabular}{|c|c|c|}
\hline $\begin{array}{l}\text { Lived experiences with } \\
\text { emotional distress }\end{array}$ & $\begin{array}{l}\text { How individuals } \\
\text { addressed/mitigated emotional } \\
\text { distress }\end{array}$ & $\begin{array}{l}\text { Impact of DHSMP on } \\
\text { addressing emotional distress }\end{array}$ \\
\hline $\begin{array}{l}\text { "I also worry about long term } \\
\text { because I know its kind of a } \\
\text { slow killer." }\end{array}$ & $\begin{array}{l}\text { "I think knowledge helps best. If } \\
\text { you understand more about it, } \\
\text { then it helps with that." }\end{array}$ & $\begin{array}{l}\text { "Just knowing the different } \\
\text { ways to calm yourself down is } \\
\text { very helpful. Sometimes when } \\
\text { I'm at a stoplight, I just try } \\
\text { breathing deeply. Those kinds } \\
\text { of things really have helped } \\
\text { me." }\end{array}$ \\
\hline $\begin{array}{l}\text { "Hospitalization, very stressful } \\
\text { for me, and when your blood } \\
\text { sugar goes to } 600 \text {...I have had } \\
\text { to fight with my doctors not to } \\
\text { put me in the hospital." }\end{array}$ & $\begin{array}{l}\text { "As long as I can do what I know } \\
\text { to do to help the situation and } \\
\text { that it's not getting any worse, } \\
\text { then my anxiety level's probably } \\
\text { going to maintain pretty } \\
\text { relatively low." }\end{array}$ & $\begin{array}{l}\text { "It was stress relief. Some nice } \\
\text { easy exercises." }\end{array}$ \\
\hline $\begin{array}{l}\text { "I worry, the only really } \\
\text { emotions is, because I feel } \\
\text { mine's genetic as much as } \\
\text { anything, that I'm passing it } \\
\text { down to my daughter." }\end{array}$ & $\begin{array}{l}\text { "I've involved myself in a } \\
\text { meditation group, and that's } \\
\text { been very helpful; becoming } \\
\text { more mindful about every day, } \\
\text { just normal things." }\end{array}$ & $\begin{array}{l}\text { "I think that [name of health } \\
\text { coach] was a very good person } \\
\text { to talk with and ... so she would } \\
\text { would've helped me with that if } \\
\text { I'd expressed a whole lot of } \\
\text { angst." }\end{array}$ \\
\hline \multicolumn{3}{|c|}{ Interpersonal distress } \\
\hline $\begin{array}{l}\text { "My probably biggest problem } \\
\text { is dealing with my wife who was } \\
\text { a nurse for } 30 \text { years but was } \\
\text { raised on limited food so she } \\
\text { became a food junkie. She ate } \\
\text { nothing but crap her whole life } \\
\text { and she still does." }\end{array}$ & $\begin{array}{l}\text { "even if you try to approach it } \\
\text { calmly or whatever, it ends up } \\
\text { being an argument when it's a } \\
\text { spousal situation. I pretty much } \\
\text { just try to ignore it, and try to do } \\
\text { the best I can with what I can." }\end{array}$ & $\begin{array}{l}\text { "...being in the classroom, } \\
\text { listening to everybody and } \\
\text { being able to talk openly and } \\
\text { without any kind of criticism." }\end{array}$ \\
\hline $\begin{array}{l}\text { "My husband's kind of sadistic } \\
\text { fellow. He says, "What do you } \\
\text { want to do that for?" }\end{array}$ & $\begin{array}{l}\text { "I'm going to a birthday party } \\
\text { tomorrow; I know there's going } \\
\text { to be cake; ice cream there ... } \\
\text { pizza, probably. All the things I } \\
\text { can't eat. So I'll probably just go } \\
\text { and not eat anything." }\end{array}$ & $\begin{array}{l}\text { "[name of the health coach] } \\
\text { was great. I mean she's, yeah, } \\
\text { she talked to me weekly and we } \\
\text { texted back and forth. I liked } \\
\text { that. I just like- the program } \\
\text { was nice because it did, it } \\
\text { allows you to be in a group of } \\
\text { people of similar issues and it } \\
\text { did provide some advice and } \\
\text { encouragement as a group that } \\
\text { you don't normally get." }\end{array}$ \\
\hline $\begin{array}{l}\text { "My mother,... she's always like, } \\
\text { "Have you checked your blood } \\
\text { sugar? Have you eaten? Do you } \\
\text { need to eat?" And that stresses } \\
\text { me out a little bit too because }\end{array}$ & $\begin{array}{l}\text { "I tell people I have diabetes. I'm } \\
\text { not ashamed of the fact that I } \\
\text { have diabetes." }\end{array}$ & \\
\hline
\end{tabular}




\begin{tabular}{|c|c|c|}
\hline $\begin{array}{l}\text { I'm like, I've got this! I } \\
\text { appreciate the uber-concern, } \\
\text { but." }\end{array}$ & & \\
\hline \multicolumn{3}{|c|}{ Provider-related/ physician distress } \\
\hline $\begin{array}{l}\text { "Even though I go to my doctor } \\
\text { after five, } 10 \text { minutes with my } \\
\text { doctor, you're just you're just a } \\
\text { mystery after that. I'm sorry, } \\
\text { you're just a number. So that's } \\
\text { how I feel about the doctor } \\
\text { situation. They're just doing } \\
\text { their best with that } 10 \text { minutes } \\
\text { or } 15 \text { minutes they're spending } \\
\text { with you and then you're out of } \\
\text { sight out of mind." }\end{array}$ & $\begin{array}{l}\text { "When I go to the doctors, I'm } \\
\text { the one ... I ask the questions, } \\
\text { and I make them explain to me } \\
\text { what ... I don't have a problem } \\
\text { with that. I usually take my sister } \\
\text { with me just so that she's hearing } \\
\text { the same things I am. And we } \\
\text { both ask questions too." }\end{array}$ & $\begin{array}{l}\text { "[Health coach] stressed and } \\
\text { emphasized the importance of } \\
\text { talking with your personal } \\
\text { physician about any issues that } \\
\text { you have with your care and } \\
\text { management." }\end{array}$ \\
\hline $\begin{array}{l}\text { "Doctors are way too worried } \\
\text { about the numbers, and they feel } \\
\text { they're doing a good job if they } \\
\text { can get your blood sugar down } \\
\text { to 100, and AlC is five or } \\
\text { something like that. ... They're } \\
\text { all focused on the number, } \\
\text { number, number, number." }\end{array}$ & $\begin{array}{l}\text { "I do my own research, and I'm } \\
\text { thinking, why am I doing this?... } \\
\text { I'm finding I've had to sort it out } \\
\text { myself, and I should take } \\
\text { responsibility for my disease and } \\
\text { take care of it." }\end{array}$ & $\begin{array}{l}\text { "At the pre-diabetes stage. I } \\
\text { really felt that it was a lack of } \\
\text { education. I think they [Health } \\
\text { care provider] felt like maybe, } \\
\text { or I just think there was lack of } \\
\text { education. It took for me to pay } \\
\text { out of pocket for the device and } \\
\text { then ask my insurance and get } \\
\text { with [employer] human } \\
\text { resources to pay for it and to } \\
\text { tell the insurance to pay for it. } \\
\text { Then it took me to take it } \\
\text { [DHSMP researcher] because } \\
\text { my endocrinologist hasn't done } \\
\text { anything. }\end{array}$ \\
\hline \multicolumn{3}{|c|}{ Regimen related distress } \\
\hline $\begin{array}{l}\text { "Just a hassle of having to keep } \\
\text { taking the insulin." }\end{array}$ & $\begin{array}{l}\text { "I've got a routine, and I check } \\
\text { my sugar at a certain time... so } \\
\text { it's like I've just got this little } \\
\text { routine going." }\end{array}$ & $\begin{array}{l}\text { "Everything was broken down } \\
\text { nicely, of what causes what, and } \\
\text { what leads to what in your } \\
\text { body, and the diabetes process. } \\
\text { And the side effects of having } \\
\text { too high a blood sugar, and } \\
\text { how you get it. What foods } \\
\text { cause it. Just all that helps } \\
\text { you... Once you understand it, } \\
\text { you can do more about it, I } \\
\text { think." }\end{array}$ \\
\hline $\begin{array}{l}\text { "...dealing with the medication } \\
\text { and the shots. And taking the } \\
\text { medication with me when I } \\
\text { travel, and things like that." }\end{array}$ & $\begin{array}{l}\text { "I just take the pill and I'm pretty } \\
\text { faithful with that. I've got a } \\
\text { pretty good system set up where I } \\
\text { take my medications at certain } \\
\text { times." }\end{array}$ & $\begin{array}{l}\text { "I'm more aware that when I go } \\
\text { to the grocery store, I read } \\
\text { labels now and I put back } \\
\text { things that I normally would } \\
\text { have eaten. I'm much more } \\
\text { aware of that. The visual } \\
\text { demonstrations that they did in } \\
\text { the class were really made an }\end{array}$ \\
\hline
\end{tabular}




\begin{tabular}{l|l|l}
\hline & & $\begin{array}{l}\text { impression. I remember this } \\
\text { pink packets...It helps me know } \\
\text { what I need to do." }\end{array}$ \\
\hline $\begin{array}{l}\text { struggled to not overdo it, and } \\
\text { I'm addicted to the real Coca- } \\
\text { Cola." }\end{array}$ & $\begin{array}{l}\text { "I take my medications like it's a } \\
\text { religion ..." }\end{array}$ & \\
\hline $\begin{array}{l}\text { Just ever since I've been } \\
\text { diagnosed with diabetes I just } \\
\text { have gained weight and I cannot } \\
\text { lose it. I've tried everything..." }\end{array}$ & $\begin{array}{l}\text { "I actually read labels now. } \\
\text { Pretty much everything I get. I } \\
\text { read a label now. Sugar content, } \\
\text { Carbo- carb pod content, calorie } \\
\text { counts, salt content, stuff like } \\
\text { that." }\end{array}$ & \\
\hline
\end{tabular}




\begin{tabular}{|c|c|}
\hline Domain & Quotes \\
\hline \multicolumn{2}{|l|}{ Emotional Distress } \\
\hline $\begin{array}{l}\text { lived experiences with } \\
\text { emotional distress }\end{array}$ & $\begin{array}{l}\text { - "I've definitely had the anger, because I know from when I } \\
\text { first was diagnosed that, I knew how I was raised ... I } \\
\text { should say, it obviously wasn't forced on me, but I just } \\
\text { think the lifestyle I lived, even up to that point was again, } \\
\text { just a bunch of bad choices, and it just created a lot of } \\
\text { anger in myself." } \\
\text { "I also worry about long term because I know its kind of a } \\
\text { slow killer." } \\
\text { "Hospitalization, very stressful for me, and when your } \\
\text { blood sugar goes to } 600 \text {... I have had to fight with my } \\
\text { doctors not to put me in the hospital." } \\
\text { I worry, the only really emotions is, because I feel mine's } \\
\text { genetic as much as anything, that I'm passing it down to } \\
\text { my daughter." }\end{array}$ \\
\hline $\begin{array}{l}\text { How individuals try to } \\
\text { address/mitigate }\end{array}$ & $\begin{array}{l}\text { - "I think knowledge helps best. If you understand more } \\
\text { - "About it, then it helps with that." } \\
\text { situation and that it's not getting any worse, then my } \\
\text { anxiety level's probably going to maintain pretty relatively } \\
\text { low." } \\
\text { "I've involved myself in a meditation group, and that's } \\
\text { been very helpful; becoming more mindful about every } \\
\text { day, just normal things." }\end{array}$ \\
\hline $\begin{array}{l}\text { Impact of DHSMP on } \\
\text { addressing emotional } \\
\text { distress \& diabetes } \\
\text { self-management }\end{array}$ & $\begin{array}{l}\text { - "Just knowing the different ways to calm yourself down } \\
\text { is very helpful. Sometimes when I'm at a stoplight, I just } \\
\text { try breathing deeply. Those kinds of things really have } \\
\text { helped me." } \\
\text { - "It was stress relief. Some nice easy exercises." } \\
\text { - "I think that [name of health coach] was a very good } \\
\text { person to talk with and ... so she would would've helped } \\
\text { me with that if I'd expressed a whole lot of angst." } \\
\text { "Everybody was supportive that had anything to say. } \\
\text { Nobody was a Debbie downer. Nobody had any negative } \\
\text { feedback at all." }\end{array}$ \\
\hline \multicolumn{2}{|l|}{ Interpersonal Distress } \\
\hline $\begin{array}{l}\text { Lived experiences } \\
\text { with intrapersonal } \\
\text { distress }\end{array}$ & $\begin{array}{l}\text { - "She's constantly, constantly got to have cookies, and } \\
\text { pies, and ice cream, and everything, all the stuff in the } \\
\text { house all the time. and candy. Just candy everywhere and } \\
\text { stuff. So it's emotionally a difficult situation for me to } \\
\text { maintain and not eat these things that are all just hanging } \\
\text { around me." }\end{array}$ \\
\hline
\end{tabular}




\begin{tabular}{|c|c|}
\hline Domain & Quotes \\
\hline & $\begin{array}{l}\text { - "My probably biggest problem is dealing with my wife } \\
\text { who was a nurse for } 30 \text { years but was raised on limited } \\
\text { food so she became a food junkie. She ate nothing but } \\
\text { crap her whole life and she still does." } \\
\text { - My husband's kind of sadistic fellow. He says, "What do } \\
\text { you want to do that for?" } \\
\text { "My husband's also ... He's kind of newly diagnosed as a } \\
\text { diabetic, so now we're fighting it together. Okay. We're a } \\
\text { pretty good team." } \\
\text { "My wife's a lot of help to me with giving me my shots and } \\
\text { stuff like that. Been really supportive, fixes the right kind } \\
\text { offoods, and make sure,"Did you take your medicine } \\
\text { today?", and all that kind of things like that." } \\
\text { "Well, I always tell my sister when I'm getting in these } \\
\text { things. She'll ask what I've learned, and what's coming up. } \\
\text { I guess she's really the person I have that is for support." } \\
\text { "My mother, I live away from her, she lives in } \\
\text { Parkersburg, I live up here. When I got sick, my husband } \\
\text { called her and she flew up here the next morning and was } \\
\text { with me in the hospital the four days I was in there. She } \\
\text { stayed at a hotel and so she was learning to. So now } \\
\text { whenever I'm home, she's always like, "Have you checked } \\
\text { your blood sugar? Have you eaten? Do you need to eat?" } \\
\text { And that stresses me out a little bit too because I'm like, } \\
\text { I've got this! I appreciate the uber-concern, but." } \\
\text { "Like when if they are planning a party, they don't plan } \\
\text { anything, and the fact that there's two people there that } \\
\text { have celiac, they don't care, they going to bring what they } \\
\text { like, they're going to bring the Hawaiian King buns, and } \\
\text { the sweet buns. They're going bring potato chips, they're } \\
\text { going to bring junk." } \\
\text { "There's not that many people to tell. I really haven't even } \\
\text { told much of my family. I honestly don't think they care." }\end{array}$ \\
\hline $\begin{array}{l}\text { How individuals } \\
\text { addressed/mitigated } \\
\text { Interpersonal Distress }\end{array}$ & $\begin{array}{l}\text { - "even if you try to approach it calmly or whatever, it ends } \\
\text { up being an argument when it's a spousal situation. I } \\
\text { pretty much just try to ignore it, and try to do the best I } \\
\text { can with what I can." } \\
\text { - "I get offered to sometimes by my aunt and I just told } \\
\text { them no, I gotta watch my sugar." } \\
\text { - "If you're at some kind of event where people are eating } \\
\text { they can think you ate before you got there. You don't } \\
\text { have to eat in front of anybody and show them how much } \\
\text { you liked what they made. They don't have to know that } \\
\text { you didn't try it. If its something they're particularly proud }\end{array}$ \\
\hline
\end{tabular}




\begin{tabular}{|c|c|}
\hline Domain & Quotes \\
\hline & $\begin{array}{l}\text { of you could try a spoonful and make them happy unless } \\
\text { you say you hate it." } \\
\text { - "I'm going to a birthday party tomorrow; I know there's } \\
\text { going to be cake; ice cream there ... pizza, probably. All } \\
\text { the things I can't eat. So I'll probably just go and not eat } \\
\text { anything." } \\
\text { "I tell people I have diabetes. I'm not ashamed of the fact } \\
\text { that I have diabetes." } \\
\text { "I don't go out of my way to tell people that I have } \\
\text { diabetes. So I guess you might say that I'm a little bit } \\
\text { hesitant to talk about it, at least to people that aren't } \\
\text { close." }\end{array}$ \\
\hline $\begin{array}{l}\text { Impact of DHSMP on } \\
\text { addressing } \\
\text { intrapersonal distress }\end{array}$ & $\begin{array}{l}\text { - "...being in the classroom, listening to everybody and } \\
\text { being able to talk openly and without any kind of } \\
\text { criticism." } \\
\text { " [name of the health coach] was great. I mean she's, } \\
\text { yeah, she talked to me weekly and we texted back and } \\
\text { forth. I liked that. I just like- the program was nice } \\
\text { because it did, it allows you to be in a group of people of } \\
\text { similar issues and it did provide some advice and } \\
\text { encouragement as a group that you don't normally get." }\end{array}$ \\
\hline \multicolumn{2}{|l|}{$\begin{array}{l}\text { Provider/physician-related } \\
\text { Distress }\end{array}$} \\
\hline $\begin{array}{l}\text { Lived experiences } \\
\text { with } \\
\text { provider/physician- } \\
\text { related distress }\end{array}$ & $\begin{array}{l}\text { - "To be honest here I'm on my own. Even though I go to } \\
\text { my doctor after five, } 10 \text { minutes with my doctor, you're } \\
\text { just you're just a mystery after that. I'm sorry, you're just a } \\
\text { number. So that's how I feel about the doctor situation. } \\
\text { They're just doing their best with that } 10 \text { minutes or } 15 \\
\text { minutes they're spending with you and then you're out of } \\
\text { sight out of mind." } \\
\text { "Second level of distress is dealing with all the damn } \\
\text { doctors. The nephrologist, pulmonologist, cardiologist, } \\
\text { ophthalmologist. There's so many of them. Having to go } \\
\text { see them is just a total pain." } \\
\text { "I'm talking maybe a decade with medication, a } \\
\text { medication regime where my sugars go up and down and } \\
\text { my doctors aren't, none of them, are adjusting my } \\
\text { medications correctly. ... because I think they were only } \\
\text { trained to offer, "Let's start with metformin." They can't } \\
\text { think outside the box." } \\
\text { "Doctors are way too worried about the numbers, and } \\
\text { they feel they're doing a good job if they can get your } \\
\text { blood sugar down to } 100, \text { and AlC is five or something } \\
\text { like that. ...They're all focused on the number, number, }\end{array}$ \\
\hline
\end{tabular}




\begin{tabular}{|c|c|}
\hline Domain & Quotes \\
\hline & $\begin{array}{l}\text { number, number. That's not the whole thing. It's insidious } \\
\text { in fact of, like I said, the heart disease that goes with it, } \\
\text { the kidney problems, the neuropathy, and these things. } \\
\text { That's the real dealing with the disease." } \\
\text { "I think, especially from the very beginning, I never got a } \\
\text { definitive diagnosis that I had Syndrome X, or pre- } \\
\text { diabetes to diabetes. .. And I basically was very proactive } \\
\text { and the fact that I have polycystic ovaries, I went and got } \\
\text { myself on metformin. I had taken it for years, so there was } \\
\text { never any ... the doctors never explained it. I had to do my } \\
\text { research myself." } \\
\text { "They were supposed to make out sample menu. The } \\
\text { sample menu they gave me, the first breakfast, the } \\
\text { breakfast, lunch and dinner, they had the sample, they } \\
\text { were all sandwiches. I said, well that's what I said. I threw } \\
\text { a fit about it, and I walked out and I went down to } \\
\text { administration and complained about it." } \\
\text { "...you think dieticians would be good at this stuff but } \\
\text { they really aren't. Well they just have this pressured diet, } \\
\text { it doesn't seem to be their research. They do all this } \\
\text { magical carb counting and crap but it doesn't really work } \\
\text { in real life." }\end{array}$ \\
\hline $\begin{array}{l}\text { How individuals } \\
\text { addressed/mitigated } \\
\text { provider/physician- } \\
\text { related distress }\end{array}$ & $\begin{array}{l}\text { - "When I go to the doctors, I'm the one ... I ask the } \\
\text { questions, and I make them explain to me what ... I don't } \\
\text { have a problem with that. I usually take my sister with me } \\
\text { just so that she's hearing the same things I am. And we } \\
\text { both ask questions too." } \\
\text { - "I do my own research, and I'm thinking, why am I doing } \\
\text { this?... I'm finding I've had to sort it out myself, and I } \\
\text { should take responsibility for my disease and take care of } \\
\text { it." } \\
\text { "Ijust think that there needs to be, I think the doctors } \\
\text { need to take a different approach... I mean like a cardiac } \\
\text { doctor, he has ideas where I can send you to cardiac } \\
\text { rehab, I can send you here, I can send you there? Why } \\
\text { doesn't when ... to an endocrinologist, one say hey I want } \\
\text { to send you to a diabetes class. I want to send you to this } \\
\text { DASH diet class, I want to send you to a registered } \\
\text { dietician. I want to send you to somebody, a personal } \\
\text { trainer. I mean, why not?"” }\end{array}$ \\
\hline $\begin{array}{l}\text { Impact of DHSMP on } \\
\text { addressing } \\
\text { provider/physician- } \\
\text { related distress \& }\end{array}$ & $\begin{array}{l}\text { - "[Health coach] stressed and emphasized the importance } \\
\text { of talking with your personal physician about any issues } \\
\text { that you have with your care and management." }\end{array}$ \\
\hline
\end{tabular}




\begin{tabular}{|c|c|}
\hline Domain & Quotes \\
\hline $\begin{array}{l}\text { diabetes self- } \\
\text { management }\end{array}$ & $\begin{array}{l}\text { - "...it took me to take it Dr. [DHSMP personnel] because } \\
\text { my endocrinologist hasn't done anything." }\end{array}$ \\
\hline \multicolumn{2}{|l|}{ Regimen Related Distress } \\
\hline $\begin{array}{l}\text { Lived experiences } \\
\text { with regimen-related } \\
\text { distress }\end{array}$ & $\begin{array}{l}\text { - Maybe there may be some subconscious stress that } \\
\text { causes me both to do the finger stick. That's probably } \\
\text { what it is. I probably be feel stressed having to do those } \\
\text { finger sticks." } \\
\text { " Just a hassle of having to keep taking the insulin. I can't } \\
\text { take the medications, because I have chronic kidney } \\
\text { disorder, and they're...they're not good for kidneys, and so } \\
\text { I have to be ... and a hassle of having to keep doing that. } \\
\text { Sometimes at night when I'm getting ready for bed and I } \\
\text { happen to forget, and I'm so dead tired, and I have to go } \\
\text { through testing my blood, and taking the insulin." } \\
\text { "...dealing with the medication and the shots. And taking } \\
\text { the medication with me when I travel, and things like } \\
\text { that." } \\
\text { "My biggest challenge, for me, is because I also am on } \\
\text { Warfarin blood thinner. Which restricts my leafy greens. I } \\
\text { have to avoid those and that's really hard sometimes. } \\
\text { That's my biggest challenge." } \\
\text { "I like sweets. I've struggled to not overdo it, and I'm } \\
\text { addicted to the real Coca-Cola." } \\
\text { "What I struggle with is ...get the more vegetables and the } \\
\text { more, to eat the right things. It's struggle to do that way." } \\
\text { "The weight gain. Yeah. Just ever since I've been } \\
\text { diagnosed with diabetes I just have gained weight and I } \\
\text { cannot lose it. I've tried everything. I've been through so } \\
\text { many different programs and I just can't lose and it's just } \\
\text { like a big circle where I need more insulin because my } \\
\text { sugar's going high and then I'm just gaining weight } \\
\text { because I'm getting more insulin." } \\
\text { and I don't know if insulin has anything to do with not } \\
\text { being able to lose weight. Like I did it one time or maybe } \\
\text { it's just as you get older it's harder to do." }\end{array}$ \\
\hline $\begin{array}{l}\text { How individuals } \\
\text { addressed/mitigated } \\
\text { regimen related distress }\end{array}$ & $\begin{array}{l}\text { - "I've got a routine, and I check my sugar at a certain } \\
\text { time... so it's like I've just got this little routine going." } \\
\text { - "I just take the pill and I'm pretty faithful with that. I've } \\
\text { got a pretty good system set up where I take my } \\
\text { medications at certain times." } \\
\text { - "I take my medications like it's a religion...". }\end{array}$ \\
\hline
\end{tabular}




\begin{tabular}{|c|c|}
\hline Domain & Quotes \\
\hline & $\begin{array}{l}\text { - "I Totally cut off pretty much sodas. I'll, once in awhile } \\
\text { I'll treat myself, but not very often. Not even, not even diet } \\
\text { soda." } \\
\text { " We buy that Ezekiel, that flourless bread. And we eat a } \\
\text { lot." } \\
\text { "I actually read labels now. Pretty much everything I get. } \\
\text { I read a label now. Sugar content, Carbo-carb pod } \\
\text { content, calorie counts, salt content, stuff like that." } \\
\text { "So, I kind of have congestive heart failure now, so I kind } \\
\text { of don't have the endurance to walk on a treadmill or } \\
\text { anything for a long time. I can only do that in little bits. I } \\
\text { still exercise, but not like I'd like to exercise." }\end{array}$ \\
\hline $\begin{array}{l}\text { Impact of DHSMP on } \\
\text { addressing regimen } \\
\text { related distress }\end{array}$ & $\begin{array}{l}\text { - "Everything was broken down nicely, of what causes } \\
\text { what, and what leads to what in your body, and the } \\
\text { diabetes process. And the side effects of having too high a } \\
\text { blood sugar, and how you get it. What foods cause it. Just } \\
\text { all that helps you... Once you understand it, you can do } \\
\text { more about it, I think." } \\
\text {-I'm more aware that when I go to the grocery store, I } \\
\text { read labels now and I put back things that I normally } \\
\text { would have eaten. I'm much more aware of that. The } \\
\text { visual demonstrations that they did in the class were } \\
\text { really made an impression. I remember this pink } \\
\text { packets...It helps me know what I need to do." } \\
\text { - "I've been walking a lot more..." } \\
\text { "Yeah, it helped make it organized, it helped me get } \\
\text { motivated, it helped me stay on track". } \\
\text { "Now that does help me, to keep track of food that I'm } \\
\text { eating. That still helps me. And I have tried to use the } \\
\text { apps for my phone as far as tracking, like the Lose It app, } \\
\text { and then on my iPhone, I use that health app that already } \\
\text { comes on the phone." }\end{array}$ \\
\hline
\end{tabular}




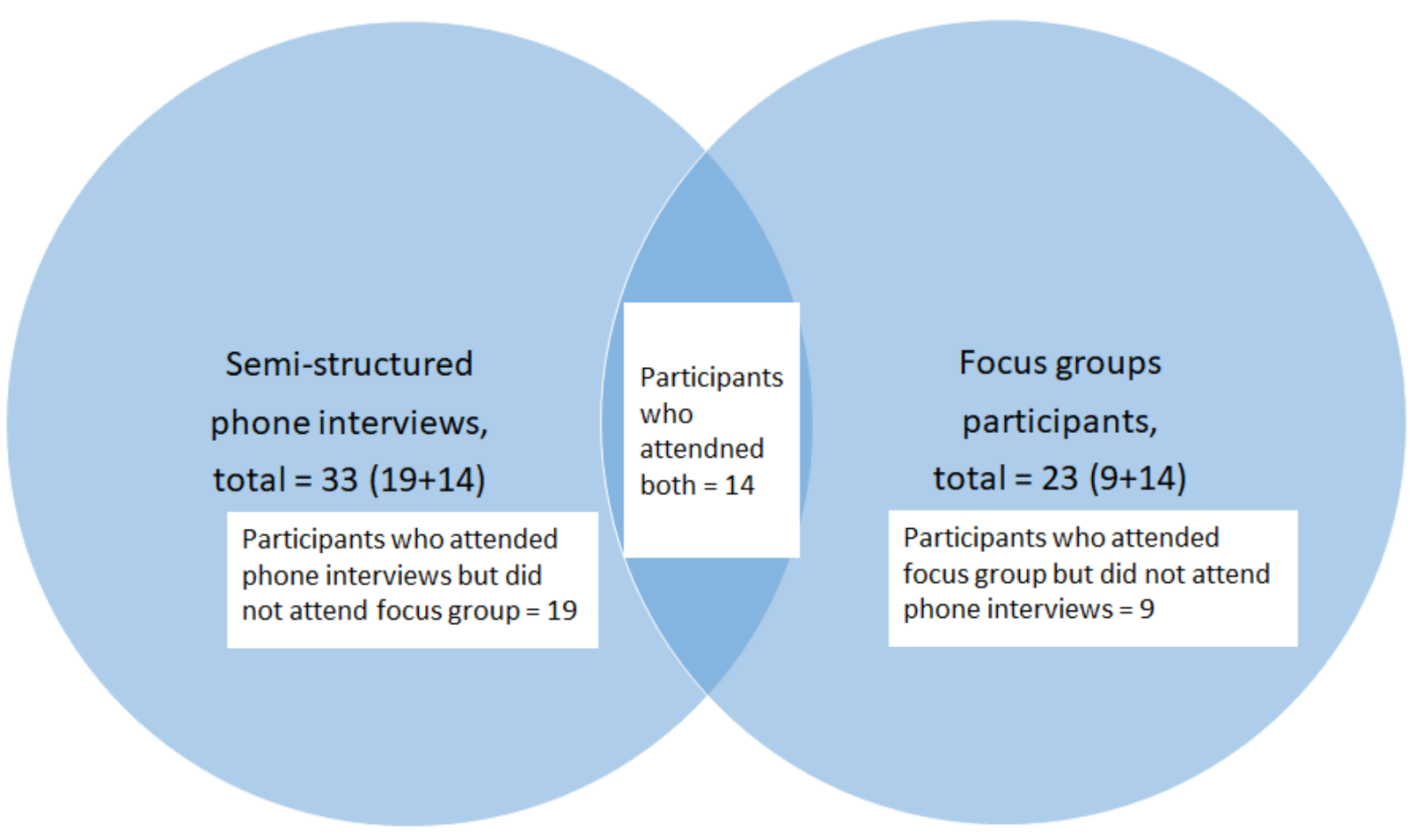

Figure 1. Sample size for qualitative focus group and semi-structured interviews. 


\section{Chapter 5}

\section{Conclusion}

\subsection{Summary}

The main objective of this study was to determine whether the diabetes and hypertension selfmanagement program (DHSMP) can reduce the burden of diabetes distress among the participants. Diabetes distress, frequently observed in T2DM individuals, ${ }^{1-6}$ is associated with depression $^{7}$, and chronic diabetes distress can lead to hypertension and worse glycemic status. ${ }^{3,8,}$

${ }^{9-11}$ However, few studies have focused on the effect of diabetes self-education (DSME) programs on diabetes distress, especially in rural Appalachian communities. The current study used data from a parent RCT, a 12-week DHSMP, to assess the effectiveness of program participation on T2DM adults' diabetes distress. Clinical and behavioral predictors of diabetes distress were also explored (chapter 2, and 3). ${ }^{12,13}$ Lastly, qualitative data (focus groups and semi-structured interviews) explored the everyday lived experiences, struggles, and distress related to the management of diabetes and comorbidities among individuals with T2DM and hypertension (chapter 4). ${ }^{12}$

Participants' diabetes distress was measured by a validated diabetes distress survey (the details are described in chapters 2 and 3) and fasting serum cortisol. The cross-sectional quantitative analysis explored associations between demographic, clinical, and behavioral factors with diabetes distress (chapter 2). Results showed a dose-response relationship between DHSMP program attendance and diabetes distress. More specifically, participants who had higher program attendance had lower diabetes distress at post-program assessment (24 weeks) as compared to those with lower program attendance, indicating that participation in DHSMP helped the participants improve their knowledge and coping skills to manage their diabetes- 
related distress. Furthermore, results showed that individuals who had a healthier diet, adhered to their medication regimen, had lower serum cholesterol and glycosylated hemoglobin levels were more likely to have lower diabetes distress. Lower levels of serum cholesterol, especially the very low-density lipoprotein (VLDL) was also associated with lower levels of serum cortisol.

Relationships between clinical and behavioral factors with diabetes distress at 12- and 24-week post-program were described in chapter 3. Overall, participants' diabetes distress declined after the program (12 weeks and 24 weeks) from baseline. Participants who followed selfmanagement guidelines to improve their glycemic status, adopt a healthy diet, adhere to their medication regimen, and reduce their serum cholesterol levels saw a reduction in their diabetes distress. In addition, diabetes distress was highest among participants who had higher education (i.e., had a bachelor, graduate or professional degree) and lower education level (i.e., high school degree) compared to those with some college education or an associate degree. In the former group, educated participants had higher diabetes distress than those with low education levels, and deviates from results of prior studies that show lowest educated individuals have higher level of diabetes distress. Hence, future studies should explore this relationship in larger sample size in rural Appalachian adults.

To address the knowledge gap in the understanding of T2DM individuals' everyday lived experiences of diabetes self-management and related diabetes distress, qualitative data was collected from participants and results are presented in chapter 4. Semi-structured interviews and focus groups conducted with DHSMP participants post-program revealed that T2DM individuals experienced the burden of disease management and related diabetes distress in their daily lives. Participants described the four domains of diabetes distress (emotional distress, provider or physician-related distress, regimen-related distress, interpersonal distress) in their lives and their 
strategies to manage them. They reported that the knowledge and skills of diabetes selfmanagement strategies learned during DHSMP helped them to cope with their distress. Participants were complimentary of the support by the health coaches as well as the educational sessions were very helpful in coping with diabetes-related distress.

The findings of the current study can be explained by the Self-determination theory (SDT). ${ }^{14}$ The educational sessions provided knowledge and skills for lifestyle modifications to improve diabetes self-care and cope with stress. Furthermore, a judgment-free zone during the group educational sessions allowed participants to discuss their health issues and concerns and problem solve. This may have helped the participants gain psychological freedom (autonomy) to develop their inherent desire to adopt lifestyle changes (competence). Peer interactions with fellow participants helped the participants cope better with the psychosocial consequences of diabetes, and getting to know each other and share their experiences. Self-determination theory states that by expressing personal experiences to peers in the program, individuals realize that others have similar health issues and challenges as their own experiences, reinforce (augment) healthpromoting behaviors and enhance self-confidence in T2DM adults. Hence, program participants developed their own support group to discuss their health issues and receive support and encouragement from other participants (relatedness).

As external motivation factors, program activities (i.e., program attendance, peer support, and support from program personnel) enabled the participants' internal drive (internal motivation) to adopt and adhere to the self-management guidelines. This motivation can lead to improved selfcompetence and a sense of autonomy among the participants to adopt recommended health behaviors. By using both internal and external motivation and eliciting the three basic human needs of autonomy, competence, and relatedness of SDT, the DHSMP was effective in 
participants' improving diabetes self-management activities and to reduce diabetes distress. This concurs with prior research that has shown increased autonomy and self-competence, improved medication adherence and quality of life, reduced glycemic status, and diabetes distress among T2DM individuals..$^{14-16}$

\subsection{Significance and Innovation}

The central hypothesis of the study was that DHSMP participation will improve selfmanagement of diabetes and other co-morbid conditions and improve diabetes distress and disease outcomes. The current study is innovative for several reasons. First, this is one of the first studies in rural WV to test the efficacy of a community-based self-management program to reduce diabetes distress. The results of this study revealed that DHSMP participation reduced can be effective in reducing diabetes distress for T2DM individuals. Furthermore, educated participants had higher distress as compared to those with lower education levels; educational level was a predictor of interpersonal distress and higher among educated participants in this study. This information is especially important for the rural Appalachian healthcare providers, and rural adults in WV, who have lower literacy and health literacy level ${ }^{16,17}$ and have the highest rate of diabetes in the nation. ${ }^{18,}{ }^{19}$ Self-management strategies provided during DHSMP has shown to improve dietary habits and glycemic status, better adherence to medication guidelines, and reduction in serum cholesterol that lead to a reduction in diabetes distress..$^{20-26}$ Lastly, the qualitative analysis provided an elaborate description of everyday struggles of dealing with diabetes distress and its domains as well as program components that helped participants cope with distress. Participants perceived the knowledge on disease self-management and the support from the health coaches and peer interactions was helpful for positive lifestyle changes that reduced their diabetes distress. Furthermore, effectiveness of the use of low-cost models, 
such as trained health coaches in disease management programs, in rural Appalachian communities should be noted and used in future programs.

\subsection{Strength and Limitations}

This study was one of the first community-based RCTs in rural WV to examine the impact of participation in a health-coach-mediated diabetes self-management program to reduce diabetes distress. This is the first study conducted in WV that assessed the relationship between demographic, clinical, and behavioral factors with diabetes distress. The DHSMP utilized an RCT design for the quantitative studies (chapters 2 and 3) that reduced bias. The detailed description of the methodology for each aim, especially the qualitative design, improves the overall transferability of this study. The use of both quantitative and qualitative methodologies enhances the credibility of the findings in chapters 2,3 , and $4 .^{27}$

The qualitative exploration (chapter 4) allowed for a better understanding of T2DM individuals' perspectives of their everyday struggles and diabetes distress and coping strategies. The qualitative study also identified program components that were perceived as beneficial to the participants in managing their diabetes distress. Although DHSMP utilized stress reduction techniques, those were not diabetes distress specific. Thus, researchers should test the efficacy of diabetes-distress-specific reduction techniques in future research.

Despite the strengths mentioned above, there are several limitations. Several demographic variables were self-reported, which contributed to self-report bias and recall bias. In addition, participants could have misunderstood some questions leading to incorrect information. In addition, dietary habits and physical activity information provided by participants may have social desirability bias. Missingness and dropouts also contributed to a lower sample size than baseline that might have reduced the statistical power and representativeness of the sample in 
chapters 2 and 3. The majority of the study participants were urban dwellers, whereas in WV, the majority of the population live in rural areas. Furthermore, the educational level of the participants was higher than the general population. Thus, the results from this study limit generalizability to the entire rural population of WV.

\subsection{Implications}

Results from this study have several implications for DSME programs, health care providers in rural Appalachian areas, and public health research. Findings demonstrated that diabetes distress was prevalent in rural adults with T2DM, and participation in DSME or evidence-based selfmanagement programs such as the DHSMP reduce diabetes distress. The high burden of diabetes and related comorbidities in WV and Appalachia calls for more DSME programs that are nonclinic based and freely accessible to patients. Despite the high rates of diabetes, WV is a medically underserved state, and low-cost models such as trained health coaches can fulfill the shortage of health professionals while allowing students in professional programs and health care field to serve communities of need. Health coaches also gain valuable experience of applying their knowledge to practice.

Since poor glycemic control, blood pressure, and cholesterol levels are prevalent in rural Appalachian regions and associated with diabetes distress; future research should address provider education on patients' diabetes-related distress and how to provide better care and guidance to improve their knowledge of self-care behaviors as well as tailor patient education to address coping strategies for diabetes distress. Information on diabetes distress should contain information on all 4 domains of diabetes distress and their management, as each domain would require a different coping strategy. The use of culturally and literacy-appropriate approaches and 
an evidence-based curriculum were acceptable and effective even for individuals with lower educational levels.

\subsection{Recommendations for Future Research}

Results from this study are particularly important for health researchers, educators, and practitioners for future studies on diabetes distress. As mentioned earlier, future research should assess the implication of provider education of diabetes distress (all 4 domains) on improving patient's diabetes distress management. Although DHSMP utilized stress reduction techniques, those were not diabetes distress specific. Thus, researchers should test the efficacy of diabetesdistress-specific reduction techniques in future research. Furthermore, examination of relationship between gender, diabetes duration, and diabetes distress is also suggested.

Although this study utilized both quantitative and qualitative methodologies, future research can utilize a mixed methodology and triangulation to better understand connections or contradictions between qualitative and quantitative data on participants' diabetes-related distress. 


\section{References}

1. Hackett RA, Steptoe A. Type 2 diabetes mellitus and psychological stress - a modifiable risk factor. Nature reviews Endocrinology. Sep 2017;13(9):547-560.

doi:10.1038/nrendo.2017.64

2. Nicolucci A, Kovacs Burns K, Holt RIG, et al. Diabetes Attitudes, Wishes and Needs second study (DAWN2TM): cross-national benchmarking of diabetes-related psychosocial outcomes for people with diabetes. Diabetic medicine : a journal of the British Diabetic Association. 2013 Jul 2013;30(7)doi:10.1111/dme.12245

3. Fisher L, Mullan JT, Arean P, Glasgow RE, Hessler D, Masharani U. Diabetes Distress but Not Clinical Depression or Depressive Symptoms Is Associated With Glycemic Control in Both Cross-Sectional and Longitudinal Analyses. 2010-01-01 2010;doi:10.2337/dc09-1238 4. Aikens JE. Prospective Associations Between Emotional Distress and Poor Outcomes in Type 2 Diabetes. 2012-12-01 2012;doi:10.2337/dc12-0181

5. Tsujii S, Hayashino Y, Ishii H. Diabetes distress, but not depressive symptoms, is associated with glycaemic control among Japanese patients with type 2 diabetes: Diabetes Distress and Care Registry at Tenri (DDCRT 1). Diabetic medicine : a journal of the British Diabetic Association. 2012 Nov 2012;29(11)doi:10.1111/j.1464-5491.2012.03647.x

6. Zagarins SE, Allen NA, Garb JL, Welch G. Improvement in glycemic control following a diabetes education intervention is associated with change in diabetes distress but not change in depressive symptoms. OriginalPaper. Journal of Behavioral Medicine. 2011-06-21 2011;35(3):299-304. doi:doi:10.1007/s10865-011-9359-z

7. Carper MM, Traeger L, Gonzalez JS, Wexler DJ, Psaros C, Safren SA. The differential associations of depression and diabetes distress with quality of life domains in type 2 diabetes. Journal of Behavioral Medicine. 2014/06/01 2014;37(3):501-510. doi:10.1007/s10865-0139505-x

8. Hilliard ME, Yi-Frazier JP, Hessler D, Butler AM, Anderson BJ, Jaser S. Stress and A1c Among People with Diabetes Across the Lifespan. Curr Diab Rep. Aug 2016;16(8):67. doi:10.1007/s11892-016-0761-3

9. Matthews KA, Katholi CR, McCreath H, et al. Blood Pressure Reactivity to Psychological Stress Predicts Hypertension in the CARDIA Study. 2004-07-06 2004;doi:10.1161/01.CIR.0000133415.37578.E4

10. Gasperin D, Netuveli G, Dias-da-Costa JS, Pattussi MP. Effect of psychological stress on blood pressure increase: a meta-analysis of cohort studies. Cadernos de saude publica.

2018;25:715-726. doi:10.1590/S0102-311X2009000400002

11. Spruill TM. Chronic Psychosocial Stress and Hypertension. Curr Hypertens Rep. Feb 2010;12(1):10-6. doi:10.1007/s11906-009-0084-8

12. Khan R, Misra R, Kirk B, Davidov D, Sambamoorthi U. Patients perspective on diabetes distress: Qualitative themes among adults with diabetes and comorbid hypertension. American Public Health Association; 2020:

13. Khan R, Misra R, Wen S, Sambamoorthi U. Can diabetes self-management program reduce diabetes distress among Patients? American Public Health Association; 2018:

14. Ryan RM, Deci EL. Self-Determination Theory. Center for Self-Determination Theory. https://selfdeterminationtheory.org/the-theory/

15. Williams GC, Lynch M, Glasgow RE. Computer-assisted intervention improves patientcentered diabetes care by increasing autonomy support. Health Psychology. 2007;26(6):728-734. doi:10.1037/0278-6133.26.6.728 
16. Lester L. Putting Rural Readers on the Map: Strategies for Rural Literacy. The Reading Teacher. 2012-03-01 2012;65(6):407-415. doi:10.1002/trtr.01062

17. National Assessment of Adult Literacy. State and County Literacy Estimates - State

Estimates. National Assessment of Adult Literacy. 2021.

https://nces.ed.gov/naal/estimates/StateEstimates.aspx

18. Appalachian Regional Commission. About the Appalachian Region. Appalachian

Regional Commission. 2020. https://www.arc.gov/about-the-appalachian-region/

19. American Diabetes Association. The Burden of Diabetes in West Virginia. American

Diabetes Association. 2020. https://www.diabetes.org/resources/statistics/statistics-by-state

20. Xiaoqin He JLBW, Qiuming Yao, Ling Li, Ronghua Song, Xiaohong Shi, Jin-an

Zhang. Diabetes self-management education reduces risk of all-cause mortality in type 2 diabetes patients: a systematic review and meta-analysis | SpringerLink. 2018;doi:10.1007/s12020-016$1168-2$

21. Vermunt PW, Milder IE, Wielaard F, et al. A lifestyle intervention to reduce Type 2 diabetes risk in Dutch primary care: 2.5 -year results of a randomized controlled trial. Diabet Med. Aug 2012;29(8):e223-31. doi:10.1111/j.1464-5491.2012.03648.x

22. Anderson JW, Kendall CW, Jenkins DJ. Importance of weight management in type 2 diabetes: review with meta-analysis of clinical studies. Journal of the American College of Nutrition. Oct 2003;22(5):331-9.

23. Stevens JW, Khunti K, Harvey R, et al. Preventing the progression to Type 2 diabetes mellitus in adults at high risk: A systematic review and network meta-analysis of lifestyle, pharmacological and surgical interventions. Diabetes Research and Clinical Practice. 2015/03/01/ 2015;107(3):320-331. doi:https://doi.org/10.1016/j.diabres.2015.01.027

24. Kela R, Davies MJ. Implications of UKPDS evidence. Practice Nursing. 2010;21(3):140142.

25. King P, Peacock I, Donnelly R. The UK Prospective Diabetes Study (UKPDS): clinical and therapeutic implications for type 2 diabetes. Br J Clin Pharmacol. Nov 1999;48(5):643-8. doi:10.1046/j.1365-2125.1999.00092.x

26. Pi-Sunyer X. The Look AHEAD Trial: A Review and Discussion Of Its Outcomes. Curr Nutr Rep. Dec 2014;3(4):387-91. doi:10.1007/s13668-014-0099-x

27. Salkind NJ. Triangulation. Encyclopedia of Research Design. Thousand Oaks, California2010. 